1 
-n last date stamped below

N

UNIVERSITY of CALIFORNL

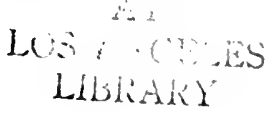




\section{A DEFENCE OF IDEALISM SOME QUESTIONS AND CONCLUSIONS}




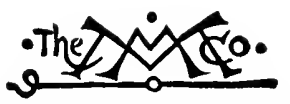

THE MACMILLAN COMPANY

NRW YORK - BOSTON - CHICAGO - DALLAS

aTLANTA - SAN FRANCISCO

MACMILLAN \& CO., Limited

LONDON - BOMBAY - CALCUTTA

MELBOURNE

THE MACMILLAN CO. OF CANADA, Ltd.

TORONTO 


\title{
A DEFENCE OF IDEALISM: SOME QUESTIONS AND CONCLUSIONS
}

\author{
BY \\ MAY SINCLAIR
}

ZNew Tark

THE MACMILLAN COMPANY

1917

All rights reserved 
Coryright, 1917,

BY MAY SINCLAIR

Set up and electrotyped. Published, August, 1917. 
A. M. A.

A. W.

E. S.-M. 
. . 


\section{INTRODECTION}

THERE is a certain embarrassment in coming forward with an Apology for Idealistic Monism at the present moment. You cannot be quite sure whether sou are putting in an appearance too late or much too earls.

It does look like personal misfortune or perrersity that,

when there are lots of other philosophies to choose from, you should happen to hit on the one that has just had a tremendous innings and is now in process of being bowled out. As long ago as the early 'nineties Idealism was supposed to be dead and haunting Oxford. I know that the New Realists hare said that it is now a fashionable philosophy. But either ther do not realls mean it. or ther mean that onls philosophies in their last decrepitude become fashionable at all. Ther mean that nineteenth century Monism is a pseudo-philosophy of the past, and that twentieth century Pluralism is the living philosophr of the future.

It is possible to agree with this riew without accepting the programme of the pluralists. I think it may be said that certain rulnerable forms of Idealism are things of the past; and that the new atomistic Realism is a thing of the future: at ans rate of the immediate future. But we know of Old Realisms that died and decared, and were buried, and of New Idealisms that died and rose again. In India the Sankra philosophy of the Many fought the Tedânta philosophị of the One. It can hardḷ be said to have driven its opponent from the field. Pragmatic Humanism and Vitalism are going from us in the flower. rou may sar, of their youth. And they were robust philosophies. M. Bergson eren made Philosophr the rogue in Mayfair 
for a whole season. And so I think that some day (which may be as distant as you please) the New Realism will grow old and die, and the New Idealism will be borm again.

It will be born, not out of its own ashes, nor out of its own life only, but out of what is living in the system that for the time being has superseded it. The drastic critieism of their opponents is what keeps robust philosophies alive. And, seeing the great part that Idealism has played in the past, I cannot think that to choose it (if you have any choice in these matters) is perversity.

It $i s$, however, a personal misfortune when your choice causes you to differ, almost with violence, from those for whose accomplishment you have the profoundest admiration. You cannot help feeling that it would be safer to share some splendid error with Samuel Butler and M. Bergson, or with William James and Mr. Bertrand Russell (if the uncompromising virtue of Mr. Russell's logic left him any margin for error) than to be right in disagreeing with any of them.

In Samuel Butler's case I feel no sort of certainty that, on the one point where I have differed from him, I am even approximately right. His theory of Personal Identity is free from certain complications which are serious drawbacks to mine. Mine, if tenable, would solve the one serious difficulty of his. It would also go far to support the argument for Human Immortality. This, however, must tell against it rather than for it, by suggesting an unscientific parti pris. Pan-Psychism has an irresistible appeal to the emotions. I like to think that my friend's baby made its charming eyelashes, that my neighbour's hen designed her white frock of feathers, and my cat his fine black coat of fur, themselves; because they wanted to; instead of having to buy them, as it were, at some remote ontological bazaar. But emotion doesn't blind me to the possibility that things may not, after all, have hap- 
pened quite in this way. And this is the only "appeal" of any sort that Butler does make. He is pure from the least taint of what Mr. Bertrand Russell, quoting Mr. Santayana, calls "maliciousness."

As for Personal Identity, both his theory and mine are open to the objection that they are not theories of personal identity at all. In this matter I feel as if I had used Butler (and perhaps abused him) for my own purposes. He has giren me an inch and I have taken an ell. Still, I think my ell was very fairly suggested by his inch.

Discorering dilemmas in M. Bergson's philosophy is an enthralling occupation while you are about it; but it leaves no solid satisfaction behind. It does not, as Samuel Butler would have said, give you "peace at the last." When it is all orer you feel as if it had not been quite worth while. What do a few logical dilemmas more or less matter in the work of a poet and a seer? I said just now that Vitalism is a robust philosophy. It is nothing of the sort. It is subtle, exquisite, fragile. To try to analyse it, to break through that texture of beautiful imagination, is to lay violent hands on a living, palpitating thing that endures only on the condition that you do not handle it.

One other part, at any rate, of what I have written calls for some apology - my criticism of Pragmatism which is associated with an honoured name. The monist who hates Pragmatism and lores the pragmatist; who, let us say, abhors William James's way of thinking and adores his way of writing; who, in the very moment of hostility, remains the thrall of his charming personality and brilliant genius, that monist is in no enviable case. But what was I to do? I believe the issue between Pragmatism and Idealism is vital. I believe in Pragmatism as a branch, and a very important branch of casuistry. I do not beliere in it as a philosophy. It is a method and not a philosophy. It is not even a philosophic 
method. Pragmatism is one long argumentum ad hominem, and it is nothing more.

Now, the argumentum ad hominem is all very well in its way, but that way should be purely supplementary. It is a perfectly fair and legitimate method when employed as an outside prop to the clean metaphysical arguments by which a clean metaphysical case must stand or fall. Anybody may use it for all it is worth, provided he gives due notice and isolates it to guard against infection. Mr. McDougall, for instance, defends Animism with a long array of arguments ad hominem; but he uses them under protest, as if he were a little bit ashamed of them; and he is careful to keep them in the strict quarantine of a chapter to themselves. Pragmatism, by its very nature, knows nothing of these precautions. It does not sterilize its instruments before it uses them. It does not want to sterilize them. It is courageous. It courts rather than fears infection. It must stand or fall by its appeal to the pragmatic instinct, the business instinct in men, or it would not be Pragmatism.

And so I do not think that the pragmatist is always fair to his opponents. I do not mean that he weakens their ease by misstatement before he demolishes it. Far from it. You might say that the mere statement of the monist's case was far safer in William James's hands than it is sometimes in his own. I mean that the pragmatic method, faithfully followed, lands the pragmatist in misrepresentation, not of his opponent's case, but of his opponent's attitude. To call Monism the philosophy of the "Thin" and Pluralism the philosophy of the "Thick" is fair enongh controversial practice. Rationalists may not like it, but they have bronght it on themselves. But would it have occurred to anybody but a pragmatist to preface a serions course of lectures on his subject with a classification of Idealistic Monists as "Tender-minded," and of Pluralists as "Tough-minded"? You might just 
as well call your opponent a fat-head at once and have done with it. It is deadly; it is damning; it is unforgettable. Such epithets stick and sting to all eternity. They keep people off Monism. They must have prejudiced William James's audience against it from the start, before he could get in any of his logic.

And that is precisely what it was designed to do.

What was that audience to think when it was told that the tender-minded are: Rationalistic, intellectualistic, idealistic, optimistic, religious, free-willist, monistic and dogmatical; and that the Tough-minded are: Empiricist, sensationalist, materialistic, pessimistic, irreligious, fatalistic, pluralistic, sceptical ?

Observe how Pragmatism appropriates all the robust and heroic virtues, and will not leave its opponent one of them. Think of the sheer terrorism of the performance. Could you wonder if, covered with that six-shooter, Professor James's audience plumped for Pragmatism before it had heard a single argument? Each member of it must have registered an inward vow: "Tough-minded? I'll be that!"

But does the classification really hold? Are the virtues and vices justly apportioned? Nobody thinks of Kant and Hegel as nice comfortable philosophers whose bosoms they could lay their heads on. The Third Book of Hegel's Logic is not exactly an Éducation sentimentale. And the Triple Dialectic is not regarded by anybody except pragmatists as suitable reading for the mentally deficient. Kant's Pragmatism (of which, of course, I shall be reminded) was an after-thought; which doesn't prevent pluralists from using him as a whipping-post when they want to. The author of Die Welt als Wille und Vorstellung was not precisely one's idea of an optimist. There are passages in Dr. McTaggart's Studies in Hegelian Cosmology from which you gather that he is not inaccessible to human tenderness; but, with a toughness that 
no pragmatist has ever equalled, he denies his Absolute to be a "person." He has stripped it bare of everything that is comfortable and nice. If it comes to that, what about the Pragmatic-Humanist's God who is so tenderminded that he cannot be held responsible for pain and evil, and collapses under the sheer emotional strain of his own universe? The God of Pantheism may have his brutal moments and his moments of unbending, but his worst enemies can't say he isn't robust. And there is no tenderness at all about Mr. Bradley's Princples of Logic. As for the Mr. Bradley of Appearance and Reality, if he has a fault, it is that, in the interests of his Absolute, he carries hard-headed, hard-hearted, thorough-paced scepticism to excess. By no possible manipulation of phrases can you make it appear that Mr. Bradley is even soft in places. He is, in fact, a "tough" whom one would have thought few pragmatists would care to meet on a dark night. Mr. Bertrand Russell is about the only living philosopher who can stand up to him. And we have heard before now of dogmatic Realism.

And after all, is it so very certain that logical ideas are tender and that facts are hard? Can you find a fact that's harder, more irreducible, than the principle of contradiction, or than any axiom of pure mathematics? Facts have a notorious habit of elusiveness and liquescence. As for thinness, is there anything more tenuous than matter, apart from our sensations of so-called material qualities? Matter of which William James says that it is "indeed infinitely and incredibly refined." The physicist is he who deals in phantasms of thought, invisible, impalpable, compared with which even Dr. McTaggart's Absolute is a perfect Falstaff.

It looks as if the only things that stand firm in this universe are Ideas. Truth, Goodness, Beauty: there is not a "fact" that bears their imprint and their image 
for long together; yet they, eternal and immutable, remain.

The backbone of Philosophy is Logic. Pragmatism has no logic; it is spineless. Idealism may have too much logic; it may be too rigid. But this, surely, is a fault on the side of hardness rather than of softness. At any rate, the method of Philosophy should be purely logical. The idealist does claim purity for his method; and with some reason. The method of the pragmatist is contaminated with its genial contacts, its joyous commerce with the metaphysically irrelevant.

Pragmatism is an unsterilized Philosophy.

I do not say it has not done good service in criticism; that it has not reminded us of the existence of things that idealistic philosophers forget. But if it were passionately adopted, consistently held, and carried to its logical conclusions, the eternal ideas of Truth, Goodness and Beauty would lose their meaning and we our belief in them. Luckily, people are seldom logical, and consistent, and passionate in their adoption even of wrong methods in Philosophy.

It is painful to differ from M. Bergson and from William James; but it is dangerous to differ from Mr. Bertrand Russell. If there is dismay just at present in the ranks of Idealistic Monism, it must be mainly owing to his formidable methods of attack. I hope there is dismay. I should be very sorry for the idealistic monist who did not feel it. His complacency would do more credit to his heart than to his head. Humanism, Pragmatism and Vitalism have all "gone for" him; but, barring the shrewd thrusts of William James, they have "gone" with no particular "flair" for his special vulnerability. And when touched he could always point to some wider chink in his opponent's armour. The assaults of Vitalism, at any rate, left his position practically intact. But the 
Realistic Pluralism of Mr. Bertrand Russell, of Mr. Whitehead, of Mr. Alexander and the New Realists is a very different thing.

For the logical structure of Vitalism is faulty, though you feel instinctively that M. Bergson "has vision," and that his vision is right. With Atomistic Logic it is the other way about. Its structure is almost flawless; though you may feel instinctively that its vision is, not wrong, but simply not there. I do not think that even an atomistic logician would go so far as to maintain that instinctive feelings and algebraic logic have nothing to do with each other, since feelings can be subjects of propositions. But he would say, and he would be perfectly justified in saying, that, if intellectual truth is your objective, you must get your logic right first and settle it with your instincts and your feelings afterwards as best you may.

Now Atomistic Realism gives no support to the "Belief in the Beyond" and very little encouragement, if any, to the "Hope of the Hereafter." And in this world there is an enormous number of people (probably the majority of the human race) whose instincts and feelings are passionately opposed to any theory which would deprive them of the Belief in the Beyond and of the Hope of the Hereafter. Many of them who would surrender the belief with composure still cling to the hope; many would give up the hope if only they could be sure of the belief. Others again, like William James, are quite genuinely indifferent to the event. The idea of life after death is even slightly disagreeable to them. Personally I do not share either the indifference or the repugnance.

But those who do not desire personal immortality for themselves may desire it for others who are dearer to them than themselves. They cannot face with equanimity or indifference the thought of the everlasting extinction of these lives. And many of them care for intellectual truth as passionately as they care for their hope and their 
belief. And between these two passions the new Philosophy draws a hard and fast line. It says: "If you are out for truth you must play truth's game. Your feelings and your instinets must take their chanee. They must not be allowed to load the dice."

That is the gist of Mr. Russell's austere and beautiful charge to the students of Philosophy; as it was Plato's; to "follow the Argument wherever it may lead"; to wait patiently when it "puts on a veil." There are passions and passions; and it is to the passion for intellectual truth, fiery and clean and strong, that he makes his irresistible appeal.

There are still a great many people who think that the Belief and the Hope are more compatible with some form of "Idealistic Monism" than with "Realistic Pluralism." They think that if Atomism is pushed to its logical conclusion there will be very little chance for God and Immortality. And I gather that Realistic Pluralists think so too.

Is Realistic Pluralism really true?

If it is, every hope and every belief that is incompatible with it must be given up.

But if it is not true, if it is even doubtful, it would be, to say the least of it, a pity that anybody should be lured from his belief and hope by its intellectual fascination. I have tried to disentangle what is true in it from what I believe is merely fascinating. I have tried to disentangle what is untrue in Idealism from what I believe to be sound and enduring. Above all, I have tried to disentangle in my own conclusions what is reasonable supposition from what is manifestly pure eonjecture. I have tried to state my adversary's ease to the best advantage for him. If I have failed in this, it will have been through misunderstanding, and not, I hope, through "maliciousness." Some misunderstanding may have been ineritable in dealing with the purely mathematical side of Mr. Rus- 
sell's argument; since mathematics are, for me, a difficult and unfamiliar country. It is here that I have every expectation of being worsted.

In all this it has been hard to free myself from the fascination of Pluralism. When exercised by Mr. Russell it is so great that almost he persuades me to be a Pluralist. If I have not surrendered it is for reasons which $I$ have tried to make clear.

There is one side of the New Realism which is not directly touched in these essays - its Ethics. This ground is covered by what has been said about its theory of concepts or "universals"; the "Platonic Ideas." But I believe that Ethics owe a greater debt to the New Realism than to any philosophy that has been its forerunner in modern time. If "Goodness" and "Justice" are not eternal realities, irreducible and absolute, "moral sanction" is a contradiction in terms; there will be no ethical meaning and no content that distinguishes "goodness" from "usefulness" or "pleasantness," or " justice" from "expediency." The work of Mr. G. E. Moore is a perfect exposure of the fallacies and sophistries of Hedonism, Utilitarianism, Pragmatism and Evolutionary Ethics. The clearest and strongest statement of the case for " $\mathrm{Ab}$ solute" Ethics is to be found in his Principia Ethica, and in Mr. Bertrand Russell's Philosophic Essays.

The reader must judge whether Absolute Ethics and the moral sanction are securer on a basis of Spiritual Monism or on the Pluralistic theory of "outside" realities. They will remember that a purely external sanction is no sanction at all. The metaphysical basis is crucial in the ethical question.

It may be that it is too late to reconstruct what Realism is destroying. It is certainly too early to forecast the lines on which reconstruction will proceed; and it would 
take a very considerable metaphysical genius to do it. These essays, therefore, only suggest the possibility of the New Idealism.

No doubt many people will find that my "Questions" are out of all proportion to my "Conclusions," and that the Conclusions themselves are too inconclusive. To these I cannot give any answer that would satisfy them. Others will object that my Conclusions are out of all proportion to their grounds, and that far too much has been taken for granted. They will protest against the appearance of an essay on "Mysticism" in a volume professing to deal seriously with serious problems. They may even look on its inclusion as an outrageous loading of the dice.

To them I can only reply that that is why I have given to Mysticism a place apart. I agree that mystical metaphysics are an abomination. But metaphysical mysticism is another matter. I would remind my readers that some psychological questions were part of the programme too; that mysticism is of immense interest and importance in Psychology; and that I have criticized certain aspects of it as severely as its bitterest opponents could desire. I am as much repelled by the sensuous variety of mysticism as I am attracted by its austere and metaphysical form. I am as convinced as any alienist that its more abhorrent psychological extravagances are the hysterical resurgence of natural longings most unspiritually suppressed. These exponents are worthy only of the pity we give to things suffering and diseased.

But there is another side even to what may be called the Saints' Tragedy. There is a passion and a strain and a disturbance of the soul, born of its struggle between religious dualism and its unconscious longing for the $\mathrm{Ab}$ solute.

And there is also a pure and beautiful Mysticism that springs from the vision or the sense of the "Oneness" of all things in God. It know's nothing of passion's dis- 
turbance and its strain. Its saints are poets and its counterpart in Philosophy is Spiritual Monism.

The fact that this sense has been evolved steadily and perceptibly from the primitive savage's sense of the supernatural is no ground for depreciating it. You might as well depreciate the mathematical attaimments of a pluralist philosopher on the grounds that they have been evolved from the primitive savage's calculations with the fingers of one hand. The question for students of comparative religion is, not whether it is a survival (for all life is a survival), but whether its presence marks a reversion or a progression-whether it is a sort of vermiform appendage, or a form inspired with the secret of the life that was and is and is to be.

But I am painfully aware of the extreme uncertainty of my "Conclusions" too. If it had been possible to give them the form of Questions, without making a mess of my sentences, I would have done so. It would have shown, perhaps, a greater courtesy to the Inscrutable. In any case I do not want to be wholly identified with my imaginary monist, who is so undaunted and cock-sure. Under the horrible mauling he gets from vitalists, and pragmatic humanists, and pluralists, he does not, I am afraid, always display the very best metaphysical temper.

Though I think the pragmatic method a wrong method in philosophy I have used it in one section of my final chapter; but I have followed Mr. McDongall's good example in placing it where it could do no harm.

So many sources have been drawn on that but a small part, if any part, of this book can claim to be an original adventure. The best of it is only a following of good examples. Where I have touched on General Psychology I have invariably followed Mr. MeDougall as the best arailable anthority; but readers who are not familiar with his work should realize that he is not responsible for 
any theories I may have based on it, and most likely he would not endorse them.

My thanks are specially due to my friends, Mrs. Stuart Moore (Evelyn Underhill), who first introduced me to the classies of Western Mysticism, and to whose work in this field I am more indebted than I can say, and Mr. Cecil Delisle Burns, who made me acquainted with the New Realists and held continually before me the risks I ran in differing from them. And to Mrs. Susie S. Brierley, for criticism relating to an important point in experimental psychology. Also to Dr. Beatrice Hinkle of Cormell University, for kindly allowing me to use her admirable rendering of the Hymn "I am the God Atum," which appears in her translation of Dr. Jung's Psychology of the Unconscious; and to the Editor of The North American Review for leave to reprint my article on the "Gîtânjali of Sir Rabindranath Tagore."

LoNDon,

May Sinclatr.

January 25, 1917. 


\section{CONTENTS}

INTRODUCTION

I The Pan-Psychism of Samuel Butler . . . . 1

II Vitalism . • • • • • • • • • • • • 44

III Some Ultimate Questions of Psychology . • $\quad$. 67

IV Some Ultimate Questions of Metaphysics . . 109

V Pragmatism and Humanism • . . . . . 127

VI The New Realisul • • . • • • • • • . 151

VII The New Mrsticism • • • • • • • • . 240

VIII Conclusions • • • • • • • • • • • . 290

APPENDIX . . . . . . . . . . • . 340 

A DEFENCE OF IDEALISM

SOME QUESTIONS AND CONCLUSIONS 


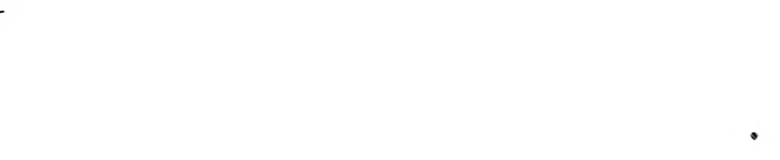




\section{A DEFENCE OF IDEALISM}

SOME QUESTIONS AND CONCLUSIONS

\section{I \\ THE PAN-PSYCHISM OF SAMUEL BUTLER}

I

THe plain man is supposed (by philosophers who are sure of nothing) to be sure that, whatever else he is or isn't, he is himself. He may or may not beliere that he has a soul, or, that, if he has one, it is the least bit likely to be immortal; but he is quite, quite sure he has personal identity; that he is not his own grandmother or his own son; and certainly not one of those objectionable Robinsons.

He may even flatter himself that he has what he calls Individuality.

It is these happy certainties, and this pride of the plain man that Samuel Butler shatters with his theory of PanPsychism. If he does not positively strip every one of us bare of those three things, he maintains that, so far as we can be said to have them at all, they are what we have least cause to be proud of.

As there certainly is a sense, and a very distinct sense, in which a man may be said to be his own grandmother and his own son (if he has a son), it may be worth while asking what we mean by Indiriduality, by Personal Identity, and by a Self ?

It is sometimes assumed, both by philosophers and plain men, that when we talk abont these three things we mean, or ought to mean, the same thing. Yet it is pretty erident that we don't, and that we oughtn't to. We say that a 
man has individuality if he has certain striking characteristics that mark him out from other men. And though, no doubt, by "individuality" we mean something rather more subtle and intimate than, say, a boisterous manner or a taste for Cubism, or for remarkable and distinctive neckwear, we are very far from knowing precisely what we do mean.

Anyhow, the term individuality would seem to stand, not so much for personal identity as for the marks and signs of it, and for something belonging to a self rather than for selfhood.

In the same way, "personal identity" is not a term we can play ducks and drakes with. It does, I think, imply something that either has identity or has it not, that either is or isn't the same something wherever and whenever it appears to be. And that "something," again, would seem to be what we call a self.

But it is by no means certain that the something that we eall a self exists. It is, indeed, highly problematical. And as the existence of the Self happens to be the problem before us we must not assume it at the start.

The trouble is that we have got to make some attempt at a definition, and that our definition must be wide enough to cover all the ground on which the problem has been previously debated. For this purpose we are driven to assume, most improperly, that the terms Self, Selfhood, Personality, Personal Identity, and Individuality all stand for one and the same thing.

For the moment, then, I shall take the simplest of these terms, Self, and define it as that which is present to all states of consciousness in any one conscious organism, and even this is a hazardous definition. Still, I can't think of any other that is more likely to satisfy any of the disputants without begging the question in dispute.

Consider what a question it is.

For materialists the Self is an illusory by-product of 
consciousness, which is itself an illusory by-product of the physical processes of the organism and the world it lives in.

For idealists like Mr. Bradley the Self is one horn of the interesting dilemma which lands him in the Absolute as his only refuge.

For idealists like Dr. McTaggart it is a fundamental, though imperfect, "differentiation of the Absolute"; a paradox that does not quite amount to a dilemma.

For pragmatic psychologists like William James it is Individuality, the bundle of its own characteristics; so its appropriate place is, quite clearly, with the things that are not selves. Which is the other horn of Mr. Bradley's dilemma.

Again, for psychologists intimidated by William James, and anxious not to compromise themselves, it is " psychical disposition," whatever that is.

Souls were "out of fashion" when William James was lecturing at Harvard; but they are coming in again with the courageous psychology of Mr. MeDougall, for whom a self is, in plain, honest language, a Soul.

For biology the self is the Individual, and the Individual is the living organism.

For biologists like Samuel Butler, so far as individuality is more than numerical identity, it is the sum of the characteristics acquired consciously by the organism after its birth, - a contemptible sum compared with the vast capital it carries over from the experience of the race. All that experience (by which it has incredibly profited) the individual keeps stored in his unconscious memory and draws upon for every occasion in his daily life. His unconscious memory is thus a vast pantechnicon of knowledges and aptitudes that serve him far better than any that he can learn or cultivate on his own account. According to Samuel Butler our unconscious life is the only life that is complete and perfect and worthy to be lived. And he drives us to the conclusion that individuality is the 
most insecure of our possessions, and that, any way, the individual does not greatly matter.

We should have had to leave it at that but for certain recent developments in the study of abnormal psychology.

Psychoanalysis, which is based on a minute and detailed observation of the same facts of unconscious memory, suggests the opposite conclusion.

It is odd that the only light that has so far been shed on this dubious question should come from that region of profound murkiness. This is not the place either for a defence or for a critique of Psychoanalysis. ${ }^{1}$ Psychoanalysis is on its trial. The result of the trial need not concern us. Psychoanalysts themselves appear to be divided into two camps. Their differences need not concern us. For our purposes they do not amount to a row of pins. For all psychoanalysts are agreed that the Unconscious is a vast pantechnicon; but a pantechnicon murky to the last degree and chock-full of hideous and repulsive things. But its murkiness need not concern us either. Granting for the moment that we know what we mean by the Unconscious, and that the Unconscious is, or can be, a pantechnicon, and that it is full to overflowing, I see no reason why it should overflow with things hideous and repulsive any more than with beautiful and attractive things. It seems fairly obvious that all sorts of things must have been put away there, and that psychoanalysts have not laid their hands on all of them. Enough that both the psychoanalysts and Samuel Butler find the mainspring of evolution in the organism's Will-to-live and tomake-live. Both assume that the Life-Force is a psychic rather than a physical thing.

For our purposes it does not matter whether the New Psychology of the psychoanalyst lays too much stress on the Will-to-make-live and too little on the Will-to-live. On 
both theories the Will-to-live is indestructible. It persists in the unconscious memory of the individual. And through his unconscious memory the individual is one with the race psychically as well as physically.

But whereas Samuel Butler says our only sane and perfect life is the life we live unconsciously, the whole theory and practice of psychoanalysis rests on the assumption that we only live sanely and perfectly so far as we live consciously, so far as our psyche lifts itself up above its racial memories and maintains the life which is its own that is to say, so far as we are individuals. The secret of individuality lies in the sublimation to consciousness of the unconscious Will-to-live.

To me this theory of sublimation is the one thing of interest and of value that Professor Freud and Professor Jung have contributed to Psychology. Unfortunately the classic literature of the subject leaves this part of it a little vague. The student is told all about psychoanalysis - more indeed than he may care to know; all the horrific contents of the pantechnicon are turned out for his inspection. But it is left to his own ingenuity to discover precisely what sublimation is and how it works. Roughly speaking, it is the diversion of the Life-Force, of the Willto-live, from ways that serve the purposes and interests of species, into ways that serve the purposes and interests of individuals. Roughly speaking, all religion, all morality, all art, all science, all civilization are its work.

Now it may be objected that (unlike Samuel Butler) the psychoanalyst is a specialist, and a specialist in abnormal psychology at that. And, as his conclusions are drawn from minute and incessant observation of the behaviour of abnormal psyches, they can be of no possible use to us. ${ }^{2}$ We are not concerned with the eccentricities of neurotics and of moral lunatics. But though we are not concerned with them, they have a vital bearing on our 
problem all the same. For the net result of the psychoanalyst's investigations can be summed up in three words: Neurosis is degeneration.

In this sphere every transgression is retrogression. Every perversion is reversion. The neurotic, or the morally insane person, has turned back on the path by which he came. He is the slave or the victim of his own unconscious memories and instincts, of that forgotten yet undying past that preys upon the present and the future.

Individuality, on this theory, is the outcome of a successful resistance to racial tendencies. The normal grown-up individual has no longer any need to struggle against the forces that would drag him back and back to the life of the child, the savage and the ape; but the more individual he is the more he will resist the pull of the generation just behind him. And all individuality - the first time it appears - is genius.

Clearly, this triumph of the individual would be impossible if the Will-to-live were incapable of sublimation, and if there were not more of it going, as it were, than what suffices for the needs of the species. We have, therefore, to assume this incalculable amount over and above, and this capacity for sublimation. And here we are up against that bogy of the psychoanalysts'- Repression.

At first sight it seems obvious that sublimation should involve repression. The instincts of the primitive savage must be repressed in the interests of civilization. The baby's sucking instincts must be repressed if the child is to be fed from cup and spoon. Adolescence must break the child's habit of dependence if it is ever to become manhood. At any age there is a limit to the desires the individual can satisfy and the pursuits he can follow with success. Sooner or later a selection must be made; and, other things equal, the beanty and worth of the individual 
will depend on the beauty and the worth of the interests he chooses for his own. All sublimation is a turning and passing of desire from a less worthy or less fitting object to fix it on one more worthy or more fitting.

In the healthy individual there is no more danger in this turning and passing than in the transition from infantile baldness to a head of hair. But for the neurotic every turning, every passage, bristles with conflict and disturbance. He goes through crises that the normal individual never knows. Repression seems to be positively dangerous to him. He cannot take even a little mild correction without it hurting him. He cannot take anything like other people.

Now the psychoanalysts tell yon that wherever there is repression without sublimation there is a neurosis or psychosis. It would be truer to say that wherever there is repression there is no sublimation, and wherever there is sublimation there is no repression. The Will-to-live has found another outlet, the indestructible desire another object, and all is well. For the happy normal individual, desire is never repressed; it is either directed and controlled, or it wanders of its own accord into the paths of sublimation. (Psychoanalysts, out to vilify the Unconscious, have not paid sufficient attention to the facts of unconscious sublimation and all that they imply.)

It is not quite clear whether with the neurotic every attempt at normal control issues in a repression. Most cases seem to point to some inhibition of the process of sublimation. The neurotic is so ticklish that both righteous reproof and tender admonition may have this arresting tendency. Anyhow, it seems pretty certain that, whatever may cause it to occur, genuine repression, the damming up of every outlet for the Will-to-live, does really, sooner or later, set up some form of neurosis.

When this happens, the repressed Will-to-live, the frus- 
trated desire, whatever it may be, turned back again into the Unconscious, is stamped down there, forsaken by the psyche and forgotten.

But it is not destroyed. You cannot destroy what is indestructible. Cut off from the psyche's real life, it sets up an unreal life of its own. It lives again, as all unaccomplished desires live, in the dream world, and in the haunted world below our waking consciousness. There it plays its part, disguised in fantastic and symbolic forms that have an ancient history.

For when Professor Freud began analysing the dreams and waking phantasies of his patients, he discovered that the persistent and recurrent symbols of the neurotic dream and the insane phantasy are the same symbols that we find, persistent and recurrent, in all primitive ritual and myth and folk-lore. For instance, in the dream - which he defines as "the disguised fulfilment of a repressed wish" a serpent, fire, wood, water, a tree, an arrow, a sword, an eagle, a wheel, a circle, a cross, a ram, a lion, a hat, have the same symbolic meaning and are used with the same psychological intention of revelation and disguise as in the oldest rituals and mythologies. Wherever they appear they stand for the Life-Force, the Will-to-live and tomake-live; and their ritual intention represents man's primitive and incomplete effort at sublimation. ${ }^{3}$

They are there, in the Unconscious, just because they were there from the beginning. The very fact that the repressed desire finds them there and arrays itself in them shows how far it has turned back along the path by which it came.

The psyche has forgotten these things and knows nothing. But the Will-to-live has been there before and remembers. It knows its old playground and is at home on it. And there it stays, horribly, forlornly enchanted; beyond the reach of consciousness, its vehicle a symbol, its clothing a dream. 
You see how dreadful it all is, and how easily the cause of neurosis and of insanity might lie there; in the cutting and casting off, the miserable isolation and abandonment of the Will-to-live, its powerlessness to answer to the psyche's call. If the neurotic cannot sublimate his Willto-live it is because his Will-to-live has been turned back so far that all conscious links with it are broken.

If this is not psychoanalysis, it is the purified spirit of psychoanalysis. It is, I believe, the truth that underlies its theory. The reality that underlies its practice is the breaking of the spell of forgetfulness; the deliverance of the Will-to-live from its bondage to the Unconscious. With its restoration to the psyche's conscious life sublimation becomes possible to it. And with sublimation the individual comes again into his own.

In this healing process it is clear that we have to do, not so much with the disclosure of a shameful secret as with the recovery of a lost Will.

It does not look at first sight as if Psychoanalysis had given us anything that amounts to very much. Only three conceptions more or less coherent: a conception of the Will-to-live, valid as far as it goes, but vague, and bound up with a conception of the Unconscious worse than vague, because it betrays its inherent self-contradiction as soon as you begin to work with it: a conception of Sublimation by which this Will-to-live perpetually transcends itself and is made manifest in higher and higher and more and more complex forms of life, - a process described in terms which sound morally satisfying, and are still anything but clear: a conception of the Individual as a being of immense importance, seeing that just thase forces within and without him which arrest and retard his individuality are backward forces; that the worst misfortune that can befall him is the backward turn that lands him in his own past; and that the peculiar malignity of his worst maladies is that they rob him of his power to assert 
his qualities against the general characteristics of the race. Still, this conception of individuality is something. The individual, at whatever stage we find him, appears as the forerumner, the master builder, that superior, swifter vehicle of the Will-to-live which carries it forward and upward. By virtue of his individuality he serves the higher functions of the Will-to-live. The plot thickens, widens, deepens, and grows infinitely richer as the individual gets his hand in more and more.

We have there a perfectly valid and comparatively precise conception.

And yet it is only when we come to the Individual and ask ourselves what we mean by Individuality that our real troubles begin.

This conception of the Individual that Psychoanalysis gives us is bound up with our vague conception of the Will-to-live, which is itself bound up with the still vaguer conception of the Unconscious. And it is this conception of the Unconscious which blocks the way.

Until now, here and elsewhere, to avoid confusion, I have followed my authors in using this term - using it in any sense which happened to serve any purpose of the context at the time. In slavish subservience I have spoken of instincts and desires, symbolic meanings and ideas hidden away in our Unconscionsness, as if our Unconscionsness were a cupboard or a cellar. Just now I spoke of stamping them down into the Unconscions, as if it were so much damp earth, and of lifting them up out of it and carrying them into the Conscions, as if this operation were performed with a spade and wheel-barrow. I even suggested, and not so very figuratively either, a going down into the Unconscious to fetch back the Willto-live.

And all the time I was doing it, it seemed to me that my authors and I were describing a perfectly credible performance. It seemed to follow from the grounds and 
from the whole trend and purpose of Psychoanalysis that the performance was credible; and with each step the Unconscious acquired more and more an almost discernible substance and a palpable power. There it was, underlying everybody's psychic processes, and doing people quite innocent people - all sorts of harm. And if I did not speak of unconscious psychic processes it was more by good luck than good management.

Now, by the Unconscious you may mean, properly, either things without consciousness, such as chairs and tables, and thunder and lightning; or living things, including ourselves, in their moments of unconsciousness. Or a metaphysical Reality conceived as unconscious.

The first sense was not contemplated in any of our contexts. (You cannot talk about stamping instincts and desires down into the inorganic.) And we should have had to be very sure of our "selves" and the "selves" of other organic beings before adopting the second. The third will appear later, but we have no need for it yet.

So our real meaning emerges. When we talk about unconscious psychic states and unconscious psychic processes, we mean psychic states and processes of which we are not conscious. It is owing to the limitations of the language that we are obliged to talk about the states as if they were or could be conscious or unconscious of themselves. We have no business whaterer to hand over our consciousness or unconsciousness to them. We may have to go on talking about conscious and unconscious states, for the sake of convenience in handling sentences, but we should be very sure that we know what we are doing.

On the other hand we cannot talk about states of unconsciousness as if the term were interchangeable with states we are not conscious of. For we have nothing immediately before us from moment to moment but the states of consciousness. A state of unconsciousness may mean any condition of unawareness, from profound sleep 
to mere forgetfulness, or inattention to what is going on around me, or ignorance - say of what President Wilson is going to do about the Blockade, or of what my neighbour is doing in his back garden. A state of which we are not conscious is a state whose existence we infer from its results when we happen to be conscious of them. Such are our so-called inherited instincts, the hidden "complexes," the hidden ideas, meanings and associations revealed under hypnotic suggestion and psychoanalysis; and all states of so-called "unconscious cerebration."

Now at any moment I may wake from my sleep, I may remember what I have forgotten, my attention may be drawn to what is going on around me, even my ignorance of what President Wilson is going to do will cease when, if ever, he should finally make up his mind, and with a little trouble I can inform myself of what my neighbour is doing in his back garden. But of my states of " $\mathrm{un}$ conscious cerebration" I am never conscious; and I may go all my life without being conscious of a single one of my "inherited" instincts or of those hidden things. And the probability is that I shall in no circumstances ever be conscious of by far the greater number of them. Even of the things I merely do not attend to - to say nothing of the million impressions that assail my sense organs every instant, of which every instant I remain profourdly unaware - the chances are that, though they must be faithfully recorded somewhere, I shall never be more conscious of them than I am now.

I am insisting on these distinctions - familiar to every student of psychology - because they help to clear up the original confusion, and because we shall have to consider them very carefully later on.

For the moment, then, we must assume that the terms Unconscions and Unconsciousness stand for any or all of those psychic or psychophysical states of which we are not conscious. And by the "Conscious" and the "Con- 
sciousness" we have been talking about we mean states of consciousness and nothing more; otherwise we shall be begging the question of the existence and the nature of the ultimate principle we desire to re-establish later on. We ought to mean this, and we must mean it; for, whatever else we want to mean and intend ultimately to mean, it is all that discreet Psychology will allow us to mean at present.

"Unconsciousness" or "the Unconscious," then, resolves itself into a negative abstraction.

But we must not forget that in our context its function was neither negative nor abstract; it played a very positive and concrete psychological rôle. And if we are asked whether in dismissing it we have anything half so good to put in its place, we may say that states, or processes, of which we are not conscious will do extremely well; and if we want to keep the old terms, "the Unconscious" or "Unconsciousness," understood as a sort of convenient shorthand for these fuller and more precise terms, we may. Or we can use them as equivalents for the sum of those processes and states.

As we have seen, by far the most important part among them was taken by the Will-to-live. It is this Will-to-live that we have conceived of as transferred and transformed, or sublimated, and as passing over from the Unconscious to the Conscious, as if it belonged reritably and by its own nature to both worlds. If it did it would be as good a bridge as any we have a right to ask for; and it may prove to be all the bridge we are entitled to have.

But we found the greatest difficulty in representing to ourselves at all intelligibly its double rôle. And as far as our conception of Individuality and Personal Identity is bound up with this conception of the amphibions nature of the Will-to-live it will be affected by its vagueness and confusion. It may be that this is inevitable, and that we cannot form any intelligible conception of either, or of 
their relations to each other; in which case we shall have to accept the problem as insoluble and put up with the vagueness and confusion.

Let it be clear that this trouble is the old trouble carried a step farther, and that the vagueness, confusion, and unintelligibility arise from nothing more or less than the intrusion of the Unconscious, with a big $\mathrm{U}$, into the region of the Conscious with a big C. As a matter of fact, unconscious states, states we are not conscious of, always are intruding, that is to say, conditioning, determining, generally influencing, and for all we know to the contrary, actually causing conscious ones. They can do this to the disturbance and the detriment of our Individuality, or perhaps (a most disagreeable thought) even of our Personal Identity.

Now, if it could be shown that there never was an unconscious psychic state that was not, at some time or other, a conscious one, and may be, at some time or other, a conscious one again ; if it could be shown that all unconsciousness at least of what we call "past" states is simply a forgetting which is never final and complete; if, further, it could be shown that what we call forgetting is never fortuitous or arbitrary, is never even involuntary, that we forget not because we must, but because we will and for our own purposes, and that we remember for the same reason, remembrance being selection and selection an act of will, and that both remembrance and forgetting serve the interests of our individuality and are part of the everlasting process of sublimation, we shall be very much nearer the solution of our problem than we are now.

I confess that I should not have known where to turn for the precise evidence which will show this if it were not for the work of Samuel Butler, the only thinker, so far as I know, except his predecessor, Professor Ewald Hering, ${ }^{6}$ who has succeeded in making the subject of Heredity thoroughly intelligible. I might have said, 
who bas made it thoroughly amusing at the same time.

The undeserved neglect of Butler's scientific work is probably owing to his incurable habit of being amusing, not mildly and academically, but startlingly, recklessly, extravagantly amusing throughout the entire course of a serious argument. What was the scientific world of the 'seventies and 'eighties to think of a man who could dream of immortalizing his Address on "Memory as a Key to the Phenomena of Heredity" under the title of Clergyman and Chickens? ${ }^{7}$ It seemed to consider that a man who couldn't control himself far enough to be serious over a serious subject like that was not to be taken seriously. Besides, though Butler could dissect clergymen very skilfully, it was evident that he had never so much as skinned a chicken in his life. So the scientific bigwigs of his day neglected Butler. And I am afraid that eren at this moment Psychoanalysts who can talk about the "polymorphous perverse" and the "Father-Imago" without the ghost of a smile will have no use for Butler either.

Still, they ought to have, for he has done more to make them intelligible than they have themselves.

I cannot help myself to as much of Butler as I should like, for I should get into tronble with the holders of his copyright. So I must refer my readers (if I am lucky enough to have any) to the four books on evolution and heredity: Life and Habit, Evolution Old and New, Unconscious Memory, Luck or Cunning? and all the passages in The Note-Books of Samuel Butler which bear on those subjects and on individuality and Personal Identity. And if in the end I accept Butler's theory of Heredity and reject his theory of Individuality and Personal Identity it is for his own reasons and for others which I hope will be made clear.

First of all (readers of Butler must forgive me if I take them over ground already familiar to them), first of all he starts with certain observations of experience. Ac- 
tions which we once performed with difficulty and with attention, with immense effort of will and intense consciousness, such as playing an instrument, writing, reading, talking and walking, we now perform automatically and unconsciously, and with a success increasing according to the extent of our practice, that is to say, according to the numbers of times those actions have been repeated, the point of perfection being only reached when the action is performed unconsciously.

All these actions, constantly repeated, have become habits of our body.

Still, a certain amount of consciousness goes with the action of walking, and a greater amount with the action of talking, and so on, while (Butler might have added) continuance of all of them past the point of fatigue will bring us back to effort and consciousness again. So that we can realize how great must have been the effort and how intense the consciousness they started with.

But the older actions and habits, such as the beating of the heart, breathing and digestion, are unaccompanied by consciousness and effort, or any memory of consciousness and effort. ${ }^{8}$ And Butler asks: "Is it possible that our unconsciousness concerning our own performance of all these processes arises from over experience?" 9

His entire theory of evolution is thus based on the simple truism that Practice makes perfect. ${ }^{10}$ When he finds an action performed with a supreme perfection, a supreme unconsciousness, he concludes - not that these actions have always been unconscious, but - that ages of practice, of effort that has been conscious, have gone to the result. ${ }^{11}$ He argues that we do these things so well only because we have done them before, because in the persons of our parents and our ancestors we have practised doing them for untold ages. (Observe that Butler regards the experience of our parents and our ancestors as our experience just as much and in as much as our bodies 
are our bodies.) Because - in short - we know how to do them.

"What is to know how to do a thing? Surely to do it. What is proof that we know how to do a thing? Surely the fact that we can do it. A man shows that he knows how to throw the boomerang by throwing the boomerang. No amount of talking and of writing can get over this; ipso facto, that a baby breathes and makes its blood circulate, it knows how to do so; and the fact that it does not know its own knowledge is only proof of the perfection of that knowledge, and of the vast number of past occasions on which it must have been exercised already." ${ }^{2}$

And what holds good of the baby and its body after birth holds good before birth.

"A baby, therefore, has known how to grow itself in the womb and has only done it because it wanted to, on a balance of considerations, in the same way as a man who goes into the eity to buy Great Northern shares. . . . It is only unconscious of these operations because it has done them a very large number of times already. A man may do a thing by a fluke once, but to say that a foetus can perform so difficult an operation as the growth of a pair of eyes out of pure protoplasm without knowing how to do it, and without having done it before, is to contradict all human experience. Ipso facto that it does it, it knows how to do it, and ipso facto that it knows how to do it, it has done it before." 13

And what holds good of the unborn baby holds good of the primordial germ plasm.

"There is in every impregnate ovum a bona fide memory, which carries it back not only to the time when it was last an impregnate ovum, but to that earlier date when it was the very beginning of life at all, which same creature it still is, whether as man or ovum, and hence imbued, as far as time and circumstances allow, with all its memories." 14

That neither the baby nor the germ consciously knows and remember any longer is what we might infer from the present ease and perfection of their performances. 
"We must be all aware of instances in which it is plain we must have remembered, without being in the least degree conscious of remembering. Is it then absurd to suppose that our past existences have been repeated on such a vast number of occasions that the germ, linked on to all preceding germs, and, by once having become part of their identity, imbued with all their memories, remembers too intensely to be conscious of remembering, and works on with the same kind of unconsciousness with which we play, or walk, or read, until something unfamiliar happens to us?" 15

This "something unfamiliar" that happens to it being birth.

And when we look at the life of the grown-up individual and of the baby and of the germ as an unbroken series, it is a "singular coincidence" that "we are most conscious of and have most control over" our distinctively human functions, and that we are "less conscious of and have less control over" our prehuman functions, and that "we are least conscious of and have least control over" those functions "which belonged even to our invertebrate ancestry, and which are habits, geologically speaking, of extreme antiquity." 16

Surely an utterly incomprehensible arrangement if we exclude consciousness and design from evolution; perfectly comprehensible, not to say inevitable if we admit them. ${ }^{17}$

There are other facts in evolution which are perfectly explicable on Butler's theory, and utterly incomprehensible if we exclude desire and design and the continuity of consciousness in all organic beings. Such are the sterility of hybrids, the instincts of neuter insects; and, to some extent, the effects of use and disuse, which fit into it without exactly calling for it. ${ }^{18}$

His conclusion is, not that memory and instinct are habit, but that all habit and all instinct are memory; ${ }^{19}$ that both are the result of practice; that both, unerring and perfect in adaptation as they have become, presuppose 
knowledge and volition on the part of the individual that displays them, and not, as we are accustomed to imagine, merely on the part of its ancestors; that when we talk about inherited memory or inherited anything, we have fallen into confused thinking and are using words without meaning; that every reflex is a lapsed volition, and all unconsciousness a lapsed consciousness; that change and growth arise in fulfilment of a need, a want, a "libido," having at one time been brought about with consciousness, with design and with volition; that the individual inherits bis own and not another's, and therefore knows it again so perfectly that he is not "conscious" of it, he himself, the irreducible entity, having been present in all experiences and in all memories we call racial or ancestral.

"What is this talk that is made about the experience of the race, as though the experience of one man could profit another one who knows nothing about him? If a man eats his dinner, it nourishes him and not his neighbour; if he learns a difficult art, it is he that can do it and not his neighbour." 20

But when we come to ask how the Indiridual has been present in the experiences of his ancestors, and in what way his ancestors, on this theory, differ from him, Butler's answer, though transparently clear, is hard to reconcile with any conception of the importance of the Individual. Not that there is the smallest confusion in his mind on this crucial point:

“. . . an impregnate orum cannot without a violation of first principles be debarred from claiming personal identity with both its parents. ..."

". . . We ignore the offspring as forming part of the personality of the parent ... the law ... perceives the completeness of the present identity between father and son. . ."

"The continued existence of personal identity between parents and offspring." (Life and Habit, pages 85, 95, 97.)

"But can a person be said to do a thing by force of habit or routine when it is his ancestors and not he that has done it 
hitherto? Not unless he and his aneestors are one and the same person." (Unconscious Memory, page 17.)

It is also expressly stated that " oneness of personality between parents and offspring" is the first of the "four main principles" laid down in Life and Habit. (Unconscious Memory, page 19).

"Personal identity cannot be denied between parents and offspring without at the same time denying it as between the different ages (and hence moments) in the life of the individual." (The Note Books of Samuel Butler, page 375.)

On this showing the individual has but little that he can call his own. It is not so much that the memories of his ancestors are platted in with his memories as that his memories - all but the comparatively few and insignificant ones contributed by his experiences after birth - are platted in with theirs. To say that this is impossible, because he has never appeared as an individual before birth, is to beg the question of his appearance and his individuality.

It is clear that Butler had no particular prejudice in favour of his own conclusion, but that he was driven to it by an impartial survey of the facts. We shall see later on that he was driven into the very last place where we should expect to find him, the last place where he would have wished to be. I repeat, there is no confusion and no hesitation in Butler's mind on this point. We were our own parents and grand-parents, we were our entire prehuman ancestry. Even after birth we are little else besides, and before birth we were nothing more.

He even regards the individual's life while yet in the bodies of his parents as superior to his life after birth, because he considers that all perfect knowing is unconscious.

"When we were yet unborn our thoughts kept the roadway decently enough; then we were blessed: we thought as every 
man thinks, and held the same opinions as our fathers and mothers had done upon nearly every subject. Life was not an art - and a very difficult art - much too difficult to be acquired in a lifetime; it was a science of which we were consummate masters." (Life and Habit, page 60.)

And yet, Butler has just pointed out that unless we have maintained our own personal identity throughout the experiences of our forefathers, those experiences will in no way profit us.

On his own showing this must be so. Equally on his showing it is difficult to see how it can be. For, throughout the entire argument the individual is identified with his own experiences after birth and with his own and his parents' memories before. (Their experience as individuals is presumably what he does not share.) All his embryonic experiences are "vicarious," and more vicarious his experiences further back. At the same time he is said to have "participated" in these experiences. The trouble is that when Butler talks about a man's being identified with his parents he does not seem to have considered all that is implied in identification. $\mathrm{A}$ is identical with $\mathrm{B}$ in this that $\mathrm{B}$ is identical with $\mathrm{A}$. If a man is identified with his grandfather his grandfather must be identified with him. But, according to Butler, identification is a lopsided affair in which $\mathrm{A}$ persists and $\mathrm{B}$ disappears, while everything depended upon B's persistence. So where, by what chink, does "he" come in? And in what cranny does he lodge? If the most that he can show for himself is this cellular, prenatal existence in the bodies of his parents and his grand-parents and of all his countless ancestors, each of whom must have enjoyed precisely the same sort of existence in the bodies of their parents and ancestors, we are still no nearer the secret of his being. Granted that he thus participated in each and all of their experiences in his primordial cellular way, still the manner of his participation remains mysterious, even if we as- 
sume, as we perfectly well may, a most extraordinary capacity for participation and for storage of experiences in the cell.

How are we to imagine participation - practical and intelligent participation, such as will enable him to perform creditably a series of complicated co-ordinated actions as soon as he is born - without a participator?

Butler's arguments are unanswerable. We cannot explain or account for the most ordinary facts of our life and consciousness without presupposing that we have lived and been conscious before.

And yet there is not one of his unanswerable arguments that cannot be turned against his own conception of Personal Identity.

Unless the Individual carried through all his previous experiences some personal identity over and above that of his progenitors, their experience will remain theirs and be no earthly good to him. For he could not profit by it to the extent he has been proved to have profited, if, at every stage of his past career, he had not been capable of absorbing and assimilating it - of taking it to himself. Therefore he must have a self, a continuous, indestructible self, distinct from his progenitors' selves, yet in direct communion with them, to take it to.

It is precisely that self, that personal identity over and above, that Butler denies to him. And in denying it to him he denies it equally to each of his progenitors all along the line. There is none to participate and none to profit. Grant him that self, and the whole process of evolution and the whole problem of heredity are transparent as a pane of glass. Deny it and we are where we were in the dark days of Darwinism. But, whereas Darwin and Wallace at least left us free to take what Natural Selection could not give us, what Butler's right hand gives us his left hand snatches from us again.

It is as if Buffon and Lamarck had opened a window on 
the dark side of our house, looking towards our past. And it is as if Butler had found that window and cleaned it, and made it bigger, and called to us to look through, and then, in sheer perversity, had closed and darkened it before we could look again and be sure of what we had seen.

Without a self, over and above organism, over and above memory, the whole series of past memories and past , experiences is unthinkable.

For we start with an individual. Even if we could conceive him maintaining his divided identity fairly well in the persons of his parents, and perhaps of his grandparents, what of the generations behind them? What of his infinite division, the scattering of him, the indivisible, throughout those geometrically increasing multitudes?

But even his pre-existences are not much more unthinkable than the poor and precarious existence which is all that Butler allows him as an individual after birth. For if it is not quite clear how he persisted in his parents, and whether anything of him persisted over and above them at all, there is no sort of doubt as to how his parents persist in him and in what ravaging and overwhelming proportion. ${ }^{21}$

Could there be a more shocking irony of fate than that Butler, who did more to destroy the prestige of parents than any writer before or after him, who so abhorred the idea of parentage that he resisted "the clamomings of the unborn" rather than commit the cruelty of giving any child a father however much it might desire a fathercould there be a more shocking irony than that this great repudiator of parents, this passionately original and individual soul, should be driven by his own terrible logic to identify himself indistinguishably with his father and his mother and his grandfather and his grandmother, and so on backwards with all his ancestors, and that he should have regarded the life identified with theirs as infinitely richer and more important than anything that he conld 
claim and call his own? Nor could he have answered that he only objected to parents as individuals, for he has made it clear that he objected to them most emphatically as parents; so that this plea would only impair his logic without diminishing the irony of his case.

Now, I think it can be shown that he was not really driven to this suicide, but that it happened to him because he put the cart before the horse, and attached personal identity to memory, and memory to organism, instead of attaching both to personal identity.

All the same, as an account of the gathering together of memories, and of the apparent miracles of psychic synthesis performed as a matter of course by every living organism, as a view of evolution which makes every stage in its process transparent as a pane of glass, Butler's theory is perfect. It is a clear vision of all life as one organism and of that organism as God. That he could not allow God to be anything over and above an organism, and was pained by the merest suggestion that he might possibly be more, was the logical consequence of his refusal to admit that the Self could be anything over and above its memories. This consistency should not be charged too heavily against him. Nor can we hope to substitute anything clearer for that clear vision of his.

Let us see whether we cannot keep it intact while adding to it the very factor that Butler left out of the account.

The problem of the relation of psyche to organism would be comparatively simple if living beings descended from one parent. It is obvious that we are following up, not one thread but two threads, each of which is soon lost in a multiplying network of threads; and we must faithfully concede the self to be present in each and all of them if it is to gather together the experience which will enable it to burst on the world as an expert in psychic and biological behaviour. Could anything well be more unthink- 
able than a theory which compels us to this vision of selfhood maintained in such a multiplicity as that? Identity where all identity is lost? Were we not better off with the old simple idea of hereditary transmission which we had accepted before Samuel Butler came among us to disturb our peace?

Well - were we?

We have an idea, a vague idea, it is true, but still an idea of the unity of individual consciousness, of the holding together in one synthesis of a multiplicity of states, and eren this idea does little justice to the astounding complexity of that synthesis. It is identity in multiplicity with a vengeance.

But we have no idea at all of how hereditary instincts are transmitted. The physical theory of the transaction leaves the essence of the thing - its psychic complexity untouched. The idea that a complicated system of experiences can be handed over as it stands to a psyche innocent of all experiences, and used by that psyche, instantly, with the virtuosity of an expert, is about as thinkable as the idea that the Central London telegraph and telephone system could be handed orer to and successfully worked by a single operator ignorant of the first principles of telegraphy.

Of the two I would back the operator.

You do not make it a bit more thinkable by regarding the heritage as accumulated by imperceptible increments from generation to generation, since in the last resort the whole of it has to be handed over en bloc.

I said it would be simpler if living beings were descended each from one parent. And, as it happens, if we follow it far enough back, the bewildering process simplifies itself, since eventually we do trace them all to one.

Supposing that we turn from our present and our future and set our faces backwards, and imagine that network of the generations - our generations - spread out before us 
and streaming away from us to our past, and that we hold the hither end of it by the single thread of self. The network is broken in many places where individuals have remained single and left no issue, and where whole families and species have dropped out. But, on the whole, it is a comparatively continuous network. If we could follow all the unbroken threads of all the meshes to their beginning on the farther end of the net, we should find them all united again in one thread, one single living being. A being of extreme primordial simplicity, but not simpler or more primordial than our own very complicated organism was when it began as a single germ-plasm.

And thus the Individual that we saw so scattered has become one again. Somewhere, in some time and earthly place, he and all the individuals he sprang from have existed in some relation to one simple, indestructible, primordial speck of protoplasm.

What is the nature of that relation?

Only five relations are possible.

1. We may suppose that the speck of protoplasm produces the personality, and in reproducing itself produces another personality; and that reproduction of organism and production of personality go on till we come to reproduction through the union of two primordial cells, which so far from altering the essential nature of the process only knits it tighter. This process of reproduction, which is what actually happens on the physical side - on the part of the organism - is, on the psychic side, unthinkable because open to all the objections which have been brought against the theory of transmission. That is to say, a personality which has been produced brand-new with each organism, by each organism, has ipso facto been absent from the past experiences it is supposed to profit by. To say nothing of the enormous difficulty of conceiving the production of a psyche, a consciousness, from a speck of 
protoplasm by a speck of protoplasm. A difficulty which will meet us again.

2. Or we may suppose that all the innumerable personalities that have been and shall be are present somehow with or in that one original speck of protoplasm, and are simply transplanted with or into succeeding specks of protoplasm as they multiply, and are developed with the development of the organisms. This theory would account all right for the sharing of the experiences, but it may be dismissed as putting rather too great a strain on one small speck of protoplasm.

3. We may suppose that the burden of reproducing its own kind is borne by the self, and that it takes an even share in the labour of a psycho-physical association, each self looking after its own future development, the business of the protoplasm being limited to producing more protoplasm and building itself up into organic forms. This theory ignores the influence of the organism, through which the self gains its experiences and therewith its development, and the influence of the self by which the organism is built into just such forms as are adapted to the needs and the ends of the self. We are not helped by any theory of the mere production of self by self. For, again, unless some portion of the original self endures in the selves it produces it cannot impart to them its own experience or benefit by theirs. And unless the selves again - have been present with it in all its past experience, they cannot share and benefit by it.

4. Let us suppose, then, that the greater strain (which is, after all, a purely metaphysical one), is borne by this hypothetical self; that the self and not the protoplasm contains within itself all selves that are and shall be, and that the relation of the self to the original speck of protoplasm, and to all succeeding organisms throughout all generations, is that of the association of an undivided, unap- 
parent being with the means of its division and appearances. We have here a much more workable conception of the self, inasmuch as our difficulties are shifted to the metaphysical sphere where anything may happen. Some awkward things are bound to happen to an unapparent metaphysical being when once for all it makes up its mind to appear. Still, they need not be too awkward. On this theory the integrity of the original self must suffer severely if it does not endure throughout all its multiplied experiences, that is to say, if it is lost in the multiplicity of selves; and the integrity of the selves suffers if they are lost in it.

Either, then, there is no such thing as the integrity of the self, or:

5. Each self is something over and above all other selves; over and above its own organism and all organisms in which it has had part; over and above its own experiences and memories gained through association with all the organisms. Until they are actually born as individuals the selves will be members of many groups, associated through the organisms they share, in such sort that the experiences and the resulting benefits are mutual. Neither experience nor benefit being obtainable unless we presuppose in each self a " personal identity" over and above all other selves in its own organism.

On this hypothesis, which I believe to be the one in strictest accordance with the theory of Pan-Psychism, the relation of self to organism will be by no means the simple affair of one self, one organism, but will stand somewhat thus. At one end of the scale, entire ownership of the first speck of protoplasm which it finds itself associated with, in the sense of one self, one organism. At the other end of the scale, practically entire ownership of the organism it is born with as an Individual. In between, starting from below upwards, half ownership of 
two specks of protoplasm, supposing the original speck to have split up into two, and to have taken up with two other selves; ownership of one-fourth of each member of the next two pairs similarly formed; ownership of one-eighth in the four succeeding pairs, and of one-sixteenth in the next subdivision; and so on till his share diminishes to a thousand millionth part, say, in a thousand million organisms.

But always, throngh all his thousand million incarnations, his thousand million shares in other people's undertakings, though his experiences are scattered and subdivided, he is never lost.

$\mathrm{He}$ is only lost if, with Samuel Butler, we insist on identifying him with his business and his innumerable partners in the business, and ignoring his constant and indestructible presence. He is only scattered and divided if we think of him, not in his own metaphysical (or for the matter of that metapsychical) terms, but in terms of protoplasm. You might just as well think of him in terms of the colour that would indicate his presence in a diagram.

As for his infinitesimal share, it is decidedly better, from his point of view, to hold an infinitesimal share in an infinitely great undertaking than to be entire owner of one speck of protoplasm.

As we have seen, the most awful consequences, for the Individual, follow if we hold the theory of heredity preeisely as Samnel Butler held it. I do not see how they are to be avoided as long as we persist in identifying the self with its memories and with the organism by means of which it acquires them. On the other hand, it must be admitted that the difficulties of the hypothesis of independent selfhood are great. But I do not believe them to be insuperable, if we bear in mind that selfhood is not necessarily interchangeable with "individuality," or numerical personal identity in the sense of one inhabitant of one body. 
In that sense an individual is not an individual until he is born, and in any case our bodies may very likely have more psychic inhabitants than ourselves.

It may be objected that on this view of the self the origin of its own and of all succeeding organisms looks a bit inadequate. But if its own original and indestructible germ-plasm was, as it certainly seems to have been, a sufficient organism, to begin with, for a self that has drawn together innumerable past memories, why should not the original speck of protoplasm be an organism sufficient to begin with for a self that harbours innumerable future possibilities? If we conceive of the organism as nothing more or less essential to the self than its means of appearing, of manifesting itself, we do greatly simplify the problem of their relation, that everlasting subject of contention for biologists and psychologists and philosophers.

Let us think, then, of the self's relation to its organism as the seeking, finding, possession, and more and more perfect use of a means to manifestation. Obviously, it can only manifest itself through its behaviour and its experiences. Instantly, then, it begins to behave and to experience. Even at this very earliest point in its extraordinary career, it knows how to behave and to experience. The first experience of any account that comes to it is when it finds that the original speck of protoplasm, sufficient for a start, is absurdly insufficient to carry on with. (If we like, we may imagine that other selves, baffled by this insufficiency, have given up their protoplasms in disgust, but that our self is more patient and more adventurous.) So, in obedience to its inner urging, the speck of protoplasm grows.

But still this humble self-contained existence cannot satisfy its unquenchable longing to appear.

And so, it compels its organism to reproduce itself, and 
the first Scattering begins. Only by scattering, by incessant subdivision, can it acquire sufficient experience and sufficient practice in behaviour to fit it for the life it is to lead, the really personable appearance it is ultimately to present. When the self has acquired enough animal experiences, and enough practice in animal behaviour, and an organism so obedient to animal promptings that it can be trusted to run itself without perpetual interference from higher authority, then and not till then, it becomes human. Literally, we can only do our work as men because, as Samuel Butler has shown, we have done all the animal part of it for ourselves so efficiently in the past. Just imagine how we should get on if, before we conld cook our dinner and while we were eating it, we had to give our personal attention to each one of our visceral functions separately; if in order to digest we had to superintend our digestion, or in order to breathe we had to superintend our breathing. Or if in order to fight we had to sce to the working of each separate unit of the fighting machine which is our body. Or if in order to write a poem ( $\mathrm{I}$ do not want to labour my instances, but the case of the poemwriter has points of special psychological importance), if in order to write a poem we had to superintend each separate operation of our hand, each separate operation of our brain, to turn back on our path in time to recover all our meanings, to travel in space to find and capture the loveliness we know. We can understand the why and wherefore of the process of our evolution when we reflect that all the selves that we have ever been, that we have put under us in the successive stages of our ascension, are working for us now, clearing up all the troublesome and boresome jobs we are tired of and so repudiate, and leaving us free for our own affairs, the work of the proud individuality we now are.

Whatever he may have been and is, the scattered one does 
not and cannot appear as a complete and full-blown Individual until he has made up his mind once for all to gather himself together and be born.

And this presumably is precisely what he has done. Therefore, throughout all the generations he has existed as want, striving, desire, will-to-live, to burst forth and be born. If we were puzzled about the striving of the One to become Many, what about this striving of the Many to become One?

\section{II}

The question now arises: What of his immortality? Is this outcome of his supreme effort his one and only appearance as an individual? Does he scatter himself again in his descendants and find his immortality only in them? Has he come to nothing if he leaves no descendants?

Now on Butler's theory, which identifies the individual with his own organism and his own parents, he has no immortality of his own, only a scattered and vicarions life after death in the persons of his descendants (if he has any) ; only a subjective immortality in the memory of posterity, if he has had sufficient forcefulness to impress posterity. In fact, on Butler's theory, his chances of existing as an individual in the first place, of ever being born at all, depend on circumstances over which he has no control. For all Butler's belief that it is " the clamouring of the unborn" that is responsible for each individual existence, so that the entire culpability of the enterprise rests with the unborn, and no child has a right to blame its parents if the enterprise should turn out badly, still, as the potential parent can and frequently does turn a deaf ear to the clamouring, the actual deeision rests with him. And his refusal, or the mere accident of his death, even if he is well-intentioned, dooms untold millions of personalities to extinction. 
The individual, then, has but one chance of existence to several million chances of extinction, and he has no possible prospect of any immortality that counts. And, if we narrow him down to his bare achievements as an individual, the small experience he acquires for himself in his short life-time, compared with his immense accumulations in the persons of his progenitors, doesn't really amount to a row of pins; so that existence itself, when it does happen to him, hardly seems worth the trouble of being born. Why all those tremendous labours of the generations for such a poor result? Why all those strivings and longings to be made manifest for such a pitiful appearance at the end? If you say it is all for the Race and not for the individual, and that the individual only exists in and for the Race, that doesn't make the affair a bit more intelligible or a bit better.

In fact it makes it worse, for we are sacrificing a reality, a poor, perishing reality, but still a reality for as long as it lasts, to an abstraction. For what is the Race but an abstraction, if it is not the sum of the individuals that compose it? And for the matter of that, races themselves are doomed ultimately to extinction.

It may be so, and if it is so we must bear it; for we cannot help it. But we are only driven to the conclusion that it is so if we accept Butler's view of personal identity, or the view of all those persons who, on this point at any rate, are agreed to agree with him.

If it can be shown, in the first place, that the achievements of the Individual are not quite so insignificant as has been made out; and in the second place, that, so far from personal identity being dependent on memory (and ultimately on organism), memory (and organism ultimately) are dependent on personal identity, to the extent that not the simplest fact of consciousness, and not the simplest operation of building up a primordial germ-cell, is possible without the presupposition of personal identity; 
if further, there is even the ghost of a reason for inferring, in the absence of any other assignable cause, that the mysterious thing we call Personality behaves as we know causes do and can behave, then, though immortality will not follow as an absolutely certain conclusion (how could it?) there will at least be a very strong presumption in its favour. Whether there will be evidence to satisfy the authority whom Butler called "any reasonable person" is another thing. People show their reasonableness in such different ways.

Even from the foregoing brief review of the latest findings of Psychoanalysis it must have been obvious that they are the corollary of the conclusions Samuel Butler drew from the processes of evolution. It is not necessary to go over all that old ground again in order to point out the correlations. The reader cannot have failed to identify that need or want, which Butler traces for us as the spring of all evolution, with the Will-to-live, the "libido" which the psychoanalysts have traced for us as the source of all life and the spring of sublimation. Only when it comes to the relative value of racial and individual qualities, of unconscious and of conscious being, do the psychoanalysts part company with Samucl Butler.

First of all then, if they did not openly declare the supreme importance of the individual, they showed us that his grown-up individuality, be its quality what it may, is a far more highly sublimated thing than the bundle of racial functions and qualities he "inherits." To say that I am inferior to my own grandmother, as I very well may be, simply means that my grandmother was the superior individual, that is to say that the functions and qualities that distinguished her from her progenitors had a higher sublimative value than the functions and qualities that distinguish me, not that the functions and qualities she, in common with all my other ancestors, bequeathed to me are more highly sublimated than mine. Yet, wretched indi- 
vidual that I am, coarse where she was fine, most stupid where she was most intelligent, ungraceful and unlovely where she was all grace and all beauty, still, by the one fact that I refused to be submerged by my racial qualities and functions, that I lifted my head above the generations and added another living being, another desire, another will, another experience to the sum of liuman experiences, by the mere fact that, after all, here I am, playing my part and not any of their parts, I prove the superiority (as far as it goes) of my sublimation.

Besides, if it comes to that, who is to say whether these undesired and undesirable traits of mine are really mine and not part of my "inheritance" ?

It is when I fall short of my part, when I return on my path and go back to them, or when I simply refuse to grow up and persist in being a child, and not a very enterprising, or intelligent, or original child at that, it is when, in four words, I resign my individuality, that I become inferior. And the one word for it is Degeneration.

To be degenerate is to fail to add the priceless gift of individuality to the achievement of the race. (Therefore it seems an inappropriate word to apply to those very considerable individuals who have given their priceless gift in the form of genius, however far they may have fallen short of the ethics of the family and the crowd, and supposing this falling short to be a more frequent attribute of " true genius" than it actually is. We may suppose that this failure in one direction is the price they have to pay for their supremacy in another; and posterity that benefits by their loss should be the last to remember it against them. As a matter of fact, in spite of the efforts of biographers to fix it firmly in its mind, posterity very seldom does remember it at all.) And if it comes to that, what debt can the individual owe to the race that is greater than the debt the race owes to the individual? What, after all, was the origin of our much-valued, much-talked-about racial character- 
istics? The instinct of self-sublimation, the desire and subsequent effort of certain enterprising individuals to outdo themselves, to be something that they are not yet, something, however small, that their progenitors were not. Think of the enterprise (compared with foregoing enterprises), the daring originality of the creature that first "improvised" a stomach because it wanted one. Can you deny an individuality, and, all things considered, a very startling individuality to that creature? And to go back to our much-valued, much-talked-about, and possibly overrated progenitors, every single one of them was an individual once; and his value for posterity was chiefly his individuality; if he only showed it in the choice he made of one female rather than another for his mate. Individuals, in their successive (and successful) sublimations, raised the primordial will-to-live from the level of mere need and want, through the stages of desire, to those supreme expressions of individuality - love and will.

There is too much talk about the Race. The race is nothing but the sum of the individuals that compose and have composed it, and will compose it. Not only so, but, without the individuality, the very marked and eccentric individuality of individuals, races and the Race itself would not exist. It is the ontstanding individuals, the "sports," that have been the pioneers of evolution. They have enriched and raised the species by compelling it to adopt their characteristics.

And yet it looks as if in the welter of unconscious and subconscious memories and instincts the individual had little, if anything, that he conld call his own. He is dwarfed to utter insignificance by the immensity of his ancestral heritage. But I do not think we have to choose between the views of the comparative value of the Individual and the Race and the comparative amounts of their respective debts to each other, for we cannot separate them. Our problem is more fundamental. 
We have to choose between a difficult (I admit it is a very difficult) theory of the continuous identity of one self in many organisms, associated for a while with the equally continuous identity of many selves to one organism, and a self-contradictory theory which insists on continuous memory as the clue to the mystery of the individual's past evolution, and yet regards him as a momentary, insignificant spark of consciousness struck out from the impact of the masses of rolled-up unconscious memories; each individual, in the series of generations that come together to form the masses, being himself such a momentary insignificant spark. At this rate continuons consciousness, that is to say, continuous memory, vanishes from the whole performance.

Between difficulty and self-contradiction there can be only one choice. The alternative to the spark theory is not handicapped by any inherent contradiction. The individual's heritage is his, if we allow him, not only that "sense of need" which Lamarck and Buffon allowed him, and that "little dose of judgment and reason" which Huber claimed for his insects and Samuel Butler claimed for all organisms, but " a little dose" of selfhood over and above his sense of need, over and above reason and judgment, over and above memory. The Individual is not his heritage. His heritage is his. It is the stuff he works with and sublimates and transforms; it is the ladder he has raised himself by, the territory he has conquered - or it is nothing.

There is, of course, that alternative.

Can we justify our assumption that selfhood is over and above?

Now there is a very strong consensus of opinion among psychologists and "mental philosophers" that Personal Identity does depend, and depend absolutely upon Memory. So strong that I have considerable qualms about putting 
forth any opinion that runs counter to that consensus. It is strongest among those who, like Mr. William James, M. Bergson, and Mr. MeDougall, by no means regard mind as entirely dependent on its physical basis. It is upheld by arguments that appear at first sight to be unanswerable, and that on no theory should be lightly set aside.

So far, I have been going all along on the assumption that we conceive Personal Identity as something which, whatever its ultimate nature may be, "holds consciousness together." We must not assume the thing we have got to prove; so we cannot take for granted that what we call Personal Identity amounts to anything we think of as a substance, or a self, or a soul, or as a being in any way separate from and independent of consciousness. For all we know, it may be no more than the relation of each conscious state to another and to the whole. We take the term as equivalent to " the unity of consciousness." Consciousness certainly appears to be a unity, whether there be a self to make it one or no. We have nothing immediately before us but states of consciousness, yet they appear to arrive in a certain order and to hang together with a certain cohesion of their own. Describe consciousness in terms deliberately chosen so as to exclude the Personality we must not take for granted; say that its states are only fortuitously associated; still, association involves, perhaps I ought to say constitutes, a certain unity. Say that consciousness is nothing but a stream, and that though it appears to have islands in it, the islands are really only part of the stream; still the stream would not be a stream if it had not a certain unity.

It must be borne in mind that, for all we are justified in saying about it beforehand, this unity may be nothing more than the relation of states of consciousness among themselves. But when we have reduced consciousness to the simplest, the least assuming terms, we have still this unity to reckon with. Even if the dream of Professor 
Huxley came true, and the "mechanical equivalent of consciousness" were found to-morrow, even if consciousness were proved to be nothing but a strange illusory byproduct of the brain, the queer spectral illusion of its unity would still confront us.

And bere is my opponent's main argument. How, on any theory of consciousness, could these appearances be kept up without memory? If, as impression supervened on impression (to take consciousness at its "lowest"), each were instantly effaced; if we forgot our states of consciousness - I mean if consciousness forgot $i t s$ states - as fast as they occurred; that is to say, if consciousness kept on continually forgetting itself; if there were no sort of even illusory registration anywhere, what becomes of even that illusory unity? And what on earth becomes of personal identity, supposing there was such a thing anyway? If we could never remember anything that happened to us we might just as well not exist at all, for we should never be conscious of our existence. Personal identity may or may not be provable, but without memory it is unthinkable.

I hope the adherents of memory as the presupposition of personal identity will not find fault with this way of putting it. I do not think it is an unfair statement of their position. I do not want to weaken their position in order to have the poor pleasure of demolishing it. It is not at all easy to demolish. And perhaps it is I and not they who are responsible for the only palpable flaw in it, the ultimate argument ad hominem; for it is clear that we might exist without being in the least aware of our existence; in fact, that is the way most of us do exist; it may even be the only terms on which it is possible for us to exist at all. I think there is something in the point; but let it pass. Let the case stand without it. Personal identity may or may not be provable; without memory it is unthinkable.

But - is it? 
It may be that neither is possible, or at any rate actual, without the other. But thinkable? If you can prove the existence of personal identity, of a self, a soul, a principle, call it what you like, that is conscious, but is not consciousness, that is inseparably present to all its states of consciousness and identifiable with none of them, unless it be with the act of will, I will undertake to "think" it.

You say you can only prove it from consciousness, that is to say, from memory. Perhaps, very likely. But that is only saying that it is dependent on memory for its consciousness, its mode of existence, not that it is dependent on memory for existence itself.

We have just seen how Samuel Butler landed himself in the very bosom of the progenitors he abhorred, as well as in a certain amount of self-contradiction, just because he would insist on identifying personality with memory. Even the "plain man" to whose common sense he was always appealing, could have told him better than that, for the plain man does not place his identity in the fact that such and such things happened to him at such and such a date, but that at such and such a date they happened to him, to such and such a person. The whole point and poignancy of their happening, and of his remembering them, is that they happened to him, and not to another, and that he and not another remembered them. The plain man very properly assumes that he has a self, that he personally was present at such and such dates, that he is personally present to each state of consciousness as it arises, and to the piling up of each state on another, and to the whole.

If you choose to say that he himself is only another bit of consciousness added to the pile - that the affirmation of self-consciousness comes forever and from moment to moment to the top - that is a theory like another. But I do not think it is a very good theory, because it overlooks the fact that he was at the bottom too, and went through all 
the layers. And most certainly the plain man would have none of it.

But let us say that personal identity presupposes memory and is dependent on it. Then it follows rigorously that whenever we forget our personal identity ceases. It goes out for long hours together in decp sleep when we have no memory and no consciousness at all. And it comes to life again with the return of consciousness and memory. I am afraid I do not see anything in the theory of its independent existence half so unthinkable as the recurrent miracle of its death and resurrection. ${ }^{22}$ Let alone the inconvenience of not knowing whether it is we who have come back and not somebody else. If you say we do know, because the revived memories are the same, and that we have no other means of knowing, the answer is that in the first place we do not know that they are the same, and in the second place that they are not the same; for ever in continuous memory all we get is a succession and a synthesis of states, a memory of a memory, and identity of them there is none. Sleep has so divided to-day's " unity of consciousness" from yesterday's that to talk about identity of states is absurd. So it looks as if memory and unity of consciousness, so far from constituting personal identity depended abjectedly upon it.

And are we so very sure that Personal Identity is unthinkable without Memory?

I do not mean merely inconceivable or unimaginable. I suppose, for that matter, we can conceive, or imagine, or present to ourselves any state of consciousness as existing independently of any other, or the whole of consciousness as existing without anything to "hold it together"; in fact, it is in this self-sufficiency that consciousness does present itself immediately and before reflection. By ruling out all presuppositions of thinking we may and do conceive it so ; and many philosophers have refused to conceive it otherwise. 
In the end it must be shown that personal identity is more than a presupposition of our thinking, if we are to avoid the fallacy of concluding that what is first in thought is necessarily first in existence. It must be what Kant called a "Voraussetzung der Erfahrung," a presupposition of Experience, something without which experience would not be what it is or what it appears to be. But for the moment let us suppose that personal identity is unthinkable without memory.

With what memories or memory did our conscious life, then, begin? Say that it started with unconscious memory (the "heritage"). Well and good. But for consciousness that is the same thing as starting with no memory at all. To all intents and purposes, I, or if you prefer it, my conscious states, start with an absolute blank behind as well as before them. In this case it will be truly my body that remembers, and not I or they; and though its memories will affect very profoundly my conscious states when they do arise out of the blank, for me or for consciousness they do not exist; nor can they exist on the theory of unconscious memory, or on any theory that precludes personal identity; that is to say, the existence of a self before memory.

We saw that "the heritage" itself, the instinct, the knowledge made perfect through long ages of practice, all that we have learned to call unconscious memory, is meaningless unless it has once been conscious, and would be utterly useless to us if it were not our memory; we saw, that is to say, that our past consciousness likewise presupposes personal identity, a self.

I admit that the argument from forgotten memory cuts both ways. But when we consider that our conscious life, the life of each individual in the series, began with a forgetting, and that in order to know perfectly we must know how to forget perfectly, it looks as if the argument that 


\section{PAN-PSYCHISM OF SAMUEL BUTLER 43}

presupposes memory has, if anything, the more dangerous edge.

And if, to avoid both edges, we turn for safety to the obvious alternative that memory and selfhood, or that memory and consciousness are neither afore nor after another, but simultaneous and mutually dependent, consciousness becoming memory before we are conscious of it, we are faced again with the annihilating fact of forgetting.

All these dangers and dilemmas are avoided if we do but put selfhood where the plain man puts it, and where our everyday thinking puts it - first. 


\section{II}

\section{VITALISM}

I sHaLL be reminded that dangers and dilemmas would be avoided much more easily and surely if we would only consent to put memory where the physiologist puts it - in the brain-cells of the organism, and leave it there. This would certainly be one way out, if memory were really that simple affair of neural association fixed into habit which the physiologist takes it to be.

But does not memory presuppose two things which are not simple - Space and Time? Time for the order of events in memory, space for their juxtaposition? It is not easy to see how any set of neural associations could yield either. Whether as presuppositions or as forms of arrangement (schemata), they stand, as it were, between memory and that hypothetical self, removing memory a stage farther yet from its supreme place as the first. Memory itself is so dependent on them that we can make no valid statement about it that does not take them into account; and it will be no use trying to show that personal identity is independent of memory unless we can show also that it is independent of space and time.

And space and time draw with a large net.

The view that M. Bergson has set forth in Sur les Données immédiates de la Conscience and La Matière et la Memoire does more to make clear the relations of Time, Space, and Memory than perhaps any philosophy before the day of Vitalism.

This clearness is not altogether due to M. Bergson's metaphysical theory; for, as we shall see, that theory lands 
him in many hopeless contradictions by the way. But his view of time and space does not stand or fall with his theory of the Elan Vital; and, whatever the ultimate destiny of Vitalism may be, no metaphysic that comes after it can afford to ignore M. Bergson's really very singular view. It is mainly owing to its author's brilliant and reckless inconsequence that Monism can suck advantage out of it. M. Bergson makes things apparently easy for himself at the start by letting the work of the mere intellect (in his own phrase) "filter through," and plunging into the thick of immediate consciousness. In order to preserve its integrity he has to break with all past conceptions of time as quantity, discontinuous, infinitely dirisible. But as this idea of time as discontinuous, divisible quantity has an awkward way of cropping up in spite of him, he distinguishes between Pure Time (Durée) and, as you might say, popular or spurious time.

Pure Time, or Durée, is intensive, and neither divisible nor measurable; that is to say, it is not quantitative but qualitative. For Time is pure succession, and never simultaneity. Simultaneity is juxtaposition, and juxtaposition is a spatial thing.

"La durée toute pure est la forme que prend la succession de nos états de conscience quand notre moi se laisse vivre." (Données immédiates de la Conscience, page 76.)

"On peut . . . concevoir la succession sans la distinction, et comme une pénétration mutuelle, une solidaritè, une organisation intime d'éléments, dont chacum, représentatif du tout, ne s'en distingue et ne s'en isole que pour une pensée capable d'abstraire. Telle est sans doute donc la représentation qui se ferait de la durée un être à la fois identique et changeant, qui n'aurait aucune idée de l'espace. Mais familiarisés avec cette dernière idée, obsédés même, par elle, nous l'introduisons à notre insu dans notre représentation de la succession pure; nous juxtaposons nos états de conscience de manière à les apercevoir simultanément, non plus l'un dans l'autre, mais l'un à côté de l'autre; bref, nous projetons le temps dans l'espace, nous exprimons la durée en étendue, et la succession prend pour 
nous la forme d'une ligue continue ou d'une chaîne, dont les parties se touchent sans se pénétrer." (Ibid., page 77.)

Time thus conceived is a bastard conception, due to the intrusion of the idea of space into the domain of pure consciousness.

Space, in which all juxtapositions occur and no successions, is purely quantitative, discontinuous, and divisible; and this bastard time, of which clock-time is the glaring example, takes on all the quantitative characteristics of space. Past, present, and future, the time we divide into moments, days and years, is quantitative, is spatial. In pure Time there is no past, present and future, only durée, the past which "bites into" (qui mord sur) the present, the present that bites into the future.

There are no interstices in time.

Let us take it at that and see what happens.

You can never say of pure Time that so much of it has passed, an hour, a minute or a second. This is the spurious time which is really spatial, measured by the shadow on the dial, the sand in the hour-glass, the hands on the clock. Moreover, shadow and sand-grains and hands move, and movement is in space.

This is plausible - and we shall presently see why.

It must follow that if I beat time: tum - tumty - tum - tum : tumty - tumty — tum, I am really beating space. For, though a tumty is equal to a tum, their equality is of space and not of time. For all the time they take, there is no difference between one hundred and twenty-five tumties and one tum, seeing that there are no interstices in Time's tum where its tumties could creep in.

In fact, time is taken by M. Bergson as a convenient stuffing for the interstices of space.

And, since Time is pure succossion and not simultaneity, no two events can happen in the same pure Time. And there is no time left for them to happen in but that impure time which is really space. So that "Every 
minute dies a man, Every minute one is born" can only mean that the death and the birth occupy the same space; which is precisely what they are not doing and cannot do.

Then there is Pure Space, which is quantitative, measurable, infinitely divisible. Space is responsible for the awkward interstices we do not find in Time. And though we think of space as divisible, we perceive it as extended, that is to say, continuous. According to M. Bergson, in pure perception, immediate consciousness, all contradictions are solved and all difficulties overcome. Let us say, then, that we do actually perceive space, or at any rate objects in space, as extended. It is in space and space alone that objects can lie peaceably side by side. But I am afraid it follows that they cannot succeed each other, for succession is of Pure Time. Therefore there can be no movement. The movements of molecules in bodies, and of atoms and of electrons in ether, or wherever it is they do move, the course of the stars in heaven, and the long succession of motor buses and vans and taxis on earth, in the Strand, is occurring, not in the Strand, and certainly not in Pure Space; but where the long succession of my thoughts is occurring, in Pure Time.

You see what has happened? Under M. Bergson's skilful manipulation space and time have simply changed rôles.

For if quantitative time, in which events are simultaneous, is an impure and spurious time that is really space, you may as well say that continuous space, in which objects succeed each other, is an impure and spurious space that is really time.

Again, M. Bergson's Pure Time is Durée, continuous duration. But surely duration and succession contradict each other every bit as much as extension and divisibility.

I do not think that M. Bergson can be allowed, more than anybody else, to have it both ways. But his contention is that in action and immediate perception which is 
based on action and on action only, you do as a matter of fact get it both ways. You have got it both ways before you have time to go back on the performance and see what you have got and how you have got it. It is a performance that sets at nought all mathematical laws of space and time and motion; that takes no account of the behaviour of hypothetical electrons in a hypothetical medium.

M. Bergson gives a reality to sensible space and sensible movement which he denies to mathematical space; consequently he has no difficulty in assuming " real" movement. He argues that, because differences of sensation depend on differences of movement, and because differences of sensation are intensive, and qualitative, and absolute, are of kind and not of quantity or degree, therefore movement is absolute.

"In vain we try to base the reality of movement on a cause distinct from it; analysis always leads us back to movement itself."

And this whether you watch the movements of objects in external space or are conscious of your own movements in muscular sensation.

"... I touch the reality of movement when it appears to me, within me, as a change of state or of quality."

Exactly as in my other sensations which are obviously qualitative.

"Sound differs absolutely from silence, as also does one sound from another sound. Between light and darkness, between colours, between shades, the difference is absolute. The passage from one to the other is, also, absolutely real. I hold, then, the two extremities of the chain, museular sensations in me, the sensible qualities of matter outside me, and neither in one case nor the other do I seize movement, if movement there be, as a simple relation: it is an absolute." (La matière et la Memoire, page 217.)

Between these two extremities M. Bergson finds the movements of external bodies properly so-called. And 
you would have thought that these bodies and their movements might have given him pause. But no. Some objects move; others remain stationary. How, he asks, can we distinguish between them? How can we distinguish between real and apparent movement here?

These questions he leaves unanswered. They are beside the point. The question is, not how changes of position in the parts of matter are accomplished, but how a change of aspect is accomplished in the whole.

You see what has happened? M. Bergson has shifted the terms of the problem from morement and immobility, that is to say, from that change of position which is the very essence of the question raised, to change of aspect of the whole, which was not in question. If you accept change of aspect of the whole, as the equivalent to change of position of the parts, you have committed yourself, without further argument, to the proposition that movement of objects in space is on all fours with my sensations of movement; it is qualitative; it is absolute.

And the real problem, change of position, with its burden of quantitative spatial relations, of distance, and the rest, has been quietly burked.

M. Bergson does not tell us how we can distinguishon his theory - between stationary and moring objects, between real and apparent movement "here." The question was trembling on my tongue long before he asked it; it excites still my burning curiosity. But he is not going to satisfy my intellectual prurience. Never shall I know how he squares it with a theory of morement as absolute and qualitative. Having demonstrated that extension or space, as we perceive and feel it, is continuous ("le caractère essential de l'espace est la continuité"); that only the unreal constructions of mathematics put asunder what the God of immediate conscionsness hath joined; and that science is in accord with immediate consciousness in returning, after all, in spite of appearances, to the "idea of 
universal continuity" (page 219), and that all breaking up of matter into independent bodies with absolutely determined contours is artificial, he finds that the irresistible tendency to constitute a discontinuous material universe comes from Life itself. 219.)

"A côte de la conscience et de la science il y a la vie." (Page

"Quelle que soit la nature de la matière, on peut dire que le vie y établira déjà une première discontinuité.... Nos besoins sont done autant de faisceaux lumineux, qui, braqués sur la continuité des qualités sensibles, y dessinent des corps distinctes. Ils ne peuvent se satisfaire qu'à la condition de se tailler dans cette continuité un corps, puis d'y délimiter d'autres corps avec lesquels celui-ci entrera en relation comme avec des personnes. Établir ces rapports, tout particuliers entre des portions ainsi découpées de la réalité sensible, est justement ce que nous appelons vivre." (Pages 220, 221.)

You could not have a more brilliant, nor, I believe, a truer picture of the evolution and behaviour of living organisms. But it is not a metaphysic that M. Bergson has given us here. Unless we are to insist that the operation of carving portions, as with a knife, out of presumably pre-existing "sensible reality" lands us in a metaphysic, and a bad one at that.

What I would like to point out is that the "faisceaux lumineux" of our needs have taken the place of the old exploded "thought-relations" of idealism, the "diamond net" into which the universe is cast, and that while the function of the diamond net was to hold together, the function of the "faiseeaux lumineux" is to break up and carre.

That is to say, Life does what Thought was blamed for doing. It gives rise to discontinuities and distinctions just now deelared to be unreal, contradictory and artificial. Vitalism may steal a horse, but idealism mustn't look over the hedge. 
And now the contradictions thicken. When we carry Life's operations further we are prolonging vital movement and turning our backs on true knowledge (page 221). Yet it is science that exacts this prolongation, and in the process "the materiality of the atom dissolves, more and more, under the gaze of the physicist." (Page 221.)

We have Life itself aiding and abetting him by starting the disastrous process which represents, for MI. Bergson, "an ordinary form of useful action mal à propos transported into the domain of pure knowledge." (Page 221.)

Why mal à propos? If it belongs to the domain of pure knowledge, it belongs; if it does not belong, we have no grounds for complaint; and anyhow Life began it.

However, the further the process is carried into that domain, the more the physicist is forced to renounce all hypotheses of solid atoms, of bodies formed of solid atoms, and of real contacts between bodies - of such a universe, in short, on which we have " most manifestly a grip."

"Why do we think of a solid atom and why of shocks? Because solids, being bodies on which we have most manifestly a grip are those which interest us most in our relations with the external world, and because contact is the only means of which we can apparently dispose in order to bring our body into action upon other bodies. But very simple experiments show that there is never real contact between two bodies which move each other; besides, solidity is far from being a state of matter absolutely cut and dried. Solidity and shock, then, borrow their apparent clarity from the habits and necessities of practical life - images of this kind do not throw any light on the ultimate nature (fond) of things." (Page 222.)

These considerations, far from leading M. Bergson to suspect that both in practical life and in the hypotheses of pure knowledge we are dealing with appearances, far from throwing doubt on the absolute reality of that time and space movement of which we have immediate consciousness, confirm him rather in his view that here, if anywhere, is the absolutely real world. 
And so, while nothing can bridge for him the gulf between this reality and pure knowledge - his whole philosophy is based on this distinction - we have the apparent contradiction that it is life, desire, action, the very things held to be most manifestly "real," that are responsible for the work of division, which, on the theory that life puts together and thought divides, should belong to the intellect.

And on the very next page we are told, indeed, that, while science tends to dissolve it more and more into forces and movements, the atom "will preserve its individuality for our mind that isolates it"; the only atom which science knows being, to Faraday, "a centre of forces," each atom occupying "the whole of space to which gravitation extends," and "all the atoms interpenetrating each other" ; while, according to Professor Thompson, it is " a ring of invariable form, whirling round and round in a perfect, continuous, homogeneous and incompressible fluid which fills space." (I am translating M. Bergson's translation of Faraday and Professor Thompson.) And, M. Bergson, caught between continuity and discontinuity, and committed to the theory that the difference between all qualities is absolute, while confronted by the view of science and of common sense that movements go on independently of us in space, which he admits to be quantitative, concludes that "real" movement is the "transport of a state rather than of a thing" (page 225).

There will, however, owing to that admission, still be an irreconcilable difference between quality and pure quantity, between the world of our " heterogeneous" sensations and the world of "homogeneous" movements independent of our sensations, unless it can be shown that differences between "real" movements are more than quantitative - that real movements are "quality itself." 
To this hopeful idea of real movement as quality $\mathrm{M}$. Bergson takes his flight.

Let us say, then, that "real" movement is quality and see what happens. All differences of movement, differences in direction, distance and velocity, will then be qualitative, absolute. There can be no degrees between approach and distance and between fast and slow. We are compelled to think of fastness and slowness, and of distance and of approach and flight in terms of absolute, irreducible moments. A strange doctrine this for a philosopher who insists on the continuity of real space and real movement and of real or pure perception. I said "compelled to think"; but this is not an affair of the compulsions of our thinking; when you come to quality it is an affair of immediate perception and of life itself. And this "absoluteness" of quality makes, not for continuity, but for discontinuity, as far as "external realities" are concerned.

True, M. Bergson distinguishes between this qualitative " real" movement and the movement which is the subject of mechanics. But when it comes, as it must come, to the relation between the two we are faced with another difficulty. The movement which is the subject of mechanics " is nothing but an abstraction, or a symbol, a common measure, a common denominator, which permits comparison of all real movements among themselves." (Pages 225, 226.) (The italics are not M. Bergson's.)

Now how, in heaven's name, can movement, thus declared to be purely quantitative, serve as a common measure and common denominator of all movements declared to be purely qualitative? In movement, as such, not even immediate consciousness, the all-reconciler, can discern the ghost of absolute quality. Not until you (and science) have translated morement into terms of energy, into intensity, which is quality again, can you escape from 
quantity. Nor can you altogether escape it here, since science presupposes amounts of energy and degrees of intensity which immediate perception knows nothing of. Not even in the interests of Vitalism should we confuse those "absolute" qualities, those immeasurable intensities of sensation which accompany the putting forth of energy with the measurable intensities of energy itself.

In the same way the movements of our bodies are attended by muscular sensations and sensations of freedom and well-being which are purely qualitative, but, I think, we have no business to argue from them to the quality of movements.

But to return to these real and qualitative movements of which quantitative movements are the common measure and denominator. Looked at in themselves (envisagés en eux-mêmes) they are

"indivisibles which occupy duration, presuppose a before and after, and bind together the successive moments of time by a thread of variable quality, which," M. Bergson says, "should not be without some analogy with the continuity of our own consciousness. . . If If we could draw out this duration, that is to say, live in a slower rhythm, should we not see, in proportion as this rhythm slowed down, colours fading and lengthening out into successive impressions, still no doubt coloured, but more and more ready to merge in pure vibrations (ébranlements)?" (Page 226.)

That is to say (unless the brilliance of M. Bergson's style blinds me to his meaning), that those differences in the movements of molecules, differences of which I am not immediately conscious, by determining the qualities of my sensations, of which I am immediately conscious, take on continuity and quality, so that their world, the world of "unreal" vibrations, reflects in some sort the continuity of consciousness.

We have seen that M. Bergson uses time as stuffing for the interstices of space. We now see him using qualities 
of sensation as stuffing for the interstices of movement, which is as good as a confession that he can no more get continuity out of his "real" movements than he can out of any other movements. And his adroit suggestion of "some analogy" does not disguise the essential truth of the matter, that from first to last it is the continuity of consciousness that has done the trick.

What are we to make of a theory which seems, now, our only clue to the very heart and secret of reality, and now a splendid mass of incoherences? We have the "real" movements of which M. Bergson has just said that the movements known to mechanics are the common measure and denominator; we know that the laws of physics are based on those very laws of mathematics which are not real in M. Bergson's sense of reality, being the work of the intellect that divides; we have the qualities - sensations of which we are told that they are absolute, that is to say, irreducible as any atom; and we have movements which, but for the quality which is called in to stop their gaps, would be as discontinuous as space itself. And with these irreducibles M. Bergson builds up his certainty.

And the Élan Vital does not help him, since it began the whole business of defining and dividing, of burrowing and digging holes, as it were, in real space and drawing the contours of bodies to suit its own purposes.

And supposing we were justified in transferring the quality of sensations to the molecular movements to which we are obliged to refer them, quantity being thus transformed into quality, the common quantitative measure and the common denominator would no longer apply.

What M. Bergson does not appear to admit is that all space, even "real space," may be an intellectual construction; that there is no perception of extension so immediate as not to presuppose it, so pure as not to include it; that, as the work of thought, it is as discrete or as continuous as thought pleases, that is to say, it may be both; and that, if 
it were continuous only, as continuous as the real space of M. Bergson's immediate perception, it would be no less quantitative on that account.

I do not want to dispute M. Bergson's conclusions: that matter is the vehicle and plastic tool of the Élan Vital; that pure remembrance is a spiritual manifestation; and that with memory we are actually in the domain of spirit. These are precisely the conclusions to which I believe the balance of the biological and psychological argument inclines. But I do not see that these conclusions are supported by a theory which begins and ends in metaphysical dualism, that tries to establish "reality" on the far from stable ground of action plus immediate perception, and that, in spite of having coolly let "filter through" every consideration inimical to its argument, lands itself in perpetual contradictions in its efforts to escape from the position it has created for itself.

For, while it takes its stand on action and immediate perception as alone affording the clue to the Real, and asks us to suppose such absurdities as that homogeneous space is logically posterior to "material things and the pure knowledge that we have of them "- knowledge that it declares, four pages later on, to be tainted with the impurity of the sensations, "qui s'y mêlent" (Page 262) - and that extension precedes space (Page 258), at the same time, we are to suppose that it is this very same homogeneous space that "concerns our action and our action alone." (Page 258).

M. Bergson's aim is to escape the pitfalls of Realism and Idealism alike, to "resoudre les contradictions," to "faire tomber l' insurmontable barrière," and at the same time to " rejoindre la science."

He finds a common error in the realism of the vulgar herd that takes for granted a world of things existing 
plump and plain outside and independent of any consciousness, and the realism of Kant that presupposes a Thingin-itself independent of and inaccessible to consciousness: "l'une et l'autre dressent l'espace homogène comme une barrière entre l'intelligence et les choses." (Page 258.)

You wonder why Kant should be lumped with the rulgar realist when he made of homogeneous space and of time, not barriers erected, but forms of the intelligence for the co-ordination of the data of sense.

The common error is that both realists made space a condition $\grave{a}$ priori of experience; whereas immediate perception has no à priori elements, nothing is afore or after another; but our experience, consisting mainly and primarily of action, so to speak, gathers space and time with it as it goes along. Space and time will thus be "given" with the sensations, co-ordinated by means of them. It is not quite clear whether M. Bergson means that sensations occur ready co-ordinated in space and time, and that our perception reflects, as it were, the given co-ordination, or whether it is we who co-ordinate as we go along. From his theory of perception co-ordination (of objects in space) would seem to be given; from his theory of action that we co-ordinate would follow. Anyhow, co-ordination proceeds hand-in-hand with experience, and is not provided for it beforehand.

The shipwreck of Idealism, rather, is in "the passage from the order which appears for us in perception to the order which succeeds for us in science." (Page 253). And Idealism and Realism proceed from a common error, in that, on both theories, "conscions perception and the conditions of conscions perception are directed towards pure knowledge, not towards action." (Page 258.)

Here M. Bergson, and the great body of modern philosophy with him, part company with the metaphysics of the past. He has put his finger on the weak spot of all the 
transcendent theories - their neglect of action; "toujours elles négligent le rapport de la perception à l'action et du souvenir à la conduite." (Page 254.)

Let us see how a philosophy fares that is directed towards action and action alone.

In order to escape Realism and Idealism M. Bergson identifies perception with "preparation for our action," having "laissé filtrer," the work of intellect, its logical constructions and presuppositions and the account that science gives us of the real or assumed action of external things, on the grounds that thought-relations and "real" action are not given in immediate perception; but, having decided that pure perception is concerned with action and with action alone, and that "the body is an instrument of action and of action only," he has less difficulty than might have been supposed in establishing the correspondence between perception and cerebral states.

Yet we find in this correspondence that the cerebral state is "neither the cause nor the effect, nor in any sense the duplicate," but simply the "continuation " of perception; perception being "our virtual action and the cerebral state our action begun." (Page 260.) It is a "correspondence" and yet it is a "continuation." It is a continuation of perception and yet not perception itself.

Now the only way in which one thing can be the continuation of another without being that thing itself is for it to be an effect of that thing, the cause passing over into, that is to say, continuing in the effect. And yet this continuation-cum-correspondence of perception is not its effect.

And this perception - already doubly tainted by identification with our virtual action of which our body is the instrument, and the action of "things" upon the instrument - is what M. Bergson calls "pure."

And the taint does not end there. This theory of pure perception must be "attenuated and completed." Pure perception is mingled, further, with affections (sensa- 
tions) and recollections (memories). We have to "restore to body its extension and to perception its duree," to "reintegrate in consciousness its two subjective elements, affectivity and memory." (Page 260.)

We have seen what has happened to extension and durée. We have now to see what happens to perception and memory. M. Bergson, plunging into the very thickness of experience, starts with the extremely one-sided proposition that our body is an instrument of action and of action only. The true rôle of perception is to prepare actions. Perception is

"nothing but selection. It creates nothing; its rôle, on the contrary, is to eliminate from the ensemble of images all those on which I should have no hold; then, from among the images retained, to eliminate all which have no interest for the needs of the image I call my body." (Page 255.)

"The body is a centre of action and of action only. In no degree, in no sense, under no aspect does it serve to prepare, still less to explain, a representation .... all in our perception that can be explained by the brain are our actions begun, or prepared or suggested, and not our perceptions themselves."

So much for perception.

When it comes to memory, the body preserves motor habits capable of bringing the past again into play; also, by "repetition of certain cerebral phenomena which prolong ancient perceptions, it will furnish to remembrance a point of attachment with the actual, a means of reconquering a lost influence over present reality." (Pages $251,252)$.

We might ask how cerebral phenomena can "prolong" what they have never been concerned with. But let that pass. We shall be involved in still more serious contradictions before we have done with this theory of perception as a preparer of actions only. We are not quite sure whether we are to suppose that the function of perception is not to perceive, or whether it is to perceive only those things that make for action. 
"Here," says M. Bergson, "is my body with its "perceptive centres.' These centres are shaken and I have a representation of things. On the other hand, I have supposed that these shakings can neither produce nor translate my perception. It is, then, outside them. Where is it?" M. Bergson has no hesitation in deciding that it is " in " material objects. My perception " ne peut être que quelque chose de ces objets eux-mêmes; elle est en eux plutôt qu'ils ne sont en elle." IIis grounds for this view of perception are that in "posing" his body he "poses" a "certain inage" and witl it "the totality of other images"; because his body has its place in this assembly he concludes that his perception must be there also.

And though the body and its cerebral shakings have nothing whatever to do with his perception, which exists outside them (can he mean as an independent object in space?), the unique rôle of these shakings is to prepare the reactions of his body and to sketch out his possible actions ("actions virtuelles"). Lest we should conclude rashly that in this case the rôles of the cerebral shakings and of perception are one and the same, he tells us that perception consists in detaching from the ensemble of objects - not particular objects or groups of objects but "the possible action of my body on them." (Page 255.)

So that, whatever else it may be, the primary function of perception is not to perceive.

Perception, therefore, is selection.

Now this is surely giving a somewhat incomprehensible and contradictory account of a complex but perfectly intelligible performance. Because perception, in addition to its obvious function of perceiving - of being aware of - and its less obvious and possibly disputable functicn of posing its own objects, has a distinct reference to action, just as it has a distinct reference to appetite and love and aesthetic emotion and moral attitudes and intellectual interest and cosmic rapture and mystic passion and every 
conceivable mode of conscious experience, because both attention and intention play a part in determining what perceptions shall dominate our experience, making all allowances for the part they play, we are still not justified in contending that perception is nothing but selection with an exclusive reference to action.

And it is the same with memory. Its primary function is "to evoke all past perceptions which have analogy with some present perception, and to recall to us what went before, and what followed after, and thus to suggest to us the most useful decision among possible decisions." (Page 254.) True, this is not all. M. Bergson distinguishes between physical memory, which is an affair of motor habit associations, and "pure" memory. Pure memory holds together "in one unique intuition the multiple moments of durée, it disengages us from the movement of the flux of things, that is to say, from the rhythm of necessity." But this mique intuition again has a primary reference to action. "The more memory serves to contract these movements into one, the more solid the grip on matter that it gives us; so that the memory of the living: being seems to measure beforehand the power of its action on things and to be nothing but the intellectual repercussion of it." (Pages 254-255.)

After all, pure memory is not so very pure. Like pure perception, it is tied and fettered to action of which alone our bodies are the instrument.

"Observe," M. Bergson says, "the position we thus take between realism and idealism."

We do observe it. We observe that in the interests of the Élan Vital, M. Bergson has ignored everything in consciousness that does not bear upon action; and that, in consequence of his wholesale rejections, his position is between the devil and the deep sea. The deep sea holds all the "relations" that he has let filter through; not only those despised ones which are the logical framerrork of 
the actual, but those which science reveals as part and parcel of the real; and the devil has run away with the possibilities of sensation and the "intermediary perceptions" which have "escaped" him.

But, however irrelevant they may be to M. Bergson's action, however slender their "grip" on matter, they" are not destroyed. The devil and the deep sea still wait for the thinker who denies them.

"Supposing that my conscious perception has an end (destination) which is altogether practical, that in the ensemble of things it emphasizes (dessine) only those which interest my possible action on them: I understand that all the rest escapes me, and that all the rest, nevertheless, is of the same nature as that which I perceive." (Page 257.)

How do I, how can I know this if "all the rest" has " escaped" me?

In order to suppose that conscious perception has "une destination toute pratique," I have had to suppose a lot of things besides: that "homogeneous space is not logically anterior but posterior to material things and to the pure knowledge that we have of them; that extension precedes space, ... that homogeneous space concerns our action and our action only, being like an infinitely divided band that we hold below the continuity of matter in order to make ourselves masters of it, to break it up in the direction of our activities and of our needs." (Page 258.)

This is all very well as long as we are considering the psychology of animals and babies, whose adventures in space and experiments in action are neither delayed nor hampered by considerations of the logically anterior; but it is to ignore immense departments of adult psychology, and it is not what is meant by a metaphysic. If it were, if what is first in experience were first in reality, why not start at once with the human embryo or the protozoon? Why bother about human psychology at all? Only you 
ought to know exactly what you are doing. If you may light-heartedly "laisser filtrer," everything that makes Realism what it is, plus everything that makes Idealism what it is, on the one hand, the "real" space of mathematics on which all the laws and conclusions of physics are based, on the other hand all psychic and logical processes which have no immediate relation to action, of which action is not the object and the aim, this is indeed to escape both Realism and Idealism; it is to escape all metaphysics; but it is hardly to "resoudre les contradictions," or to "faire tomber les insurmontables barrières," or to "rejoindre la science."

But, when criticism has shown up all its weak points, it remains a superb attempt to reduce the phenomena of consciousness, with all its multitudinous references and loves and interests to a unity which shall not leave life and action out of the account. For it is true that in action, in life taken in the thick as it is lived, we do get a fusion of perception and of memory and interest and will, of time and space, in a continuity and oneness which knows nothing of the contradictions, the dilemmas, the presuppositions, the infinite dividings and limitings of the intellect.

It is no less true that neither Life nor action in itself will deliver the secret of that fusion and that continuity.

In the very effort to escape those contradictions and dilemmas M. Bergson has added to them those special contradictions and fallen into those special dilemmas of his own which I have just tried to make clear.

And what has happened to M. Bergson is what happens to every philosopher who is out looking for his unity in the wrong place. That is to say, he has put Pure Time before the Self. He has given to Time that special form of continuity, the duration that belongs only to a self. He has made Pure Time in which action happens the beginning that it cannot be, and thus brought it again under 
all the categories of spurious time. To avoid the pitfalls that await him as the result of his rash choice in priorities, he has transferred all the contradictions and dilemmas of spurious time to space, in the evident hope that they will find reconciliation and solution there. Moreover, to escape the net of illusion he has thus prepared for himself, he gives to space - which he has identified with spurious time - the purity and reality he denies to spurious time. $\mathrm{He}$ is bound to do this in the interests of that "outside world" which is the playground of the Élan Vital - that is to say, in the interests of that ultimate dualism in which Vitalism begins and ends.

But he has shown us that time and space are correlatives, and that neither is to be thought of without the other, that they work in and out of each other and play into each other's hands. We are aware, both of the position of objects in space and of the movement of objects from point to point in space, which is as it were a sort of succession in space. We are aware, both of the succession of events in time and of their simultaneity, which is as it were a sort of stationariness in time. But it is neither space in itself nor time in itself which is holding objects together. With pure space alone you will never construct a synthesis of objects in space, nor with pure time alone a synthesis of events in time; but if either construction is to be valid and intelligible a synthesis must be made of both.

And that construction and that synthesis, if it is to be at all, will depend in the last resort on personal identity, on an unchanging self.

On any theory except that of the "mechanical equivalent," the construction and the synthesis will be made in the last resort in consciousness, whether it repeats or whether it corresponds with the arrangements of the independent "Real," or whether construction and synthesis in consciousness is all the construction and synthesis there is.

For, if the self changed to each momber of a final syn- 
thesis, or to each member of an incomplete and provisional synthesis, if it changed to each term of the intricate system of relations within each synthesis - to all the multitudinous changing events in time, to all the multitudinous changing objects in space - if it had no unity and no duration, there would not only be no final synthesis, but no synthesis anywhere at all.

There would, obviously, be no time, and (not quite so obviously) no space. Certainly no perception of space.

And this is positively the last opportunity for the upholders of the superior necessity and priority of Memory. They may say, with the most perfect obviousness: Much more obviously there would be no time and no perception of space without memory.

For, if time is the form of inner perception, and space is the form of outer perception, is not memory the synthesis of both?

But is it? Could it be? Because memory holds together all remembered objects in space and all remembered events in time, does it follow that it is responsible for the synthesis of time and space taken together? Or for the entire synthesis under each head?

It would not be possible unless all consciousness, and time and space themselves, were nothing but memory. But what of the original synthesis - the pcrception of objects in space? What of the perception of the first member of a series in time? Because they have been buried under layers upon layers of repeated images that are memories you cannot say that there never was any original synthesis, never any perception of a first member of a series. And we are continually confronted with new arrangements of old material, new successions in time, new juxtapositions in space, and though the material is old, recognized, therefore, and remembered as much as perceived, the synthesis is new. The new perceptions, the new synthesis escape for erer the net of memory. 
What then holds perception and memory together? And is it more truly memory or the Self that makes us "seize in one unique intuition the multiple moments of duration, frees us from the movement of the flux of things, from the rhythm of necessity"? 


\section{III}

\section{SOME ULTIMATE QUESTIONS OF PSYCHOLOGY}

IN what, then, does Individuality consist? Not in our memories, even supposing that they are pure, for we bave seen that they presuppose us. Not in our individual experiences, in the fact that such and such things happened to us and to nobody else; for this is to plant our individuality outside ourselves in precisely those events over which it has least control. Besides, we have no reason to suppose that our experience is unique and every reason to suppose the contrary. Still, when we reflect, we do suppose it, in the sense, not that our experiences are in any way extraordinary, but that precisely this order and arrangement of experiences which we call ours has never occurred before.

But no possible arrangement of experiences will yield or make recognizable a self that is not presupposed in the arrangement and has had no hand in it. We have a sense of individuality; we find, if we look for it, that we have a sort of self-feeling. I do not mean self-consciousness. I am not thinking of our general feeling of possessing a body, a feeling which is made up of muscular sensations more or less insistent, and of visceral sensations more or less vague. I am not thinking of what is called feeling-tone, ${ }^{23}$ for this may differ, if not from moment to moment, from day to day, or even from hour to hour. All these feelings which come to us through our bodics help our sense of individuality. But I am thinking of something more akin to memory, of that feeling which is not memory but which 
accompanies it and gives it the quality which makes it ours, saturating it like a perfume, staining it like a colour, always recognizable as the same perfume and the same stain. To place our individuality in self-feeling is so far satisfactory that it does at least attempt to explain why our memories are recognizable as ours. It is as if we scented ourselves out all along our track. I may say I do not know whether my experience is really mine, or whether I am simply part of an experience labelled mine for convenience' sake; or, granting that I am I, I still do not know from moment to moment whether I am the same self, or whether another self arises on the top of me and takes possession of my memories; but I do know that something reacts with the same feeling to all my memories all along the line, that it is reacting now to the contents of my immediate consciousness, and that when I dream I shall find it in my dreams; and $I$ take it that this something either is me, or involves somewhere a continuous and not a discrete me.

Does self-feeling yield the secret of individuality?

No. Self-feeling helps to fix our floating sense of individuality, and so far justifies us in calling it self-feeling; and no doubt it enters largely into the building up of the superstition of the self. But our sense of individuality is one thing and the existence of the self another. Mere selffeeling goes no way towards proving that the self is more than a superstition. Self-feeling, though a fairly continuous accompaniment of memory, is vague; and from its peculiar vibrant emotional quality we may suspect it to be nothing more than a sort of general reverberation of the memories themselves. Even if it be something more than that, it is something that accompanies consciousness and not anything that could conceivably bind it together and make it one. And if Personal Identity is nothing more than such an accompaniment it will fare no better than if it were nothing more than memory. 
But what about that peculiar vibrant and emotional quality we noted? This accompaniment of self-feeling is not always the same. It has degrees of intensity; it attaches itself more to some memories than others; it is stirred to a stronger glow by some associations than by others. It seems to know and to remember" almost " on its own." It, then, has preferences. In short, self-feeling, this indestructible haunter of memories, has about it more than a suggestion of the Will-to-live in its aspect of interest and desire.

Are we to say, then, that the secret of Personal Identity and Individuality is to be found in Will?

This certainly seems to bring us nearer to the root of the matter. And it has the advantage of being definitely thinkable as antecedent to experience, and therefore to memory, and of being traceable in the lowest conceivable germ of Personality - the will-to-live, the need to appear, to grow, to reproduce the self, to gather experience and appear more and more. In a sense it is the stronghold of individuality. For it is with his will that the indiridual fences himself off and asserts himself against other individuals. It is with his will, in the form of interest and love, that he draws near to them and is drawn, and so makes his personality greater through theirs and theirs through him. And at every stage of his biological ascension it is his will that is the mainspring of his sublimations. It is through his will, through his need, want, desire, interest, affection, love, that he appears as self-determined.

It is his will as energy that, whether in resistance or obedience, knits him to the forces of the "real" world outside himself.

It is his will that in submitting or aspiring, in adoration or in longing, links him to the immanent and transcendent Reality that he calls God.

The perfect individual is the person perfectly adapted 
to reality through the successive sublimations of his will.

It is clear that the will of such a creature is not, any more than his perception or his memory, concerned with action only.

Before we go farther let us take stock of our results so far.

We have refused to identify the self entirely with its own memories, to find the secret of personality in the fact that such and such experiences have been ours; for this is to plant our personality outside, in extraneous and probably accidental happenings, without taking account of its interior reactions; besides begging the possible question of its existence.

We found a faint aroma of selfhood in the self-feeling that accompanies consciousness; and though this may be, and very probably is, due to some inner working of a self, and though it has a warmth and intimacy that we look for in vain in what we call "self-consciousness," it was not comprehensive enough for us to hope to find in it the secret of selfhood.

So far as that secret is discoverable at all, we seem to find it in the Will. The will seems to us at once the most ancient, the most comprehensive, and the most intimately self-revealing of the powers of self. It seems the surest and the most conspicuous bridge from the inner to the outer world. Also we have seen every reason for supposing that processes and actions which are now involuntary and unconscious were once conscious and willed; we had even some reason for supposing that the very machinery of such processes may have been built up gradually under the impulse of the will; that the will, working through countless generations, may be itself the builder and the engineer of our bodily and mental machinery.

We considered the theory of Vitalism, with its assumption of Matter as an independent outside solid substance offering itself to the "grip" of Spirit and carved by our 
needs as by a knife. We found that this theory, and its attempt to base perception and memory upon action only ends in contradiction and dilemma; and we concluded that to refer will likewise to action only is to ignore the actual range of desire and interest and love.

So wide is that range that we might well rest in the conclusion apparently forced on us that the will is the Self.

And yet, if we were to put our conclusion to the test, we should find that, though it has served us so far infinitely better than self-feeling and memory, though, so to speak, there is more self in will than in memory or self-feeling, it still falls short of complete selfhood; because, though intimate and comprehensive - more intimate than either memory or self-feeling - it is not comprehensive enough ; not nearly so comprehensive, in fact, as memory. It will not give us the synthesis we want; the synthesis of all our states of consciousness, itself included; so far as will is a state of consciousness at all.

That is to say, so far as consciousness includes states which are not states of willing, but states of feeling, perceiving, remembering, conceiving, judging, reasoning and imagining, the unity of consciousness cannot be found in Will.

We have now three alternatives. A complete irreconcilable dualism between Will and Idea: a dualism that may fall "outside" conscionsness, between the Will as the Unconscious and consciousness as the Idea ; or that may fall "inside" consciousness itself, in which case it is all up with the unity of consciousness; or a partal dualism within consciousness, which allows of the interpenetration of Will and Idea, and of interaction between them, without necessarily admitting selfhood as the unity of all conscious states.

(These two forms of dualism will face us equally, whether we regard consciousness as a by-product of the 
physical mechanism, or as wholly or partially independent of it.)

Or there is a unity of sclfhood, of personal identity, prior to consciousness as its condition, or arising with it, at any rate, in no sense arising from it, a unity in which alone Will and Idea can be held together.

For it may be argued - it is argued with extreme plausibility - that Will and Idea are in no more awkward position than any other two states of consciousness considered out of relation with each other; and that when they are taken in relation, the very relations themselves provide all the plaster necessary to stick them together; that this will hold good whether the relations are regarded as thought relations in consciousness, or as "real" relations outside it; that if these relations do not and camnot bind, there is no conceivable unity that, added to them, will do their binding for them; while if they do bind that is enough; it is at any rate all we have any right to ask. For instance, will and idea come together and are sufficiently held together in purpose or design. Thus the unity of selfhood is either powerless or superfluous.

This argument is much more formidable than it looks at first sight. So formidable that it can only be dealt with later on when we are considering the ultimate questions of metaphysics. For the moment our problem is psychological.

Needless to say, the hypothesis of unity is thoroughly incompatible with the mechanical by-product theory of consciousness, and does not necessarily "go with" the partial independence theory in itself.

Now I have tried to make it clear under separate heads that personal identity is not memory, is not self-feeling, is not will; but it may be just possible that this disposing of under separate heads was the secret vice of my whole procedure, and that, though the self cannot be any one of the three, it may very well be all three taken together. Per- 
sonal identity, the self, the unity of consciousness may be the sum of our states of consciousness taken together, and it may be nothing more; in such sort that when there are no more states of cousciousness there is no more personal identity.

And though I have stated repeatedly that this unity and this sum presuppose personal identity, I am aware that logical presupposition is not enough unless it can be shown that this unity is more than a sum, and that it is of such a sort that it is not only unthinkable, but unworkable without personal identity.

It should not be forgotten that there was another alternative, the mechanical by-product theory, the theory on which consciousness is, as it were, given off (like a gas) by the neural processes which are its physical antecedents and correlates, is resolvable into them, and ceases when they cease.

If I have not paused to dispose of this theory before going further it is because I mean to return to it also later on. Meanwhile, if we succeed in establishing personal identity as a working hypothesis, the indispensable condition of conscionsness as we know it, the importance (for Psychology) of the by-product theory will collapse in the process. $^{24}$

But Personal Identity must do something for its living before we can be allowed to presuppose it in the lighthearted manner of the foregoing.

And as I took Samuel Butler as a classic authority on the behaviour of the psyche in its human and pre-human past, I am going to take Mr. William McDougall as a classic authority - and on the whole, the clearest, simplest, and most convincing authority - on the behaviour of the psyche here and now. Not that the two behaviours can be separated, or that any modern psychologist would dream of separating them, but that, while onc large part of Mr. McDougall's work necessarily overlaps Butler's, a still 
larger part deals with psychic powers and processes, all the synthetic and higher mental functions which Butler leaves untouched. And though a great deal of Mr. McDougall's work is necessarily founded on that of William James (every psychologist's work is bound to cover the same ground as his predecessors, and Mr. McDongall would be the last to claim a superior originality), it also covers ground that has appeared since the publication of William James's Principles of Psychology, besides emphasizing several important points of difference, and disengaging the ultimate issue, if anything, with greater clearness and directness and simplicity.

So simple and direct and clear is Mr. McDougall that he puts a pistol to our heads and presents us with two alternatives and two alone: Psycho-physical Parallelism and Animism.

It should be stated at once, for fear of misapprehension, that Mr. MeDougall does not make his psychology a diving-board for a plunge into metaphysics. He tells us in his Preface that metaphysical Dualism is an "implication" he is "anxious to avoid." But he will have none of Psychic Monism on any system. He affirms a distinct dualism between soul and body. And it should be borne in mind that, in the absence of any higher unifying principle, his Animism lands us logically in the Pluralistic Universe of William James.

Still, he not only allows us to have a soul, but his aim is to make us see that, our consciousness being what it is, Animism is the only theory which will be found to work.

Before he consolidates his position he overhauls all the alternative philosophical theories, and finds that all but two are reducible to some form or other of Psycho-physical Parallelism.

The two outstanding forms are both Monisms and both by-product theories:

Physical Monism or Materialism, which regards con- 
sciousness as the illusory by-product of the meehanical process of Matter (Epiphenomenalism), and

Subjective Idealism or Solipsism, or Complete Egoism, which regards the whole universe, including matter and its mechanical processes, as an illusory by-product of the Self Alone.

The three remaining forms are grouped under the head of Parallelism : namely

1. Strict Psycho-physical Parallelism, which regards physical processes and psychic processes as running on two parallel lines that never meet, and have no braneh lines that intersect them, each line representing a distinct and different system of causation. According to this view there is no sense in which the two may be considered one.

2. Phenomenal Parallelism, which regards physical proeesses and psychic proeesses as two aspects, modes or appearances of one underlying Reality. They run on purely phenomenal parallel lines that never meet. The underlying Reality is Spinoza's Substance or God, Kant's Thing-in-Itself, Herbert Spencer's Unknown and Unknowable, Schopenhauer's and von Hartmann's Unconscious. All these philosophers agree in regarding their underlying Reality as neither mind nor matter, and in deelaring that, though it might be a neeessary postulate, it could not be known.

They all affirm the complete phenomenal Dualism of mind and matter. And Mr. McDougall is one with their opponents in demonstrating that their metaphysical Monism does nothing at all to bridge the gulf. But in deference to the underlying Unknown they all figure as holders of Identity-Hypothesis A.

3. Psychical Monism, or Objective Idealism (Identity- 
Hypothesis B), which regards all physical processes and Nature, the sum of them, as products of Thought. It is the redoubtable theory of the world as "arising in consciousness."

I am following Mr. MrcDougall rather than my own inclination in including the Objective Idealist as a Parallelliner. But Mr. McDougall's classification will serve my purpose as well, for his sinister intention is to expose the latent dualism of that system, not in the interests of any metaphysical Monism he may have up his sleeve nor yet of a Pluralistic Unicerse, for he does not exalt his souls to ultimate principles, but for the sake of the cross correspondence he is to prove.

I do not think that Mrr. McDongall's dealings witb "Psychical Monism" are always entirely satisfactory. Objective Idealists might object to being called Psychical Monists, and they would certainly be surprised to find their universe described as the "shadow of thought." Again, I think Mr. McDougall somewhat underrates the importance of strict Psycho-physical Parallelism, which is, after all, his real, or at any rate, his legitimate adversary. For in an encounter with any of the alternative systems he runs the risk of attacking ultimate metaphysical principles with merely psychological weapons; that is to say, he may be carrying an argument that loolds good in one sphere into another where it may not hold good at all. Moreover, his own theory of Animism - interaction and all - is by no means incompatible with "Identity-Hypothesis A," for which the soul itself may figure as a phenomenon or aspect of the underlying Reality.

We will see how he disposes of his five alternative theories.

Materialism, and Subjective Idealism, the mechanical by-product and Self-Alone theories fall an easy prey.

Materialism has on its side a formidable array of arguments from facts. It can point to certain undeniable and 
invariable sequences of cause and effect. All sorts of disturbances and alterations of consciousness arise when poisons are introduced into the blood, from the excitement or stupor of intoxication to the profound coma of Bright's disease. Again, my brain processes slacken down, and I pass into the unconsciousness of dreamless sleep. They are interfered with by the rupture of a blood-vessel, and, either special departments of my consciousness are interfered with, or I lose consciousness altogether, or for so long as the interference lasts, that is to say, according to the extent and persistence of the lesion. My brain processes cease altogether, and - the inference seems too obvious to state.

And yet the extreme conclusion does not follow unless materialism can show that physical processes give rise to consciousness in the first place. If they cannot, there will be no need to infer that their ceasing must cause its extinction. And ultimately the argument for materialism rests on two laws and a corollary: the law of causation, according to which the cause passes over into its effect, and is discernible therein; and the law of the conservation of energy, according to which all the energy in the universe is a constant quantity which ean neither be added to nor diminished; ${ }^{25}$ the corollary being the biological law of the continuity of evolution. Mr. McDougall points out (Body and Mind, Pages 150, 151) that the mechanical theory of consciousness saves the law of conservation of energy at the expense of the law of causation; for there is no sense in which it can be said that molecular change, the presumed "cause" of sensation, passes over into its effect. It also breaks the biological law; since, however undefined, however dim the borders between the conscious and the unconscious, there could hardly be a greater breach of continuity than the appearance of consciousness when it finally emerges at some point in the course of erolution.

As for the Subjective Idcalist or the Self-Aloner, Mr. 
McDougall does not take the trouble to demolish him, regarding the mere statement of his case as sufficient demonstration of its absurdity. "With the Solipsist we eannot argne, but all of us are agreed that Solipsism is an impossible attitude for a sane man." 26

So that the true alternative, the real opponent is Psychophysical Parallelism in its three forms: Identity-Hypothesis A, Identity-Hypothesis B, and Strict Psycho-physical Parallelism.

The theory of the "two aspects" and the Underlying Identity (Identity-Hypothesis A) is open to the objection that as the "aspeets" are "two events of radically different orders and are apprehended in two radically different ways," that is to say, are incommensurable and devoid of any common term, they are not intelligibly referable to any real process underlying them.

I confess I cannot understand Mr. MeDougall's "still more serious objection." He says very truly that a thing can appear under two different aspects "only if and when both aspects are apprelsended by the mind of some observer"; and he argues that because

" in the case of the physical and the psychical processes which are said to be the aspects of one real process, there is no such observer occupying the inner standpoint and apprehending the inner or psychical aspect of the real event, except in the altogether exceptional case of the introspecting psychologist," (Body and Mind, Pages 157, 158);

therefore, neither the real event, nor the physical event nor the psychic event are apprehended at all. All we know of the real event is its two aspects; and all we know of the physical event is known, not in its own terms, but in terms of consciousness which is the other aspect; and only a conscionsness that was aware of its own brain processes could oceupy the position of observer of the inner event.

Surely all that the theory takes for granted is the un- 
deniable fact of a stream of consciousness, and the undeniable fact of a stream of physical events; on the one hand, the mysterious behaviour of mind, on the other the mysterious behaviour of matter, including our brain processes (which are part of the outer and not of the inner event), and is not obliged to presuppose an inner spectator of the entire inner stream. You might as well argue that, as the physical events are only apprehended partially and not entirely, the underlying reality is not manifested in them. The real crux of the position being, not that there is no spectator of the inner event, but that there is one inner spectator of both outer and inner events; while of the real event there is not any spectator at all; and while both aspects are to some extent given, and both to some extent known, the underlying reality (substance or process) in which both are one, remains unknown and unknowable. A situation baffling to the intelligence; yet its supporters might answer that they can't help it if it is, and that intelligences were born to be baffled.

Next comes the theory of Psychical Monism or Objective Idealism; the theory of Consciousness as the All, the Only Reality, and of the world as arising in consciousness.

This theory is held in too many forms to be broken quite so easily as Mr. M.cDougall breaks it, on the "unity of consciousness," thongh his argument is destructive to the loose Monism of his own principal opponents.

"My consciousness is a stream of consciousness which has a certain unique unity; it is a multiplicity of distinguishable parts or features which, although they are perpetually changing, yet hang together as a continuous whole within which the changes go on. This then is the nature of consciousness as we know it. Now it is perfectly obvious and universally admitted that my stream of consciousness is not self-supporting, is not self-sufficient, is not a closed, self-determining system; it is admitted that each phase of the stream does not flow wholly out of the preceding phase, and that its course cannot be explained without the assumption of influences coming upon it from with- 
out. What then are those influences? The Psychical Monist must reply - They are other consciousnesses. How then about the process by which the other consciousnesses, the other streams of consciousness, influence my stream of consciousness? Is this also consciousness? (For, we are told, all process is conscious process.) If so, it also is a stream of consciousness, and it must influence my stream through the agency of yet another stream, and so on ad infinitum. Thus my consciousness itself, by reason of the fact that it hangs together as a stream of process relatively independent of other streams of process, implies the essence of what is meant by substantiality, namely, the continuing to have or to be a numerically distinct existence, in spite of partial change." (Body and Mind, Pages 162, 163.)

The faet of the unity of conseiousness can certainly not be accounted for or explained on the simple theory of consciousness as a stream or streams, or as any sequence or even conglomeration of merely " associated" states. The inner weakness of this form of Psychical Monism is confessed by one of its ablest representatives, Professor C. A. Strong, who turns up more than once in Mr. MeDougall's pages with his distressful query, " What holds consciousness together?" As it is manifestly impossible to get any unity out of a stream, or rather out of many streams, he is driven to the hypothesis of "psychical dispositions" as a substitute for a soul. But psychical dispositions must either also be part of the stream or streams; in which case it is not easy to see how muity is to be got out of them; or they must be " raised to the rank of extra mental realities, and a system of such realities neither 'simple' nor ' undivided,' yet quite sufficiently active, will form our substitute for the soul," so good a substitute that Mr. McDougall sees no difference between this theory and Animism.

I am still following Mr. McDougall, and for the moment I must ignore, as he does, the older theories of Objective Idealism. Its adherents, so far from regarding consciousness as a flux, saw it held together in a firm net of " thoughtrelations" to which it owes its "objectivity." For them 
the unity of consciousness was as the very rock of their belief.

Mr. McDougall, like his opponents, Professor Strong, Professor Paulsen, Professor Münsterberg, and all the witnesses to Psychical Monism whom he summons up, look upon consciousness both as a stream and as something essentially disjointed; and they all cry aloud for something to "hold it together." $\mathrm{He}$ has no difficulty in breaking all their backs one after the other over the " unity of consciousness," and finally settling them with the problem of unconsciousness. It is obvious that a stream of consciousness, even with central whirlpools in it of psychical dispositions, cannot have periods or even moments of unconsciousness without ceasing to exist. There are other arguments, drawn from other qualities of consciousness; but these two are sufficient for the destruction of the Psychical Monists. Fechner, the author of strict Psycho-physical Parallelism, is twice broken, once as a Parallelist, and once as a Psychical-Monist.

It is hard to see why Fechner should be involved in the special ruin of the Psychical Monists; though he certainly held a somewhat unstable position mid-way. Fechner's case is peculiar. He starts with a vigorous Parallelism, and then, by what seems the masterly inconsistency of his enthusiasm, lands himself in Psychical Monism with his theory of Pan-Psychism. All the same, he never abated one jot of his Parallelism in his serious Psycho-Physik. But his Pan-Psychism lands him peacefully in Animism, side by side with Mr. McDongall, so far as he gives the ghost of personal identity to his souls. ${ }^{27}$

But after all, what does his inconsistency amount to? He held that wherever we find matter we find mind in some degree, however low. Not the smallest grain of inorganic dust that has not its psyche. And he held that wherever we find mind we find matter. This position he defended to the last against all his opponents. So far 
Fechner must be judged a Parallel-liner. Inside his system he is almost fanatically consistent. But he had an imaginative genius that would have been dangerous to any system, and it carried him far beyond the limits of his own.

But when we come to the strict Psycho-physical Parallel-liners, back-breaking isn't quite so simple a matter. For they are the people who are punctiliously just in weighing the claims of both sides; they refuse on any consideration to let the balance tip to one or the other. And as Mr. McDougall is, if anything, still more punctilious and still more just, it is not so easy for him to make out a case for Animism against them. They are less vulnerable because less adventurous.

Fechner's follower, Wundt, who outdoes his master in simple Parallelism, is a formidable adversary, whose views require rather more detailed consideration. He lays down his parallel lines with laborious science and strenuousness, and he runs his system along them with sobriety and discretion. If it leaves the rails it is not because Wundt allows himself to be distracted by ecstatic visions of the cosmic soul.

Never, on Wundt's theory, can the two lines, the physical process and the psychic process, hope to meet. Between them there is equivalence and point to point correspondence, for every neural change a psychic change; for every psychic change a neural change; with a sequence so invariable that where we can detect the one we may infer the other; but no connection, no cross-correspondence from line to line, no interdependence, no interaction.

In psycho-physical organisms

"body and soul are, for our immediate knowledge, one being, not different. . . . When from all natural phenomena, and therefore from all phenomena of physical life, we carefully abstract the nsychic processes, it is obvious that from these objective processes, thus stripped of their subjective side, subjective prop- 
erties could never be deduced, just as, vice versa, the deduction of physical life-processes from psychic experiences as such is impossible. Porly and soul are a unity, but they are not identical: they are not the same, but they are properties that are found together in all living beings." (Physiologische-Psychologie, Vol. III, Chap. XXII, Page 767 et seq.)

They are not the same. How are we to conceive the relation between them - their unity? We are to conceive it as a parallelism. And the Law of Parallelism runs thus :

"Wherever and whenever we find ordered relations between psychical and physical phenomena, these are neither identical nor interchangeable (in einander transformirbar). For they are not comparable one to the other; but they are related to each other in such a way that certain physical processes correspond regularly with certain psychical processes; or, to use a figurative expression, they go 'parallel to one another.' This definition, which we prefer to keep now that it has been once for all introduced into psycho-physiology is, however, only half correct. It expresses very aptly the fact that the groups of phenomena here brought into correlation are not identical, but not that there is no ground of comparison between them." (Ibid.)

There is no bridge from the mechanical causality that rules on the physical line to the teleological causality that rules on the psychic line.

"Take the case of an act of will, try to break up the links proper to the combined psycho-physical series completely into their physical elements; in such a process starting point and ending point will be connected up through all the intermediary links in the chain, and through all the conditions that accompany them; but this connection can never be thought of otherwise than as a purely causal one. Whereas we cannot make the proper teleological connection between ending point and starting point of the (psychic) series until after the series is actually completed, according to the universal character of teleological connections." (Ibid., Pages 754, 755.)

That is to say, in tracing the steps of the physical proc- 
ess we go back and find the cause at the beginning and the effect at the end of the series; while in the psychic series we go forwards and find the cause - the design or purpose of our act of will - at its end and not at its beginning. An act of will has always reference to the future, is grounded in the future, while the physical event is grounded in the past.

Again, in physical causality, cause and effect are equivalent; the cause passes over into the effect, so that there is nothing in the effect that was not already contained in the cause. In psychic causality the effect is by no means already contained in the cause and may be out of all proportion to it. And, it may be added, like causes do not necessarily produce like effects. Only of subjective motive, as distinct from objective end or purpose, can it be said that it is already contained, not in the actual result of any given action, but in its general direction or tendency. The actual result may be something that goes far beyond anything contemplated in the purpose, something for which the motive is utterly inadequate. For instance, I want to inflict a slight physical injury on my neighbour for his good. Reformation is my motive, chastisement my end or purpose, death by unrealized and undreamed-of violence, the actual result. Neither violence nor death were a part of my purpose; they are in no way contained in, nor are they commensurate with my motive; but chastisement may be said to be included in my general policy of reformation.

I suppose it is something of this sort that Wundt means by motives being "already contained" in the "direction" of these results, as causes are in their effects.

"In this sense," he says, "every psychic connection of the immediate contents of consciousness forms both a causal and a teleological series. And that, not merely in the general regressive sense which holds good of all natural causality, but also in that specially progressive sense by which the End itself be- 
comes cause, and as such precedes its effect. To be sure, here too, the end which, as motive, precedes its effect, is not identical with it; and thus far in this case also there remains a margin of causality which stretches beyond causality itself." (Physiologische-Psychologie, Vol. III, Chap. XXII.)

Teleological judgment is based on this discrepancy between the end proposed and the end accomplished. It is a nice question of

"on the one hand comparing such and such results with the motives which inevitably tend towards them (welche die Richtung auf jene enthalten), and on the other hand, of valuing motives according to the probable results." (Ibid.)

It will be seen at once that Wundt does not by any means belittle the Psychic rôle. He has made over to it the whole realm of teleology - a very handsome concession - and of moral values. We shall see how much more he has conceded when we come to his law of the "creative resultants."

For the moment the chief points to notice about his parallel lines are, first, that there is no common term and no common value between them, no bridge of any sort between the dual systems of mechanical and teleological causality; next, that every causal change is the last link in a series of changes having their starting-point in the vast physical universe outside the body; whereas the psychic changes have, apparently, no world of equivalent vastness to which they may be referred. On the other hand, the psychic processes show what William James would have called a "thickness" of their own. They are not only sequences but syntheses. They not only follow on, but stick together, and stick together in such a way that the whole has a different quality from its parts; that is to say, it is something more and other than the sum of the several states which compose it, and is therefore a new thing. 
For this newness and unexpectedness and otherness that we meet with in every psychie synthesis, Wundt found an admirable expression in his principle of the "creative resultants." He calls them "resultants" to show that

" it is from single and empirically provable elements, or groups of elements, that the synthesis is made, and in a strict accordance with law analogous to that synthesis by which the components of a mechanical movement give rise to their resultants."

But he qualifies the process with the adjective "ereative" to show that

"the effect is not, as in the case of a resultant movement, of the same kind and value as its components, but that it is a specifically new event, made ready but not ready made, by its elements (vorbereitetes aber nicht vorgebildetes) and that its characteristic value marks a newer and a higher stage than theirs."

\section{For instanee,}

"A sound is more than the sum of the tones that compose it. While these are melted into a unity, the ground-tone gains a colour of its own through the overtones which, because of their lesser intensity, have become powerless as independent elements; these make it a very much richer sound than it could be as a simple tone.

"Likewise every spatial perception is a product, or result, in which, again, certain elements have lost their independence, and impart to the result a completely new property - the spatial order of sensations."

\section{Again :}

"In processes of willing the multiplicity of motives finally gives rise to more and more complex forms of willing, which again, as original psychic products, are differentiated from the single elements of motive which compose them."

But, lest we should build too much on this creative principle, we are warned unmistakably that it refers

"only to syntheses and relations of such psychic contents as 
hold together immediately, and never to such as are completely separated; even when these belong to a single individual consciousness. In short, it is a principle that applies only to particular psychic events; not a law that rules in spiritual evolution generally." Physiologische-Psychologie, Vol. III, Chap. XXII.)

And we can no more draw conclusions from it as to the future of existing spiritual values (or of spiritual beings) than we can argue as to the future of the physical world from the law of conservation of energy.

Meanwhile, the back of materialism is broken. In psychic processes we have got another principle of causality altogether. We have something so new, so different, that it cannot possibly be accounted for by any mechanical or material process.

So far so good. But can strict Parallelism be kept up? Surely Parallelism implies correspondence of the events on one line with events on the other. And on a system of strict correspondence we should expect to find that all events on one line were represented somewhere on the other, or at least that all ascertainable sequences could be shown to correspond point for point; even when physical groupings do not correspond with psychic groupings, and vice versa. But it is difficult to see, on the one liand, how several million vibrations, whose psychic correlate is a sensation of colour, are represented in the psychic erent, or, on the other hand, how any conceivable grouping of nerve and brain cells could represent or correspond with the perception of objects in the field of rision.

Even if different qualities of sensations of the same class are represented by differences in the rate of vibrations, it is still difficult to see how differences between classes - the difference, for instance, between sight and hearing - are represented by any conceivable differences in the construction, or disposition, or chemical quality of molecules in the visual and auditory nerves. 
So that, from the first moment of rudimentary consciousness, Parallelism breaks down. And when the psychic plot broadens and deepens, and its "thickness" becomes apparent, the system definitely leaves the rails. If it cannot stand the strain of such a simple psychic process as elementary sensation, how is it going to stand the strain of any psychic processes less simple than those which are supposed to be accounted for on the "association" theory ? ${ }^{28}$ True, if memory and the association of ideas are no more than the psychic response to repeated stimulus of the same associated nerve and brain cells, the faithful correlate of a purely physical association, fixed by repeated treading of the same nervous track, then physical habit and psychic habit will run perfectly parallel. The parallelist's task is even simpler than the associationist's, since he has not got to account for the psychic process causally at all.

We shall see how it is this too great simplicity of his that wrecks him.

Here the crucial question raised by $\mathrm{Mr}$. McDougall turns on meaning.

"The parallelist has to believe that purely mechanical determination runs parallel with logical process and issues in the same results. He has to believe or at any rate assert, that every form of human activity and every product of human activity is capable of being mechanically explained. Consider then, a page of print, the letters and words of a logical argument are impressed upon the page by a purely mechanical process. But what has determined their order? Their order is such that when an adequately educated person reads the lines, he takes the meaning of the words or sentences, follows the reasoning and is led to, and forced to accept, the logical conclusion."

As for the author, for him the meaning and the logical drift of his words and sentences was present in his consciousness before and during and after the process of writing; his foreseen and foregoing purpose was to demonstrate his meaning; 
"his choice of words and order was determined by this purpose, by the desire to achieve an end, a result, which existed only in his consciousness. Now the parallelist necessarily maintains that all this process ... is in principle capable of being fully explained as the outcome of the mechanical interplay of the author's brain-processes: that a complete description of the mechanies of these processes would be a complete explanation of the ordering of the letters, words and sentences." (Body and Mind, Pages 174, 175.)

I do not think that it is fair to the parallelist to fasten on him a belief that the mechanical process, if known, would account for the teleological process; for that is precisely what the strict Parallelist denies. And Wundt would have been the first to insist on the purely teleological character of the process described.

Enough, if the Animist can show that there is a teleological process on the physical line, that interaction gives a better account of what goes on on both lines, and that causation and teleology, so far from being mutually exclusive, involve each other.

Mr. McDougall then asks: "Is there or is there not any complete brain correlate of that part of our consciousness which we call meaning?"

The same question is crucial for memory.

Memory as nerve-habit association is the great psychic stronghold of the parallelist; and if it can be shown that meaning is a determinant of association and of memory, the stronghold will be very badly shaken.

In considering how associations are actually formed, Mr. McDougall gives us a rery clear and simple statement of the case.

"Our consciousness comprises again and again complex conjunctions of sensations which show no appreciable tendeney to become associated together. It is only when the attention is turned upon the objects that excite sensations, and when the sensations enter into the process of perception (serving as cues that bring some meaning to consciousness) that associations are 
formed. And even then, the forming of an effective neural association is by no means an immediate and invariable result. ..."

He illustrates this point by his own experience in teaching his son, a clever and observant child of six. The boy had no difficulty in learning the alphabet and recognizing the forms of the letters. But, when it came to naming each letter separately, many hundreds of repetitions were required to fix the mechanical association between the form of the letter and its name. In learning to name numbers from one to ten

"an even larger number of repetitions of the naming were required to establish really effective associations.

"This experience brought home to me very vividly the great difference between memory and mechanical association. For the boy, who required so many hundred repetitions for the establishment of these simple mechanical associations, would often surprise me by referring to scenes and events observed by him months or even years previously, sometimes describing them in a way that seemed to imply vivid and faithful representation. Yet the memory pictures of such scenes involved far more complex conjunctions of partial impressions than did the remembering the name of a printed letter or number.

"The essential difference between the rememberings of these two kinds was that in the one case meaning was at a minimum, and remembering depended almost wholly upon mechanical or neural association of the nature of a habit; whereas the complex scenes and events remembered (in some instances after a single perception only) were full of meaning."

How crucial this factor of meaning is will be realized when we consider the established psychological fact that

" an impression which is already associated with others acquires new associations with more difficulty than one which is free from previously formed associations, and that the difficulty is greater the greater the number of the previously formed associations."

Hence, on the theory of mechanical association, "the richer the meaning the greater should be the difficulty of 
combining any complex of sense impressions and of reproducing them as one memory picture; it is therefore impossible to account in this way for the fact that impressions which convey much meaning are combined and remembered with so much less difficulty than those of little meaning." (Body and Mind, Pages 340, 341.)

Mr. McDougall might have added that mechanical associations have the longer ancestral history; they have been practised longer; so that we should expect their physical machinery to work with such an ease and readiness as to render them pre-potent in determining remembrance. What actually happens is clean contrary to this - the higher, and biologically more recent, power of appreciation of meaning rules the event.

It must not be supposed that Mr. McDougall by any means underrates the other side of the question.

"Neural associations or habits may so link groups of sensory elements of the brain as to lead to successive revival of the corresponding sensory complexes ... in so far as each sensory complex has evoked meaning in the past, it tends to revive it upon its reproduction and reinstate the idea in consciousness. This is the process of the evocation of an idea from the neural side. It plays only a subordinate part in the higher processes of remembering."

For the idea is more than its sensory content; it is a " compound of sensory content and meaning." And meaning, as we have seen, has escaped the net of neural association. Yet the pre-potency of meaning argues its persistency.

But - how or where do meanings persist?

"Clearly," Mr. MeDougall says, "they do not persist as facts of consciousness. But the development of the mind, from infancy onwards, consists largely in the development of capacities for ideas and thoughts of richer, fuller, more abstract and more general meanings. If then meanings have no immediate physical correlates or counterparts in the brain, and if the meanings themselves do not persist, we must suppose that the persistent 
conditions of meanings are psychic dispositions." (Body and Mind, Page 343.)

If anybody has a lingering doubt as to the possibility of what is ealled the "psychic increment" - of psychical dispositions and of psyeho-physieal interactions - let him ask himself what would happen if the automaton theory of association really held good. The question is crucial; for, while all the higher mental processes are based on association, it is still possible to acknowledge the "creative" value (in Wundt's sense) of a logical synthesis, and to deny strenuously that the psyche has a hand in the associations themselves.

Let us suppose, then, that it has no hand; that it must always take what associations are given to it, without any means of seleetion and rejeetion other than the automatic stamping out of weaker and less frequent associations by stronger and more frequent ones; and that these associations are formed strictly by neural habits. We are told that, when two or more impressions are received together, either often enough or with sufficient intensity, a neural track from one to the other is set up within the brain cell where both have met, a track which henceforth becomes a line of least resistance; so that, either on the actual repetition of the one impression, or its revival in memory, the other - through the revived stimulation of the brain cell - spontaneously and inevitably leaps forth. Suppose that this is all there is in it; suppose that we remember, never because we choose, but always because we must; and that our memories are at the mercy of all sorts of random associations, being nothing but the revived stimulation of the brain cells where neural paths having once met, meet for ever; suppose that there are no psyehie dispositions, no psychic interferences, no psychic preferences, and no selections and rejections of associations, then our consciousness would be like nothing on earth but an immense fantastic 
telephone exchange; an exchange where messages, indeed received and registered and answered themselves, but all at once, and in overwhelming multitudes; an exchange deafened and disorganized; bells ringing incessantly all through its working hours; messages rushing in from all parts of the city and suburbs at once, crossed and recrossed by trunk calls from all parts of the outlying country; casually crossing and recrossing, interrupting and utterly obliterating each other.

On these lines, neither logical departments nor central control could possibly exist. Yet without some one central sorting and supervising system, a system which refused more calls than it received, mere automatic association would have no more method about it than that mad telephone exchange.

What is the more likely, not to say more conceivable, theory: that the brain, which is itself the exchange, the distracted hall where the infinite number of wires meet and mingle, without aid selects and rejects, orders, gives meaning, supervises, and controls? Or that the psyche uses the brain, and the memories which have become the habits of its body and its brain, as its machine, and its vehicle; and that the secret of its remembering and forgetting is its own?

But if "psychical disposition" determines the higher forms of memory, what, then, determines "psychical disposition"?

As Mr. McDougall does not raise this question, we may take it that he considers "the soul itself" to be sufficient answer.

But, as you cannot cut the individual soul clean off from its own history, from its long past existences, it is just possible that preacquired experience may have determined its individual " disposition," in the absence of any permanent factor persisting in and partly determining those experiences themselves. 
If there be such a permanent factor persisting through past experiences, and in part determining them, it is the Will; and the Will itself will be in part determined by past experience; so much enterprise in seeking new experience, so much adaption to each experience found. Go back to the earliest experiences of all; say that the first bit of protoplasm is formed in fulfilment of some need, that the amoeba "improvises a stomach because it wants to," and that our protoplasmic forefather did the same thing for the same sufficient reason; he may be supposed to have taken the next step, and the next step after that, also for the same reason, his want or will determining his development and slowly but surely shaping his memory, his associations, and his meanings (when he has any), till in the long run (his intelligence immensely helping) it has shaped the psychical disposition he is born with. If at the top of the scale to-day, Mr. McDougall's son's memory is determined by meaning, is not that because of his psychic predilection or choice of meanings?

Is it rash to suppose that some such cumulative effect of will comes under the head of that "psychic increment" of energy, which, as Mr. McDougall suggests, may in all probability influence the behaviour of organisms? ( $\mathrm{He}$ is trying to show that the law of conservation of energy is not in itself fatal to the hypothesis of the psychic increment.)

“. . all living organisms show certain peculiarities of behaviour that are not established by any inorganic aggregations of matter. The peculiarities of behaviour of living organisms, especially the power of resisting the tendency to degradation of energy which seems to prevail throughout the inorganic realm, are correlated with, that is to say, they constantly go together with, the presence of psycho-physical processes in them, and this fact of correlation implies causal relation between the two things.... The few experiments which go to show that the energy given out by an organism is equal in amount to the energy taken in, are far too few and too rough to rule out the possibility that psychical effort may involve increment of energy 
to the organism; for increments far too small to be detected might effect very important changes in the course of the organic processes."

If this hypothesis remains unjustified we have the alternative possibility " that mind may exert guidance upon the brain-processes without altering the quantity of energy." In either case, the physical law of conservation is not one that can be legitimately applied to energies presumably of a different order.

It seems to me that both alternatives, that of the psychic influx (or increment) of energy, and that of the guiding influence of mind, are a little vague; besides being vulnerable to any experiment that may yet establish the law of conservation of energy in living organisms. Whereas we do find that every act of will is accompanied by the release of energy; so much so that desire seeking fulfilment may be said to be psychic energy itself. Anyhow, whether as release or as influx, it is the one psychic factor that appears the fittest to play the decisive evolutionary rôle. It is the one that lies nearest to life itself, that has the deepest ground in our past and the highest reach into our future.

We have seen how the "psychic increment" may work at the human level in the case of Mr. McDougall's son. Let us see now what part it plays at a level slightly lower than the human - in the case of Professor Thorndike's Cat.

Mr. McDougall is considering the process of acquiring " new modes of bodily response to impressions" by adaptation and movement. (Body and Mind, Page 318.) Professor Thorndike, testing animal intelligence by various experiments, hit upon the simple one of shutting up a hungry cat in a cage within sight of a saucer of milk placed outside. The door of his cage was closed with a latch which it was just possible for the eat to open by a happy accident in his struggles to escape. 
"The cat, stimulated by the sight of food placed near the cage, makes a great variety of movements, clawing, scratching and squeezing in all parts of the cage; it runs through its vocabulary of movement without the least indication that it appreciates the presence of a door, or of a latch by moving which the door may be opened. Sooner or later, in the course of these random movements, the latch is moved by happy accident and the cat escapes to enjoy the food. Now it is found that in nearly all cases, if the cat is put back in the same cage on many successive occasions, it gradually learns to escape more and more quickly; until eventually it goes straight to the latch and makes the necessary movement." (Ibid., Page 319.)

Now on any theory which absolutely excludes the psychic factors of desire and choice, and denies that movement can be determined by anything but neural habit associations, the cat's readiness to acquire the habit of the right movement is inexplicable. Why just that particular movement of all the movements he has made and repeated, each repetition setting up a neural habit? Why should the habit of the successful movement override the habits of the unsuccessful movements, which have had the advantage of the start, if desire and its fulfilment, if success or failure are not to count?

It is not necessary to keep a cat hungry and shut him up in a cage within sight of food in order to test the power of psychic associations over neural ones. Everybody who has lived with animals, and loved them and gained their lore, must have observed what I may call the pre-potency of their acquired affections over long established habit associations. (I am not sure whether one may speak of the prepotency of acquired characteristics! But an illustration will make my meaning clear.) My own cat, like other cats, is obsessed by his motor habits. Perhaps his most persistent motor habit is his garden game of ruming away and hiding in the bushes when I try to eatch him. Indoors, he is not happy unless he is sitting in my lap. There he may be easily caught, and will even offer him- 
self to be carried like an infant in arms. Out of doors he will not come to any call; he will not be caught or touched by any hand. My approach is the signal for his flight. All through this summer, and last spring and summer and autumn, all through the spring and summer and autumn before that, he kept up his garden game, with the same fixed gestures, the same lovely ritual of play; a ritual so invariable as surely to have become automatic. This autumn I went away for seven weeks. When I came back he was not in the house. I could hardly suppose that if he was in the garden he would come to me, since he had formed no habit of coming when he was called. Still, I called him; and in an instant he appeared on the wall of the next garden but one. He stood there and stared at me till he had put the voice and the figure together. Then he came running fast, along the connecting wall into his own garden, and straight into my arms. The rush of affection and of reminiscence had carried it over all the motor habits of the garden game, and over all his ancestral memories of pursuit and flight.

Now if Parallelism cannot well account for the behaviour of Professor Thorndike's cat, still less can it account for the behaviour of my cat.

There are yet other psychic factors besides desire and its opposite, aversion, which are not represented on the physical side. There are pleasure and displeasure. And there is a further problem: Do these psychic factors, or does some neural process determine the movements of organisms? Grant that pleasant experiences are beneficial and unpleasant experiences hurtful.

"If then" (I am still quoting Mr. McDougall) "pleasure and displeasure are themselves the determinants of movements of appetition and avoidance, we can understand how this general agreement between the beneficial and the pleasurable and between the hurtful and the disagreeable has been brought about by natural selection. ..." 


\section{And if}

"we adopt the Parallelist's assumption that two neural processes, the physical correlates of pleasure and displeasure (which we may call $x$ and $y$ ) are determinants of appetition and aversion, then the correlation throughout the animal world of $x$ with the beneficial and of $y$ with the hurtful, bodily affections follows ... from the Darwinian principle. But that $x$ should express itself in consciousness as pleasure and $y$ as displeasure would remain an insoluble problem."

Again :

"And if it be asked - Are we then to believe that the feelings themselves act directly upon cerebral processes? the answer must be, I think, No; they act only indirectly, namely, by exciting conation or psychical effort, for conation is, essentially, the putting forth of psychical power to modify the course of physical events."

Now, the parallelist and the materialist with him might say: Why drag in psychical effort to account for movements of appetition and aversion which you have allowed to be determined by $x$ and $y$ ? On the theory, psychical effort can do no more than show itself as a movement of appetition and aversion which has been already accounted for. The Animist can only " down" him by showing that psychic effort does do more. It does so much by way of modifying physical events that its teleological action deflects the teleological line from the parallel and sends it cutting across the causal line continually.

The parallelist's diagram of the transaction should stand thus:

Physical and Causal Line.

Movement

accomplished.

Neural process.
Psychic and Teleological Line.

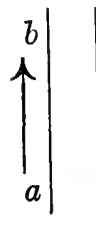

$\begin{array}{ll}\text { Movement desired } & b^{\prime} \\ \text { as end. } & \uparrow \\ \text { Sense-impression. } & a^{\prime}\end{array}$ 


\section{SOME QUESTIONS OF PSYCHOLOGY}

These are positively all the factors that the strict parallelist is justified in taking into account, if his lines are to remain strictly parallel, and if point for point correspondence is to be perfect. The diagram is absurd; but it is beautifully simple, as on any theory of rigid Parallelism it is bound to be. You will notice that interaction is inexorably barred. There is no bridge to or from the causal physical process on the one side to the psychic teleological process on the other.

You will also notice that no teleological action has talien place. It need not take place, because neural process $a$ has led directly to the accomplishment of movement $b$. And it cannot take place because, clearly, movement $b$ is accomplished on the physical line, and there is no means of transferring it to the psychic line.

So the parallelist must either give up his teleology, or, agreeing that teleological action has taken place, he must admit that it has contributed to an effect (the movement) accomplished on the physical line; in which case he gives up his Parallelism, and goes over to the theory of interaction.

I do not want to complicate this problem unnecessarily, but if we introduce the factor of time - and we cannot ignore it - some very odd consequences will follow.

For we have not forgotten that, on the two lines of physical and teleological causation, what is last in the physical series as effect appears first in the psychic series as cause.

Physical Process. Instants of Time.

Psychic Process.

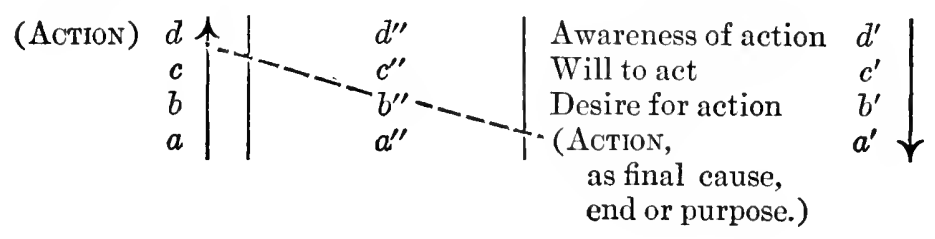


I am not trying to circumvent Parallelism by arguing that an action accomplished is identical with an action designed; and that, consequently, the same thing, besides existing both as the cause and the effect of itself, must exist (as cause) at the same instant of time when (as effect) it has not yet come into existence. For there is no reason why the same thing should not behave as cause and effect respectively at different instants of time; and it is quite impossible to establish point for point correspondence of the series of instants in time with the series of physical and psychic events, so as to force the conclusion that the time of those different behaviours is the same. I suggest none of these absurdities. On the contrary, in spite of that diagram, I would insist that action physically accomplished, and action as purpose or end, are two separate events - divided, it may be, by a long period of time and by many intervening processes - of which one event, invisible, incalculable, psychic, most truly determines the other which is visible, calculable and physical; inasmuch as the inner event is the one factor without which the outer event would not have happened. And I would suggest that, this being so, it is not the antecedent neural process but the antecedent psychic process that is the prime causal factor.

But - to return to the case of Professor Thorndike's cat - there were other psychic factors, not represented on that diagram, which cannot be ignored.

What has happened in the case of Professor Thorndike's cat?

The cat has received his pleasant sense-impression of the milk outside his cage. He has hit on the lucky means of escape, and established a pleasant memory of the beneficial result. After a few experiments, which he makes himself, a connection (but what connection?) is established between $a^{\prime}$, the sense-impression of the milk, and $b$, the movement which unlatches the door; so that, in future, sense-impression $a^{\prime}$ is instantly followed by movement $b$. 
Now, besides these two terms, there stands on the psychic line, a third term, $c^{\prime}$, the cat's pleasure or satisfaction. (His pleasure and his pleasant memory are really two terms; or, if we count repetitions, they are as many as you like; but for the purpose of the problem they may be taken as one). This third term is of supreme importance in determining $b$. It, not $b$ (the movement itself), is the real final cause, the motive, purpose or end of $b$. For the pleasure or satisfaction of drinking milk is that for which the cat makes his experiments and his successful movement.

But, though the psychic event $c^{\prime}$ will no doubt be represented on the physical line by some point of neural change, $c$, on the parallelist hypothesis $c^{\prime}$ (again) must be a superfluous and impertinent interloper, since the sense-impression and the memory of $a^{\prime}$, the sight of the saucer of milk, or rather, its representative neural change, $a$, is sufficient to bring about the movement $b$ by nervous discharges along a path of least resistance, going direct, that is to say, without psychic intervention, from $a$ to $b$. (Direct, because the question is not of the neural reflexes naturally involved, but of psycho-physical interaction.) So direct is it (in this sense) that, given strict correspondence, the process on the psychic line - each term accompanied, if you like, by its meaningless note of neural change - ought to stand $a^{\prime}-b^{\prime}$, without any intermediary $c^{\prime}$. The cat's pleasure (which, by the way, has grown by repetition from one more or less simple sensation to a perfect pile of memories and anticipations of pleasure), the Cat's Pleasure, so immensely important and personal to him, counts for nothing in the parallelist's programme; though to the cat and to his master it must rank as the chief actor in the psychic drama.

If it comes to that, is it, can it be, really the chief actor? Or eren the chief motive power? Behind the cat's movement is his memory, and before it his anticipa- 
tion of pleasure; so that, even if we count the sensation and the memory and the anticipation as one determinant, the psychic plot thickens before our eyes. And if we are really to do justice to the whole action, we must assume a fourth factor, $d^{\prime}$, the Cat's Desire.

Eliminate his desire, and his whole behaviour becomes meaningless. His pleasure is meaningless; his movement is meaningless; he might just as well keep quiet in his cage. True, he would not desire the milk if he had no pleasure in it. It is equally true, however, that he would have no pleasure in it if he did not desire it. And the peculiarity of this factor of desire is this: that it does not enter the series as a single member of the series $\left(a^{\prime}, b^{\prime}\right.$, $\left.c^{\prime}, d^{\prime}\right)$, but is present to each member of the series, $\left(a^{\prime} d^{\prime}\right.$, $\left.b^{\prime} d^{\prime}, c^{\prime} d^{\prime}\right)$, and to the whole, in a way in which they are not present to each other.

For instance, he desires his pleasure; and he desires the movement which is his means to his pleasure; but he has no pleasure in the movement itself. His desire saturates his sense-impression, $a^{\prime}$, of the saucer of milk, and his pleasure $c^{\prime}$, and his memory and anticipation of pleasure, and it is surely the true causal determinant of his movement $b$. And if you say (the parallelist is bound to say it, since he is committed to the telcological view of the series $a^{\prime}, b^{\prime}, c^{\prime}$,), if you say and insist that his desire $d^{\prime}$, is determined by his pleasure $c^{\prime}$, which thus appears as the final cause of the movement $b$, still, you cannot eliminate the factor of desire without doing violence to the whole series with which it is so intimately platted up. I think, therefore, you are driven to acknowledge it, not as the final cause - for pleasure fills up that rôle quite adequately - and not as the immediate working cause - for that is a complicated affair of nervous discharges and muscular tissues - but as the determinant of (or ruling causal factor in) the movement $b$. 
Then you have got as clear a case of that trespass which is interaction as the Animist could well desire.

And the Parallelist's dilemma stands thus: If he was justified in regarding the series, $a-b$ which stands for the neural lines of least resistance representing habit association and habit memory, if he is justified in regarding this series as sufficiently determining $b$, he is obliged to ignore the obviously existing psychic factors of pleasure and desire, determinants of series $a^{\prime}-b^{\prime}$. But as, in any case, on his own showing, it must have been sense-impression $a^{\prime}$ that started the whole business, some form of causation other than the teleological has surreptitiously crept in on the psychic line, contrary to the sacred law laid down by himself in the beginning. For, clearly, without the psychic intervention of the original sense-impression, $a^{\prime}$, the precise and particular fact we are considering, though possible, would not have been actually accomplished.

So that, in the most elementary process of psychophysical life, his rule which forbids interaction has been broken.

If, on the other hand, he acknowledges - as he is bound to do - the existence of the psychic factors, pleasure and desire, he will find one of them, desire, breaking loose obstreperously from the teleological line and invading (again!) the causal side as determinant of the movement $b$.

In this case he has, to add to his embarrassment, a whole psychic series within $a^{\prime}-b^{\prime}$, in which $c^{\prime}$ and $d^{\prime}$ stand as the chief factors, a whole psychic series for which it would be hard to find point for point correspondence on the physical line.

Parallelism therefore breaks down badly in three places: its law which demands correspondence breaks down; and its law which forbids cross-correspondence breaks down; and its law which distinguishes between causal and teleological lines breaks down; and a better diagram of the real situation would stand thus: 


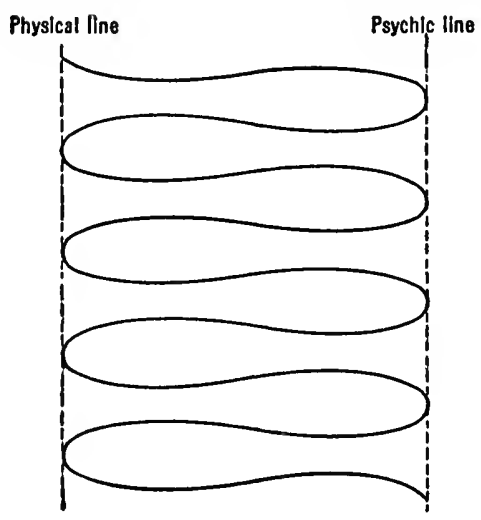

You have there a vision of the entire collapse, of the most obvious crumpling and buckling and cross-cutting of the lines; while the Animist has established a sort of ascending spiral as his image. (I must not father this image on Mr. MeDougall; but I think it is justified by the ensemble of the process.)

And yet we have not got farther than the simple psychology of Professor Thorndike's Cat.

Imagine then what a diagram would look like that attempted to represent the higher psychic processes of man, the complex play of many motives, determining one of many actions seen to be possible and desirable; the conflict between desire and will; the element of choice - the will darting like a shuttle to and fro among all those infinite threads and weaving them to its own pattern. Add to this the emotions saturating the web with their own colours; and consider that you have not yet allowed for the intellectual fabric, different and distinct from this play of action and emotion and desire, yet hardly distinguishable, so close is the psychic web, so intricate the pattern.

When you come to the work of the adult human intelligence (we do not yet know enough about animal intelligence to say with any certainty what goes on there), to 
even such an apparently simple operation as the perception of an object in space, and of its relation to other objects in space, it is even more obvious that you are no longer dealing with a series alone but with a synthesis. Add to this - what is inseparable from it - the perception of change, of the succession of events in time, and your synthesis will be a synthesis of successions and juxtapositions, or contemporaneous existences, in which erents will be perceived as moving one after another and altogether, against a complex background of objects immobile in space. Add to this the mere perception of their innumerable relations, and to this the higher operations of the intellect, the innumerable concepts involved in the most elementary process of acquiring knowledge, and you get a series of syntheses and the synthesis of this series. Add the operations of judgment and of reasoning, inseparably bound up with this process; then abstract these operations from the process and examine them; you will find, not only that they follow a certain fixed order of their own (the laws of inductive and deductive logic), but that yet another operation has crept in - analysis, and that these syntheses, so laboriously built up in consciousness, are in consciousness dissolved and broken up, in order that new syntheses, new combinations, associations and arrangements may be formed.

This is Wundt's principle of the "creative resultants" with a vengeance.

As Mr. MeDougall points out, with that one rash word "creative" Wundt gives the whole show of psycho-physical Parallelism away. And I do not think it is unfair to hold him to it. There is no wriggling out of the awkward position it has created for him. And if we are offered our choice between Parallelism and Interaction I can see no grounds for hesitation.

Parallelism is a sort of psychological book-keeping by double entry, under such conditions that the values, on 
whose constancy the integrity of the result depends, change, not only between the dates of invoice and account, but with every separate item in the ledger. So that the parallelist's books never really balance. Whereas the Interactionist allows for every fluctuation in the values, while equally pledged to the austerity and sanctity of book-keeping.

Now I think the fact of psycho-physical interaction is fairly demonstrated. But so far from giving us the metaphysical security we are seeking, it leaves that side of the problem as much as ever in the dark. Psychology suggests the ultimate questions it cannot answer.

We cannot strike a balance of interactions and say whether physical or psychic action tips the scale. We do not know how far psychic action can modify the order of physical events. There are certain long-established, not to say invariable sequences, such as the course of the stars and the formation of water from the union of $\mathrm{H}_{2} \mathrm{O}$ with which we are pretty sure it cannot interfere. You can persuade a plant or an animal to breed and grow the way you want it - within certain strictly defined and very important limits. But you cannot force a single particle of inorganic matter to behave contrary to its pre-established habit. Still there are certain physical alterations that you can effect. You can dam back the tides and divert the course of rivers. You can change the outward appearance of the habitable globe by merely displacing things on its surface. You can turn steam into a cylinder so as to drive an engine. You can so regulate a current of electricity or an explosion of petrol as to make them do the same thing. So that, if a diagram could be drawn showing the physical results of the psychic processes of a few enterprising individuals it might not equal our imaginary psychic diagram in complexity, but it would be a very imposing and intricate affair.

Shut up a puppy by himself in your study when he is 
teething, or let loose a speculative builder over a square mile of virgin wood and field; and observe the change their psychic processes will effect in the order and integrity of material objects. In twenty minutes the puppy has gnawed the backs off your books and worried the hearthrug to shreds, stained the carpet by upsetting the ink over it, and, having eaten the best part of your manuscript, he is about to change its chemical composition when you find him at his work. In a year's time the builder has caused the virgin wood to disappear and has covered the fields with streets of houses which show in outward forms of conglomerated bricks and mortar the inner hideousness of his soul.

True, the puppy and the builder have been obliged to use physical machinery to achieve these physical results, pitting one set of physical forces and one arrangement of molecules against another. Still, all this continuous construction and destruction has inrolved continuous psychic effort; so that all along the series there will be innumerable points where the physical processes are no longer traceable, and the psychic processes come into play.

But when we try to estimate the proportion of psychic effort to physical result we find we are dealing with incommensurables. ${ }^{29}$ So many bricks laid, so many psychic processes involved in the laying of each. We can count the bricks; but we cannot count the psychic processes; neither can we gauge the intensity of the psychic state at each moment of the process.

And so far we have only been dealing with one side of the total operation, with extension, and the displacement and rearrangement of objects in space. When we come to time, all possible correspondence ceases. You can measure the time taken to lay each brick, and calculate from it the number of months it will take to complete the entire scheme of the Estate; but you camnot measure the time of the psychic processes, for the simple reason that those proc- 
esses are more than processes, they are syntheses. And with them we are brought back once more to the unity of consciousness.

And we are once more driven to ask:

1. Is there any unity outside our consciousness that corresponds with this unity within it?

2. If so, is that unity also a unity of consciousness? Or rather: Is there anything in that unity from which we may infer that where it is there is consciousness?

3. Is there anything in both unities from which we may infer an ultimate unity?

Once more, the long round that we have fetched by way of biology and psychology has landed us in ultimate questions of metaphysics. 


\section{IV}

\section{SOME ULTIMATE QUESTIONS OF METAPHYSICS}

IT will be remembered that we adopted Mr. McDougall's classification of metaphysical systems provisionally, and with considerable reservations, in order that he might do his own deadly work among them unhindered. We have seen him do it. We have seen how far he has justified the hypothesis of a self or soul as the unique ground of the unity of consciousness. And we must admit that he has certainly delivered it from the worst assaults of the physiological psychologists.

$\mathrm{He}$ has done this, apparently, by demonstrating the principle of psycho-physical interaction.

But this is by no means the end of the matter. I think we may ask him at least four questions.

1. How, without recourse to some metaphysical principle, does he propose to maintain the unity of consciousness throughout the interactions?

2. How would he explain the soul's action in the construction of time and space?

3. What holds body and soul together?

4. What holds the multiplicity of souls together?

Surely (1), unless body and soul are one, or aspects of an underlying Reality which is one, each interruption of either into the other's territory must be a break, however slight, of their respective unities. And this, whether the law does or does not hold good eternally, that the cause must pass over into its effect. Interaction is interaction. Now, whatever the unity of matter may be, unity of conscious- 
ness is the unique arm of the Animist. Take it from him and he is powerless.

Mr. MeDougall is aware of his danger, and he tries to reduce the soul's action to something less than cause and more than correspondence. But the danger is only masked and not removed. Onee admit interaction, with its resulting changes, and not only is the powerful charm of Parallelism broken, but the Animist himself is committed to the whole causal relation.

That relation is not like an unhappy love-affair with the "reciprocity all on one side." It is not the simple affair of body as cause, telescoping into soul, and soul, as cause, telescoping back into body; but each contributes to the effect. This double relation of cause and effect alters the ensemble so profoundly that to talk any more of dualism is absurd.

Even granted (2) that each interaction is simultaneous and not successive, the whole series of interactions constitutes a process, a series in time. If you presuppose a " real" time, you are promptly landed in all the dilemmas which M. Bergson, for one, has shown to be inherent in that idea. ${ }^{30}$ If the soul supplies, as it were, its own time, then you have a psychic action covering the whole psychophysical performance in one very extensive and necessary relation. And the same holds good of space.

What holds the high interacting parties, body and soul, together? (3)

(This question follows from Question 1.) As long as they were parallel they could be considered as holding themselves together; but, as we have seen, their unities are broken. Surely a system of interactions cries for a unity just as loudly as a system of states of consciousness?

As for the fourth and last question: What holds the multiplicity of souls together? Since the souls interact on each other, their system of interactions calls for unity.

I do not think that these questions can be set aside as 
frivolous. They are perfectly legitimate problems arising out of the case; and Animism provides no solution of them.

When it comes to unities, as on the Animist's own showing it must and does come, if the unity of consciousness only holds good within and of consciousness, then physical unity, if there be any, will hold good within and of bodies or matter generally; so that, in the last resort - and there must always be a last resort - each unity will form a "closed system"; and the Animist must be numbered among the parallelists. I do not see how, without recourse to a metaphysical principle and a metaphysical unity, he is to escape from the position.

It is clear that in that classification of systems which I have borrowed from Mr. McDougall we are dealing with two things: Psychophysics, which has no philosophic axe to grind, and Metaphysics.

Neither Animism nor Psychophysical Parallelism professes to give us a Metaphysic or a Metapsychic; but only certain psychophysical postulates.

It should also be clear that, however much we may wish to separate them, we cannot, as a matter of fact, keep them apart, if we are to go on with - I won't say finish - our thinking.

And I think it should be transparently clear that neither empirical nor $\grave{a}$ priori metaphysies can take up any impregnable position outside Psychophysiology, and will not advance very far, or at any rate very safely, as long as it ignores the psychophysical facts, however radiantly honest its attitude may be.

But it may not have been equally clear that Psychophysiology cannot keep itself unspotted by some Metaphysic or another; that is to say, if it is to go on with its thinking. It can, and we have seen that it does, voluntarily arrest its thinking on its own borders and refuse to take the metaphysical plunge; but, with the first step over, and not even with the first step but with the first look, with 
the affirmation that there $i s$, and with the affirmation that there is not a region beyond its border, it is in. Only the non-committal attitude that acknowledges that there may $b e$ a region will save it from the plunge.

But if the Psychophysiologist goes on thinking he is committed to a metaphysic. For there is a lurking metaphysic in his most empirical conclusions, and even in his non-committal attitude.

Let us look back at the systems we considered. They may be reduced to three types, as far as body and soul are concerned.

1. Monism: the systems of the One.

2. Parallelist Dualism: the systems of the Two (with or without assumption of an underlying One).

3. Animism: or the theory of the Mixed.

To these, as we leave the ground of Psychophysics, we shall have to add Pluralism in its three forms of:

1. Pragmatism,

2. Humanism, and the

3. New Realism, which are all systems of the Many.

Of these the New Realism is so new, so revolutionary, so dangerous to every form of Monism we have considered hitherto, that it calls for special treatment later on and in a place apart.

I have not insulted the Animist by putting him among the Parallel-liners, where, I think, if he finished his thinking he would have to go; because he may quite honestly and legitimately decline to finish it. But I have not followed Mr. McDougall, this time, in putting Objective Idealism (which is somewhat inadequately rendered by "Psychical Monism") among the Parallelisms; for I do not think this arrangement is fair to a philosophy which cuts the knot by maintaining, with a stoutness verging on apoplexy, that the world arises in consciousness, that it 
exists in and through and for consciousness, and that consciousness is the "Thing-in-Itself"; which thus begins its thinking with consciousness as the totality of experience, and finishes it there.

If we consider each one of these systems in turn we shall find that there is not one of them, no, not even the most non-committal that has not its own dilemma.

The dilemma of the out-and-out Materialist is that he must either admit that consciousness does not come altogether into his net, or he must break his own sacred law of the conservation of energy. In any case, if he says that psychic processes are an illusory by-product of physical processes, he fails to show why they should be conscious processes.

The dilemma of the out-and-out Subjective Idealist, or Self-Aloner, is that he must either deny the existence of other consciousnesses, and of things he is not conscious of and never could be; or he must give up his fundamental hypothesis of his own solitary existence. If he turns the materialist's position upside down and says that his ego produces the physical series as the illusory by-product of its own psychic series, he fails to show why it should be at the pains of projecting any physical aspect of its psychic states, why there should be an illusory appearance of a parallel at all. If he says that there is no parallelism and only one series, his own psychic states, he fails to account for the existence of any consciousness other than the one he started with - his own. Still less can he account for the order of physical things in ante-psychic time. For if there is no universe outside his private consciousness, the universe that physical science shows us as existing previous to the appearance of his consciousness is a retrospective illusion; and the manifestations of his neighbour's consciousness are a past, present and future illusion; and his neighbour's consciousness itself, with the universe it carries about in it, is the illusory hypothesis of his 
thought. Worse still, as he is not conscious of his own neural processes, they also cannot be allowed to exist; their existence for another consciousness, that of the scientific observer, is not existence in any consciousness; it must therefore share the illusory quality of all that attaches to his neighbour and his neighbour's consciousness.

Worst of all, his own ego, the self which should be at the bottom of the whole show, to produce and maintain the system of illusions, can have no existence either; since it does not and cannot appear in its own consciousness. The formula for this theory must be: Consciousness is just consciousness, of nothing, for nobody; and it is nobody's consciousness.

So that the out-and-out Self-Aloner must either show reason why he should exist in this solitary and unsupported manner; which he cannot do, as he has no grounds to establish his self on except himself; or he must acknowledge the existence of a world - if it be a world of selves - outside himself, in which case he is no longer a SelfAloner.

Mr. McDougall has very clearly shown the sad plight of the Parallelist. His attitude has no intervals of repose. The more strictly parallelist he is, the more he denies interaction, the more he has to keep jumping backwards and forwards from one of his lines to the other; in which case he has to admit that there is a jumping-offplace and a landing-place somewhere, that is to say, a common terra firma for thinking and acting on both lines. His dilemma is like the Materialist's. He cannot keep his rules and his principle too.

The dilemma of the Animist, as I have tried to show, is that without some "higher unity" to solder them, his unity of consciousness, and the unity of all physical things, finally form closed systems of penultimates running parallel; so that in the long run (his long run) he is landed in a dilcmma as serious as any he has exposed. Either 
he must make the totals of psychic and of physical interactions equal and opposite, an assumption which he has no grounds for; in which case, by the law of causation, they will cease to be interactions, and will form one action and one phenomenon; or, while insisting on partial interaction, he must acknowledge a greater unknown second quantity of actions and phenomena running parallel. In either case the unity of consciousness is broken.

There are dilemmas and dilemmas.

There are dilemmas inherent in the nature of a system. Such are the dilemmas of the Materialist and Idealist by-product theories.

There are dilemmas which are latent in a system, of which the upholders of the systems are more or less aware. Such are the dilemmas of the strict Parallelist and the Animist. Wundt virtually abandoned his Parallelism in his principle of the creative resultants. You feel that Mr. MeDougall has either a monistic or a pluralistic solution up his sleeve, if his conscience as a man of science would allow him to produce it.

And there are dilemmas which are much more apparent to the critics of a system than to its supporters. Such are the dilemmas of the Imperfect Parallelist, or devotee of the Underlying Unknown, and of the Psychical Monist or Objective Idealist.

I have left the dilemmas of these Monists to the last, because there are dilemmas and dilemmas; and because, since it must needs be that dilemmas come, they seem rather less unbearable than any of the others.

The dilemma of the upholders of the Underlying Unknown and Unknowable is that, in order to prove that it is there at all, they have to assume it to be knowable, and indeed known; inasmuch as it is the ground of its own aspects and appearances. When you have said of your Un- 
knowable that it is Underlying, or that it is Substance, or the only Reality, or the Thing-in-Itself, you have already dragged it in the net of knowledge. When you have added that it is Infinite or Absolute, you have to all intents and purposes caught it and made it the object of your thinking. The one thing you absolutely don't know about it is whether it does or does not exist. You cannot predicate of it that reality which was the raison d'être of your affirming it at all.

Either you must give up its reality, by virtue of which you declared it to be unknown and unknowable; in which case your Monism has the bottom knocked out of it, and you are left with the dual aspects on your hands; or, declaring it to be the only real, you give up its unknowableness, and, by defining it, have brought it in under that aspect and manifestation which is thought.

This feat which his predecessors performed involuntarily, is the serious and deliberate accomplishment of the Objective Idealist. There is but one step from the Underlying Unknown Reality to Thought as the Thing-inItself.

The Objective Idealist does not worry about dilemmas. Consciousness can swallow them all. There is nothing that it cannot swallow. They are logical dilemmas, are they not? Very well, then. Already they fall within consciousness. They are expressed in terms of consciousness and lend themselves most obligingly to the expression. He does not worry about the world outside him. It is outside his body, not outside consciousness; his body is part of it, and both it and his body are expressible in terms of consciousness. Why seek, or why assume other modes of expression? If you remind him that, on his own showing, Nature is the "other" of Thought, he will say, What if it is? Doesn't that prove that it falls within consciousness, since otherness is a "thought-relation"? 
What is Nature but a network of relations, and what are relations but the work of thought? The terms of the relation? You don't suppose I've been so simple as not to allow for them? What are your precious terms when all's said and done, and you've analysed all the thought out of them? Sensations; and if sensation is not consciousness I should like to know what is. Changes, you say, not of consciousness nor for consciousness? Changes, let me tell you, that wind up in sensation, bang in consciousness. Changes, every one of them, in the outside world. World outside what? Consciousness? Not a bit of it. Outside and inside are terms - if it's terms you're talking about - of consciousness, or rather, they are thought-relations. Can you see "outside"? Can you hear "outside" or touch it? Outside (and inside) exists only in and for thought.

World in time and space? I believe you; and where, if you please, are time and space if not in consciousness? And what are they if not terms - there you are again of consciousness?

Changes of matter? All we know of matter is expressible in terms of consciousness; and what we don't know of matter is not material to my argument. Your argument? Your argument doesn't matter so much, either; but - since you insist - you're not claiming, are you, that matter is the Thing-in-Itself? Consciousness is the Thing-in-Itself. You think matter as we do not know it may be? But what sort of matter is that? I thought you were an empiricist; if you are, you've no business to jump like that from the known to the unknown; and if you're not, you'd very much better come in with me. Direct his attention to the triumphant existence of the Parallel-liner's physical line (or what is left of it after the Animist has done with it), the neural and brain processes which never are in consciousness, and he will smile patiently at your fatuity while he tells you that, if they do not exist 
as sense perceptions for your consciousness, or his, they exist in and for both as knowledges; and, even if they were not in his consciousness, or yours, they are in some consciousness as knowledges; and that there is no reason why they should not exist as sense-pereeptions for a consciousness so constituted as to perceive them sensibly. Talk to him of forces and of energies, and of the conservation of energy, of the imperceptible ultimate constituents of matter, of ether and electrons, and all the impalpable and imponderable postulates of physical science, and he will floor you with the same argument. Draw for him the picture of the aeons of past time, of solar systems rolling unperceived through space, of lifeless seas, and of glacial ranges subsisting in their august and solitary unknownness before sense and thought were ever dreamed of, and he will repeat that the picture itself is not only drawn in lines of consciousness but coloured deeply with its dyes; and he will ask you where and when these spectatorless dramas could have been played, if not in space and time, which he maintains, not without a show of reason, to be thought-relations which need no duplicate; and he will invite you in your turn to eliminate all possible forms of consciousness from the miverse, and picture, if you can, how much would be left of it.

Mr. McDougall cannot hope to disconcert him with that little joke about eating without an eater and without anything to eat, any more than you could shatter Kant with the old pragmatist wheeze of the thousand thalers; both instances being drawn from a region below the level of the enquiry. He takes his stand on the firm ground that consciousness at any rate is "given"; and if you are indiscreet enough to talk about eating, his obvious answer is that he alone among philosophers is not trying to eat his cake and have it too. He alone is unthreatened by either horn of a dilemma.

And when angry with him, this time, you turn and ask 
him how he dare mention Kant, who was worth fifteen of him, he will refer you to Kant's Prolegomena to any Future Metaphysic, and swear that Kant was on his side all the time with his unity of apperception, only that he hadn't the courage to say so. He will add that Kant deliberately dished the Transcendental Realist (or Absolute Idealist) show in order to exalt Practical Reason at Pure Reason's expense, and prove himself the most moral man in Königsberg. He will suggest, not without plausibility, that if people would only read Kant's Prolegomena and his Critique of Judgment more, and the two Critiques of Reason a little less, they would see that there wasn't such a great difference between him and the Idealists after all.

At this point you will perhaps remind him that Hegel's Naturphilosophie was not exactly a work its author could be proud of ; and that Naturphilosophie was ever the weak spot in the Idealist's armour; but he will stand his ground, protesting that, if Hegel had not been so bent on keeping his chair at Berlin by bolstering up the doctrine of the Trinity, ho would have been more in earnest with the "otherness" of Nature; he would, that is to say, have seen that if Nature is to be the "other" of Thought, the more otherly she behaves the better, and that that is why Nature kicks against the Triple Dialectic.

If you ask him what he will do, supposing, just supposing, it should be proved to-morrow that Nature did get in first, and that consciousness really was an illusory byproduct, he might be staggered for a moment, but he would recover on the assurance that, even in this case, consciousness would come out on top; seeing that, once the affair was known, the scientific explanation of it must necessarily be given in terms of consciousness.

In fact, I don't think the prospect would really stagger him even for a moment. You cannot starve into surrender a system with such a prodigious "swallow," nor 
"down" an opponent with such an inexhaustible capacity for retort.

Almost you could believe that Objective Idealism is the winning horse, and that you could do worse than back it.

Almost, but not quite. The Objective Idealist's horse is a remarkably fine animal, and of an incomparable speed. He can cover the greatest possible space in the smallest possible time, and you cannot "wind" him. That the $\mathrm{Ob}$ jective Idealist's wind is his only merit is the opinion of most people who have tried to hold out under his interminable recitative; whereas his great and undeniable merit is his almost infantile simplicity. But he is vulnerable in two places.

Ask him what he makes of unconscious thinking, of sleep and of forgetting, which are small holes, but still palpable holes in the general web of consciousness, holes which can never be filled up by the device of calling them knowledges; he ought to be able to say that no consciousness is lost for ever, but that things lost for us and forgotten are stored and remembered in the Absolute; but unless he is an Absolute Idealist he cannot say it.

Ask him what he makes of the great energies of instinct and of love, of will and purpose and action, of conscience and ethical values and aesthetic values, and he will tell you that he makes nothing of them except that they are states of consciousness like any other, and - if he is consistent - that one state of consciousness is as good, because it is as real as any other.

$\mathrm{He}$ is either so absorbed in his vast vision of the world "arising in consciousness," so satisfied with his fairly easy reduction of everything in the universe to states of consciousness, or so intent on his series of unanswerable repartees, that he has never paused to consider what consciousness itself may be doing all the time, and how its states are behaving among themselves.

And his secret dilemma, which he will not acknowledge, 
is this: He has cut the Thing-in-Itself very cleverly out of the problem and packed all Reality into states of consciousness; not my states, or your states, but all the states of all the consciousness there is; so that the sum of Reality will be simply the sum of the states. No state of consciousness, on his own showing, can be more real than any other state. But Totality, the sum of all states, must be more real than any one state or any number of states. So that his Reality is purely quantitative, and every lapse of consciousness, no matter whose or what - and these lapses are constantly occurring - will be a dead loss of reality to the Universe. And unless he can show that this loss is made good somewhere and made good all the time, reality must suffer very seriously. In order to make good the loss, he must give up his assumption that all states of consciousness are equally real; so that he may protect himself by the further assumption that what the Universe has lost in quantity it has gained in quality (which is impossible to prove). In this case he must either abandon his theory of consciousness as sufficient reality in itself, or he must take refuge in an Absolute Consciousness. Say that, like a wise man, he takes sanctuary. Even then he is no better off. For he cannot contend that his Absolute is real quâ Absolute. Consciousness being the only reality, his Absolute can be only real quâ Consciousness. So that, strictly speaking, he had no right to summon it quâ Absolute to his aid. But he has done it, and is now faced with the further dilemma. If Consciousness is only real qua $\mathrm{Ab}$ solute, all those states of consciousuess which, on his own showing, consisted chiefly, or entirely, of thought-relations are unreal. He cannot save himself by picking out the terms of the relation from the relation and declaring them real; for it was just their capacity for entering into relations that entitled them to reality within his closed system. Nor can he purchase reality for them by merging them with his Absolute, except at the price of the Oneness 
to which he was pledged. For then he has indeed found the true home of the irreducible term (shorn of its thoughtrelations), which must be held henceforth to exist within the Absolute with all the absolute reality of the Absolute; yet, at one blow, he has deprived of reality his entire system of thought-relations. It is all up with the "diamond net" in which he had so skilfully ensnared the universe.

He must now confess that appearance, not to say unreality, in the form of relativity, enters largely into consciousness; since Absolute Consciousness is the only Real. This appearance must either exist within Absolute Consciousness, infecting it with relativity; besides setting up a schism inside it as against the "real " terms; or it exists in states of consciousness outside it; in which case Absolute Consciousness will be set up over against Relative Consciousness in a relation of absolute to relative; when it is all up with the Absolute.

Even the Self-Aloner is not in a more horrible position. He can swallow the entire Universe, and the Absolute with it, in one sacramental mouthful, since at least he has given himself a "Self" to swallow with.

Now, when we behold the collapse of one metaphysical system after another, and of one psycho-physical theory after another, and find the cause of the collapse in some inherent dilemma, three courses are open to us.

We may abandon all systems and all theories henceforth and for ever. This is the counsel of prudence and of caution. It is also the counsel of intellectual despair.

Or we may try to build up another system and another theory out of all the old ruins on a new site. This is what has been done with metaphysical systems from time immemorial, and done with perfect ease; it merely involves shifting the material and rearranging the already generalized terms of the problem. But we cannot play in the 
same light-hearted fashion with psychophysical material, which has its own attachments and its own territory, and refuses obstinately to be shifted on to new ground. In any case, the chances are that our precious erection would have most of the bad points of its predecessors with a special and incurable shakiness of its own.

Or we may go back to the old systems and the old theo- 1 ries, to see whether they had anything in common, and if so what, and try to find out the root of the dilemmas which were the cause of their collapse. We have got to face the fact that the psychophysical problem has complicated our problem very seriously.

Supposing we find that all, without exception, have a common interest and a common end, and that their several dilemmas have a common root, we shall have gained, not perhaps enough to build with, but enough not to despair of building henceforth and for ever.

Now it cannot be maintained that all metaphysical systems and theories seek unity, in the teeth - the really very sharp and ferocious teeth - of the New Realism which has gone out of its way to avoid it. The New Realism is out and out Pluralism. But certainly all the systems and all the theories we have considered yet have this thing in common - the quest for unity, some kind of unity, no matter what. The desired One may be matter, or it may be mind; it may be the Ego ; it may be just Consciousness; or it may be an unknown and unknowable tertium quid, Substance, Thing-in-Itself, the Absolute, the Unconscious, the Life-Force. It is implicit in the very dilemmas of the systems that have repudiated it.

First, then, we have to see whether the dilemmas we have considered have a common root.

We have seen Vitalism fall from one dilemma into another, because of the ultimate reality it ascribed to matter, and the metaphysical importance it gave to action. It seeks unity, it seeks reality, but it cannot find it. And 
the root of its dilemma is that it looked for ultimate reality in a penultimate place.

The dilemma of the thorough-paced materialist was that he could only save his materialism at the cost of the empirical law he based it on. Clearly he would not have fallen into that dilemma if he had not given to matter an ultimate reality, and conceived it as doing what, as a purely mechanical phenomenon, it was powerless to do; besides giving to a purely physical law a metaphysical validity he should have been the last to claim for it. In other words, he looked for ultimate reality in the wrong place.

The dilemma of the thorough-paced Subjective Idealist was that, in denying the existence of any reality outside himself, he cut away the ground from any possible proof of his own existence. Again the root of his dilemma was the quest of ultimate reality in the wrong place.

The dilemma of the less consistent types of Parallelliners was that, placing Reality in a mysterious third Something, expressly stated to be either Unconscious or not definable in terms of conscionsness, they straightway fell into either defining it plumply and plainly in terms of conscionsness, or bringing it into such relation with consciousness as to compromise very seriously its neutrality.

The root of their dilemma was that, while they distinguished clearly between appearance and reality, and recognized that body and soul, matter and mind, brain processes and consciousness, are equally phenomenal, they yet placed Reality in some Third Principle from which they had previously abstracted every sign and mark of the Real. They also were looking for Reality in the wrong place.

The dilemma of the thorough-paced Parallel-liner was that, the harder he drove his system on two lines, the more it tended to leave them. And the root of the dilemma is again the same. In renouncing the quest of the Ultimate Reality he is obliged to ascribe to mere psychophysical 
processes the metapsychic and metaphysical functions they have not. If you cannot say that he, too, has looked for ultimate reality in the wrong place, since he was not looking for it at all, he has looked on at the usurpation of its place and power.

Nor can it be said that Objective Idealism, or even that Absolute Idealism escapes; in spite of its tremendous swallow. If the Vitalist makes too much of action, the Objective Idealist makes too little. His dilemma was that, having defined reality in such terms of consciousness as to eliminate all elements of consciousness other than thought-relations, he infected his Absolute with relativity, and was forced to deny to Thought the ultimate reality he had claimed for it in the beginning.

The root of his dilemma is transparent. He, too, looked for ultimate reality in the wrong place, in consciousness held together by thought-relations and by nothing else.

Animism is safe from dilemma only so long as it has not declared openly against metaphysical Monism. It would be unfair to press any argument hostile to Pluralism against Animism as represented by Mr. McDougall, still more unfair to fasten on him an opinion he would disallow. His is clearly a case of suspended judgment. So long as he forbears to take the final plunge into any metaphysical gulf I have no right to picture him as hovering on the brink.

Leaving Animism, then, to its suspended judgment, we may say that, with this doubtful exception, all those systems and theories, psychophysical or metaphysical, had some one ultimate reality for their common end. And all, in mistaking one or other set of appearances for ultimate reality, or one part of reality for the Whole, have betrayed the common root of their dilemmas.

All looked for Reality, looked for Unity, and looked for it in the wrong place. 
It would seem, then, that the universe is not built up from the Life-Force in action upon matter alone; nor from Matter itself alone; nor from the Individual Self alone; nor from an Unknown and Unknowable alone; nor from Body and Soul alone; nor from Consciousness alone; still less from Thought alone that lands you in the barren Absolute.

But, if there were one term that would cover all these terms: Life-Force; Matter; Individual Self; Substance; Thing-in-Itself, the Unknown and Unknowable or possible Third; Soul; Consciousness; Thonght; the Absolute; one term which, besides covering all these, covers also that which has slipped away from them - Will and Love, that term, could we find it, would stand for the Reality we want. We want a term infinitely comprehensive, and perfectly elastic; and a term that does some modest sacrifice to the Unknown. For the vice of those terms was that none was elastic, none was comprehensive; but that some one excluded, inevitably, some other.

If we could put that term in every place where we have used those others I do not think that the same dilemmas would arise.

To the Unity and the Reality we are looking, for we can give no name but.Spirit. This leaves a wide margin for the Unknown. 


\section{$\nabla$ \\ PRAGMATISM AND HUMANISM}

THE doctrine of the One has been worked so hard and so incessantly and with such passionate variance among its adherents as to the nature of their "One," that the reaction against it was bound to set in, and the tendency of modern metaphysical thought is in favour of the Two or the Many.

It was said that there are dilemmas latent in a system, of which the upholders of the system are more or less aware.

But a system may have a dilemma lurking in it of which its upholder is not at all aware.

Pragmatism and Humanism are such systems. At first sight they seem, like Psychophysical Parallelism, to be exceptions; but they also are exceptions that pay an unconscious homage to the rule, an unconscious craving for the unity they spurn.

The spurning, of course, was inevitable, by way of a change. Mr. F. C. S. Schiller, ostensibly a Pluralist, subsides into a sort of ethical Dualism; ${ }^{31}$ while Mr. William James is all for a Pluralistic Universe. Even Mr. $\mathrm{McD}$ Dougall, who may be suspected of cherishing some sort of metaphysical principle up his sleeve (he has at least deprecated the imputation of metaphysical Dualism), even Mr. McDougall joins with the pragmatists in robust derision of the monist, the slare of his "appetite for unity." They deny that the craving for unity is a universal craving, or eren a legitimate hunger. They do not 
feel it; no good pragmatist could feel it; the vast majority of mankind are born utterly without it; therefore it is clear that it is by no means a universal need. They do not go quite so far as to say that it doesn't exist, since certain absurd people do feel it; but they let you see that they regard the sincerity of these people as more dubious than their absurdity.

Besides this suggestion of insincerity, the unpopular monist is taunted with his supposed belief that his One is holier and "nobler," than the Many; whereas what he does believe is that, as an ultimate metaphysical principle, it is more necessary.

The driving wedge of the pragmatic humanist's attack on Monism is practically its argument ad hominem. "Humanism," Mr. Schiller says, "like Common Sense, of which it may claim to be the philosophic working-out, takes Man for granted as he stands, in the world of man's experience as it has come to seem to him." For, "even Pragmatism is not the final term of philosophic innovation: there is yet a greater and more sovereign principle now entering the lists, of which it can only claim to have been the forerunner and vicegerent." This is only an inspired way of saying that Pragmatism lands you in Humanism, as indeed it does. As for the principles the miserable monist deals in - "Pure Being, the Idea, the Absolute, the Universal I" - what are they "but pitiful abstractions from experience, mutilated shreds of human nature, whose real value for the understanding of life is easily outweighed by the living experience of an honest man?" 32

There you are; could anything be plainer? If Man is not the Measure of all things, an honest man, besides being the noblest work of God, is the measure of metaphysi. cal truth - and no other sort of man is.

If the monist does not like the turn affairs are taking, he has nobody but himself to thank for it. 
Now the honest man, the plain man, the man in the street, l'homme sensuel moyen, to whom Pragmatism makes its plain common-sense appeal, does not reckon among his familiar interests any conspicuous appetite for unity. He can grasp a working hypothesis applied to everyday life; he can see the point of the little joke about Pot-and-Pantheism; but you may "work" with two or five hundred ultimate principles for all he cares. And in the last resort it is on his utter indifference to the event that the pragmatist is banking when he frames his neat arguments against unity as a metaphysical ultimate and a necessity of metaphysical thought.

It may turn out that unity is no such necessity; but surely the honest man's unawareness of it is neither here nor there? Ten to one the honest man will be equally unaware of the unity of consciousness until some psychologist or metaphysician explains the point to him; but, when he sees it, ten to one, if he doesn't tell his informant to go - where bad metaphysicians do go, he will let him know that he could have told him that, in fewer words and with less trouble. For in matters that he does understand the honest man is very far from lacking in a sense of unity.

Where the pragmatist will seem to the plain man to score is in taking the existence of the Many for granted "as it stands." The Many undoubtedly are there, and their existence does not, on the first blush of it, suggest the existence of the One. And the assumed existence of the One does not, in itself, help you to understand the existence of the Many.

This statement sounds like common sense to the plain man. And as long as you are dealing with an abstract One, and an abstract Many (for the pluralist's Many is every bit as abstract as the monist's One), it is a true enough statement. But the humanist and pragmatist do not deal in abstractions. They deal with the Many of 
honest human experience, the Many as they stand. And the monist might retort: "Does the Many, then, as it stands, explain its own existence? Do not all attempts to wring its seeret from it end in generalizations which are unions and unities, not suggested by the Many as they stand, yet irresistible? Did not the high priest of Pragmatism declare that: "The most important sort of union that obtains among things, pragmatieally speaking, is their generic unity'? And that: "With no two things alike in the world, we should be unable to reason from our past experienees to our future ones?' And that: 'Absolute generic unity would obtain if there were one summum genus under which all things withont exeeption could be eventually subsumed'? (William James, Pragmatism, pp. 139-140.) And does not Mr. Sehiller declare that Matter is a 'baseless abstraction' (Riddles of the Sphinx, p. 69); that 'the development of Matter and Spirit proceeds along converging lines; and that by the time the supersensible is reached, a single reality will be seen to embrace the manifestations of both'?" (IIumanism, p. 298.) So that unity would seem to have even a pragmatic sanction.

Under all the pragmatist's cheerful appeals to the honest man there lies, half suppressed, a still more serious argument. It turns on the combined unthinkability and nonexistence of the One without the Many. But as the Many is equally unthinkable and equally non-existent without the One, this argument euts both ways. Either side gains its advantage from the insidious substitution of the relative, predicative, quantitative, numerical "one" for the Absolute One of the monist. You might argue in this way that one pragmatist is unthinkable without many pragmatists, and one God (if there is a God) without many gods. The trouble is that, while we are sure of the pragmatists, we are not sure of the God. And this is precisely where the pragmatic pluralist's argument lands him; and it is where 
he wishes to land, and always meant to land. For by insisting on the patent relativity of the one and the many, he is still sure of an easy victory when he works it the other way round: Many pragmatists are unthinkable without one pragmatist, and many gods without one god; a proposition where the one pragmatist and the one god figure as the first units in a numerical series, which lands you again in palpable plurality. So that, by this surreptitious substitution of unit for unity, and of quantity for not-quantity, the pluralist gets plurality both ways, at either end of his proposition.

But all that has happened is that, by his surreptitious substitution, he has insidiously transferred the tainted relativity of his predicates, one and many, to his substantive God; or, let us say, the One Reality. And when he goes on to argue that unity is unthinkable and nonexistent without multiplicity, the two-edged nature of the argument reveals itself at once. Multiplicity is unthinkable and non-existent withont unity. Neither side has the advantage; but, this time, the pluralist doesn't get his multiplicity both ways. For unity, in the monist's sense of one all-embracing Reality, is certainly not the first number in a numerical series.

It is now pretty evident that both sides are dealing, not with the necessities of thought, but with the barest abstractions.

But when the monist contends that his One is not the divisible, multipliable, numerical "one" of mere quantity, but the Absolute One of self-contained and selfconditioned Being, the pragmatist turns on him and exposes the relative nature of his Absolute. If all things are one in the Absolute, then the Absolute, being all things, is not one but many. If the relative is not the Absolute, then the Absolute is not all things. Again, if the Absolute is not all things it is not the $\Lambda$ bsolute; because it will then stand in relation both to the things it is not and to 
the things it is, and thus cease to be Absolute. It holds its thin prestige of Godhead or of cosmic unity at the cost of all god-like or cosmic attributes; for the moment it begins, either to be anything or to do anything, it needs must " enter into relations." At every turn the Absolute of the monist must face that awful and incredible "self-diremption," which makes of it a sort of Judas Iscariot in the potter's field of Philosophy, a Judas without any bowels. The sad process of the Absolute is the suicide of the eternal through time.

The Absolute, in short, is the most flagrant instance of an empty, impotent, adjectival abstraction - and a negative abstraction at that - posing as a cosmos or God.

And Being is in no better case. What is Being, anyhow, but an abstraction of the copula "is," by which predicates are hooked on to their substantives? It is hard indeed to see wherein either is holier, or nobler, or more convincing than any dual or any plural principle. The pragmatic pluralist can at least show that his plurality is concrete, that it is something, and that it is " given."

It must be owned that this form of the pragmatic pluralist's attack sounds very formidable. All the same I think the monist's monotonous answer meets it. The driving point of the pluralist's wedge is the assumption that the relativity which is at the bottom of all the dilemmas, and which holds good of the world of appearances, holds equally good of the world of Reality; and that, while you may and indeed must have dilemmas in the sub-metaphysical world, they should be strictly excluded from your metaphysics. And the Absolutist's answer is: Quite so. The sub-metaphysical world is the very birthplace and the home of dilemmas, which is precisely the reason why $I$ am driven to assume a better and a safer one. And to the pragmatist's sinister assurances that his metaphysical world is not safer, that it is not really half so safe, his reply is that the pragmatist wilfully ignores 
his point, and for purely pragmatic reasons. His point, which he reiterates with sickening persistency, is that what appears as a dilemma in the sub-metaphysical world is not a dilemma in the metaphysical one; doubt of appearances here is the very foundation of certainty there, and denial of unreality is its crown.

But the good pragmatist will have none of this. It doesn't matter what you happen to be denying, denial is bad Pragmatism.

\section{"Du bist der Geist der stets verneint."}

He is desperately afraid of any hand being laid on the actualities he loves. Mr. Schiller protests against Mr. Bradley's " conclusion that everything which is ordinarily esteemed real, anything which any one can know or care about, is pervaded with unreality, is 'mere appearance' in a greater or less degree of degradation." He finds that "this antithesis has become to me a considerable nuisance, and also, it must be confessed, a bit of a bore." In the heat of Pragmatism he forgets that it was his Mephistopheles who tempted Faust to say to the fleeting moment,

"Verweile doch, du bist so schön,"

and that the soul's perdition lies in confusing the passing loveliness with the Eternal and the First Fair.

But, after all, what has Mr. Bradley done? He has never, so far as I know, said a word about " degradation," or denied that an appearance may be a very noble and beautiful and even useful thing. He has said nothing to destroy pragmatic "values." The pragmatist is annoyed with the antithesis, which seems to him to exalt Absolute Reality at the expense of appearances; though he knows perfectly well that, since appearances are "there," since they have contrived somehow to get in first, they are not a bit the poorer for the metaphysical excesses of Mr. Brad- 
ley's Absolute. Yet the pragmatist pays homage to that principle in his heart when he ascribes absolute reality to the things he knows and cares about.

And under all his Pragmatism lies the monstrous assumption that the honest man's knowing and caring are the measure of all the knowledge and all the passion in the universe. Of Mr. Bradley's Absolute he says, pragmatically and humanistically: "If It be not fair for me, what care I how fair It be?"

Now in the first copy of Appearance and Reality that came into my hands, fifteen years ago, I found that the owner had written on the fly-leaf these words of Saint Augustine: "Thou hast made us for Thyself, and our hearts are restless till they rest in Thee." So that somebody seems to have cared about Mr. Bradley's Absolute.

I do not know anything about the state of Mr. Bradley's affections, or whether he has more or less "heart" than a pragmatist; I am quite sure he has more imagination. He would probably find it no end of a nuisance and a bore if all the nice, useful things the pragmatist knows and cares about turned out to be "absolutely real."

Now, in the first copy of Appearance and Reality pragmatic. Assume, as he does, that Man is not the measure of all things, but only of some things, and that even those things are not as they appear to him, and you will not worry about dilemmas. In a world of appearances a few dilemmas more or less will not very greatly matter. But assume, as the pragmatist does, that things are as they appear, and a dilemma becomes a very serious affair indeed. Assume an ultimate Dualism or Pluralism; then, since this is the only world that Pragmatism allows us to know and care about, the only world it allows us to assume, there is no hope of a solution in the "highest synthesis" of another. The pluralistic pragmatist abandons the hope of any highest synthesis, and is happy ; because his genius, his Will-to-believe, inclines him towards Humanism. The 
absolutist claims that the perfection of his principle is its capacity to swallow all dilemmas. It is what it is there for.

Observe that there is an implicit charge of arrogance in all that the pragmatist says about the absolutist. As if the absolutist had not made the Great Surrender, and as if it were $h e$ who had made human thought and human emotion, and human conduct and morality, "as they stand," binding on the transcendent and everlasting Reality; as if he had not stripped himself bare for his adventure into the "untrodden country." It is an adventure on which he has staked his all.

This recklessness of his is precisely what the pragmatist has against him. It is, you see, a question of "values." Either your relations with the Unseen are good business, or they are nothing. The pragmatist feels that the absolutist is not getting back his money's worth. He is buying in the dearest market and selling in the cheapest. What is worse, he is sending good money after bad. Instead of driving a profitable bargain with Reality, as any sensible man would, he is plunging. And Pragmatism abhors the plunger. The Absolute, in pragmatic language, "does not pay." How can a "pitiable abstraction," a "mutilated shred," even of " human" nature, be made to pay?

Now there are sereral ways in which the absolutist may meet this common-sense attitude. He may say that it is not a question of values, but of truth or falsehood, of sheer logical compulsion or the reverse, and that logic drives him to the assumption of the Absolute. He may say that, whether the pragmatist likes it or not, the conception of the Absolute is not a mutilated shred of human experience, but a necessity of thought. It is not to be accounted for by any description of the way in which the human psyche arrives at conception in the course of its evolution. It is not obtained by picking human experience to pieces. So 
far as it is "obtained" at all, it is obtained by testing all the "ultimate" principles of empiricism and finding them wanting. And they are found wanting precisely because they are - not absolute.

This, his opponent says triumphantly, is making human thought the measure with a vengeance. You see, you cannot get away from Humanism after all.

It is nothing of the kind, the absolutist retorts. You are simply quibbling. My principle is expressly stated as transcending human thought, in so far as thought is human, yours is not. It is presupposed in human experience, but - unless we are agreed to include the Beatific Vision as part of human experience - it is not found there.

He may also say that the Absolute is under no obligation to pay him, and that he is not looking for payment. Or, if he takes the line that he has faith in the Absolute, and believes that it will pay him in the long run, I don't see what the pragmatist is to do about it. He is pledged to the principle of the Will-to-believe, and the absolutist's Will-tobelieve is as good as his.

In any case, it is the pragmatist who begs the question when he says that the Absolute is an abstraction. So it is, from his point of view. When you have pinned your whole faith to the plump reality of a pluralistic universe, strictly conditioned, the Absolute must needs be the emptiest of abstractions. But even an uncompromising absolutist like Mr. Bradley would claim that his principle is the most concrete of all concrete things, since, on the theory, it has swallowed up the whole Pluralistic Universe of the pragmatist, and is ready to swallow as many more as fast as the pragmatist produces them.

For his is not the frivolous contention that his Absolute has merely the largest swallow. As M. Bergson distinguishes between Pure Time and spurious, popular clocktime, he distinguishes between the true Absolute, which is the Self-conditioned, and the spurious, popular Absolute, 
the Unconditioned tout court, which he grants you is nothing better than a negation, and liable to be bowled over by the first robust "condition" that comes its way. He distinguishes between the true Infinite, which includes the finite, whose image is the circle, and the spurious Infinite which is the finite all over again, the infinitely divisible, the process ad infinitum, whose image is the line. There is no end to the dilemmas of the Infinite if you insist on tainting it with the unrealities of space and time. If you taunt the absolutist with his everlasting negations, he can retort that the negation of a negation is not a negation, and that it is up to you to prove the reality of things, "as they stand," since you care so much about their status.

There is one metaphysical situation, and only one, which would give rise to the dilemma which the pragmatist urges against him. He will agree that if the situation were such that his absolute Reality were relative to another absolute Reality, the two absolutes would then be relative, and in their mutual relativity would kill each other. Which is his reason for contending that there are not two absolute Realities or many absolute Realities, but one Absolute Reality.

But as for his Absolute "entering into relations," like an Honest Man entertaining a business proposition, he denies that it does anything of the kind. It could only enter into relations if it were one term of the relation only; but it is both terms, and the relation; for, on the theory, it is all that is. Its function, as Absolute, is to maintain itself and manifest itself through things in relation, and, as One, to maintain and manifest itself in multiplicity. If you appeal to the Law of Contradiction, and protest that two contradictory propositions cannot be upheld seriously by any sane mind, he can point triumphantly to the fact that they can be, and are, united, both in conception and in actuality. What God hath joined, let no pragmatist put asunder. 
In short, the pragmatic-pluralist finds multiplicity everywhere he goes and unity nowhere apart from it; while the absolute monist has to go no farther than his own consciousness to find the unity which is always, so to speak, top dog. And there would not be a pin to choose between them if the absolutist did not mean rather more than he actually commits himself to saying, and if the pragmatist had not a sharper appetite for unity than he cares to own to.

For the student of metaphysics there may be something nobly serious in this desperate contention, conducted on one side with scorn and derision, and on the other with imperturbable aplomb. But, to the student of literature, born without any metaphysical prejudices, it looks as if each side were criticising the other with the crudest literalism, a literalism which he would be ashamed to bring to the interpretation of a classic.

To him it seems that, under the interminable webs of reasoning the absolutist wraps his meaning up in, his meaning is simplicity and clarity itself. He is trying to say that Spirit is absolute, a law unto itself from beginning to end of the world-process (if it has a beginning and an end). The whole performance, as he sees it, is neither one-sidedly psychic nor onc-sidedly physical, but is one spiritual act. He may think that he arrives at this conclusion by a subtle dialectic, but he really jumps to it by that spiritual recognition we call analogy. Jumping from what goes on in his own self, he knows of no élan vital to compare with the élan vital of spiritual encrgy. For, raise either psychic energy or physical energy to their highest pitch of intensity, and you get Spirit; you get something that, either way, is immaterial. Whether this is what the absolutist really means, to the student of literature, who has his business among the high intensities of art, this is what he ought to mean. And so far as both Human- 
ism and Vitalism admit this, Humanism and Vitalism are good enough for him.

And the absolutist is too densely literal if he cannot see that the pragmatist's plural principles are every bit as spiritual as his one; with, of course, his private reservation that, so far as they are spiritual, they are one. The rest is an absurd juggling with terms of arithmetic which, on either theory, do not apply.

In short, the unprejudiced student of literature cannot for the life of him see what the two are worrying about, and why they should not come to some arrangement. Pragmatism, if you fancy it, for the affairs of life, and Monism in its proper place.

But we renounced this light-hearted attitude in the beginning when we decided for the rigour of the game. We are now committed to the metaphysical adventure, and must see it through.

There is one more consideration which may bring a strange and unexpected food to the appetite for unity.

The pragmatist has another and a stronger line of argument, the moral line.

He says the blatant Pantheism of the monist lands him in moral catastrophe. If his One, his Absolute, his God, is all things, He is evil as well as good. The pragmatist cannot face the awful consequences of what is to him an immoral God. If God's All-mightiness is incompatible with his Goodness, then for God's sake give up the Allmightiness and let us, at any rate, have moral peace. Because man hates evil and shrinks from pain, there must be a Dual principle; there must be Another, the scapegoat of a God not quite almighty, upon whom all the evil in the world may be fastened. Or there must be Others, a host of Evil Ones, abominable spirits that have existed in their abomination, if not from all eternity, then from incon- 
ceivable time. If you ask how and why abominations should spring up spontaneously in the universe, the pragmatic humanist cannot enlighten you. He can only point to the existence of evil in the world as it is and has been since man knew it or since it knew man. We can only ignore it, Mr. William James says, by "taking a moral holiday." We can only meet it, Mr. Schiller says, by this assumption of the incompetent God. The Infinite and the Absolute are up against man's morality and his dislike of suffering, and they must go. God is only infinite in His good intentions, which presumably pave the hell of the Evil One. God, though infinitely well-meaning, is powerless to prevent this Evil One or those abominable spirits. But better, thrice better, that he should be powerless than that he should be immoral; for he is not so powerless that he cannot struggle. The pragmatist is happy in that he can point to an actual state of struggle in the cosmic order. Given a Good Principle, struggling with an Evil One, there is always a chance that he may overcome him in the end; that evil may be swallowed up in good.

Really, this is not an unfair statement of the pragmatio humanist's problem and his heroic position. But, lest I should be suspected of loading the dice in favour of my monist, I will let Mr. Schiller state it in his own words.

(Mr. Schiller rejects Dualism, although it " seemed able to preserve the all-important distinction between good and evil, for which Monism left no room." Dualism is "virtually disposed of with rejection of the ultimate difference of Matter and Spirit.")

"The real battle has to be fought out between the champions of the One and of the Many, between Monism and Pluralism. And, contrary to the opinions of most previous philosophers, we are inclined to hold that the Many is a far more important principle than the One, and that Pluralism, consistently interpreted and properly explained, is the only possible answer to the ultimate question of ontology." (Riddles of the Sphinx, pp. 350,351 .) 
"The finiteness of God depends on the rery attributes that make him really God, on His personality, on His being, like all real beings, an individual existence. God is one among the Many, their supreme ruler and aim, and not the One underlying the Many. The latter theory makes the Many inexplicable and the One indifferent. God, therefore, must not be identified with Nature. For if by Nature we mean the All of things, then Nature is the possibility of the interaction of the ultimate existences, and of these God is one. And the existence of these ultimate existences explains also why God can be finite; $\mathrm{He}$ is limited by the co-existence of other individuals. And from His relations to these other existences, which we have called spirits (chap. ix. § 31) arise all the features of our world which were so insoluble a problem to Monism - its Becoming, its process, and its Evil." Ibid.p. 361.)

"... though Matter, being nothing in itself, cannot be the principle of Evil, and is not in itself evil, it is yet characteristic of an essentially imperfect order of things: it is, as it were, the outward indication and visible reflection of Evil. For Evil is, like all things, ultimately psychical, and what is evil about Matter is the condition of the spirits which require the restraint of Matter ... if evil, i.e., inharmonious spirits were permitted the full realization of their conscious powers, they would be able to thwart and delay, if not to prevent the attainment of the divine purpose of the world process ... the lower existences, i.e., the less harmonized, have their consciousness limited and repressed by material organization, in order that their power for evil may be practically neutralized, and that in the impotence of their stupidity they may have little influence on the course of events." (Ibid. chap. ix, § 31, p. 303.)

Observe, in passing, that, though Matter is " characteristic of an essentially imperfect order of things," though it is "the ontward indication and visible reflection of Evil," it is the weapon in the hands of the ferociously good God (apparently the only weapon that he has). It is "the check upon consciousness": a sort of poison gas which the Good God sends into the enemy's lines, to smother and stupefy and reduce to impotence the Evil Ones.

"We start with a number of spiritual beings struggling against and opposing the Divine Power, which may overpower, 
but cannot destroy them. What is to be done? To leave them in the full possession of their powers and intelligence would be to give them the power to do evil, to reduce the spiritual order to a chaotic play of wild antagonisms."

(For, after all the fuss the humanist has kicked up about the existence of Evil, it is "practically neutralized" !

To return to the Evil Ones:

"To destroy them is impossible. But it is possible to do the next best thing, viz., to reduce their consciousness to the verge of non-existence. In such a state of torpor it would be possible to induce them to give an all but unconscions assent to the laws of the cosmos, and gradually to accustom them to the order which the divine wisdom had seen to be the best. . .." (Ibid. p. 362.)

That is the Humanist's solution: a moral God, one against many, armed with lumps of Matter. He cannot destroy his enemies (besides, it would be immoral to destroy them) but he can knock them senseless. So, you see, he hasn't done so badly after all.

"For to impress on fools and beasts even a dim sense of the rationality of the scheme of things, is a task more difficult by far than to prevail over the dissent of superhuman intelligences."

I do not know why it should be more difficult, except that Mr. Schiller says it is, and he ought to know about his own God. Anyhow, these are the triumphs of the Good God. The rationality of the cosmos is proved by a knockyou-down argument which prevails with fools and beasts!

Well, well, the problem of Evil is a very hard one. But this particular solution overlooks two rather glaring facts: the fact that stupidity causes most of the moral evil that we suffer from; so that by deliberately causing stupidity the good God becomes a cause of evil. There is really no sense in which stupidity can be made out to be a good thing. The other fact is the behaviour of Matter, which is 
the cause of most of the physical pain we suffer. On Mr. Schiller's theory, Matter at any rate seems to be under the control of the Good God - why then, if he is all that the humanist would like him to be, does he allow Matter to get so intolerably out of hand? You would have thought, that (even if the Evil Ones can dispose of war material, and have all the best designs for armaments) $\mathrm{He}$ might have put down, for instance, earthquakes. An earthquake, after all, is not an ultimate spiritual existence. But no, his effieiency is limited in that direction, too.

Oddly enough, it is this well-meaning but incompetent God of Humanism that has caught the fancy of Mr. H. G. Wells. Mr. Wells has given to the conception a poetry and a dignity which is not its own, but he has not succeeded in disguising either its inherent absurdity or the moral hysteria to which it owes its being.

"Mr. Britling's" son has been killed in the Great War, and "Mr. Britling" - type of all Britishers and honest men - realizes, contrary to his usual way of thinking, that there is a God. But not a God who "lets these things happen." A God, amiable and ineffieient, who ean't, for the life of him, help them happening.

"Letty," who has lost her "Teddy," insists that he must let them happen. "Or why do they happen?"

Mr. Wells, like Mr. Schiller, tells us why.

" 'No,' said Mr. Britling; 'it is the theologians who must answer that. They have been extravagant about God. They have had silly absolute ideas - that he is all-powerful. That he's omni-everything. But the common sense of men knows better. Every real religious thought denies it. After all, the real God of the Christians is Christ, not God Almighty; a poor mocked and wounded God nailed on a cross of matter. ... Some day he will triumph. .. . But it is not fair to say that he causes all things now. It is not fair to make out a case against him. You have been misled. It is a theologian's folly. God is not absolute; Gorl is finite.... A finite God who struggles in his great and comprehensive way as we struggle in 
our weak and silly way - Who is with us - that is the essence of all real religion.... I agree with you so-Why! if I thought there was an omnipotent God who looked down on battles and deaths and all the waste and horror of this warable to prevent these things - doing them to amuse himself I would spit in his empty face. . ." (Mr. Britling Sees It Through, p. 397.)

If Mr. Britling had left it "at that" we might have been sorry for him. But when the flood of hysteria subsides, he blunders up against the Open Secret.

" God is within Nature and necessity. Necessity is a thing beyond God - beyond good and ill, beyond space and time, a mystery, everlastingly impenetrable. God is nearer than that. Necessity is the outermost thing, but God is the innermost thing. Closer is he than breathing and nearer than hands and feet. $\mathrm{He}$ is the Other Thing than this world. Greater than Nature or Necessity, for he is a spirit and they are blind, but not controlling them. ... Not yet. ...'" (Ibid. loc. cit.)

"Necessity is the outermost thing, but God is the innermost thing." When Mr. Wells comes to see that Necessity is an illusion, and that space and time and our good and ill, are not absolute and ultimate realities, and that the " innermost thing" is the Real Thing, he will be at the end of his Research Magnificent. Meanwhile, he has shown his wisdom in not attempting any picture of the actual procedure of the good and inefficient God in his duel with Evil.

You cannot very well state the humanist's position in any terms that will not make manifest the absolutist's advantage; but I think Mr. Schiller's own statement shows it, if anything, better than mine.

The monist's reply to this innocent Manicheism is that it is the pragmatic humanist and not he who is deifying Evil, since he has endowed it with ultimate reality. $\mathrm{He}$ will suggest that an Absolute that is both good and evil (since the pragmatist will have it so), is not evil, even for 
one fleeting moment of his infinite existence; and that, for that matter, he is just as capable, in fact ten times more capable, of bringing good out of evil than a God, desperately moral, but of imperfect power; since the Absolute as immanent is the world-process, and as transcendent is also everything that may be left over and above it; that, if there is to be a final victory, if the Evil Principle, or Evil Principles, are ultimately to be swallowed up in the Good, you have an ultimate unity; that, with his struggles and his victories and his ultimates and finals, the humanist is giving a metaphysical reality to time that time cannot be made to bear; and that, since there is to be a final swallowing, and a final unity, he might just as well have had it first as last.

Here, I think, it must be admitted, the absolutist scores. The pragmatist has betrayed his secret appetite for unity. His evil must be swallowed up in good. If the pragmatist is not playing with words, if there is to be a real swallowing and a real assimilation, the two must be potentially one. It does not matter whether his resulting unity be a moral unity, or a metaphysical unity; unity it is, and union and At-one-ment; and really he might as well have had it first as last.

The absolutist does not take a "moral holiday." $\mathrm{He}$ does not deny, and he does not ignore, the serious and bewildering difficulty of the problem of evil. It is a difficulty from any point of view. But I cannot see that it bears with a more awful weight on the theory of an immanent and transcendent God in whose reality evil, as such, has no meaning that we can recognize, than on these two alternative theories of a Dual Principle or of Plural Principles. Humanism either exalts Evil, in all the prestige of an independent metaphysical reality, or it poisons life at its source by fixing it in matter, which should be, of all things, innocent if life is to be kept holy. Or if it does not fix it there, it fixes it in the human will, which is even worse, 
besides not being altogether true. The one theory that it does crush, you would think, should be the old theory of the absconding deity, God the Creator, who is above all things, Blessed for ever; who sits outside creation, with no part or lot in its conflict or its suffering. And yet it does not crush it utterly. Incompetent as he is, the humanist God, the God of the cosmic arena, has a certain trait in common with the God who sits above it. "Resistance," we are told, the resistance of matter, the resistance of the hard, recalcitrant Evil Ones, is "necessary" to the putting forth of his power, to the heroic spectacle of his prowess. Who designed this accordance of evil with the requirements of the gladiatorial God? Not the Evil Ones, you may be very sure. Suspicion falls upon the gladiator. He has engineered the existence of Evil to gratify his taste for combat and for personal display.

But the immanent Spirit of the absolutist truly bears his part, he truly labours and suffers, in so far as he is all Nature and all mankind. He has literally shirked nothing. Von Hartmann's one merit as a thinker was that he saw that God the Creator is the intolerable God. If he had had a little more metaphysical vision, and a little less moral cowardice, he would not have called upon man to save God, to deliver the Absolute, by bringing the worldprocess as quickly as possible to an end. He would have called to him rather to save God by saving himself, by behaving as much like a spiritual being as possible. In no other way can he hasten the end of the world-process - the tendency of all spirits towards self-determination, after the likeness of the Absolute Spirit in whom they live and move and have their being.

So that Pragmatism and Humanism, in spite of their closeness to life, and their admirable freedom from the bonds of system, have broken out into a dilemma almost as bad as any inherent in the systems. In the very act of whitewashing its deity so as to bring him up to the paro- 
chial standard of purity, Humanism has lapsed into the unity it repudiated. Horn one. Horn two, which is a moral point, is not quite so obvious; but it will become so if the situation is examined. The Good God, being good, is opposed to the evil He did not cause but cannot help. He must, therefore, struggle against it that his goodness may be proved. If he refuses the heroic combat he is not a good God. If, having entered the arena, he does not come off conqueror he is not, he cannot be, so very good. If he conquers, the Evil One is not destroyed, but merged in Good; and you have, not two principles, or many principles, but one principle. And this is moral Monism.

The humanist, you see, is not quite so naif as the Semitic theologies that have produced him. Uncompromising in the face of his moral dilemma, he boldly throws over God's Almightiness so that his All-goodness may be kept intact. On no account must he be identified with the trivialities and absurdities and iniquities of existence. He should not, for instance, be held responsible for the presence in our universe of "so many millions of fleas."

Mr. Schiller seems to suggest that it is Mr. Bradley who should be responsible for the many millions. It does not occur to him that they might have been designed for the express purpose of demonstrating that man is not the sole end of the universe, and that humanist man is not the measure of all things, but that the humblest organism may have its point of view, and its right to a say in the matter of existence.

Having relieved his principle of its worst embarrassments, the humanist has now got God almost, but not quite as moral as himself. But he has not avoided All-in-Allness; he has simply conceived it in the form of human morality. Human morality, evolved by processes of alternate conflict and readjustment from various instincts of desire and repugnance adapted to the social and physical conditions of the inhabitants of this planet, this precious 
morality of his is what he solemnly refers to transcendent Reality. And this, mind you, after jibbing at any identification of deity with the absurder details of our daily life.

And mark the dilemma that arises from an honest man's attempt to whitewash God. After all, he can only save his moral whitewash at the expense of his Pluralism, and his Pluralism at the expense of his whitewash. And, even then, he has not saved his Good God entirely from the suspicion of complicity in Evil. The Good God challenges, provokes, demands resistance. $\mathrm{He}$ is no more All-good than he is All-powerful.

There is another very serious objection that the absolutist might make. The pragmatist's helpless and unhappy God is not good at all, any more than he is all-powerful. For, on the pragmatist's theory, the good is the useful; it is what pays. The good God, then, is the useful God, the paying God; and Evil is swallowed up in usefulness, in payment. So that Evil, also, is what pays in the long run.

It would seem, after all, then, that unity, in some form or other, is a necessity of thought. If the appetite for it is frustrated in one place it will break out in another. It is implicit in the very dilemmas of the systems that have repudiated it.

But, to be just to Pragmatism and Humanism, they have deserved well of philosophy in reminding it of things it is apt to forget; little things, like Will and action and moral conduct, which Idealism really renders little or no account of.

And I do not think either pragmatists or humanists claim to have established a metaphysic. Concerned as they are with the human will and with action, and with moral conduct, they aim at something which they believe devoutly to be nobler and better and more useful - they conceive themselves to be much more profitably engaged in laying 
the ethical foundations of the Universe. They do not worry about the foundations of Ethics; they worry about the ethical behaviour of the Universe. Whatever the Universe does or does not conform to, it must conform to human and pragmatic ideas of morality.

But the Universe is nothing if not ironic. And in the fate of Pragmatism and Humanism there is a peculiar and a perfect irony. They have been taken at their word; and, as they have insisted on putting conduct first, and Ethics first, or Ethics, if anything, a little after conduct, and on ignoring everything in the Universe that does not square with conduct, or account for conduct, or presuppose conduct, that is not related to conduct, or referable in some way to conduct, they are left, in consequence of their vast repudiations, without any ethical ground for Ethics; and therefore without any ethical ground for conduct at all. "Thought-relations" are irrelevant to conduct, therefore "thought-relations" must go. Relativity is fatal to ethical conduct, therefore relativity must go. The Infinite and the Absolute are indifferent to ethical conduct, therefore the Infinite and the Absolute must go. Monism will not account for ethical conduct. Monism is even incompatible with ethical conduct, therefore Monism must most emphatically go. So that, though Pragmatic Humanism does not claim to have established a metaphysic, it does claim to have destroyed one, which is to be metaphysical with a vengeance.

And it does not seem to have occurred to either Pragmatism or Humanism that a dead metaphysic could revenge itself in its turn. It did not and it could not occur to them that in this clean sweep of non-moralities, Morality itself must go. The pragmatist's eyes are fixed on conduct and the useful, the paying results of conduct; and the humanist's eyes are fixed on the origins of conduct and the end of conduct, and neither have paused to ask themselves the one question that is vital and crucial for Ethics: Is there 
anything that is good in itself, apart from its results or its origin, or its end? The logical outcome of Pragmatism is that the good is what pays; the logical outcome of Humanism, with its evolutionary Ethics, is that the good is the pleasant or the desirable or the beneficial.

With all their air of brand-new modernity, neither Pragmatism nor Humanism have added anything to the Utilitarianism of the middle nineteenth century, nor to the Hedonism of the year 400 B. c. Pragmatism wears a Quaker's hat, and Humanism has vine-leaves in its hair. Their quest is not for Ultimate Reality, but for steamengines and motor cars and synthetic chemistry; or for Tango, if that is pleasant, desirable, and beneficial.

But it is only fair to add that their dilemmas are of the unconscious kind, and that they have made no specious promises. They say: I find this Dualism or this Pluralism, and I leave it at that. It does not make a tidy universe, but I can't help it. It's not my job to tidy up the Universe. And I prefer things left like that with their ends hanging all loose; it is more picturesque, more like Nature and like real life. 


\section{VI}

\section{THE NEW REALISM}

$\mathbf{I}$

WE have seen that, after heroic struggles, neither Pragmatism nor Humanism succeeded in shaking itself wholly free of the abhorred unity. In their exclusive concern with conduct and morality both betray a strong subjective bias fatal to the pretensions of a philosophy that is out against subjectivism in all its forms. We have seen that their too great zeal for goodness and the ultimate triumph of goodness defeated its own end, and left them with a universe on their hands in which Goodness had neither metaphysical sanction nor logical ground, and, so far from being a reality, is not even that which to every pragmatist and humanist is a miserable makeshift for reality - an idea.

I had got so far when it was pointed out to me that to deal faithfully with those philosophies is to slay the slain, and that my time would be very much better employed in considering the New Realism, which has nothing in common with them but its abhorrence of unity. It was also pointed out to me that the claims of the New Realism are so well founded that there is no likelihood or even possibility of Monism raising its head again, and that the mysterious Snark, "ultimate reality," has disappeared from the universe. I gathered that, this time, there can be no more temporizing, no more fooling about with relativity; no more fencing and dodging, and no more playing fast and loose with the law of contra- 
diction; no more sheltering of reality behind appearances; no more conjuring with the unity of consciousness; in short, that all the little games of Monism are played out. It is a case of either swallowing the New Realism, or being swallowed, with no possible doubt as to the actual issue.

There is nothing for it but to approach the monster with as bold a front as is possible for a devout monist inwardly quivering with fear. It must be confessed that he is in some danger. For the New Realism is before all things a mathematical method; and it cannot be said that every monist is as strong in mathematics as by the nature of his case he ought to be. Still, he will do himself no good by ignoring the gravity of his position. He has got to look he has cleared his mind of Kant, whether he spells it with a small $\mathrm{c}$ or a big $\mathrm{K}$.

Now he cannot look it squarely in the face until he bas stripped himself of every prejudice that clings to him, until he has got rid of the traditions he has been born and bred in (for the monist is usually born, not made); until he has cleared his mind of Kant whether he spells it with a small $\mathrm{c}$ or a big $\mathrm{K}$.

He must, I think, acknowledge that his real, live, and formidable enemies are, not the Dualism of "Messrs. Dewey and Schiller," nor yet the Pluralism of Mr. William James, but the Pluralism of Mr. Bertrand Russell, Mr. G. E. Moore, Mr. Alexander, and the new realists of the United States.

At the same time, it would have argued a most unreasonable negligence to have ignored the brilliant and powerful work of Mr. James and Mr. Schiller. By their very brilliance and their power, and the grace of their appeal to the thought and feeling of the plain man, they are likely to hold their own, if not after the New Realism has been forgotten, at any rate long before it has begun to be remembered by the plain man. The chances are that it is 
neither Pragmatism nor Humanism, but the New Realism that will succeed in establishing itself as the dominant philosophy of the twentieth century. Still, they prepared its way before it; they anticipated it to some extent in their criticism of abstract intellectual Idealism, and in their insistence on those irreducible elements of will, feeling and action which abstract Idealism leaves out of its account.

And the New Realism has not been grateful to the two pioneers. It comes triumphantly and relentlessly into its own, and you may say its first act of power is to give both of them the coup de grâce where it finds them, loitering contentedly on the very road they had made smooth for it.

Well, the plain man is not going to think the worse of Pragmatism for Mr. Bertrand Russell's attack on it, even if Pragmatism is not hereafter to be counted among serious philosophies, and if Humanism is in no better case.

To what does the New Realism owe its deadly force?

Mainly, I think, if not entirely, to its method. Not to its newness, for it is not by any means so new as would appear from its claim to have revolutionized Philosophy, much as Copernicus revolutionized astronomy, by taking the sun as the centre of the solar system instead of the earth. Indeed, the New Realism has gone one better than Copernicus. It has decentralized Philosophy altogether.

And it has done this by applying the method of Mr. Bertrand Russell's " atomistic logic" to the universe without and to the universe within; that is to say, to the sum total of experience.

The first result of this searching and implacable analysis is to demonstrate that the two are by no means conterminous. On the contrary, you are led, step by step, through a series of unwary admissions, to the conclusion that there is no universe within; but that the sum total of the 
within is, in a vigorous and undebatable sense, part (and a very small part at that) of the universe without; while of the universe without there is no sum total, but an infinite number of kinds or classes of existences and an infinite number of existences within each class or kind. The extreme pluralistic conclusion follows wherever and whenever the analytic method is applied. There is no escaping it, because, in the last resort, it rests upon a limited set of incontrovertible axioms of mathematical logic. There is no escaping the extreme realistic conclusion, because it also rests on an incontrovertible law of pure mathematics. All mathematics in their turn flow from a score of premisses of Symbolic or Formal Logic. ${ }^{33}$

This fact, that "all Mathematics is Symbolic Logic," Mr. Bertrand Russell declares to be "one of the greatest discoveries of the age" 34 and he shows that it is impossible to exaggerate its importance to Philosophy and its influence on the fate of Monism.

"The Philosophy of Mathematics has been hitherto as controversial, obscure and unprogressive as the other branches of philosophy. Although it was generally agreed that mathematics is in some sense true, philosophers disputed as to what mathematical propositions really meant: although something was true no two people agreed as to what it was that was true, and if something was known, no one knew what it was that was known. So long, however, as this was doubtful it could hardly be said that any certain and exact knowledge was to be obtained in mathematics. We find, accordingly, that idealists have tended more and more to regard all mathematics as dealing with mere appearances, while empiricists have held everything mathematical to be approximation to some exact truth about which they had nothing to tell us." (Principia Mathematica, i, p. 4.)

The strength of Idealism has hitherto lain in the poverty of Formal Logic, the impossibility of bringing the sacrosanct deductions of mathematics into line with deductive logic as it then existed. Philosophers, when they looked 
for the cause of this mysterious divorce and contradiction between two orders of truth supposed equally incontrovertible, so far from suspecting that the machinery of formal logic might be at fault, were apt to throw the entire blame on mathematics. Mathematics was accused of relying on axioms which were so many unproved and unprovable hypotheses. They might depend on an $\grave{a}$ priori intuition, or they might not; in either case their boasted logical certainty was an illusion. What was much worse, so far as pure mathematics could be said to be certain, they had no valid application to the world of experience, the world of space and time.

All Idealisms, constructive or destructive, are based on the ultimate inability of mathematics to defend its own position. And it is claimed that with the reform of Symbolic Logic, the perfecting of the formal machinery, the bottom is knocked out of Idealism.

For it follows that if all mathematics is symbolic logic, if "all the entities that occur in mathematics can be defined in terms of those that occur in the above twenty premisses," we have no longer got two orders of truth, but one order of truth. Pure mathematical truth will not be purer than any other; it will not constitute a different, a higher, holier and more certain kind of truth. Any unmathematical proposition that follows faithfully from the same laws of symbolic logic will be as certainly true, as high and holy as mathematical truth.

And lest the monist should take heart and see in the Great Discovery a confirmation of his theory that all logic, that is to say, all thought, all truth, and therefore all existence, is one, it should be broken to him at once that he is doomed to disappointment.

This unity of supreme logical law is not a unity in which he can hope to recognize his own. It is a purely formal and provisional unity. So far from being any good to him, it is the thin end of the wedge by which his uni- 
verse is prised open, torn asunder and scattered to the infinite. This logic is not his logic. Instead of the twelve comfortable categories which he could wrap round his universe like twelve woolly blankets, with the one vast eiderdown of the Absolute on top, it gives him a plurality of logical indefinables, as hard as marbles, which hurt him in all his tender places; instead of the rhythmic and dynamic throb of the Triple Dialectic, with its rich, rolling song of unity in difference, it gives him vibrations as multitudinous, as discordant and irrelevant as the noises in a Futurist symphony.

The New Realism is before all things a method, and a mathematical method. For, if there is to be any philosophy - any discussion as to the nature of the known, of knowing and the knower - at all, you must begin somewhere; some axioms, or at any rate one axiom, must be accepted as certain, if there is not to be an infinite going back upon all propositions whatever. And the only certain axioms are the axioms of pure mathematics; that is to say, of Symbolic Logic. If we start anywhere, we must start with these.

Starting with these, Pluralistic Realism stands or falls by mathematical logic. Its four vital theories are based on it: its theory of the mathematical infinite; its theory of relations; its theory of concepts or universals; its theory of immediate perception, or of our knowledge of the external world. It ought not to matter which of these we take first; for from each Pluralistic Realism will follow. Each leads us safely to its source in some incontrovertible law of mathematical logic. But, as it happens, we cannot consider the realistic theory of perception apart from the theory of the Infinite and the theory of relations, on both of which it depends.

Say, then, that we begin with immediate experience, the perception of an object in space.

(It is, to say the least of it, extremely debatable 
whether the perception of an object in space is in any sense an immediate experience; but I must leave this crucial point for consideration later on. I want to state the position of Pluralistic Realism, as far as I understand it, with the greatest possible clearness and cogency, and for present purposes we may very well assume that the perception of an object in space is an immediate experience. We must start somewhere; and it is important for a proper understanding of the "new" position that we should start with an experience into which these three terms: "object," "space," and "perception," enter.)

Whatever consciousness may be supposed to have done or not done originally with its sense data, there comes a point when those data are "referred" to an object perceived as in a space external to the perceiver. We know what Idealism makes of this, and with what plausibility. It makes of it something like this:-

Let us grant that the only space in which objects are immediately known (otherwise perceived), is a "private space," 35 which the perceiver carries about with him, and that the shapes, sizes, lights and shades, and positions of objects in this space are not absolute, but relative to the position of the perceiver. Let us grant that the nature of pure or mathematical space has laws of its own and a nature of its own such that it is not and cannot be known in immediate perception. On these two points Monists and Pluralists are, I believe, agreed. Now, as long as it could be supposed that pure mathematical space was as much infected by illusion and relativity as any "private" space of yours or mine, and that it was therefore a perfect hotbed of contradictions and dilemmas (what applied to space applying equally to time); then, though the truth of all the intermediate laws of physics rested on the truth of the assumption that their space and time are "real" and contain no contradiction, Idealism was still within its rights in denying absolute and independent reality to 
space and time. The more contradictions and dilemmas Idealism could find in relations, above all in the relations of space and time, the better it was pleased. For, since there is nothing known that is not known as standing in relation to something or other (except the Absolute), it could then charge the whole multiplicity of outer and inner experience with unreality and set up its Absolute, which is One, as the only Real. Physical science could not lift a finger to prevent this annihilation of its universe, as long as the pure mathematical laws, on which it rests, themselves involved the very worst contradictions and dilemmas. Its universe of space and time, matter and motion, was infected at its source.

The most destructive of those dilemmas turned on the nature of the Infinite and its relation to the finite. It was argued that finite events, such as motion or any other change, simply could not happen because of the infinity they involved. And if they are perceived as happening, if they are, in fact, known to happen, that fact goes to prove that all our perceiving and all our knowledge is of appearances and not of realities, and that the only real object of a real knowledge is the Absolute, the motionless and unchanging One.

This relativity on which Monism battens is found, not only in the changes and motions of things, but in things themselves. Their being is to be related. Take the simplest of static relations, the relation of the thing and its qualities. It seems obvious that, if there are qualities, they must be qualities of something. There must be something that holds them together. (At least so it seems to the Idealistic Monist.) The thing and its qualities will then stand to each other as the two terms of a relation. But it is evident (the Monist thinks) that the relation must depend upon what the thing is, and what qualities it has, that is to say, upon the nature of its two terms. The relation itself will be related, and doubly related. 
We have, then, instead of the single chaste and simple relation that we started with, a relation of dependence holding between the relation itself and each of its two terms; that is to say, the relation that we thought so innocent has itself given birth to two terms and a relation; and that relation, being likewise dependent on the nature of its terms, will be likewise related; and so on for ever and ever, the terms and the relations multiplying, like generations, in geometrical proportion. You will find all this maddening behaviour of relations described in Mr. Bradley's Appearance and Reality, pages nineteen to thirtyfour.

We started with a thing and its qualities, and the relation between them, and we have got an infinite regression. But, by the very fact that it possesses quality and that the qualities are possessed by it, the thing is finite, the qualities are finite, and the relation between them is finite. So that we have again the contradiction and dilemma of a finite set of terms and relations involving an infinite series of terms and relations. A contradiction and dilemma which can only be avoided by taking both term and relation, the thing and its qualities, and whatever it is that makes them its qualities, as appearances and not as realities.

Apply the same argument to the supreme relations of subject and object, of the self and its consciousness, and the entire universe of the without and the within is revealed as an illusion and a contradiction. And once more our flight is to the Absolute as the only Reality.

This conclusion is revolting to the intellectual conscience of men of science and to the common sense of the plain man, however much it may delight the Monist and the mystic to be thus driven into the bosom of his God.

We have seen how Vitalism and Pragmatism have tried to escape it and wherein they have failed. It must, I think, be owned that the New Realism is more successful. 
Neither Vitalism nor Pragmatism had a logic and a method. Vitalism took its stand on immediate perception and the facts of life. It observed them, as the biologist or the psychologist observes them; it found that neither what it called Realism nor what it called Idealism provided or accounted for the most important data of perception and the most vital of the facts of life. But it had no logic whereby to test the apparent contradictions and dilemmas of immediate perception; it attempted to solve them uncritically and by rule of thumb, trusting to the plain man's common sense to find no fault with its pronouncement: The problem of Life is solved by living, as the problem of walking solvitur ambulando. And although Mr. William James has dealt very faithfully indeed with Abstract Idealism, his method is, on the whole, so akin to M. Bergson's want of method that it consists mainly in an open appeal to the imagination and the common sense which Vitalism satisfies and Abstract Idealism does not. It is hard to resist Mr. James when he is quoting Fechner, almost as hard as it is to resist Fechner himself. Fechner appeals with fervour and without shame to the desire of God and the hope of immortality that still stirs the hearts of some of us outside the Universities of Cambridge and Harvard. But so long as there is left in this hospitable pluralistic universe a single stickler for the rigour of the game, one solitary professor whose heart remains impervious to the desire of God and the hope of immortality, the appeal of philosophies which have no Logic is urged in vain.

For it should be remembered that this is not a question of who thinks closest to life, Mr. William James or Mr. Bertrand Russell, but of what guarantee we have that when we think our thinking is true. We cannot dash in and snatch at a highly complex, ready-made reality like Life and test our thinkings by their correspondence with 
it, even if we knew what life is and what thought is (which we are very far from knowing). For life, anyhow, is a highly specialized and subordinate part of the whole context of experience, which includes many more things than immediate perception can lay its hands on; and, as for thought, it may have no higher or more comprehensive place in the total hierarchy than life; and philosophy cannot test thougnt by its correspondence with reality, when the reality of experience is the question before us to be solved.

We owe it to Mr. Bertrand Russell that Logic has been restored to its proper place as the organ of philosophy. We also owe it to him that Synthetic Logic has been succeeded by Analytic Logic, if it is only for a time. The result is the most drastic criticism of preceding philosophies that has been known since the Critique of Pure Reason smashed the systems that were before it. If the conclusions of Atomism hold good all along the line, it means the complete break-up, not only of Absolute Idealism, but of all the great syntheses that ever ruled in Philosophy - with some revolts and revolutions - since Philosophy began.

The synthetic systems were based, one and all, on criticism, more or less drastic, of the assumptions of immediate perception. Where the axioms of pure mathematics were held to be true they were also held to be inapplicable to the objects of immediate perception. Every attempt to reconcile the two orders of assumption led to contradictions and dilemmas. The truth of the mathematical axioms themselves was considered to be open to doubt. Though the most tremendous consequences flowed from them, there were no axioms more ultimate and more simple from which they themselves flowed. The validity of every generalization and every deduction of physical science hung on them. They hung unsupported in a world of their own. Mathematics had thus a peculiar and mysterious existence. No 
valid conclusion about the actual physical world could be reached without them; yet the objects they defined had no existence in the actual physical world.

That position remains unaltered.

"As a branch of pure mathematics Geometry is strictly deductive; indifferent to the choice of its premisses and to the question whether there exist (in the strict sense) such entities as its premisses define." (Principia Mathematica, p. 372.)

"Until the nineteenth century Geometry meant Euclidean Geometry, i.e., a certain system of propositions deduced from premisses which were supposed to describe the space in which we live."

\section{Then there were only two alternatives:}

"Either we must be certain of the truth of the premisses on their own account, or we must be able to show that no other set of premisses could give results consistent with experience."

Kantian Idealism held out for the first alternative. Empiricism for the secoud.

"But objections were raised to both. For the Kantian view it was necessary to maintain that all the axioms are self-evident, a view which honest people found it hard to extend to the axiom of parallels. The second alternative . . could only be tested by a greater mathematical ability than falls to the lot of most philosophers. Accordingly the test was wanting till Lobatschewsky and Bolyai developed their non-Euclidean system. It was then proved with all the cogeney of mathematical demonstration that premisses other than Euclid's could give results empirically indistinguishable, within the limits of observation from those of the orthodox system. . . G Geometry has become (what it was formerly mistakenly called) a branch of pure mathematics, in which assertions are that such and such consequences, follow from such and such premisses, not that entities such as the premisses describe really exist. That is to say, if Euclid's axioms be called $\mathrm{A}$, and $\mathrm{P}$ be any proposition implied by $\mathrm{A}$, then, in the Geometry which precerled Lobatschewsky, $\mathrm{P}$ itself would be asserted since $\mathrm{A}$ was asserted. But nowadays the geometer would only assert that $\mathrm{A}$ implies $\mathrm{P}$, leaving $\mathrm{A}$ and 
P themselves doubtful. And he would have other sets of axioms $A_{1}, A_{2}, \ldots$ implying $P_{1}, P_{2}$, respectively, and the implications would belong to Geometry, but not $\mathrm{A}$, or $\mathrm{P}$, or any of the other actual axioms and propositions. Thus Geometry no longer throws any direct light on the nature of actual space. . . . Dimensions, like order and continnity, are defined in purely abstract terms, without any reference to actual space." (Ibid. pp. 372-376.)

Now the former state of mathematics suited the idealistic monist admirably, for it provided all the contradictions and dilemmas that he wanted. And he may have still drawn consolation from the assurance that Geometry is farther than ever from throwing "any direct light on the nature of actual space." But he has now to learn that "indirectly, the increased analysis and knowledge of possibilities resulting from modern Geometry has thrown immense light upon our actual space."

If Pluralistic Realism can show, in spite of the high irrelevance of its mathematics, that there are definitions and there are axioms that hold good of the universe of space and time, matter and motion; if it can remove the contradictions and dilemmas which have been held to attach to the conceptions of space and time, matter and motion; if it can show that the relations of finite and infinite contain no contradiction or dilemma, it can then go on to prove the continuity of space, the absolute reality of space and time, matter and motion, and of that curious collection of qualities we call an object in space. That is to say, it undertakes to show that the existence of the external world is independent of our consciousness and of any consciousness whatsoever.

We shall see that those conclusions do not exhaust the possibilities of Pluralism. It claims to have established the external and independent reality of such things as concepts and "thought-relations," and the external and independent reality of sensatious, which even philosophers 
hostile to Monism have for long enough surrendered to the inner world.

It makes out its case, first, by dealing with all mathematical laws and all mathematical reasoning as laws and reasoning of Symbolic Logic; secondly, by giving the entities defined by pure mathematics - points, lines and planes - an external reality peculiar and apart; thirdly, by cutting away the ground from under the monist's most cherished contradiction, the contradiction involved in the very idea of mathematical space. As long as you were compelled to think of pure space as a mysterious continuity made up of discrete elements either infinitely divisible, or indivisible and infinite in number, the idealist was within his rights in denying the reality of space and time, and of matter and motion and everything else that depends on space and time.

The New Realism admits, I think, that he was within his rights. Things cannot move, that is to say, cannot change their positions, in an unreal space, nor real events happen in an unreal time, nor real things be tied together by unreal relations, nor real parts be contained in unreal wholes.

So the first thing that Mr. Bertrand Russell shows is that the laws of pure mathematics are the laws of Symbolic Logic. They have no superior cogency, but they have all the cogency that Formal Logic can confer on them, and there arise no contradictions or dilemmas in them anywhere.

This could not be shown as long as the axioms of mathematics can be held debatable; and they can be held debatable as long as finite and infinite are affected by each other's behaviour; and finite and infinite could be very seriously affected by each other's behaviour as long as pure mathematics dealt with quantity and magnitude. But pure mathematics no longer deals with quantities or magnitudes, but with pure numbers. Pure numbers are re- 
duced to "classes" or terms, the simplest elements of purely logical formulæ; they can therefore be treated like any other terms in purely logical propositions.

We have seen that the mutual compromising of finite by infinite and of infinite by finite is the root of the contradiction by which Idealism stands. But their differences have been adjusted for ever, we are told, since, some time in the 'eighties, George Cantor, the mathematician, made a certain interesting discovery as to the nature of the Infinite. He found, and proved, that to or from an infinite series any number, even an infinite number, can be added or taken away without either increasing or diminishing the series. That is to say, finite and infinite are not affected by each other's vagaries. They neither negate nor limit nor do they define each other.

Mr. Bertrand Russell contends that this discovery has made secure the whole ground of mathematical philosophy, and with it all the foundations of applied mathematics, and with them all the laws of physical science that depend on the laws of space; and with these, again, the ground of the reality of the external world is made secure.

For the reality of motion depends on the continuity of space, and the reality of change on the continuity of time. Before Cantor's discovery it could be argued that change and therefore motion, which is change of position, were relative and unreal; that real motion could not take place, for the simple reason that there was no place for it to take, and that no real event could happen in time because there never was a quiet, steady instant for it to happen in. As long as space and time were held to be discontinuous, to consist in a finite or infinite number of separable points or instants, these dilemmas, so distressing to Realism, followed. For progress of bodies and succession of events will always be from one point to the next beyond it, and from one instant to the next beyond. Always, between points, the body said to be occupying space will be out of 
space, and, between instants, events said to be occurring in time will be out of time. M. Bergson does not cause these dilemmas to disappear by calling space the net that intellect spreads out under matter to catch it as it tumbles, and by using time to stuff the gaps in space. For there is nothing to stuff time's gaps with, except durée which is not time. There is no space and no time that can cover the awful, the unthinkable jump from next to next.

Therefore, in Zeno's problem, Achilles never can overtake the tortoise; because, however fast he runs, he can do no more than jump from next point to next point; and the tortoise, however slow he is, can do no less. Neither of them can skip a point, so that Achilles can't settle it by jumping over either the tortoise or the ground that he has travelled. Swiftness and slowness are irrelevant to the problem. Time, which is all important to it, suffers from the same discontinuity as space; from instant to instant is on all fours with from point to point.

Into this dreadful gulf between point and point, instant and instant, the modern mathematician shovels in - the Infinite.

Continuity, for the modern mathematician, is not an affair of infinitesimals, but of infinitely divisibles. More than all, it is an affair of order in a series. From Cantor's discovery it follows that there never is a next point, a next instant, a next number; there never is any nextness at all. The next point, the next instant, the next number, are finites. And as the Infinite is neither increased nor diminished, nor limited, nor in any way affected by any behaviour of the finites, it follows that, start at any finite point, or instant, you will, between it and the next point, the next instant, there will be an infinite number of points and instants, and between any two numbers an infinite number again, and so on to infinity, the gaps filling up before your eyes.

You will find the entire proof set forth in the chapters 
on Infinity and Continuity in the Principia Mathematica. Meanwhile Mr. Russell simplifies the problem by an illustration.

“. . . Let us imagine a tiny speck of light moving along a scale. What do we mean by saying that the motion is continuous?... If we consider any two positions of the speck occupied at any two instants, there will be other intermediate positions occupied at intermediate instants. However near together we take the positions, the specks will not jump suddenly from the one to the other, but will pass through an infinite number of other positions on the way. Every distance, however small, is traversed by passing through all the infinite series of positions between the two ends of the distance." (Our Knowledge of the External World, pp. 133-134.)

It is obvious that this feat would be impossible if time could not be treated in the same way.

So there is no nextness anywhere. And if there is no nextness there is continuity. And if mathematical space and time are continuous, then all spaces and all times are continuous; and if continuous then real. This conclusion, which is by no means self-evident, is the result of further logical constructions and correlations. What bolds good of actual space will hold good of matter occupying space. What holds good of actual time will hold good of ehange and motion occupying time; change and motion will be absolute and real, and unselfeontradietory, in the sense that there is no state of ehange, and no state of motion. And sinee all material things are continuous, that is to say extended, extension, and with it the primary qualities of matter, will be absolute and real.

There were, as we have seen, three outstanding objections to the older Realisms: the alleged hypothetical character of the axioms of pure mathematies; the supposed fact that sense-perceptions are illusory; the supposed dependence of a relation on its terms.

We have seen how the New Realism deals with the first. 
We shall see, later on, in another context, how it deals with the third. Its business, at the point where we are now, is with sense perception.

When it comes to sense-perception it betrays a certain consciousness of difficulty. The appearances of an object in space do certainly differ according to the point of view and the optic apparatus of the perceiver. Its size, shape, colour, and relation to other objects in space vary with the position and distances of the perceiver. If a humorous creator had given to the lens of the eye the extravagant convexity and concavity of the little mirrors placed at the doors of Pierce's restaurants, the world of creatures would appear as a world of grotesques.

But suppose that the New Realism accepts as the standard lens the lens of the normal human eye, appearances presented to the normal human eye will not rank as appearances, but as real objects normally perceived, and all variations from the normal will be attributed to flaws in the mechanism of perception.

(This question of the standard is crucial for the New Realism. It raises difficulties which I will not dwell upon at present.)

Still, the variations, which we may call objective variations due to the perceiver's objective changes of position, will remain. Also the fact that to one object of perception there will be a considerable, not to say an infinite number of perceivers, each bringing to the problem an individual angle or point of view, which itself will change with each change in his position. So that the New Realism has to assume at least three kinds of space to begin with, and as many more kinds as may be necessary: Pure space, the space of the mathematician; private space, the space which every individual perceiver carries about with him; and public space which is the same for everybody, and to which each separate private space has to be 
added and adjusted as a system of private cubicles is adjusted to a public dormitory.

All these spaces, purged from the uncleanness of contradiction and relativity, are real and outside consciousness. Even private space is real and outside. It is, indeed, in its own mysterious way, not perhaps part of public space, as the cubicle is part of the dormitory, but one of the infinite, sliding, interpenetrating planes of the pluralistic Real. On this system private spaces may be imagined as being like so many transverse, intersecting beams subsisting in public space, cleaving their way through it and through each other (as rays of light pierce their unique and untroubled paths through so many sheets of thin glass), and constructing with public space a system of most indubitable outsideness.

I must leave it to Mrr. Bertrand Russell to describe the manner of their adjustment.

"If two men are sitting in a room, two somewhat similar worlds are perceived by them; if a third man enters and sits between them, a third world, intermediate between the two previous worlds, begins to be perceived. . . . The system consisting of all views of the universe, perceived and unperceived, I shall call the system of 'perspectives'; I shall confine the expression 'private worlds' to such views of the universe as are actually perceived. Thus a 'private world' is a perceived 'perspective'; but there may be any number of unperceived perspectives.

"Two men are sometimes found to perceive very similar perspectives, so similar that they can use the same words to describe them. ... In case the similarity is very great, we say the points of view of the two perspectives are near together in space; but this space in which they are near together is totally different from the space inside the two perspectives. It is a relation between the two perspectires, and is not in either of them; no one can perceive it, and if it is to be known it can be only by inference. Between two perceived perspectives which are similar, we can imagine a whole series of other perspectives, some at least unperceived, and such that between any two, however similar, there are others still more similar. In this 
way the space which consists of relations between perspectives can be rendered continuous, and (if we choose) three-dimensional. . . . There are as many private spaces as there are perspectives; there are therefore at least as many as there are percipients. . . But there is only one perspective space, whose elements are single perspectives, each with its own private space. ... .

"These private spaces will each count as one point, or at any rate as one element, in perspective space. They are ordered by means of their similarities. Suppose, for example, that we start from one which contains the appearance of a circular disc, such as would be called a penny, and suppose this appearance, in the perspective in question, is circular, not elliptic. We can then form a whole series of perspectives containing a graduated series of circular appearances of various sizes: for this purpose we have only to move (as we say) towards the penny or away from it. The perspectives in which the penny looks circular will be said to lie on a straight line in perspective space, and their order on this line will be that of the sizes of the circular aspects. ...

"In order to explain the correlation of private spaces with perspective space, we have first to explain what is meant by 'the place (in perspective space) where a thing is. ...'We can form another straight line of perspectives in which the penny is seen end on and looks like a straight line of a certain thickness. These two lines will meet in a certain place in perspective, i.e., in a certain perspective, which may be defined as "the place (in perspective space) where the penny is." . ...

"Having now defined the perspective which is the place where a given thing is, we can understand what is meant by saying that the perspectives in which a thing looks large are nearer to the thing than those in which it looks small: they are, in fact, nearer to the perspective which is the place where the thing is.

"We can now also explain the correlation between a private space and parts of perspective space. If there is an aspect of a given thing in a certain private space, then we correlate the place where this aspect is in the private space with the place where the thing is in perspective space." (Our Knowledge of the External World, pp. 87-92.)

We are meant to see at once that such a space bequeaths its own reality and peculiar ontsideness to the things that 
occupy it. Given that the adjustment of private to public space is an outside affair it is possible for New Realism to proclaim boldly the outsideness and publicity of sensedata. There is no sensation so elementary and so immediate that it cannot rank as perception of an outside real thing. Only from the private point of view of the perceiver can it be regarded as a private object enshrined in private space. Sensations: red, hot, loud, rough, hard, heavy, are not my internal and private response to an external nerve stimulus, nor are they yours; they are planted out in the object; or rather, they subsist in the object by its and their own right. They are objects.

It follows that for Realism, as for Idealism, there will be no difference between the so-called primary and secondary qualities. If position, extension, size, shape, weight and impenetrability are real, we have no reason for supposing that the secondary qualities of matter: colour, and sound and taste and smell are not real too.

This point is too important to be passed over with a summary reference.

Again it is a question of logical construction and correlation, and the inferences we make therefrom. Such sensedata, whatever else they may be, are to be classed among what Mr. Bertrand Russell calls "hard" facts. They are given, not inferred; they are irreducible to anything simpler than themselves. We infer that they have an objective or "independent" reality from the fact that they enter obediently into the context of objective or "independent" realities; they can be correlated with them so as to form part of the same logical construction; they show themselves as belonging not only to the same universe, but to the same order of reality within the universe. For the thorough-paced realist and thorough-paced idealist alike the distinction between the illusions and realities of sense is irrelevant. They are distinguished only by their respective contexts. 
But it is a distinction which makes all the difference between Realism and thorough-paced Idealism.

Thus Mr. Bertrand Russell in Our Knowledge of the External World:-

"The first thing to realize is that there are no such things as 'illusions of sense.' Objects of sense, even when they occur in dreams, are the most indubitably real objects known to us. What, then, makes us call them unreal in dreams? Merely the unusual nature of their connection with other objects of sense. $I$ dream that $I$ am in America, but I wake up and find myself in England without those intervening days on the Atlantic which, alas! are inseparably connected with a 'real' visit to America. Objects of sense are called 'real' when they have the kind of connection with other objects of sense which experience has led us to regard as normal; when they fail in this, they are called illusions. But what is illnsory is only the inferences to which they give rise; in themselves, they are every bit as real as the objects of waking life." (Pp. 85-86.)

Thus Mr. Edwin Holt in The Place of Illusory Experience in a Realistic World, taking up the idealistic challenge: -

"Not the illusory or hallucinatory image as such, it was rightly said by our opponent, but such an image when it asserts itself to be, or when the realist asserts it to be a real object, is the crux for realism." (The New Realism, p. 356.)

"Now the secondary qualities present interrelations, both fixed and intelligible, so that those persons who seriously study them begin to see that they form a system like the systems discovered in mathematics; and this fact alone, as some one has said, already sets them off from the purely 'subjective,' individual, and incalculable." (Ibid. p. 331.)

Mr. Holt's argument is too closely and elaborately knit to bear quotation of any single passage. This is the gist of it: Take a whole class of so-called sense-illusions (errors of space), the diminution, duplication, and distortion of an object. A suitable apparatus can produce mechanically and objectively the perfect counterpart of 
these effects. There is a certain mechanical focussing of the eyes by which, when our eyes are shut, near things can be made to seem nearer and smaller. There is a certain mechanical focussing by which a machine for manufacturing shoe-lasts copies its model. "The machine at work has quite the air of seeing its model." So much so that the nearer the centre of the last is brought to the cutting edge of the machine, the smaller the model that the machine turns out. Again, "The stereoscopic camera habitually sees double," as human eyes will if their several perspectives are divided. A roubly cut lens distorts as badly as an astigmatic eye.

And the realist argues thus: As in these cases there isn't any question of the self-subsistent reality either of the single, undiminished, undistorted object, or of its doubling, reduction and distortion, so there should be no question in the case of the human apparatus which is equally mechanical. Both affairs are of the same order.

As for the so-called subjective hallucinations, for instance, of dreams, they are precisely on the same footing as "objective" sensations.

"The nervous system, even when unstimulated from without, is able to generate within itself nerve-currents of those frequencies whose density factor is the same as in ordinary peripheral stimulation." (Ibid. p. 352.)

And Mr. Alexander is no less explicit. For him sensedata are on precisely the same footing as an "object of thought," and equally independent of the mind that thinks or senses.

"For us, both the sensum and the so-called object of thought are equally objects, non-psychical; they are equally objects meant, though they are not equally important.

"Doubtless it is difficult enough, without natural and philosophical prepossessions, to treat the sensum as an object independent of the mind, for which the mind with its sense organ, through its act of sensing, is the mere vehicle of reception. 
Partly this arises from our theoretical ignorance of what exactly in the object the sensum is as compared with the percept. To call the sensum blue, as I have done, using a Leibnizian metaphor, a fulguration of the quality blueness is admittedly but a metaphor. And I am not yet prepared to supply the defect in theory. The sensum is so fragmentary and elementary. But at least we can say that, whatever it may be, it is that which exists in the thing at the moment and place to which it is referred, and that it is equally and identically apprehensible by me and another person who should put himself into the same situation of place and time as I, and who is supposed for simplicity to be equally normal with me, and to be suffering from no special subjective condition different from mine which might differently affect his susceptibility to the sensory object." (The Basis of Realism, pp. 16, 17.)

\section{Again :}

"I see the table in different perspective according to $\mathrm{my}$ position. But this does not prove the visual object psychical a mere content, but only that the object looks different from different angles ... the appearances are real characters of the thing. And so when the stick is seen bent in water, its visual character is bent because of the refraction of the light; the illuminated outline is bent. But of course the touched stick is not bent.

"These facts ... point to the superior value of touch-experience and the greater importance of primary qualities, as in the first place apprehended by touch, over the secondary ones ... the primary qualities are in precisely the same position with regard to our minds as the secondary ones. Either both of them are mental or neither." (Ibid. pp. 17, 18.)

The plain man ought to rejoice at this rehabilitation of the world he takes for granted; the irreducible real world outside conseiousness, resonant as a drum, hard as marble, bearing all the heraldry of its colours in its own right; the world that Dr. Johnson believed in; the world that Reid and Wolf - the Wolf who sent Kant into a dogmatic slumber - took for granted without any aid from analytic logic.

Consider what has happened. This world was badly 
shaken when Berkeley melted down the primary objective qualities of matter into secondary subjective qualities, and declared their esse to be percipi, when Hume reduced causation to fortuitous sequences of sensation, and Mill defined the result as "a permanent possibility of sensation." And when Objective Idealism proved that consciousness is considerably more than a stream of sensations, when it raised up the world again out of the flux and stuck the broken bits of it together with "thoughtrelations," its indubitable "outside" reality was still "inside" universal consciousness. And it is this universality of consciousness that the New Realism has laid its hands on.

So far Idealism and Realism can get along fairly comfortably together: they can, at any rate, both agree that all the qualities of matter are in the same boat: there is no difference on either theory between primary and secondary qualities. It is over the "thought-relations" that the decisive battle is to be fought.

The New Realism abolishes the entire system of thoughtrelations which Idealism has built up. It repudiates the idealist's theory of "internal" relations, relations snugly, yet inscrutably housed in their "terms." For Realism there are terms and there are relations. But, though relations are concepts, they are not "the work of thought." And in no case is a relation dependent on its terms, or grounded mysteriously in their secret inner nature. Every relation is an outside and self-subsistent reality, independent both of the relater and the related. There is, properly speaking, no relater. A relation is a thing devoid of secrecy or mystery, plain as a pike-staff or the nose on your face, and offering not the smallest foothold to Idealistic Monism. Useless to enquire how a relation and its terms come together. They are together, for shorter or longer periods; that is enough: that is the beginning and the end of - the relation. 
And, as sense-data - the greenish-gold, the loud, the cold, the smooth, the heavy, the acrid-smelling, the bittertasting, all the secondary qualities that I sense, say, in a brass trombone - are outside and self-subsistent objects of sensation; and as percepts, such as the brass trombone itself, localized, for me, in close and intimate relation to my sense organs as I play it, and in more or less distant relation to the concert hall I play it in, to the other instruments in the orchestra, and the other things in the hall, as the brass trombone, the percept, is the outside and selfsubsistent object of perception, so the concepts, brass trombone, greenish goldenness, loudness, coldness, smoothness, heaviness, acridity and bitterness, are outside and self-subsistent objects of conception. But they are no more "in" the object of sense-perception than they are "in " or "of" the perceiving consciousness. They would have given considerable trouble, and raised the most disconcerting dilemmas if they had been; so they, too, are planted out; not in space, not in time; but in a world of their own; the world of the changeless and eternal Ideas. If there be any world of the Absolute it is theirs and theirs alone.

Here, after twenty-three centuries, Platonic Idealistic Realism has come again into its own.

There must be no misunderstanding about the position of ideals, concepts, or "universals" in the New Realistic scheme.

"No sentence can be made up without at least one word which denotes a universal. The nearest approach would be some such statement as 'I like this.' But even here the word 'like' denotes a universal, for I may like other things and other people may like things. Thus all truths involve universals, and all knowledge of truths involves acquaintance with universals."

The universal cannot be a so-called "abstract" idea; an idea seated firmly in particulars and picked out of them by the mind. Take, for example, the idea of white- 
ness or the idea of the triangle that Bishop Berkeley argued about, the triangle which must be "neither oblique, nor rectangle, neither equilateral, equicrural, nor scalenon, but all and none of these at once," an unqualified triangle, a triangle tout pur.

"A difficulty emerges as soon as we ask ourselves how we know that a thing is white or a triangle. If we wish to avoid the universals whiteness and triangularity, we shall choose some particular patch of white or some particular triangle, and say that anything is white or a triangle if it has the right sort of resemblance to our chosen particular." (Bertrand Russell, The Problems of Philosophy, pp. 146, 150.)

But this is only putting off the evil day when we have to recognize the presence of the universal. For

"the resemblance required will have to be a universal. Since there are many white things, the resemblance must hold between many pairs of particular white things; and this is the characteristic of a universal. It will be useless to say that there is a different resemblance for each pair, for we shall have to say that these resemblances resemble each other, and thus at last we shall be forced to admit resemblance as a universal. The relation of resemblance, then, must be a true universal. ..."

"Consider such a proposition as Edinburgh is north of London. Here we have a relation between two places, and it seems plain that the relation subsists independently of our knowledge of it. ... The part of the earth's surface where Edinburgh stands would be north of the part where London stands, even if there were no human being to know north or south, and even if there were no minds at all in the universe." (Ibid. pp. 151, 152.)

This follows, as we have seen, from the realistic theory of perception, so that, before we go on to consider the doctrine of universals, we may assume it to be true that

"nothing mental is presupposed in the fact that Edinburgh is north of London. But this fact involves the relation 'north of,' which is a universal, and it would be impossible for the 
whole fact to involve nothing mental, if the relation 'north of,' which is a constituent part of the fact, did involve anything mental."

(Idealists will again agree heartily with this view. It would, indeed, be impossible.)

"Hence we must admit that the relation, like the terms it relates, is not dependent upon thought, but belongs to the independent world which thought apprehends but does not create. . ."

"If we ask, "Where and when does this relation exist?" the answer must be 'Nowhere and nowhen.' There is no place or time where we can find the relation 'north of.' . . . It is neither in space nor in time, neither material nor mental; yet it is something. . . ."

"Thoughts and feelings, minds and physical objects exist. But universals do not exist in this sense; we shall say that they subsist or have being, where being is opposed to 'existence' as being timeless. The world of universals, therefore, may also be described as the world of being.

"The world of being is unchangeable, rigid, exact, delightful to the mathematician, the logician, the builder of metaphysical systems, and all who love perfection more than life." (Ibid. pp. 153-156.)

Thus Mr. Edward Spalding in his Defence of Analysis:

"The concept is not the printed or spoken sign, the word. It would subsist, did the signs not exist. . . . It is not the knowledge or idea of the state of affairs." [The concept or group of concepts. 7 . . "It is not identical with the individual cases, whatever these be. Number is not any one number, man is not a man, etc. It is not necessarily even physical or mental, even when the individual cases are physical or mental existents." (The New Realism, p. 233.)

Thus Mr. Cecil Delisle Burns in William of Ockham on Universals:

“. . The facts of experience necessifate the supposition of (1) particulars differing numerically and not as collections of 
different qualities, and (2) likenesses implying the existence of some sort of reality which is different from the reality of the particulars" ... " the likeness 'between' particulars has to be explained by reference to a third thing which we may call a universal. Nor can the mere addition or blurring of particulars (thisnesses) produce a likeness (whatness). The universal, therefore, must be a kind of reality in relation to which the particulars are 'alike.' Thus it exists beside, and, if you like it, above or beyond the particulars." . . "We may say that universals are 'in mente,' but that they are and are independently of our knowledge of them there is no doubt. Therefore they exist in some other way than the way particulars exist; hence we say that the likeness 'in' things is not the universal but indicates the universal." (Pp. 13-19.)

The italics are mine. They emphasise the most important point of all.

The reason for this planting out is not far to seek; it follows from the law of analytic logic, which postulates the independence and the reality and the infinite number of its universals.

For the validity of all reasoning, both inductive and deductive, depends on the presence, somewhere in the chain, of a universal proposition, either arrived at or assumed, either expressed or implied. In deduction, which proceeds from the universal to the particular, it is obvious that this is so. But it is no less imperative in all induction, which proceeds, at its logical peril, from the particular to the universal. Logical peril: for, consider, that by no possible conjuring can you obtain a universal proposition from the simple enumeration of particular cases. Not if you went on enumerating for ten thousand years, untold generations of observers taking up the tale. For the peculiar, indefinable, indestructible validity of a universal law is not born of tireless and vociferous repetition.

But deduction must obtain its universal somewhere. You must therefore assume the existence of as many universals as there are possible propositions if there is to be any reasoning at all. 
It follows that, if reasoning is to hold good of the real world, universals must be as real, as independent of consciousness, as any of the realities which analytic logic has shown to be firmly established in space and time.

Universals, then, are concepts; but concepts are not "thought-relations" in the idealist's sense; nor are they in any sense constructed or constituted by thought. They are entities; objects of conception, independent of the conceiver, standing on their own feet in their own spaceless and timeless world, as objects of perception stand in space and time.

There is a concept or universal, not only of every number and quantity, and every thing and every quality, but of every possible relation that obtains between all or any of them ; and of every proposition that can be made concerning all or any of them ; ${ }^{36}$ so that the world of the universals is as infinite as the world of space or time. If you ask how, apart from their logical functions, they may be said to be, the answer is that they are as objects of conceptual contemplation.

Now it is clear that on this theory the rôle of consciousness is reduced to the very narrowest margin; and that the Self will be nothing more than the spectator of existence.

As Mr. Joseph Conrad says: "This is purely a spectacular universe." There is nothing in it which can be said to have arisen in consciousness. Thus, a magnificent spectacle has been provided, at the expense of consciousness, by the ruthless planting out on to a distant stage of everything once held securely within it.

If we ask whether, within the Self's narrow border, there remains anything at all that is the work of consciousness, we are told: Yes; besides the primary and secondary qualities of matter there are certain tertiary qualities that cannot be planted out with them. Such are the aesthetic feelings and values, the moral feelings and values; 
delight, charm, and their opposites, all that Mr. Alexander calls " the richness of mind," and all that is creative in the objects of creative art. These are purely subjective. They have no home anywhere but in the Self that feels them. It is interesting to see that $\mathrm{Mr}$. Alexander includes among them beauty and goodness, which to Mr. G. E. Moore and Mr. Bertrand Russell are essentially objective realities, universals; and that Mr. Ralph Perry recognizes what he calls "content patterns," as determined exclusively by the agency (selective and combining) of the subject of consciousness. Mr. Perry also admits that

"higher complexes, such as history, society, life, or reflective thought, are dependent on consciousness;"

but whether he would get any backing here from his brother realists is open to doubt.

The emotions and the passions, which might have loomed so large, are left out of the accounts I have referred to probably as too glaringly subjective for special notice.

Personally, I do not see how, on the theory, the Self can be justly credited with the work of its imagination. For imagination deals with universals, and has its home in the eternal. Therefore one would have supposed that creative Art was the least subjective of entities. Its works are planted out for ever in the spaceless and the timeless world.

I do not know whether this conclusion would be held to follow strictly from the premisses of the New Realism. But I think it should follow. There is, however, I believe, considerable divergence of opinion on this point.

I think it must be allowed that the New Realism has made out a strong case for itself, and that where Pragmatism and Humanism have failed it has succeeded.

I do not think that the idealistic monist will gain any- 
thing by refusing to concede to it the full measure of its success. I believe that, if he meets it courageously, so far from driving him out of the bosom of the Absolute, it will fold him more securely in. If he thrives on what Walt Whitman called "the terrible doubt of appearances," if there is nothing terrible to him in that doubt, it is because to him the terrible thing would be to be shut up for ever in this prison of space and time and matter, and to know nothing for ever but appearances, when it is reality for which he hungers and thirsts.

To begin with, whatever Pluralistic Realism does to him, it does not shut him up in any prison. On the contrary, to borrow Mr. Bertrand Russell's phrase, it "gives him wings." It proves to him that the bosom he desires, the barren bosom of the Absolute, is a prison indeed. The universe it opens to him has no walls, not even the walls of all-containing deity. It is only to be conceived, so far as it can be conceived at all, as an infinite number of infinitely intersecting planes of reality, each one of which is infinite. Each plane represents a different kind or order of reality, and maintains an infinite number of realities within or on it. Time and space and matter are not prisons; for time and space and matter are infinite, and there is an infinite number of times and spaces and matters and motions. Time and space contain an infinite number of separate planes, as it were, of spatial and temporal and material realities; of these there are an infinite number of objects of sensation, an infinite number of objects of perception, and an infinite number of their relations in time and space.

There is also an infinite number of " universals," the objects of conception, out of time and out of space, corresponding with every class of object in time and space: and again, an infinite number of relations ont of time or space, and an infinite number of universals, or class-concepts corresponding with each relation. And as every single num- 
ber of this infinity of infinities is a real thing, an entity, the monist cannot justly complain of any lack of reality.

But while the New Realism gives him reality, more reality than he asked or dreamed of, reality in embarrassing, overwhelming quantities, it does not give or profess to give him the kind or quality of reality he wants. The New Realism, in its turn, complains of his bad taste in wanting any other reality and of his impudence in asking for it. But there is no reason why the monist should not admire this largely spectacular universe Realism has provided. What he has reason to complain of is its lack of unity.

Then the pluralist tells him that unity, except in the peculiar and limited form of a Whole, is precisely what he cannot have. And since the Whole was, after all, what the monist performed nearly all his monistic tricks with, he may seek to bargain with his adversary and say: You may keep all your infinities, for all I care, if only you will give me back my Whole to do what I like with (for he thinks he may yet succeed in packing all those infinities inside it in some supreme synthesis). And then he will learn to his bewilderment that it is no longer his to do what he likes with.

In fact, he will not recognize his Whole by the time analytic logic has done with it.

To begin with, it raises all over again the apparently innocent but really formidable question which Monism has hitherto answered with an unhesitating affirmative: Is the relation between whole and part such that, given the concept of the whole, the concept of the part follows? That is to say: Is it a relation of logical priority? If it is, it ought to follow as strictly as the two propositions: " $\mathrm{B}$ is greater than $\mathrm{A}$," and " $\mathrm{A}$ is less than $\mathrm{B}$ " follow from and imply each other. 
"Then we should be able to define the relation thus: $A$ is said to be part of $\mathrm{B}$ when $\mathrm{B}$ is implies $\mathrm{A}$ is, but A is does not imply B is." (Principia Mathematica.)

Now at first sight this looks a very straightforward and satisfactory definition of the relation between whole and part. And it looks as if it might favour Monism by attaching the whole inseparably to the part and the part inseparably to the whole in a "unity." But not a bit of it. Mr. Bertrand Russell rejects the definition on the grounds that this relation of logical priority cannot be made to run on all fours with the relation of simple mutual implication between " $\mathrm{B}$ is greater than $\mathrm{A}$ " and " $\mathrm{A}$ is less than $\mathrm{B}$ "; that it is not a simple but a highly complex proposition; inasmuch as it implies other propositions asserting the being of $A$, and the being of $B$, and the being of the relation, each of which is simpler than itself; and that it rests, not only on the proposition " B implies A," but on the further proposition " A does not imply B."

The invalidity of the definition by logical priority will be seen at once if we introduce an element of another kind and value.

"For example, ' $\mathrm{A}$ is greater and better than $\mathrm{B}$ ' implies ' $\mathrm{B}$ is less than A'; but the converse implication does not hold: yet the latter proposition is not part of the former."

Again, from "A is red," it follows that A is coloured.

"Yet the proposition ' $\Lambda$ is red' is no more complex than ' $A$ is coloured.' . . . Redness in fact, appears to be a simple concept which, though it implies colour, does not contain colour as a constituent."

And Mr. Russell argues that, " having failed to define wholes by logical priority, we shall not, I think, find it possible to define them."

Now, I think, the monist would agree heartily that if the relation of whole and part is not to be defined by logi- 
cal priority, it is not to be defined at all. He would not be at all so certain that the definition he thinks so satisfactory should be flung aside because analysis finds that it is less simple than it looked at first. He would, I think, protest against propositions, that is to say, judgments covering concrete complexes being ruled out because it can be shown that they will not hold good when reduced to the strictly abstract terms of formal logic. He defies the analyst to discover any flaw in the definition: $\mathrm{A}$ is said to be part of $\mathrm{B}$ when " $\mathrm{B}$ is" implies " $\mathrm{A}$ is" but " $\mathrm{A}$ is" does not imply "B is." And Mr. Russell admits that "this state of things is realized when A is part of B." It seems to him, then, sheer wantonness to infect this still comparatively simple relation by complicating it with irrelevant elements drawn from other sources; and then to argue that, because "worse" is very far from being part of " better," and because colour, implied by red, is not a part of red, therefore logical implication must not be allowed to infect any definition of whole and part, when it has been admitted that it holds good when, that is to say, whenever and wherever $A$ is part of $B$.

But Mr. Russell is out to prove that this particular relation of whole and part is an indefinable and ultimate relation, a concept as irreducible as goodness or badness, redness or colour, and that there is no question of the whole holding its parts together in a unity, or of the parts as existing only in and for a unity. Correlation, for the, logical atomism of the pluralistic realist, does not involve either "higher synthesis," or mutual dependence of relations on terms, or of terms on each other. Concepts are hard, irreducible, mutually repellent entities, and relations are hard, irreducible, mutually repellent entities; and when propositions are broken up they are broken. What analytic logic hath put asunder, let no man join.

But this is not the end of the matter. Besides this indefinable and ultimate relation there are others. And 
we are now told that the nature of the relation will depend upon "the nature both of the whole and of the parts." For it would appear that though a relation is not allowed, on pain of an infinite regress, to depend upon the nature of its terms when this dependence suits the monist, it may do so for the convenience of the pluralist, who in this case blinks the dilemma with tolerance and bonhomie.

Thus three kinds of wholes may be distinguished: (1) Collections or aggregates of single terms. (2) Collections or aggregates of terms that are themselves aggregates. (3) Collections of propositions which relate or qualify.

It is only when we reach the third and last kind of whole that we arrive at unity.

As this whole always consists of propositions in which something is related to something, or something is qualified by something else, it must be regarded as radically and irreducibly different from any whole which is simply a collection or aggregate, whether of single terms or aggregates. And the relation of whole and part in any unity will be radically and irreducibly different from the relation of whole to part in any collcction or aggregate. So much so that we may say that there are not three kinds of whole but two kinds: Collections (or aggregates) and unities.

And the radical and irreducible difference between these two kinds is this: that in a collection, whether of single terms or aggregates,

"such a whole is completely specified when all its simple constituents are specified: its parts have no direct connection inter se, but only the indirect connection involved in being parts of one and the same whole."

Whereas wholes containing relations or predicates

"are not specified when their parts are all known." (Ibid. p. 140.) 
For, take the simplest instance, "A differs from B," and let $A$ and $B$ be as simple as you please, you cannot reduce this whole to anything simpler, i.e. to fewer terms than "A," "B," and "difference." Simple as it seems, "A differs from $B$ " is really a very complex synthetic statement. Under analysis it yields, as we have seen, "A, B, and difference" as a subordinate aggregate of three terms, and the whole involved in its implication, " $\mathrm{B}$ differs from A." " A," "B," and " difference," must be thought of as three single and irreducible terms before ever the business of joining up $A$ to $B$ in the relation of their difference can begin. The relation itself is a new thing that will not be found in the analysis, and is "not even specified by specifying its parts."

So that the only unity which Analytic Logic allows him, so far, is a unity that doesn't yield an inch of ground to the struggling monist. In fact, he is, if anything, worse off with it than he was with the whole as a "collection"; since the collection at least collected, and the whole could be specified by its terms when the terms were known. We have got to realize that always

"the whole is a new single term, distinct from each of its parts and from all: it is one, not many, and is related to the parts but has a being distinct from theirs." (Ibid., loc. cit.)

And the pluralist argues that, since this is so, we can no longer talk about identity in difference, or about the whole being present in its parts, or about the parts existing in the whole.

And as the monist surveys the ruins which Analytic Logic has made of his neatly ordered and closely articulated world, several things are bound to occur to him. I think he will say: All this may be true of finite things and of finite wholes. I have never denied the plurality of finites. But $m y$ Whole is Infinite.

Let us see, then, what the pluralist's account is of In- 
finite Wholes, and whether they are in any better case.

"We must then admit infinite aggregates. It remains to ask a more difficult question, namely: Are we to admit infinite unities?... Are there any infinitely complex propositions? ... A unity will be infinite when the aggregate of all its constituents is infinite; but this scarcely constitutes the meaning of infinite unity. ...

"An infinite unity will be an infinitely complex proposition: it must not be analysable in any way into a finite number of constituents. . . . Now, for my part, I see no possible way of deciding whether propositions of infinite complexity are possible or not, but this at least is clear that all the propositions known to us (or probably all that we can know) are of finite complexity. ... Thus the question whether or not there are infinite unities must be left unanswered, the only thing we can say on this subject is that no such unities occur in any department of human knowledge, and therefore none such are relevant to the foundation of mathematics." (Principia Mathematica, pp. 145, 146.)

There is no comfort for the monist here. The only sort of infinite whole that Pluralism will allow him is an infinite collection; and an infinite collection, so far from being any good to him, carries on the business of plurality for ever and ever, world without end. 
So far, it must, I think, be admitted that, where the logic of the new realist meets the logic of the monist, the encounter has been apparently to the disadvantage of the monist. Hitherto the monist has either neglected mathematics altogether, or he has seized on them greedily to nourish his appetite for dilemmas. Thus his position becomes vulnerable from the first moment when the mathematician cuts off his nourishment at its source by solving the dilemmas.

It remains to be seen whether his Idealistic Monism has sufficient vitality, or sufficient command of other resources to survive the blockade.

His ultimate and complete overthrow must follow if he has no other resources than the slender synthetic methods he has employed hitherto; if, that is to say, he stands or falls by the entire epistemology of the past. It must follow, in any case, whatever his unexplored resources, if the New Realism succeeds in its attempt to make the laws of pure mathematics binding on a universe which, as known and experienced, is anything but pure; and if it succeeds in keeping those laws secure from the assaults of any countering analysis which may reveal in them a secret contradiction and dilemma.

I do not say: if its doctrine of Pluralism, and its account of knowledge in general, and of immediate perception in particular, should hold water; for I think it will be found that, so far as these do not follow as corollaries from its mathematical arguments, they have been deliberately arranged to correspond.

Now, there is no doubt that the idealist's habit of rash 189 
synthesis has laid him open to attack. Whatever happens to the constructions of the New Realism, much of its critique of the older Idealism must remain as perhaps the most vitally important and necessary work that any philosophy has yet done. This is why I shall consider this part of it in rather more detail than the slight form of these essays warrants. Readers who have no taste for abstract thinking will do well to skip the next thirty pages or so; for I warn them they will be taken over a very dry and difficult piece of ground. At the same time they should remember that we despise abstractions at our peril. There never was an abstraction so abstract that it or its kind was not at some time or other the burning centre of man's passion; and, even now, it may be that our hope of God and heaven and immortality, and the present existence of our very selves hang on as thin a thread.

We will begin with Mr. Bertrand Russell's criticism of the Monistic Theory of Truth, for it amounts to a criticism of the Monistic Theory of Reality.

The monist says that the Truth is the Whole. And Mr. Russell argues that, if this is so, no part of the truth can be true. When Mr. Joachim says that "the truth is one and whole and complete" it means

"that nothing is wholly true except the whole truth, and what seem to be isolated truths, such as $2+2=4$ are really only true in the sense that they form part of a system which is the whole truth ... the truth that a certain partial truth is part of the whole is a partial truth, and thus only partially true; hence we can never say with perfect truth this is part of the Truth. Hence there can be no sense of truth which is completely applicable to a partial truth, because everything that can be said about a partial truth is a partial truth ... thus the complete truth about any part is the same as the complete truth about any other part, since each is the whole truth." ${ }^{37}$

I do not know whether every monist would accept this statement of his position. He ought not to admit the very 
first construction which Mr. Russell has foisted on him, as it stands, but he would, I think, amend it thus: Nothing is wholly true of things that are wholes except the whole truth; by which he will secure his position when he defines Reality as the Whole. He would distinguish between isolated truths and isolated facts; and while admitting that truths, artificially isolated by logical analysis, may be "wholly true" as far as they go, he would insist that if facts could be isolated, torn from the living context in which they are born and by which they continue, if they could be stripped bare, that is to say, of their "relations," no truth could be known about them at all; thus he would deny that "isolated facts" and "the whole truth" can be made to run logically on all fours. For instance, though it may be wholly true that water consists of $\mathrm{H}_{2} \mathrm{O}_{1}$ in chemical combination, it is not the whole truth about water; it is not the whole truth about hydrogen or oxygen. And by this time he would begin to see that the trap that was laid for him is a logical quibble turning on the "whole truth" and "wholly true."

The only construction that he would accept without reservation is the last, "the complete truth about any part is the complete truth about any other part since each is the whole of truth." The point which Monism and Pluralism will contest for ever is the point at which the complete truth may be said to have been reached. For the pluralist, if he is logically consistent, there can be no such point, since the parts of his universe are infinite. For the Monist, it cannot be reached anywhere short of the Absolute.

We shall see, later on, that the pluralist reaches it every+l where by the erection of an infinity of independent absolutes.

To go back to the assault on Mr. Joachim. My monist has accepted the first and the last construction put on him. It is in the intermediate propositions that he would be 
likely to suspect a humorous parody of his position: "What seem to be isolated truths, such as $2+2=4$, are really only true in the sense that they form part of the system which is the whole truth. ..." "The truth that a certain partial truth is part of the whole is a partial truth and thus only partially true; hence we can never say with perfect truth "this is part of the truth.', The monist who believes that nothing is wholly true, in his sense, except the whole truth, is not bound to deny that $2+2=4$ is part of the truth; he is only bound to deny that it is the whole truth about 2 and about 4 , and that the whole truth about 2 and about 4 is the whole truth about number, and that the whole truth about number is the whole truth about reality. He would insist that if you isolate that apparently self-evident proposition about 2 and 2 in such a way as to ignore the other " isolated truths" about number, for instance, that $16+16=32$, or $4 \div 2=2$, or even that $7 \times 7=49$, you have only a partial knowledge of $2+2$. And again he would protest against the quibble that turns on taking a partial truth as equivalent to partially true.

But the sterner problem for the monist arises when you isolate all the truths you know about number from all the truths you know about quality, and find that, although within their own wholes none are completely true when torn from their respective contexts, yet the whole set of arithmetical truths, and the whole set of qualitative truths stand apparently on their own feet, and in the most perfect isolation and independence. If it were not true that $2+1=3$, it would still be true that water consists of two parts of hydrogen to one of oxygen. That in this case we should have considerable difficulty in measuring the parts is not any argument from the pluralistic realist's point of view. Wherever water is there will be $\mathrm{H}_{2} \mathrm{O}_{1}$ whether you measure and number them or not. In the same way the numbers two and one and three, and all the 
relations between them, would persist as eternal realities, and all the truths about them would be eternally true, whether there were any thing to be numbered in the universe or not. (In this case the numbers would still have the resource of numbering each other.)

And yet, without quantity, so much hydrogen to so much oxygen, without proportion which can be expressed by number, the qualities of water cannot be. You cannot, except by an artificial logical analysis tear those two wholes apart. Therefore they are not wholes; they are only complexes, knit together, with all their several complexities, into the structure of the universe. Isolate them, not from each other, but from that greater Whole, and what independence and what reality will they have?

That is the crux. The pluralistic realist says they have their own reality and that is enough. The monist says that in that state of dismemberment they have no reality; they are only appearances; Reality is the Absolute whole of Spirit (or of some consciousness) which alone holds them together. Both agree that somehow or other they are together. The monist says, or ought to say, that they can only be separated by an arbitrary process of abstraction.

It looks as if the realist, rashly supposing that the idealist is always talking and thinking about ideas, had taken for granted that he could be floored by an argument that rests on an unreal abstraction; whereas the world the monist is considering is the same real and related world, the world of intricate connections and mutual dependencies and correspondences, of things linked and platted together and interwoven, and separable only in thought. Nobody is contending that the truth $2+2=4$ is an unreal abstraction, or that it is not a holy and eternal truth, if all the other truths about number are holy and eternal too; or that a partial truth is not true as far as it goes. The idealist is, I think, well within his rights in protesting against Mr. Bertrand Russcll's use of the terms "the whole 
truth" and " a partial truth" as equivalent to wholly true and partially true.

The destructive force of Mr. Russell's argument rests on this dubious equivalence and on nothing else.

Let us take things as they are, in the concrete. It is wholly true that Mr. Bertrand Russell is a brilliant mathematician, but it is not the whole truth about Mr. Bertrand Russell. Mr. Bertrand Russell is more than a brilliant mathematician, he is a brilliant logician, he is a brilliant writer, he is (unfortunately at the present moment), a pacifist, and he is a number of other things besides. He is a pluralistic universe in himself.

But he is a universe, a whole.

And that he is a brilliant mathematician is so far from being the whole truth abont him that it is not the whole truth about the brilliance of his mathematics, which is inseparable from the brilliance of his logic. If we knew the whole truth about Mr. Bertrand Russell, we should know why he is a brilliant mathematician and logician. We should even know why he is, at this unfortunate moment, a pacifist. What we do not know about all this brilliance is its inevitableness as a quality of Mr. Bertrand Russell.

Mr. Russell would point out that our proposition can perfectly well stand alone; that it is wholly true and sufficiently significant in itself. And I do not see that the monist is pledged to deny this, even while maintaining that we are as far as ever from the ultimate truth, the ultimate reality of Mr. Russell.

Mr. Bertrand Russell, and his mathematics and the rest of it, is an instance that serves the monist very well. For the personality of Mr. Russell is precisely that sort of spiritual whole he has in mind when he declares that the Whole is present in its parts, and that the parts have no complete significance apart from the whole. Whether he 
has grounds for maintaining that the Reality of the universe is of that nature remains to be seen.

Meanwhile, when Mr. Joachim, the monist quoted by Mr. Russell, says, "The erring subject's confident belief in the truth of his knowledge distinctly characterizes error and converts a partial apprehension of the truth into falsity," he certainly lays himself open to the attack of Mr. Russell's brilliant logic. But he is deserting the game of Monism, and stating a private theory of truth. All that his metaphysical theory commits him to is the statement that, if a man believes a partial truth to be a whole truth, he is in error. And he is in error precisely in Mr. Russell's sense. His error consists in a false judgment about reality. The confidence of his belief has nothing to do with it except so far as it is calculated to keep him in his error.

According to Mr. Bertrand Russell, the unfortunate monist has no means of distinguishing between truth and error. The two propositions "Bishop Stubbs was hanged for murder," and "Bishop Stubbs used to wear gaiters," are, for him, on the same level of truth and of reality. The monist who looks beyond the partial truth that Bishop Stubbs used to wear gaiters to that whole episcopal phenomenon of which gaiters are but a part, has no logical grounds for denying that Bishop Stubbs was hanged for murder.

And yet the monist's grounds are the same as anybody else's grounds, and he has the same right to them. If he were defending Bishop Stubbs from a charge of murder, he would appeal, not only to the integrity of the episcopal phenomenon, but to the whole of the evidence, the whole sequence and conglomeration of facts by which it is established beyond doulbt that Bishop Stubbs did not, as a matter of fact, commit murder.

That murder and Bishop Stubbs are in no possible way 
connected cannot be said with perfect truth; since Bishop Stubbs shares the common humanity of all the murderers that ever were. In their hypothetical ultimate reality as immaterial beings, there is no difference, except a numerical difference, between all those murderers and Bishop Stubbs. And in their hypothetical oneness in the Absolute (with which numerical identity has absolutely nothing to do), there would be absolutely no difference between them. All the same, as an apparition (wearing gaiters), in space and time, Bishop Stubbs could not, and did not, commit murder.

So far Mr. Russell's arguments have been destructive only to a Monism of logical abstractions, the quantitative finite whole which is the sum of its parts, the numerical one, the abstract absolute. They have no grip on the hypothesis of a real, living whole, a real Absolute, a real unity of finite and infinite, a real Spirit immanent or transcendent.

But Mr. Russell has another and more formidable argument. He deduces the whole doctrine of Monism from the axiom of internal relations: "Every relation is grounded in the nature of the related terms."

Mr. Russell says that Monism stands or falls by this axiom, and tries to show how impossible it is that it should be stood by. The discreet monist will therefore think twice before he gives his assent to it, for it is the weapon Mr. Russell is coming out to slay him with.

Perhaps he will think of certain obvious relations between subject and object, cause and effect, the thing and its qualities; between premisses and conclusion, subject and predicate; or between positions in space and sequences in time, and will say without a moment's hesitation: Yes, of course the relation is grounded in the nature of its terms. For surely the terms of a relation imply each other. That the subject $A$ perceives the object $B$, implies that it is in the 
nature of $\mathrm{A}$ to perceive $\mathrm{B}$, and of $\mathrm{B}$ to be perceived by $\mathrm{A}$; even though nobody knows what that nature is, and though the relation remains for ever mysterious. That $\mathrm{A}$ is the cause of B implies that it is the nature of A to cause B, and of $B$ to be caused by $A$; it is the nature of such and such premisses to lead to such and such conclusions, and of such and such conclusions to follow. If it were not the nature of $A$ to have the quality $B$, it would not have $B$, and $B$ must be such a quality that it can belong to $A$. The same will hold of subject and predicate in every statement made with regard to truth. If $\mathrm{A}$ is eternally to the left of $B$, and therefore $B$ eternally to the right of $A$, there is something eternally in their natures which makes these positions eternally possible (they must, that is to say, be material objects occupying space, and conditioned so as to occupy it in that particular relation); or, if these positions are only temporary, then there is something in their natures, a tendency to move or a tendency to perish, which makes these positions tenable only temporarily. In saying all this, the monist may think that he has stated both the correct and the common-sense view of relations. Remember, he has not yet committed himself to any explanation of their mystery.

And all the time he is playing disastrously into Mr. Russell's hands.

First of all, it is assumed that he does not distinguish between the terms and the nature of the terms. In this case he is floored with the same arguments which were brought to bear against his theory of the whole and the parts. On that theory he cannot make a true statement about any relation between two terms without knowing all the relations in which each term stands to all other things, and without knowing all other things which enter into that relation. Say it is the relation of perceiving subject to object perceived, he cannot say with perfect truth that $\mathrm{A}$ perceives B without knowing how many other subjects B is 
perceived by. And then he hasn't got further than the two terms. There is still the relation of perceiving. He must therefore know all perceiving wherever perceiving occurs. He must therefore know all subjects perceiving and all objects perceived.

I have taken a relation which by its very simplicity and comprehensiveness is most dangerously exposed to $\mathrm{Mr}$. Russell's attack; but it is clear that his argument applies with equal ferocity to all the other instances that have been given.

Again, if relations are grounded in the nature of their terms, there can be no diversity of things. Consider the relation of diversity. $A$ is different from $B$, therefore $B$ is different from A. Simple unqualified difference cannot be predicated as a common adjective of both. They must be different in some way. (Mr. Russell does not say so, but his argument requires us to consider that $\mathrm{A}$ and $\mathrm{B}$ differ in some way.) They have, then, different predicates. In what way do the predicates differ? They have different predicates. In what way do these different predicates differ? They have different predicates. In what way -

But, as it is clear that the process must stop somewhere (for even Mr. Russell's Pluralistic Universe would not provide the differences necessary to follow up the infinite regression), we are driven to the conclusion that $\mathrm{A}$ and $\mathrm{B}$ are not different from each other. Neither are C or D or $\mathrm{E}$ or $\mathrm{F}$. In fact, there are no two things that are different from each other.

"It follows that there is no diversity and that there is only one thing. Thus the axiom of internal relations is equivalent to the assumption of ontological Monism and to the denial that there are any relations. Wherever we seem to have a relation, this is really an adjective of the whole composed of terms of the supposed relations." (Philosophical Essays, p. 163.)

In other words, things are predicates of one Thing. It follows that 
" the one final and complete truth must consist of a proposition with one subject, namely, the whole, and one predicate. But as this involves distinguishing subject and predicate, as if they could be diverse, even this is not quite true." (Ibid.p. 164.)

And this is assuming that the monist does not distinguish between his terms and their nature. If, with a misguided subtlety, he does distinguish them, then the same pitfall awaits him. For then, not only do we have the same trouble that we had just now with $\mathrm{A}$ and $\mathrm{B}$, but the terms and their nature will enter the relation of diversity with all its consequences of infinite regression.

If he sticks to it that the "term" and the "nature" are one term, then

" every true proposition attributing a predicate to a subject is purely analytic, since the subject is its own whole nature and the predicate is part of that nature . . .; in that case, what is the bond that unites predicates into predicates of one subject? Any casual collection of predicates might be supposed to compose the subject if subjects are not other than the system of their own predicates." (Ibid.p. 167.)

Finally, Monism is challenged to account for

" the apparent multiplicity of the real world. The difficulty is that identity in difference is impossible if we adhere to strict Monism. For identity in difference involves many partial truths, which combine, by a kind of mutual give and take, into one whole of truth. But the partial truths in a strict Monism are not merely not quite true; they do not subsist at all. If there were such propositions, whether true or false, that would be plurality." (Ibid. p. 168.)

On the other hand, if we accept the realist's proposal and give up the axiom of internal relations (if we give up Monism),

"'Identity in difference' disappears: there is identity and there is difference, and complexes have some elements identical and some different, but we are no longer obliged to say of any pair of objects that may be mentioned that they are both identi- 
cal and different-'in a sense,' this sense being something which it is vitally necessary to leave undefined. We thus get a world of many things, with relations which are not to be deduced from a supposed 'nature' or scholastic essence of related things. In this world, whatever is complex is composed of simple related things, and analysis is no longer confronted at every step by an endless regress." (Ibid. p. 169.)

These passages, I think, show that Mr. Russell has not really grasped the monist's position. The endless regress is the very last thing that the monist desires to give up. His insistence on the endless regress is sufficient proof that he is no more out for a supposed " nature," or "scholastic essence," than the pluralist. The "sense" in which he declares two things to be both identical and different is something which it is "vitally necessary" to his theory to define. He has no earthly interest in shirking the definition. His sense is not the pluralist's sense, and they are therefore arguing at cross purposes. His multiplicity, his difference, refers, or should refer, always to appearances, to the manifestations of reality. For him, identity in difference does not mean that two manifestations are one manifestation, but that there is one reality in two, or, if you like, in an infinite number of manifestations. His Monism may be wrong or it may be right, but it is not self-contradictory.

Challenged to account for the apparent multiplicity of the real world, his answer must be that it is apparent, and not real, and that the world of appearances is not the real world. When he is told that partial truths, in a strict Monism, do not subsist at all, because " if there were such propositions, whether true or false, that would give plurality," the retort is obvious: Precisely; it is incompleteness that gives plurality. Plurality is the expression of partial truth.

As for "the bond that unites predicates into predicates of one subject," he might ask, in his turn, how there can 
be such a bond without identity in difference? And, talking of casual collections, how does the pluralist propose to make his collections stick? We shall see later on that he cannot do it without recourse to the very principle he repudiates.

Still, it cannot be denied that a great deal of this critique is formidable. It is the heavy artillery of a ferocious enemy out to slay. And I think it must be owned, in humility and contrition, that Idealism has brought it on itself, by its increasing "thinness," its more and more exclusive cultivation of epistemology. Hegel, as William James admitted, has "thickness" (as Fechner has thickness), but his followers have persisted in following the very path he warned them off - the narrow way of abstract intellectualism that leadeth to destruction in the barren Absolute. They have tried - as if their master, and Kant before him, had lived in vain - they have tried to build up a universe out of those very categories of the understanding which Hegel himself had told them were unfruitful. They have stopped at the Third Book of his Logic, where all the categories are rounded up in the Absolute Idea, and have not pursued the game of the Triple Dialectic any further. It does not seem to have occurred to them that in the Logic Hegel is only getting into his stride, and that, if they are to play the game, they must go on till Nature and Thought together are rounded up in the Absolute Spirit which is God. An Absolute as thick, as concrete as the universe itself. Thought itself, which in Hegel's hands is alive and kicking, becomes sterile and motionless under their treatment. ${ }^{38}$

Now it may turn out that there is no such thing as Spirit; or that if there is it cannot play the all-embracing part assigned to it. But, anyhow, Hegel's assumption of Spirit made all the difference to the sncessful working of his Dialectic; whereas his followers distrust the Dialectic, 
and their tendency has been to drop it, and to drop the assumption in the interests of what they believe to be a sounder logic. And it is at least a question whether their logic, though far simpler, is really somder. Hegel's "thought-relations," by whatever unsafe à priori process he arrived at them, really did relate, because they are themselves related, because they are moments in the manifestation of Spirit, links between its immanent and transcendent life. His followers have turned them into logical abstractions, and abstractions are hard, unyielding things, unsuited to the rhythmic and elastic play of Spirit. And so, having stopped short where the Hegelian plot is thinnest (though Hegel's "Logie" is still considerably thicker than, say, Mr. Bradley's), they fall an easy prey to any philosophy that takes account of such things as nature, and life, and will, and sense, and passion, and moral behaviour. Their organic whole is not a whole, and cannot by any manipulation of the terms be made to do duty for the whole. Their "interual relations" are so far from being internal that at the first touch of analysis they seem to fall away from the "things" they are supposed to constitute, or at any rate to hold together. Their unity is not a real unity, for the simple reason that the supreme and ultimate form of it, their Absolute, is not a real Absolute.

As abstractions, "thought-relations" are specially vulnerable to Analytic Logic, which can be trusted to produce off its own bat as many more as may be wanted and to deal with them after their kind. When the monist asserts that all relations are grounded in the nature of their terms, he starts with a rash generalization; and when he stakes all his hopes of his Absolute on the dilemma of the infinite regress which ensues, his Absolute is in a perilous state. The position is attackable from above and from below. You have only got to show him one relation, equally abstract, which is not grounded in the nature of its terms, and you have mined the very foundations of his dilemma. 
Or, if he takes his stand on a relation that is so grounded, then, with the first step of his regress, he is again in the thin air of abstraction; and the superstructure of his dilemma is exposed to any opponent who presses on his attention some irreducibly uncontradictious definition of the terms. Thus the ingenious analyst "has" him either way. For it is clear that, if the relation is grounded in the terms, and the terms are irreducible, the relation itself is irreducible; while, if the relation is not grounded in its terms, it is irreducible to begin with. And this irreducibility of the whole complex holds up his regress at the start.

Yet, so far is Monism from being vanquished that this game of abstractions has one great and glorious advantage for the monist - two can play at it. And, as we shall see, it is a game at which ultimately the realist stands to lose.

That both sides are dealing in abstractions is evident from the realist's theory of the monist's theory of "relation."

"Philosophers," Mr. Bertrand Russell says (and by philosophers I think he means monists), "scem really to assume - though not so far as I know, explicitly - that relations never have more than two terms: and even such relations they reduce by force or guile to predication. Mathematicians, on the other hand, almost invariably speak of relations of many terms" (Principia Mathematica, p. 212); and Mr. Russell both assumes, quite explicitly, and argues that a relation of many terms is incompatible with any monistic theory of relation. You would have thought that, the wider and more complex the ramification of any one relation, and the more terms you could rope into it, the more unity would triumph. But no, you have only to abstract your mind from the relation and fasten it on the terms to see at once that it is Pluralism that scores. And so it does, if you have given in to the proposition that a relation can exist apart from and independently of its terms. 
And when the realist has shown that this separateness and independence is found in the most intimate and sacred of all relations, the relation of subject and predicate, the conclusion is apparently forced on you that the game of Monistic Idealism is up. Idealism, seeking unity before all things, is supposed to have assumed faithfulness in the union of subject and predicate. Realism, on the look-out for plurality, finds, on the contrary, that subjects are polygamous and have many predicates, while there never was a predicate yet that could remain faithful to one subject for very long. The rose is red; but so is the dawn and so is Bardolph's nose. And, unless you adopt the realistic theory of universals, you are in danger of arguing that the nose and the rose are not red, because redness is not a rose nor a nose. In short, the relations of most subjects and most predicates are temporary and fortuitous, and their behaviour, from the point of view of monism and monogamy, an open scandal. Therefore, the pluralist argues, you had much better agree with him that relations are irreducible and independent entities, and that so are their terms.

But there is no reason why Monism should be assumed as banking on the permanence of these unions, except on the further assumption that it stands or falls by the theory of internal relations. If the relation of subject and predicate is grounded in their nature, clearly the relation must be permanent; subjects and predicates must not chop and change.

Now, though the statements of certain monists may have given some grounds for the assumption, it is not justified by Monism itself. Monism does not stand or fall by the doctrine of internal relations. It stands or falls by the dilemma.

That is to say, it stands or falls by the dilemma involved in the opposite theory, the realistic theory of external relations; or rather, by the dilemma inherent in the very idea of the thing and its relations. No predicament, short of 
the double dilemma, will really serve. Given the double dilemma, you are confronted with the plain illusion of all relative existence.

In chapter ii, page 21, of Mr. Bradley's A ppearance and Reality you will find Mr. Russell's argument against the doctrine of internal relations turned in precisely the same way, with precisely the same plausibility against the doctrine of external relations.

Thus, even at this apparently profitless game of abstractions, the monist scores; seeing that the double dilemma, so advantageous to him, is disastrous to his opponent. For Realism stands or falls by its freedom from dilemmas and from contradictions.

So what are we to say when on one page of the Principia Mathematica we read: "The whole doctrine of subject and predicate ... is radically false and must be abandoned," and on another page, in that chapter iv to which the context refers us for the definition of "thing": "Every term" (which is here equivalent to "every thing") "to begin with is a logical subject. . . . Again, every term is immutable and indestructible. What a term is, it is and no change can be conceired in it which would not destroy its identity and make it another term." So that, as some terms, on Mr. Russell's admission, are also predicates, every term must be what it isn't, contrary to the definition.

If a monist had made a statement like that he would never have heard the last of it. And there is no reason why he should not have made it, since the contradiction involved would help him rather than not. But it is very far from helping Mr. Russell.

And if we go on we shall find him involved in contradictions that would make the fortune of a monist. Thus:

"We shall say that Socrates is human is a proposition having only one term; of the remaining components of the proposition one is a verb, the other is a predicate." 
It is implied, then, that a predicate is not a term; yet in the preceding paragraph, terms are divided into "things" and "concepts," and concepts into adjectives, or "predicates," and relations or verbs. There may be terms that are not predicates, but how on earth can there be any predicate that is not a term?

"Predicates, then, are concepts other than verbs, which occur in propositions having only one term or subject."

For if two terms were allowed in subject-predicate propositions there would be mity in difference. Therefore, contraxy to the definition, it is not to be.

\section{Again :}

"When a man sccurs in a proposition (e.g. I met a man in the street) the proposition is not about the concept a man but about something quite different - some actual biped, denoted by the concept. Thus concepts of this kind have meaning in a non-psychological sense: And in this sense when we say, "This is a man' we are making a proposition in which a concept is in some sense attached to what is not a concept."

We are, that is to say, involved in what, on a theory of immutable and indestructible terms, is a contradiction, but is not a contradiction on any other theory.

But, after all, the analyst has some uneasiness about this most crucial question of the subject-predicate relation.

"If we were right in holding that 'Socrates is human' is a proposition having only one term, the is in this proposition cannot express a relation in the ordinary sense. In fact subject-predicate propositions are distinguished by just this nonrelational character."

You see the realist's implacable hostility to the subjectpredicate relation? Just because in it there lurks a secret danger to his Pluralism. Still, Mr. Russell is a most honest and honourable logician, and he owns very handsomely that 
"nevertheless, a relation between Socrates and humanity is certainly implied, and it is very difficult to conceive the proposition as expressing no relation at all. We may perhaps say that it is a relation, although it is distinguished from other relations in that it does not permit itself to be regarded as an assertion concerning either of its terms indifferently, but only as an assertion concerning the referent."

That is to say, "humanity" is not exemplified in Socrates, otherwise it would be implicated as a term.

"But it is so hard to know what is meant by relation, that the whole question is in danger of becoming purely verbal." (Principia Mathematica, p. 49.)

Hard, indeed, if you are a pluralistic realist bent on eliminating unity at all costs.

One mole admission of the analyst, $\grave{a}$ propos, this time, of organic unities, the existence of which he strenuously denies.

"It is said that analysis is falsification, that the complex is not equivalent to the sum of its constituents and is changed when it is analysed into these. In this doctrine ... there is a measure of truth when what is to be analysed is a unity. A proposition has a certain indefinable unity, in virtue of which it is an assertion; and this is so completely lost by analysis that no enunciation of constituents will restore it, even though itself be mentioned as a constituent. There is, it must be confessed, a grave logical difficulty in this fact, for it is difficult not to believe that a whole must be constituted by its constituents."

He comforts himself with the reflection that

"for us, however, it is sufficient to observe that all unities are propositions or propositional functions, and that, consequently, nothing that exists is a unity." (Ibid. p. 467.)

It is, the monist may observe, not sufficient for him; and he would point ont that the consequence is not so rigorous as Mr. Russell seems to think.

Also, I think he would suggest that the whole question of 
how Knowledge is possible hangs on this admitted unity of the proposition and propositional function. How does the amazing multiplicity of the real outside universe get itself expressed in propositions or in propositional functions, if, in that universe, there is no unity to correspond? If the pluralist is allowed to assume that every logical atom discoverable by his atomistic logic tallies with or constitutes an atom there, why may not the monist just as well assume his logical unity to be there also?

And to the whole atomistic critique he might reply: All this is mere analysis; and you yourself admit that "analysis of a whole is in some measure falsification." Is it likely, then, that, after the damage you have inflicted on my universe, I shall not hold you tight to that admission and to all that it implies? If the parts of the whole are really its parts, if they are, as you admit, presupposed in it, "in a sense" in which it is not presupposed in them for I grant you that "in a sense" the whole is a "new" thing, though not that it is ever a new "single term," except provisionally, as part or as one of many aggregates in a larger whole - then the relation of the whole to its parts will still be more intimate, more vital, than anything that analysis can show; and it is precisely this intimacy and vitality that analysis destroys. And surely it is this intimacy and vitality that logic itself discerns and acknowledges when it is driven to the conclusion that, in the last analysis, the analysis of collections, when the whole is only completely specified by its parts, the relation is peculiar and undefinable? So peculiar and undefinable that, when the precious collection consists of but a single term, we are still compelled to think of that term as contained in a whole. Does it not look as if the whole were as necessary to the part as the parts are to the whole?

As for your arguments drawn from multiple relations, from propositions containing many more terms than two, and from many subjects with one predicate and many 
predicates with one subject, I do not see that they necessarily make more for your ultimate Pluralism than for my ultimate Monism. I am not obliged to look for my unity anywhere short of the Absolute. Therefore it really does not matter to me how many terms a proposition contains, nor how you distribute and arrange the relations of subject and predicate.

Analytic Logic, then, has not entirely smashed up even his system of abstract Thought-relations. But supposing that it had, the monist's only legitimate concern is not abstract relativity but concrete relatedness, the bare fact that the universe is contextual, that all things in it, that is to say, all things within the range of immediate perception and of logical induction and deduction, are in some way connected, interdependent and related. His claim that each is related to the Absolute in one way, the way of the appearance to the reality, is a just claim. The further claim that they should all be related to each other in one way is the suicidal mania of Monism. It is to ignore their place in the relation. It is to tear them from the context in which they appear and are known, in which we are obliged to perceive them and to think them; it is to isolate them and thus turn them into abstractions which at once become the prey of Analytic Logic.

For every abstraction set up within the sphere of the related is a little tin-pot absolute.

The monist is even worse off with his claim that every lesser whole should have the clear, illuminating, penetrating, truthful quality of the Whole. For this is to create a series of little tin-can wholes, which are none the less isolated, and none the less abstract for being set up inside the relation.

Nevertheless, since two can play at this game, it is with a plurality of such little tin-pot absolutes and such little tin-can wholes that the New Realism builds up its uni- 
verse. Or, to be strictly correct, it is such a universe of little tin-can wholes and little tin-pot absolutes that it claims to have discovered.

Now, there is no reason why the monist (when he is not a Subjective Idealist) should not take a hand in this game of discovery, too. There is, in fact, every reason why he should claim to have discovered, for his part, a universe where nothing is isolated, nothing is absolute, and where nothing is contingent and conditional that is not related in some way to something other than itself. He would do well to accept and acknowledge the frank plurality of such a universe, instead of patching up little unities and wholenesses inside it where unity and wholeness are not, and creating little infinite regressions and supererogatory dilemmas for himself as he goes along.

Then, in the face of the infinite regression - the endless chain of contingencies - that he finds and does not create, he has every rcason to plead that in such a universe there is no moment of self-subsistence; that it escapes, from moment to moment, the diamond-net of Thought; that terms should be every bit as dependent on relations as relations are on terms; and that this relativity is proved rather than disproved by the pluralist's ability to play ducks and drakes with subjects and predicates. He will maintain that "this is a purely spectacular universe," in the sense that it has every appearance of being an appearance rather than a spontaneous and automatic reality; that, in short, its relativity cries aloud for the Absolute and its multiplicity for unity. He will define his rich and concrete Absolute as that which is not related to anything other than itself.

Such an Absolute can only not "enter into relations" because it is all relations and all terms, and is more than the sum of all terms and all relations. Only such a Whole is absolute, and only such an Absolute is the whole.

Thought is perhaps the thinnest and the poorest pred- 
icate of this Ding-an-sich. It is quite clear that such an Absolute escapes the net of thought by so much as it is more than thought.

Realists, will, of course, deride the suggestion that it escapes the net of Analytic Logic by so much. For, in one sense, it does not escape. Logic can dislocate and lay out in fragments the whole world of its appearances; and I confess I do not see how the monist is to stick it together again with thought-relations, or to round it up into one whole of Thought. He cannot conjure the universe out of such feeble propositions as that Thought is unity and Unity is thought, or that Absolute Spirit is Thought because Thought thinks it. For on the same showing a pluralistic universe would be a universe of thought. The monist's only chance is to abandon his Epistemology ; even if the alternative has to bear the dreadful and dishonoured name of Spiritualism. 
But even with the complete abandonment of Epistemology, the monist's position is untenable if the New Realism can make good its claim at all the other points along its admirably defended line. If, that is to say, it can prove its own hypothesis of the independent, self-subsistent reality of the world as external to any and every form of consciousness. For that hypothesis, if made good, rules out his as, to say the least of it, superfluous.

Why look behind the veil of appearances for ultimate reality when there isn't any veil, when realities as ultimate as you are ever likely to get are spread out under your nose, and absolute being is planted out all round you in embarrassing quantities?

But are the foundations of Atomistic Realism, after all, so very sure?

It is just possible it may prove, after all, more vulnerable than it looks. For, to begin with, it gains an immense advantage from the fact that, in spite of the influence of Mr. Bertrand Russell, it is not a one-man philosophy as Hegelianism and Kantianism were one-man philosophies. It is difficult to bring criticism to bear on a theory that is not yet built up into a system. You know where you are in the Critique of Pure Reason by merely looking at the headings of the Parts and Sections. You can find your way from Kant's basement, through all his floors, to his Transcendental attic by a process as simple as going upstairs. But the New Realists, though no doubt they all have the same architectural plan in their heads, are not yet housed under one roof. The American "Symposium of Six" suggests a colony of Young Men's 212 
Christian Association Huts rather than a solidly built and many-storied house of thought. The stain is not yet dry on their walls, and the corrugated iron is very new. So far, not even the mathematical philosophy of Mr. Bertrand Russell is completely systematized. The timid monist, wandering among their scattered habitations, never knows what disaster may lurk for him behind some door or window. The critic of the New Realism has to arrange it according to his own plan, and it is open to any new realist to complain that his arrangement is wrong.

But at any rate it falls into two main divisions: its Critique and its Construction.

It must be owned that its critique has accomplished something, if not quite all that it set out to do. It has completely shattered Subjective Idealism or Solipsism. Not a very difficult or a much-needed enterprise; and its particular success would be hardly worth mentioning but for our new realists' very evident and very naiff belief that certain arguments fatal to Subjective Idealism are equally destructive to idealisms that are not subjective.

It has destroyed a great deal of the abstract Epistemology that superseded Hegelianism, and it is hardly likely that there will ever be any return of Idealism in precisely that form. It may even be conceded that in all probability there will be no return of Idealism at all for another generation, unless the excesses of the realists produce a violent reaction. It has, in short, swept away so much old rubbish that any future Idealism must reap the benefit of the space cleared for it.

Its constructive half lends itself to five subdivisions: The Organon, or Atomistic Logic; the Mathematical Foundations; the Theory of Space and Time, Matter and Motion; the Theory of Universals; the Theory of SensePerception.

For reasons which will appear I shall consider these in their reverse order. I do not think this is taking an unfair 
advantage of a philosophy which has not yet got itself systematized; since the new realists have declared their position to be impregnable at all points. In justice to them, however, it should be remembered that their theory of sense-perception rests on the mathematical foundations, which, again, rest on their Atomistic Logic. Hence the impregnability.

It must be borne in mind that Atomistic Logic, the bedrock of the entire philosophy, is purely formal.

Now, since the mathematical foundations are pure, and sense-perception admittedly is not, is it impertinent to ask how the one can be based upon the other? Mind is not more different from "matter" than mathematical points are from a point perceived in an extended surface, let alone that they are not and cannot be perceived at all. Neither are they the causes of sense-perception. If anything is a "cause" in the external world it is the behaviour of the ultimate constituents of matter in "public" space. And it is difficult to see how mathematical space in its purity and absoluteness can be in any sense a condition of the behaviour of matter. Further, on the theory, there has to be, in any case, an adjustment of "private" spaces to "public" space. Surely this is pretty active and constructive work on the part of a perceiver who, on the theory, is supposed to be a passive spectator of ready-made realities outside himself?

Again, if all atomistic realities, even when they are relations, are such very absolute, and, ontologically speaking, self-repellent entities, it is difficult to conceive how they come together in one undivided act of perception.

The realist will, no doubt, say that they come together becanse they are together, and that they are never " in" perception at all; so let us put the problem in another form: How are they in their absoluteness and plurality related to that single and undivided act? When, on the theory, the relation of these relations is itself an outside entity? 
In vain the realist decentralizes the entire performance. $\mathrm{He}$ has got his problem at the periphery instead of at the centre, that is all.

We know that his is not " naif realism," like the realism of the bonhomme Reid. It is, indeed, realism of the most highly sophisticated sort. But all its sophistications do not disguise the essential naïveté and difficulty of its problem. Things aren't as easy as all that. The New Realism leaves that problem precisely where the old Realism left it, for Idealism to solve as best it can.

Let it not be supposed that my monist is a "naiff" idealist: he does distinguish between subjective hallucinations and objective phenomena; or, if the realist likes, between subjective and objective realities. But this distinction is, for the moment, beside the point. We are dealing now with objective realities - to give them their courtesy title - with independent, outside things; with the carpet which exists in the room, and the room which exists in space, whether I (or my neighbour for that matter) are or are not in the room beholding these existences. The new realist is mistaken if he imagines that any idealist, who is not also a solipsist, supposes for one moment that these appearances cease by his absence and are revived again by his presence. What he does suppose is that, if all sense-perceptions changed or ceased, all sensible qualities would change or cease also, and that if $h$ is ultimate and absolute Reality, which he calls absolute Conscionsness or Thought or Spirit, were to cease, the whole universe of its appearances would cease with it. But as, on his theory, he cannot conceive of it as ceasing, the question has no more significance for him than for the realist. That is to say, on his theory, the universe will not and cannot abate one pulse of the energies, one atom, or one shade of the qualities that for the realist constitute its claim to be considered real, until it or any one of its essential constituents are annihilated. Idealism does no violence to the 
dignity and decency of science, or to the plain man's sense of reality. It leaves all these matters precisely where they were.

But what does Realism do?

It divides what for science and the plain man's sense were never yet divided. It joins what for them were never yet joined. It talks about irreducibles and undefinables where science and the plain man see palpable unities and relations. It gives to the abstractions of its own logic a reality as august and far more permanent than the solar system. It perpetuates the old fallacy of arguing that what is outside a human body is outside all consciousness, and that what is inside human consciousness is therefore inside the human brain. It swears by Psycho-physical Parallelism; yet it regards consciousness as a mysterious and unnecessary spectator of external events, a spectator who only departs from the purely passive rôle to manufacture "tertiary" psychic qualities which have no physical parallel.

Still, let us suppose that it gets its backing from the higher mathematics and that it is irrefutably true.

Philosophy is then in an even worse position than it was before Kant; faced with a universe of realities of which an infinite number are harder and more irreducible than brickbats, utterly different from and independent of consciousness; a universe which has contrived to exist by itself for infinite ages without being known, and superlatively indifferent as to whether it ever is known or not; which, at some moment of finite time, is suddenly confronted with an infinite crowd of finite knowers, utterly unnecessary to its existence, utterly mysterious in their origin, yet demanding an origin by reason of their finiteness.

The fact of Knowledge becomes once more the intractable problem of philosophy, with no hope of tackling it, as Kant tried to tackle it, at the knowing end. It is as if 
Kant had been shut up with Wolf in Wolf's library, and had gone to sleep there with nobody to wake him from his dogmatic slumber. When the new realist in his realism says that Kant's slumber's, if everlastingly prolonged, would have been no misfortune for the human race, since Idealism has had no effect on physical or mental science, he is confusing physical and mental science with philosophy. It may be doubted whether the Realism of the twentieth century is going to have any effect on physical and mental science either, seeing that these have hitherto managed to get on very well without it; whereas Realism owes much of its alleged security to the support it professes to receive from physics and applied mathematics.

But, before considering its security, we must look closer at its treatment of the problem of immediate perception.

It is no longer Berkeley's question of how realities, hard as brickbats, contrive to penetrate from an outside world into an inside consciousness which is tenuous and tender; since on the theory they do not penetrate into consciousness at all.

Nor is it Kant's question of how synthetic judgments are à priori possible, since it is not for judgment to make any synthesis at all, but only to look on and constater. So far as there is any synthesis at all, the synthesis is performed with efficiency by realities themselves.

Now, unless we remember that this theory has a high mathematical backing, this part of it looks almost too simple and easy to be true. And we must admit that there is something fascinating and even plausible in its simplicity and easiness. It also looks (stated thus without reference to the higher mathematics) as if it were a question-begging theory. Still, it would be unfair to press that point, as idealists may claim an equal right to isolate a theory for observation.

But the realist is dodging the issue when he argues that the existence of hallucinations - of red carpets in con- 
sciousness that are not in the room - is no objection to his theory. It is an objection, as we shall see, and a fairly formidable objection, but it is not the crucial one. Hallucinations, on any theory, may be supposed to arise from a flaw or a kink in the apparatus of perception; from something, that is to say, abnormal. But the true crux is the normal and permanent memory image, the faithful reproduction of the spectacle that arises as the spectator's subjective response to the stimulus of those nerve and brain cells that were associated so mysteriously with his uninterrupted view of the original performance. The realist cannot say that this repetition of the spectacle is taking place in public space, nor in that private space which is adjustable to public space. ${ }^{39}$ Red carpets are in his consciousness now, at any rate; that is to say, they are subjective in the sense that his memories are not my memories or anybody else's memories. But, though subjective, they are spatial, they are extended, and they are red. To be spatial, then, to be extended, to be red, are not hallmarks attaching to things that exist only outside consciousness. They are, after all, properties also of things that arise in consciousness.

I think the new realist can hardly argue that memories arise anywhere else. But if he does, he will get an infinite regressus of outside simulacra and no genuine memory at all. Genuine memory should, one would imagine, be saturated with subjectivity, and in the experience of most of us genuine memory is. I do not ask him how he distinguishes between the memory of the spectacle and the spectacle itself; he distinguishes precisely as the idealist distinguishes, by the difference of the complexes in which each occur; for one thing, he distinguishes by the very saturation which he ignores as being of the essence of memory. But I do ask him how he reconciles the fact of their common share in all so-called primary and secondary qualities with his theory that these qualities only 
exist independently of consciousness and outside it.

This objection cannot be met by simply saying that the original sense-data, their images in memory, and what he may call dream-spectacles and hallucinations, are all equally realities, but of different orders. It is their likeness and not their unlikeness that is the problem.

Hallucinations are important. In psychology, over and over again, abnormal occurrences have been our guides to the laws and the significance of normal behaviour. Hallucinations, the new realist says, can be referred entirely to some kink or flaw in the apparatus of perception. The apparatus of perception can then produce of its own initiative a very tolerable imitation of reality; a power which it really ought not to have if the realist's account of perception is the true one. Still, dream-consciousness can do as much or more; and in neither case is perception of a real outside object involved.

But take hallucinations of the lesser sort, the temporary distortions and duplications of perception which we are all familiar with - perception, mind you, of a real outside object. These also are due to some kink or maladjustment of the apparatus - easily corrected, the new realist says, by readjustment or by reference to the real object. The error is in the false judgment of the perceiver. No doubt; but the possibility of correction is really not the point. The point is that the apparatus is important. We have here not the simple affair of spectator and spectacle that Realism supposes. There is a go-between, a medium. And the medium can distort; it can duplicate.

We would not be aware that there was a medium if it were not for its occasional aberrations. And its abnormal behaviour is the clue to its normal functions.

The medium, then, distorts or duplicates - what? The realist says, Not the real object. An image of the object? Realism has no use for images in immediate perception; it has ruled them sternly out. The appearance of the object, 
then? Realism says that in perception the appearance is the reality. Agree that it is the apparatus, the medium itself, that is duplicated or distorted, and we are where we were before. Perception is still as much the thrall of its apparatus as of its object. If its duplicate - for the experiments or accidents which yield duplicates amount to its duplication, and I am giving Realism the benefit of any doubt there may be on this point - if the duplication of the medium can make one perceiver perceive two objects; and if its distortion can make him perceive the real object as if it were distorted; if its correct adjustment is essential to his correct perception of the object, it is clear that his perception of objects, correct or incorrect, is not precisely what you might call immediate. How can he then be sure - as cock-sure as the realist is - that he is perceiving a reality and not an appearance?

And when we consider the pure sense-data, those secondary qualities which Realism declares to be, not warm, intimate sensations, but objects of sensation, planted out, and no more at home in conscionsness than the north pole is, the old problems turn up again as persistently as if the New Realism had never arisen to solve them.

For if, disregarding the apparatus of perception, we take the New Realism's primary, secondary, and tertiary qualities as simply as it would have us take them, we shall not find the tertiary qualities, which it admits to be subjective, divided off from the secondary or objective ones as sharply as we should expect on a theory which distinguishes between realities dependent on consciousness and realities not so dependent.

On the contrary, starting with the tertiary qualities and working outwards from the subjective centre, we pass through a reaction zone of tertiary qualities merging into secondary, in a gradation of shades so subtle as to defy the arbitrary division that Realism has set up. The aesthetic feclings, wonder, admiration and awe, the passions 
and emotions, love, desire, fear, pleasure and displeasure, and disgust are not qualities that Realism would dream of planting out in the objects that excite them; and it requires some stretch of imagination on Idealism's part to realize sound and colour, hardness and heaviness as sensedata rather than as sensations. And it requires a bigger stretch still to plant out tastes and odours in the particles of matter that excite them.

But what about heat and cold? Supposing the idealist agrees that it is the fire that is hot and the air that is cold, and not the idealist. Then, when by imperceptible gradations the fire grows hotter and hotter, and the air colder and colder, and pain is his reaction to the higher intensities of the same stimulus, is he to plant out the pain into the fire and the air? I suppose the realist will say he need plant it out no farther than his own body; but eren that is too far for the intimately subjective thing that pain seems to be. Besides, you have now left it unsettled whether the heat is in the fire or in his body. If the new realist says that, obviously, it is in both, then how about the pain?

How are you to distinguish as secondary and tertiary between the heat that is outside consciousness, and independent of it, and the pain which is in consciousness, which without consciousness would not and could not be?

And you can take all the secondary qualities and increase their intensity with the same result. Intense light and sound, taste and odour will bring about violent reactions, your objective secondary sensations merging into subjective tertiary agony.

What is more, your sensation of primary qualities will behave in the same way. Increase the heaviness of your suit-case, or the impetus of your contact with the table, and heaviness and hardness will pass into sensations that are not sense-data at all as the realist defines them. The problem is not affected by the consideration that in all 
these instances (notably in that of the suit-case and colliding table) your body is the medium of the reaction. Realism cannot get over the damning fact that somehow, at some point, the transition from primary or secondary, to tertiary, from outside consciousness to inside consciousness, has been made.

Realism allows for the transition from secondary to primary qualities by its theory that extension is coloured and can be perceived as a sense-datum. What it refuses to admit, and cannot account for, on any theory (either of Psycho-physical Parallelism or of reality independent of consciousness), is that all these unbroken transitions taken together constitute a very considerable haul for consciousness; while the performance is fairly explicable if we suppose that consciousness takes over the whole show.

We must now consider the realist's doctrine of universals, when it will be evident that there was good reason for taking his theory of sense-perception first. From their place in the logical programme of Realism it might be supposed that the theory of sense-perception followed from the doctrine of universals, as the doctrine of universals followed from the atomistic logic. But the consequences are the other way about. (Thus in the chapter on "The World of Universals" in Mr. Bertrand Russell's Problems of Philosophy, you find the theory of sense-perception relied on to support the theory of the independent existence of a relation which is a universal.)

It is true that Realism finds its universals and does not create them. It is also true that if its universals did not exist it would have had to invent them. Without them its theory of sense-perception will not hang together for a moment. For, assume a consciousness that brings no bridges with it, whose sole business is to find and to constater, there can be no logical passage from one atom of reality to another. Perception of outside reals cries aloud 
for conception of outside reals in order to make both memory associations and judgments possible. So the one is used to bolster up the other.

To constater is impossible without concepts. And concepts must be universals in order to ensure that the reality perceived at this moment and in this space is the same reality which was perceived the moment before, or at any period of time before, or in another space, supposing it to have changed its position.

The universal, therefore, must be out of time and out of space. It is that which has the same meaning in all contexts in which it occurs.

Universals thus serve as standards or tests of the identity of reals; they are Plato's "patterns laid up in heaven."

Now I think Idealism ought to acknowledge that it has no grounds for quarrelling with the New Realism here. It ought rather to be grateful to it for restoring universals to their ancient place of freedom and purity and splendour. There is something about a universal that has always provoked the derision of the playful empiricist. Bishop Berkeley thought there was something downright funny about a triangle that was neither oblique nor rectangle nor equilateral nor equicrural nor scalenon, but " all and none of these at once."

But it remained for M. Anatole France to extract the full delicious flavour of its humour. According to the fallen angel Nectaire in his Discours sur l'histoire universelle de Bossuet, there were only two Schools of Schoolmen: “L'un des camps soutenait qu'arant qu'il y eut des pommes il y avait la Pomme. qu'avant qu'il y eut des papegais, il y avait le Papegai ; qu'avant qu'il y eut des moines paillards et gourmands il y avait le Moine, la Paillardise et la Gourmandise; qu'arant qu'il y eut des pieds et des culs en ce monde, le Coup de pied au cul residait de toute éternité dans le sein de Dieu. L'autre 
camp repondit que, au contraire . . le coup de pied au cul n'exista qu'après avoir été dument donné et recu" ("Révolte des Anges").

Now the New Realism certainly saves its universals from this ridiculous predicament. There can be no question of a kick in the ribs dwelling to all eternity in the bosom of the Absolute; because, for the new realist, there is no Absolute and no bosom. The universal kick in the ribs is itself an absolute; and of its dwelling nothing can be said but that it is not in consciousness, and not in space or time. And of universals out of their context nothing can be said but that they are realities.

But observe that the peculiar outsideness of their reality, their independence on conscionsness, hangs even more on the realist's theory of perception than his theory of perception hangs on it. Concepts, that is to say, have been brought into line with percepts. Like percepts, they are realities over against consciousness. On the theory, conscionsness is simply confronted with them, and in their presence it ought to be able to do nothing but stare at them and constater. And each constatation is a recognition.

So that, in order to constater, it has need of another universal, confronted with which it can do no more than recognize and constater; and so on, in as beautiful an infinite regress as ever delighted the heart of Mr. Bradley.

There is only one way in which to arrest that infinite regress at the start, and make the universals do the logical work required of them; and that is, not to drag them down from their high place in heaven, but to recognize that their heaven, the eternal Kingdom of these blessed ones, is within; that they are, as Idealism should have always held them to be, the work of Thought. They are none the less august, and none the less real, on that account. It is Thought that is exalted, and not they that are abased.

The New Realism has revived a Realism very old, older than Scholasticism. It will have none of Aristotle's de- 
velopment of the Platonic philosophy. It refuses to admit

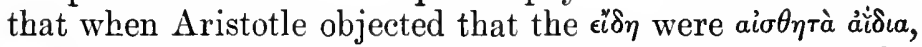
eternalized sense-data, he was playing Plato's game for him. It will not see that when he said Ideas are not idle, they have hands and feet, he was again playing Plato's game and playing it better, getting a "move on" to the Ideas, so as to make them do the twofold work required of them, the work of logic and reality.

And consider what happened later. After Scholastic Realism, Nominalism, the inevitable reaction; after Nominalism, Conceptualism, the forerunner of modern Idealism. It is just possible that history may repeat itself, and that after the New Realism of the twentieth century

But $I$ am reminded that our Realism is in a very different case. It is so securely based on a mathematical discovery unknown to Aristotle, unknown to the Scholastics, unknown to the Idealists of the eighteenth and nineteenth centuries, that it defies avenging time. It follows (or should follow) in one unbroken logical sequence from Cantor's discovery of the behaviour of the Infinite, through the desired proof of the continuity of space and time, resolving their antinomies. It is thus linked up with the physical sciences. It has continued to do what Vitalism vainly attempted, "faire tomber l'insurmontable barrière" and "rejoindre la science."

"Rejoindre la science!" To join hands with Science, physical science that has always looked askance at it, that will have none of its "thinness" - that (between its Idealisms) has always been Philosophy's passion and its dream; the passion and the dream which have produced Materialism and Agnosticism, Psycho-physical Parallelism, and all the naif empiricisms and realisms.

You would suppose, then, that the space and time it receives from the mathematician, purged of all the contra- 
dictions and dilemmas of discreteness, would have something in common with the space in which extension occurs and the time in which things happen. For the truth of Realism hangs, in the last resort, on the mathematical solution of the contradictions and dilemmas of space and time. Realists are never tired of reminding us that we have now got a continuous space and time to work with, and that idealists cannot any longer insist on the impossibility of the passage from point to point and from instant to instant; for, as we have seen, in infinite space there are no next points, and in infinite time there are no next instants, and consequently no gaps.

From an infinite series any number of members can be taken and to an infinite series any number can be added without either diminishing or increasing it.

Does it not follow, then, that a finite series is not, in any sense, part of an infinite series?

This is a question for mathematicians, and for all I know it may be either so obvious or so irrelevant that no mathematician would dream of asking it. Therefore I suggest it with the utmost difficlence and some misgiving. It does seem to me to follow, not only from Cantor's law, but from the definition of part and whole, combined with the axiom, that there are no infinite wholes; from the impossibility of arguing from finite to infinite; from the realist's assumption of the absoluteness of space and time, and the plurality of absolute spaces and of times; and from the atomistic theory of the intransigeant and mutually repellent character of absolute entities.

And if it follows, the bearings on our problem would be very relevant indced. For, consider. Pure space and pure time are continuous, in the sense that between any two points and any two instants there is an infinite number of points and of instants; nor is there any other sense in which they could be continuous. So that, in an infinite series there are no two consecutive points or instants. 
Now "between any two points" is surely just as much a relation of finites as is the relation of two consecutive points; and as such it has no business in an infinite series; so that you cannot speak of an infinite number occurring between any two points. And from this it would seem to follow that an infinite series is not a series at all, and that there can be no infinite order of any sort. Yet, though a point has no magnitude, it has, or should have, position. But how can it have position in a series (or any other order) that isn't a series (or any other order); where, that is to say, there are no positions that do not presuppose the space they are said to constitute?

So that we are back again in the dilemma of the infinite regress. If you say that the point that has position is the Euclidean point, and that the points in question do not have positions, but that they are positions, I do not see that that helps you ont of the difficulty. For if points cannot have positions where there are no positions to have, neither can they be positions where positions cannot be. The contradiction is simply shifted from the discrete or consecutive continuity to the pointless point or positionless position.

Again, a point, on any definition, has no magnitude; therefore it is indivisible; therefore "between any two points," or any two instants, will mean between any two indivisibles. And between any two indivisibles there must be some hiatus which, perhaps, we cannot call spatial or temporal, since space and time are continuous, but which must surely be held to exist; so that in space composed of an infinite number of points there must be an infinite number of non-spatial gaps. And the same will hold good of time. And if this isn't discreteness, I do not know what is. It is also, by the axiom, continuity.

It must be so, if these points and these instants are neither to overlap or coalesce, or otherwise behave like magnitudes. 
And, again, any two indivisibles thus separated will be finite.

So that in the Infinite two fine and flourishing contradictions have broken out, making six in all: (1) the contradiction of the infinite regress; (2) the contradiction of the non-serial series ; (3) the contradiction of the positionless position; (4) the contradiction of the non-spatial spaces and non-temporal times (already considered); (5) the contradiction of discrete continuity; and (6) the contradiction of the finite infinite; contradictions which are only to be avoided by dilemmas.

Lastly, on this system, perception of the world of $\mathrm{Be}$ coming is an act of reporting, divisible into an infinite series of reports, corresponding to the infinite series of moments constituting the process of change. Each atom in the moving show of Becoming, is an absolute entity, reported as such. It follows there can be no justifiable anticipatiou of events; no reason why, of the connections and sequences reported, one should obtain rather than another.

I have not seen any refutation of Mr. Bertrand Russell's mathematical metaphysies, and I can only dimly imagine the lines it would be likely to take. But I think my idealistic monist, with liis back against the wall, might put up some such defence as this.

If my monist is right, he is better furnished with dilemmas now than ever he was under his own ontological scheme. For if motion was a contradiction on the old theory of the infinitely discrete, rest is a contradiction on the new theory of the continuous infinite. For with this sort of continuity you can indeed go on; but you can never, never stop.

Positionless position affords no rest for either Achilles or the tortoise.

And with discrete continuity there can be neither motion nor rest. What could an idealistic monist wish for more? 
And when it comes to finite space his hope does not fail him. What about the mile-long line that contains no more points than the inch-long line? The thousandth part of the inch-long line that contains no fewer points than a thousand mile-long line? Both, indeed, containing an infinite number. It looks as if the finite contained infinity.

But no - that would be too good to be true. The monist does not really want that seventh contradiction. His cup is already fairly running over.

Now it may be said that, even supposing these contradictions and dilemmas were genuine and not solvable by Cantor's law, non-mathematical monists have no right to assume that they cannot be solved by mathematics in some way, probably by calculations involving the fourth dimen. sion. But, as the new mathematical logic does not stop at four, but provides an infinite number of dimensions, the monist may not unreasonably hope to reap a second crop of contradictions and dilemmas from these. For the series of the dimensions is apparently obtained by every term in the series of one dimension itself giving birth to a series, every term of which again gives birth to another series, and so on for ever and ever, a new dimension being generated with each series. But the whole process of generation has its rise in the series of one dimension, in which my monist was supposed to find his six fine contradictions; each series therefore will bear within it some taint of the original infection. And, in any case, if no finite number of points is any part of an infinite series of points, mathematical logic itself apparently gives him the right to stick to it that no finite number of dimensions (as might be three), can be any part of an infinite series or order or arrangement or collection of dimensions. So that three-dimensional space will be no part of infinitely dimensional space. Thus, from the very start, he can catch sight of his contradictions of the non-serial series, the non-ordered order, the 
non-collective collection, with the dilemma of the finite infinite; and, on the far horizon of dilemmas, on all fours with his positionless positions, the non-dimensional dimension.

But suppose my monist does not reap his second crop of contradictions, or his first crop either. Suppose he really has no business to insist that "between any two points" in any series is a relation of finites. Suppose there are grave mathematical reasons (as for all I know there very well may be) why "between any two points" in an infinite series is to be held, contrary to all apparent reason, as a relation of infinites, without begging the question of the series and its infinity. Suppose there is no mathematical sense in which the discreteness he discovers is to be thought of, and that his harvest fails in consequence. Is he therefore obliged to abjure his Monism and his Idealism? Remember the unique raison d'etre of his strange passion for contradictions and dilemmas. He does not wallow in contradiction for contradiction's sake, out of sheer perversity. He desires that the contradiction may be solved. Therefore he flies to his Infinite and Absolute.

In spite of Hegel and Mr. Bradley, he must have wondered how in the world it was going to perform its conjuring trick. Well, if the higher mathematics really do all that they are said to do, they will have shown him how.

\section{"Das Unbeschreibliche, \\ Hier ist's gethan."}

They may pile universe on universe and multiply infinities by infinity (on their own showing an impossible operation). He will hold to his Monism, maintaining, as I think he has every right to maintain, that these purely mathematical operations have every mark and sign of ideality, of being "the work of Thought," of some sort 
of a God who "geometrizes eternally." If the constructions are infinite in number, from the sheer monotony of the mathematical obsession, he gathers that their constructor, their builder and maker is one. When pragmatists have twitted him with the thinness and poorness of his ultimate principle he may have wondered how thought could be infinite and absolute. Now it has been proved to him that it is so. If challenged to show how the foundations of a material universe can be immaterial, he has only to refer his opponent to Mr. Bertrand Russell's Principia Mathematica.

Above all, he profits by the realist's happy thought of rehabilitating universals.

For these primordial entities, whose serious and indubitable reality mathematical logic compels him to believe in, on whose reality the material universe depends, are immaterial. He has only got to fetch them "in" from "outside" to prove that the unseen reality of every mortal and material thing is immaterial and immortal, having its habitation ont of space, out of time. Not out of thought; for its presence there is the ground of all thinking, the reason why things are recognized and known. Really, universals are a priceless haul for the idealist. For they justify his distinction between appearance and reality.

(If realists will revive Plato, they must abide by the consequences of his resurrection.)

And when you have said that they are spaceless and timeless, formless and immaterial, they remain delightfully undefined and undefinable. The least that can bo said of them is that they are immaterial. The most that can be said of them is that they endure.

For the New Realism, after criticising Aristotle so severely for his handling of Plato, condescends to adopt his emendation of the doctrine of the Ideas. It very properly refuses to see in them eternalized duplicates, patterns 
of the things of sense, or any common "property" shared by things. Every thing, every quality and relation has its own universal; and there are universals of unique and solitary things, when, clearly, there can be none to share. For the New Realism white things do not partake of whiteness; the relation is not and cannot be that of whole and part, nor yet of possession as Plato maintained. Whiteness is not white. It is not the whiteness of white things: it is the whiteness, the universal $\epsilon$ 'ios of the whites. Now Realism does well in thus improving on the Platonic doctrine of ideas. You might suppose, from the important distinction that it makes, that it regards the relation as something incomparably more subtle, more intimate, and more strong.

But, as a matter of fact, it docs nothing of the kind. It makes the distinction, not that it may establish intimate relations which would argue a secret unity, but that it may put asunder the reality of whiteness from the reality of white, and bring pluralistic atomism into the world of the universals.

I think that in this it has defeated the ends of logic, which are, after all, its own ends. Its failure is the monist's opportunity.

The conception of that sacred communion in which aio $\theta \eta \dot{a}$ partook of $\epsilon^{\prime} \delta \bar{\partial} \eta$ was Plato's solution of the everlasting problem; it was an attempt to escape from his own Dualism, the logical consequences of which he saw clearly. The New Realism, in resuscitating Plato, makes everything of his Dualism and nothing of his escape. Its interpretation of Plato is peculiar. It takes from Plato what suits its Pluralism, and everything that will not fit into the programme it dismisses as a poet's fancy or the agreeable jest of a literary diner-out. Surely Plato's desperate attempt to round up all the ideas in the one supreme Idea of the Good might have served as a reminder 
that it is easier to interpret him than to appreciate his drift?

And Atomistic Logic has prepared the ground for the first idealist who comes along and resuscitates the Absolute. Its really great discovery - that there is necessarily a universal of unique and solitary cases - turns against Atomism from the moment that the idealist lays his hands on it and converts it to his own use.

For by no logic can you get over the fact that things in this universe of ours have relations and that relations relate. If particulars are related, so are universals. Their atoms cannot be kept apart. They gather together to form logical molecules, which form bodies, which form worlds, which form the universe of thought. Because thought can analyse this universe into atoms again, it does not follow that its universe is not one. The fact that your logical atoms are free to enter many combinations is no disproof of their ideal or spiritual unity. You may be pleased to ignore the incurable tendency of atoms to form a universe; but you do not destroy unity by calling it a collection; though apparently you thus make Atomistic Logic an easier game to play.

But only apparently. For when you insist, as Realism insists, on taking the spectacular view of universals by divorcing their reality from the reality of thought, you have made it impossible to use them in your thinking with any spectacular effect. And when you do use them, it is as logical counters which have every appearance of being inside conventions rather than outside realities.

And it will not only be their absoluteness and separateness that lands you in this impossibility of thinking. You might, indeed, get over that difficulty by saying that you do not think, you only look on at a spectacular process of thinking; and there every idealist who is not a solipsist would agree with you. But what, in Heaven's name, are 
realities, defined as independent of any and every thought, of any and every consciousness, doing in a process of thinking which is nothing if not conscious? What sort of spectacle will universals treated as independent realities provide? Not only is whiteness not white, and a universal kick in the ribs not a kick in the ribs, but they have no content and no more conceivable relation (not even the relation of likeness) to white or to a kick in the ribs than they have to consciousness.

The New Realism has provided another contradiction for the idealist to rejoice in - the mnconceived and unconceivable concept.

And yet another. For there is a universal, both of every actual proposition and of every possible proposition. And the number of propositions is infinite. For there is a universal of everything that exists and has existed and will exist; and of everything that is and was and will be - from the infinite number of physical atoms to the infinite number of numbers and of mathematical points and instants; and about every one of these a true proposition may be made. And for every true proposition, made or unmade, there is a false proposition that denies its truth. Therefore there will be an infinite number of false propositions denying the existence or the being of these things. It is also an axiom that from even one false proposition an infinity of consequences will follow; and for every one of these consequences there is also a universal. Therefore, there will be an infinitely infinite number of universals standing for an infinitely infinite number of lies, all equally exalted to the high and holy estate of reality; all, in fact, horribly real, ineradically planted out, since (on the theory), as concepts, they are, whether any irrelevant person comes along to make the propositions or not; all much more assured of immortality than any person.

So that the realist's pluralistic universe is thick with the infinitely infinite numbers of the non-existent. Even 
allowing for the necessary distinction between being and existence, I do not see how reality can be claimed for these objects of conception if reality has any meaning. Yet real they are, since they endure in utter indifference as to whether there will ever be a conceiver to conceive them. The realist can't say: "Somebody's telling a lie." $\mathrm{He}$ can only say: "There's a lie. Somebody's looking at it." And the idealist may add to his collection of contradictions this infinity of unreal realities, which is worth all his other harvests put together.

Contradictions are fatal to the realist who prides himself on not having any. But, as we have seen, they are meat and drink to the idealist, who does not exalt them to the position of realities. He has no use for the things of sense eternalized; but he can take over the whole show of universals in a bunch, purified from all taint of the particular and the finite. He can treat them as the mysterious entities he needs to build up his universe. Like so many absolutes they are definable only by negation. They are not definable ontologically by their logical functions. They make known, but they themselves have no content by which they are known. They are not knowers, they are not in any sense selves. Yet through their logical function they serve as carriers of the invisible and impalpable secret of selfhood.

All this is exceedingly important for Idealistic Monism.

The monist must have had moments of awful insight when he realized that the relation of whole and part was not quite equal to the strain he was putting on it. He must have been aware that a contradiction and a dilemma here would wreck him. But he has not got to stand or fall by that incompctent relation now that Realism has restored universals to their ancient place and power. They have solved for him what must, if he had finished 
his thinking, have become a dilemma that would have finished him.

For, if he is honest, he must have asked himself how a logical function can at the same time be an objective reality. Now he knows.

From the relation of the whole and part it was not quite possible for him to prove that things to be known perfectly must be known as they are in the Absolute. But he has only got to read his three fat volumes of the Hegelian Logic again in the light of the Logic of Mr. Bertrand Russell to find his proof staring him in the face. To be sure, the Logic of Hegel has a thickness you could cut with a knife, and beside it the Logic of Mr. Russell has the consistency of fine dust or of a thin gruel. But no matter. He can make out for himself that universals are the absolute reality of things. They, if anything is, are things as they are in the Absolute. We do not know them. We only know their appearances; yet it is through them that the things we do know are known.

The idealist has now got most of the things he wanted. If his mathematics are right he has found seven contradictions in his opponent's theory, making nine in all. If they are wrong, he has got two fairly crucial ones. In any case, his appearance and his ultimate reality are as secure as they were before the new realists attacked them; he has got them tight. White is the appearance of whiteness, and whiteness is the ultimate reality of white. And he has got what he never could be quite sure of before their relation. And if he has not got all the unity in multiplicity he wanted he has enough to satisfy any reasonable monist. A universal is most undeniably one in many, and its appearances are undeniably many in one.

It is true that Analytic Logic rules out all hope of ascension to a highest universal, on pain of the contradiction of the One Subject-Predicate combination. It is true that there can be no rounding up of an infinite number of 
realities in one Ultimate Reality on the lines it lays down; and that ultimate reality is, for it, a contradiction in terms; or rather, every reality is immediate and ultimate.

This is where the ways of Pluralism and of Monism part.

But I think that it is here that the monist scores with his theory of universals and his theory of appearance and reality. For you can conceivably round up an infinite number of appearances in one Reality if your one reality is the one and only Absolute. And if, as he maintains, universals are not realities outside Absolute Spirit, but owe their reality to the very fact that they are in it, that they are spiritual, there need be no infinite number of them; that is to say, no infinite progress that removes his highest universal for ever from his grasp. His highest universal will be Spirituality.

He can now maintain without any contradiction that Spirit is all things, and that all things are Spirit. You cannot floor him with his own distinction between appearances and reality. There is appearance and there is reality. But if the spiritual universal truly is the reality of appearances; if there is no other reality but Spirit, the appearances cannot assert an independent unspiritual reality of their own over against that universal. Appearances and reality are not mutually exclusive opposites. They are correlatives; and the distinction between them falls inside the "spirituality" that includes them both; so that there will be no contradiction in the statement that Reality is its own appearance, and that appearances are reality. But the realist who denies the unity must, also deny the distinction, since he maintains that Reality appears as it is. Whereas the monist not only does not deny the distinction, but has every interest in affirming it; and be merely says that appearances are Reality as it appears, and that Reality does not appear as it is.

The new realists, like M. Bergson, aspire to join hands 
with Science. They should remember their ambition when they charge the idealist with arrogance. It is not he but they who overstep the modesty of Science. What they call "realities" Science and Idealism have agreed to call "phenomena." Nobody accuses Science of reducing its universe to one vast spectral hallucination or infinity of hallucinations. Appearances have this much of hallucination about them that they exist, but they do not subsist. To say this is not to deny the power and the glory of existence.

It was suggested in the beginning of this essay that if the idealistic monist would only walk humbly and acknowledge and renounce his crrors all might yet be well with him. Hope was even held ont that if he would only face the New Realism fairly and squarely, without any absurd depreciation of its strength, by surrendering certain positions he might still hold others better worth keeping.

I have supposed him to have put up his defence, I have even imagined him advancing on the enemy's positions. I might have made him show a more furious impetus in attack, but not, I think, a greater discretion in retirement. It is quite clear what Idealistic Monism must surrender if it is to hold its own in Philosophy.

It must give up its narrow philosophy of Thought. It must give up looking for unities and identities and ultimate realities where they are not. It must give up its faith in the incompetent relation of the whole and part. It must admit that Metaphysical Logic is in need of reform. And it must admit that Mr. Bertrand Russell has reformed it. It must admit the existence of a Pluralistic Universe. It must admit that as far as human consciousness is concerned this miverse is very largely "spectacular." But it need not accept the Pluriverse that Realism has thrust upon it. 
Above all, it must not say that its righteous suppositions are ontological certainties.

If it observes these precautions it can hardly lay itself open to the charge of arrogance.

All philosophers are a little arrogant. But which is the more arrogant, the one who says, either dogmatically or critically: This is a spectacular universe; but the spectators do not count; and there is no reality behind the scene? Or the one who says: This universe appears to be largely spectacular; therefore it would be rather odd if there were not a reality behind it?

If he goes beyond this modest speculation it is because he finds himself intimately and mysteriously mixed up with the spectacle, like one of Mr. Russell's ultimates, in “ a peculiar and undefinable relation." $\mathrm{He}$ is, in fact, part of it. He finds an immaterial reality for ever behind precisely that portion of the spectacle that he constitutes; as if a rent had been torn in the scene just there.

$\mathrm{He}$ is not considered arrogant or rash when he concludes that untold millions of spectators, also mixed up with the spectacle, intimately and mysteriously, in a peculiar and undefinable relation, constitute likewise so many spots, as it were, of immaterial reality discerned behind the scene. He finds that these spectators are mixed up with each other in an intimacy and a mystery more peculiar still. Is he, then, so very rash or so very arrogant if he concludes that the immaterial realities discerned through those untold millions of rents are spots of one immaterial reality that is continuous behind the scene? 


\section{VII}

\section{THE NEW MYSTICISM}

There are certainties and certainties. There is the blessed certainty that two and two make four. There is the still more blessed certainty that if $\mathrm{X}$ is greater than $\mathrm{Y}$ and $\mathrm{Y}$ is greater than $\mathrm{Z}$, then $\mathrm{X}$ is greater than $\mathrm{Z}$.

There is the certainty that the sun will rise to-morrow.

So far as this last certainty is based on repeated experiences of sunrises, it is not a certainty at all. All you can say is that what has happened a thousand million times will happen again if there is the same reason for its happening; if, that is to say, the cause or causes of its happening continue to work; which, again, can only happen so long as the conditions of their working hold good. Causation applied to sequences is a pure hypothesis, and an hypothesis that will not work. And mere sequences provide no grounds for assuming causes. Still, fenced round with conditions, the certainty that the sun will rise to-morrow is a reasonable certainty.

It cannot be said that at the end of our metaphysical quest we have reached any such certainty as this. We have not even established our contention that all metaphysical quests seek the same end. Pluralism gives the lie to our complacent assurance that their goal is unity.

Still, we made out that all, with the one exception of Pluralism, are out for unity of some kind, if it be only the unity of utter negation. And Pluralism, in declaring that immediate reality is ultimate enough for it, is out for ulti240 
mate reality. It eren pays its tribute to the Absolute in regarding all its realities as absolute.

Unity, then, or Ultimate Reality, or both, are the objects of the metaphysical quest. And in the contest between the sticklers for the One and the sticklers for the Many, we found that Spiritual Monism has reason on its side only if it lowers its claim to something less than certainty. The spiritual monist plays high, and he stands to lose more, if he should lose; but he is still within the rigour of the game.

But outside these certainties, outside the rigour of the game, and outside the paths where reason leads so cautiously, there is a region of so-called certainties which we have not yet explored. It would be easy to say of these certainties that they are true for those for whom they are true, but that the claimants are all agreed both about their truth and about the way by which it is to be found; and but that the object of their quest is the object of the metaphysical quest, Ultimate Reality. They are so unanimous, that, divided as they are by centuries and continents, there is less distance between a Christian mystic of the thirteenth century and a Buddhist mystic of the present day than there is, say, between Mr. Bertrand Russell and Mr. Gilbert Chesterton.

They are the real plungers. They stake their lives upon the game and their sonls upon the end of the adventure. Though they are many they go alone, on a dubious and dangerous way, to the "quiet place," the "untravelled country," the "City of God," "The Sorrowless Land."

The region of their certainty is not a region where the laws of mathematics, and the laws of nature, and the laws of thought are suspended; where two and two do not make four, but something else; and where miracles happen. Miracles are not by any means an essential part of the 
mystic's game. Still, he can give no rational account of his procedure. Reason does not reject him more than he rejects reason - in the wrong place. In the place where his adrentures happen two and two do not exist, and their behaviour is irrelevant.

But, if it comes to that, there is no reason why two and two should make four. They simply make it. There is no reason why the mystic should perceive Ultimate Reality. He simply perceives it. Extremes meet. The pluralist's perception of ultimate reality is immediate. So is the mystic's. But, if the mystic is right, the pluralist's reality is not ultimate.

Now, it cannot be denied that Mysticism is suspect. It has a bad history. In faet it has two histories, an ancient and a modern history; and it would be hard to say which of them is the worse.

Mysticism goes back to the most primitive of primitive times; it is part of our ancestral heritage, of our submerged and savage past. This past is the skeleton in the monist's cupboard; for Monism itself is inrolved in this ancient history. That is why healthy pluralists and healthy pragmatists will have none of it. They abhor the taint. The monist is always suspected of some mystical parti pris. He is like a man with a history of drink in his family; he cannot escape the damaging imputation. Yet it by no means follows because every mystic is a monist, that every monist is a mystic. It does not follow because the mystic gets at his Ultimate Reality by way of passion and vision, that the monist is implicated in his orgies and hallucinations. At this rate Mr. Bertrand Russcll's Principia Mathematica should be gravely compromised by the ancient history of Sacred Numbers.

But let us say that Monism is the lineal descendant of Mysticism, or that the two are collaterals and have the same ancestry. If Mysticism has had an ancient history, 
it must have been evolved. It must have become what it once was not. It cannot now be what it once was. All the same, the stages of its evolution must be linked together by one and the same thread.

That thread is the same thread that we found in tracing the evolution of the psyche - it is the Will-to-live, the Desire to have life, and to have it more abundantly. As the psyche grows this desire grows with it; or rather it would seem to be the very mainspring of its growth; anyhow it grows; it grows into a consuming passion; it passes beyond physical bounds; and the Love of Life becomes the Love of God.

The primitive and savage form of it is the desire for fertility, the desire to live and to make live; primitive and savage Magic (the humble origin of Mysticism with which it is reproached) is fertility magic; the earliest rites, the rites de passage, the rites of tribal initiation, of adolescence, of marriage, the funeral rites of death itself have one and the same object, to bring life, to ensure the virility of the tribesmen. The ghosts of the dead must be appeased with sacrifices that they may bring fertility to the earth. For ghosts (Miss Jane Harrison is my authority) were conceived first of all as underground things, as "germs from the grave"; ${ }^{40}$ the very earliest Greek vase paintings show them as diminutive psyches, or winged Keres fluttering in a grave-jar. The savage placates the ghosts of his forefathers first of all that he may obtain their strength, their mana; he drinks the blood of human secrifices, or of the sacrificial animal, that he may get their life. Later on, he divines a god in the dead hero, and in the form of the sacrificial animal. In partaking of the flesh and blood of the animal, he gets the life of the god.

So far we seem to have hardly adranced a step beyond savagery. But presently Magic beeomes Mystery. The initiate aspires to mion with the God ; mion, first of all, 
for the sake of fertility. The Lesser Mysteries seem to have had, frankly, no other aim. It is in the Greater Mysteries of Eleusis, in the Sacred Marriage and the Sacred Birth that the conception of fertility broadens and deepens, and that the Life-Force appears as the stupendous and the divine thing it is. It does not matter whether the Sacred Marriage was an actual physical union between priest and priestess, hierophant and initiate; or whether, as Miss Jane Harrison assures us, it was an entirely spiritual and symbolic rite; or whether, again, it was originally actual and physical, and became spiritual and symbolic afterwards; or whether it was originally spiritual and was afterwards debased. Miss Harrison seems to me to have proved her ease; the Sacred Marriage that began, there can be little doubt, as a fertility rite, ends in the adoration of Life itself; and becomes itself a rite de passage from the Lesser Mystery of the body to the Greater Mysteries of the soul. And by the time the Orphies have taken the thing in hand there is no doubt as to what has happened and is happening. The last and greatest initiation is accomplished. The dangerous passage from the physical to the spiritual life has been made. No matter if the Orphic mystic covered himself from head to foot with white clay, like his descendant the Pierrot and like his ancestor, the savage "white-elay man" of tribal rites of adolescence. His whiteness is now symbolic of the New Life. It does not matter whether the Orphic always was or was not the utterly spiritual person his whiteness proclaimed him to be. The spiritual life now appears as the object of desire and ambition; and desire and ambition we have seen to be always in advance of actual achievement. When Magic becomes Mystery we are on the threshold of Ultimate Reality. Henceforth there is no doubt as to the meaning of the words "New Birth" and "Union with God."

Now it is possible to read into the Orphic Mysteries more of Plato than they will bear; but this much seems 
certain, that before Plato's time the sense of life had widened so far as to make way for Platonism, for NeoPlatonism, and for Christianity. And the sense of life becomes more and more the sense of the Unseen; the love of God becomes more and more the passion for the Absolute.

I am quite willing to give up Neo-Platonism to anybody who wants to go for it on the grounds that it carried the passion for Godhead to drunken excess. Neo-Platonic Mysticism is a psychological phenomenon like any other. It was the phenomenon you might expect when East and West were violently flung together in the great melting-pot of Alexandria.

What I want to point out is that, at the very finest period of Greek civilization, Philosophy was turning from the doctrines of the Many: from the doctrine of the flux, and from the doctrine of Atomism, from the Pragmatic $\mathrm{Hu}-$ manism of the Sophists, to the doctrine of the One; and that the distinction was then made between appearance and Reality; and that the passion for God and the metaphysical quest of the Absolute ran together. Or rather the metaphysical hunt was foremost. Thought led and passion did its best to follow. Those people who will have it that Monism is the offshoot of Mysticism, a disease of thought reverting to a savage ancestry, should really read their Plato all over again, and Aristotle on the top of him, and Plotinus and Philo and Porphyry on the top of Aristotle; when it may become clear to them that Mysticism owes more to philosophy than philosophy could ever owe to it. Plato gives a point now and then to pluralistic realism; but if they are going to stretch that point, and insist that Plato was a Pluralist, and that Aristotle, the detestable Aristotle, was the accursed thing, all the better - they will hare some difficulty in bringing home a charge of Mysticism against him!

I would also suggest that the primitive savage had no monistic prejudices; the more ghosts bestowed on him 
their mana, the more sacrificial animals gave him their life to drink, the more everything all round him increased and multiplied, the better he was pleased.

You cannot get away from it. The quest of Ultimate Reality is as much a necessity of thought as it is a passion of the soul. And the idea of the Absolute is not primitive. It is a very late and highly "sublimated" idea.

Because Greek art has preserved for us the earliest origins of Greek religion; and because Greek literature and Greek philosophy are still alive among us at this day (thank Heaven!), we are able to trace the stages of this development and the links of these connections. But if you will read those Sacred Books of the East which the robust (the almost too emphatically robust) pragmatist regards as so much Benger's Food for sick souls, because he has lost his mature and healthy appetite for unity, if you will read the Vedas and the Upanishads, and the commentaries of the Vedânta, and the Buddhist Suttas, and the Texts of Tâoism, you will find the same development and the same connections. Here again, thought leads and the passion for the Absolute follows; until thought overthrows the thinker; and thought and passion, and the desire of Life are consumed (or consummated) in Nirvâna, or in the "Emptiness and Nothingness" of the Great Tâo.

But the Old Testament gives you pause. The links between primitive fertility magic and mysticism, between tribal initiations, rites de passage, sacrificial ritual and redemption, between the desire for physical life and the desire for spiritual life, are as apparent as you would expect them to be. But the lead of thought, the metaphysical flair, is entirely wanting. The Hebrew's thirst for God was a consuming thirst.

"Like as the hart panteth after the water-brooks, so longeth my soul after Thee, $\mathrm{O}$ God.

My soul thirsteth for God, even for the living God: when shall I come to appear before God?" (Psalm xlii.) 
But the philoprogenitive Jew thought of God as the Creator, the Father. He never rose to the metaphysical conception of the Absolute. To the very last, Jehovah preserved some of the old ways of the tribal deity. He was a struggling and a battling God; full of mercy when he got his own way, and of vengeance when he didn't. In his milder moods he was very like the pragmatic God of Humanism. The first Jew who developed a passion for the Absolute was cursed by his people and driven out of their synagogues. And if Baruch Spinoza had lived in the first century instead of the seventeenth they would have crucified him.

Still, though the God of the prophets is not and never can be the Absolute, he is One. Religion that begins in the fear of the supernatural and ends in the consuming love of it, is the historic witness to the passion for unity. Polytheism, which might be supposed to prove the contrary, is a case in point. Ancestor worship, which seems to have been at the bottom of the whole business (fathers being fertile), gives way to hero-worship. When the pantheon is inconveniently crowded, the merging of the gods takes place. The gods make a fine show of multiplicity when they are all gathered together in one heaven; but apparently ${ }^{41}$ there is none of them that did not start as a more or less single tribal or local hero. The most ancient of all, the underground gods of fertility and life in death, were so indeterminate in person, and so universal in power and function, as to count as one. When the gods multiply by migration of local heroes, their mysterious godhead diminishes with their multiplicity; until ultimately they are gathered up again into one: one Jehovah, one Zeus, and practically one Ormuzd, one Mithra, one Shang Tî, and, where ancestor-worship has persisted, one Mikado.

On any theory with a pluralistic bias it is remarkable, to say the least of it, that where polytheism is most rampant, 
as in India, the reaction to Pantheism and to Mysticism has been strongest; and that in Japan, where ancestor-worship has persisted into civilized times, the great refuge is Buddhism. Does it not look as if the inappeasable passion was, and is, this longing to escape from multiplicity and from the importunity of ancestors, this refusal to have the eternal spaces bewilderingly thronged? The same uneasiness is at the root of the craving for the mystic union with God; and it is fiercest in a religion like Christianity, which is based on a metaphysical and moral dualism, antagonism between soul and body and separation between God and man. It tries in vain to bridge the gulf with its makeshift doctrine of Incarnation and Atonement.

It would be absurd to say that Christian asceticism was worse than any other, but none has been more unclean and more profane in its repudiation of the earth. Christianity took to itself the ritual of the world it conquered; but it refused the one thing in that ritual which was necessary to its own salvation - the simple, sacramental attitude to life. In spite of its beautiful doctrine of love and mercy and pity, it was instinct with the spirit's cruelty to the flesh.

And it is precisely this atonement manqué, this failure of a spiritual religion to be spiritual enough, that is at the root of half the evil and the sickness and the suffering of the modern world. A religion spiritual enough to have made a genuine atonement between God and man would have conquered, not Europe and America only, but the whole world.

But if such an ideal can be conceived without a metaphysic, it could not be born from the ruins of Paganism and of a Roman Empire, and from the conquests of halfsavage Goths and Visigotlis. It was the secret thing conceived in the soul of Christ, that has its dwelling in the prophetic need and in the dreams and in the heart of man. But it is still waiting to be born. 
That other profoundly unChristian Christianity is important for our assumption; for it is the unique source of the moral argument which is the most serious objection the pragmatic humanist has brought against the monist. By a peculiar irony that argument bears hardest upon Dualism's own god, the absconding Deity of historic and popular Christianity; and we have seen that there is no solution of his moral problem that does not land the humanist in Monism again.

And, by yet another irony, the Christian dogma of the Atonement is the most powerful indictment of the absentee Almighty, and an implicit confession that the God of Pantheism is our only refuge.

Monism, I think, has shown itself to be imperishable under some form or other, and to be about as much tainted with primitive savagery as, say, the higher mathematics.

But what about Mysticism?

Mysticism may be no more tied to its ancient history than any other of our instincts and aptitudes, but it does betray a shocking tendency to revert. At least Western Mysticism has betrayed that tendency.

And its modern history is every bit as bad as its past.

I know that one of the most distinguished authorities on Western Mysticism, Evelyn Underhill, has assured us that this is not so; that, though Magic and Mysticism have a common traffic in the supernatural, their interest and their object are essentially different.

"The fundamental difference betreen the two is this: magic wants to get, mysticism wants to gire ... We may class broadly as magical all forms of self-seeking transcendentalism. ... The object of the thing is always the same: the deliberate exaltation of the will, till it transcends its usual limitations, and obtains for the self or grouns of selves something which it or they did not previously possess. It is an individualistic and acquisitive science. ..." (Mysticism, pp. $84,85$. 
This is no doubt true in a sense. It is also true that the object of Mysticism is to get something, and that all its giving is a means to getting. The mystic wants to get illumination, to get peace, to get deliverance, to feed on life and drink life - to eat His flesh and drink His blood - to get spiritual sustenance, the mana of the God. The parallel is very close indeed.

But there is this prodigions difference: primitive man desires to get by magic physical things that, without it, would come to him of their own accord, in due season; only he does not yet know that: the mystic desires to get spiritual things. And still the parallel holds so far that both are ensuring against possible failure.

And between these two regions of desire and expectation there is a dubious borderland: the region of the so-called supernatural powers, of which the mystie himself cannot say whether they are magical or spiritual: the power of healing, of vision, of clairvoyance and clairaudience, of control over matter. This is the region where "miracles" are said to happen; thongh neither the believer in magic nor the mystic know what is really happening. "It," whatever "it" is, happens in the East and West wherever magic and mysticism are known and practised.

The Tâoist, the "Perfect Man," says Kwang-zze, "is spirit-like. Great lakes might be boiling about him and he would not feel their heat; the Ho and the Han might be frozen up, and he would not feel the cold ... he mounts on the clouds of the air, and rides on the sun and moon, and rambles at ease beyond the four seas."

"If," says the Buddhist Sutta, " a Bhikkhu should desire to exercise one by one each of the different mystical powers, being one to become multiform, being multiform to become one; to become visible, or to become invisible, to go without being stopped to the further side of a wall or a fence or a mountain, as if throngh air; to penetrate up and down through solid ground, as if through water; to walk 
on the water without dividing it, as if on solid ground; to travel cross-legged through the sky, like the birds on wing; to touch and feel with the hand even the sun and moon, mighty and powerful though they be; and to reach in the body even up to the heaven of Brahma ; . . . to hear with clear and heavenly ear, surpassing that of men, sounds both human and celestial, whether far or near," there is nothing to prevent him; he has only got to "fulfil all righteousness," to be "devoted to that quietude of heart which springs from within," and not to "drive back the ecstasy of contemplation." He must "look through things" ; he must be " much alone." 42

Anybody with the smallest knowledge of abnormal psychology will see that this is the region of telepathy, and of suggestion and auto-suggestion, and of "psychic phenomena" generally. And nobody with the slightest intellectual caution will deny that it is a region of the utmost uncertainty and danger.

Now there is not one of the mystic's claims that is not under serious consideration at the present day. They cannot be settled with and dismissed at sight as palpable absurdities. The things he calls spiritual and the things other people call psychic are too closely platted together to be easily disentangled. What is more, the belief in the supernatural, even Magic itself, have never died out of human history. Mysticism itself, in some form or other, has never died. All the philosophy and all the science of the nineteenth century have been powerless against it. So far from being near its death in this century, it seems to be approaching a rather serious revival.

The modern psychologist and the psycho-analyst will tell you that there is nothing mysterious about this indestructibility and persistence. Mysticism is as indestructible as the human libido, and as persistent as human folly; and its revival in the twentieth century is precisely what 
you might expect in an age in whieh neurosis is the prevailing malady. The specialist in morbid psychology will tell you that the history of Mysticism is a history of neurosis. ${ }^{43}$ He will point, not in undue triumph, to the saints and mystics of the Salpêtrière. He will assure you that the great saints and mysties are in no better case; but that, on the contrary, the life of the religious recluse provides in a supreme degree all the conditions of the hysterical neurosis; its repressions are the classical repressions; its results the classical results. He will ask you to consider dispassionately the awful record of ill-health revealed in the lives of the Saints, and, piling proof upon proof, he will show you in their visions and phantasies a perfect correspondence with the visions and phantasies of the neurotic and the insane.

And the sting of his observations will be in their truth.

What is to be said of these utterances of Saint Teresa herself? She speaks of "the great shocks I used to feel when our Lord would throw me into these trances." And again, "it is like a person, who, having a rope round his neck tries to breathe." "On other oceasions the soul seems to be in the utmost extremity of need, asking itself and saying, Where is Thy God?" "I saw myself dying with a desire to see God, and I knew not how to seek that life otherwise than by dying. Certain great impetuosities of love, though not so intolerable as those of which I have spoken before... overwhelmed me." "This prayer is like the sobbing of little children, who seem on the point of choking and whose disordered senses are soothed by giving them to drink." "Some slight mitigations may be had, and the pain may pass away for a little by praying God to relieve its sufferings: but the soul sees no relief except in death, by which it hopes to attain the fruition of its good. At other times these impetuosities are so violent, the soul can do neither this nor anything else; the whole body is contracted, and neither hand nor foot can be 
moved: If the body be upright at the time it falls down, as a thing that has no control over itself. It cannot even breathe; all it does is to moan - not loudly, because it cannot: its moaning, however, comes from a keen sense of pain." Again, an angel appears to her in a vision. "I saw in his hand a long spear of gold, and at the iron's end there seemed to be a little fire. He appeared to be thrusting it at times into my heart, and to pierce my very entrails: when he drew it out, he seemed to draw them out also, and to leave me all on fire with a great love of God." 44

Of St. Catherine of Genoa it is said that "at times she would seem to have her mind in a mill; and as if this mill were indeed grinding her soul and body." "She would at times, when in the garden, seize hold of the thorn-covered twigs of the rose-bushes with both her hands; and would not feel any pain while thus doing it in a transport of mind. She would also bite her hands and burn them, and this in order to divert, if possible, her interior oppression." 45

St. John of the Cross speaks of " an intense and amorous impetus," answering to St. Teresa's "impetuosities." 46 And what are we to make of his confession that the ecstasies of the soul's union with God are often so poignant that they interpenetrate the body itself, so that it is awakened and partakes of the soul's passion after its own kind? ${ }^{47}$

Even Lady Julian of Norwich, that most exquisite and lovable of all mystics, whose love of God was not greater than her love of her neighbour, who saw "that each kind compassion that man hath on his eren-Christen it is Christ in him," even Lady Julian was tormented. Her beautiful soul was haunted by the most horrible risions, the result of concentrated meditation on the Passion.

"I saw the bodily sight lasting of the plenteous bleeding of the Head. The great drops of blood fell down from under the Garland like pellets, seeming as it had come out of the veins; and in the coming out they were brown-red, for the blood was 
full thiek; and in the spreading-abroad they were bright-red; and when they came to the brows, then they vanished; notwithstanding, the bleeding continued till many things were seen and understood. The fairness and the lifelikeness is like nothing but the same; the plenteousness is like to the drops of water that fall off the eaves after a great shower of rain, that fall so thick that no man may number them with bodily wit; and for the roundness, they were like to the seale of herring, in the spreading on the forehead. These three came to my mind in the time: pellets, for roundness, in the coming out of the blood; the scale of the herring, in the spreading in the forehead, for roundness; the drops off eaves, for the plenteousness innumerable.

"This Shewing was quiek and life-like, and horrifying and dreadful, sweet and lovely." (Revelations of Divine Love, pp. $15,16$.

\section{She has this vision of Christ's thirst.}

"For this word was shewed for the bodily thirst: the which I understood was eaused by failing of moisture. For the blessed flesh and bones was left all alone without blood and moisture. The blessed body dried alone long time with wringing of the nails and weight of the body. For I understood that for tenderness of the sweet hands and of the sweet feet, by the greatness, hardness, and grievousness of the nails the wounds waxed wide and the body sagged, for weight by long time hanging. And (therewith was) piercing and pressing of the head, and binding of the Crown all baked with dry blood, with the sweet hair clinging, and the dry flesh, to the thorns, and the thorns to the flesh drying; and in the beginning while the flesh was fresh and bleeding, the continual sitting of the thorns made the wounds wide. And furthermore I saw that the sweet skin and the tender flesh, with the hair and the blood, was all raised and loosed about from the bone, with the thorns where-through it were rent in many pieees, as a eloth that were sagging, as if it would hastily have fallen off, for heaviness and looseness, while it had natural moisture. And that was great sorrow and dread to me: for methought I would not for my life have seen it fall. How it was done I saw not; but understood it was with the sharp thorms and the violent and grievous setting on of the Garland of Thorns, unsparingly and without pity. This continued awhile, and soon it began to change, and I beheld and marvelled how it might be. And then I saw it was because it began to dry, and stint a part of 
the weight, and set about the Garland. And thus it encircled all about, as it were garland upon garland. The Garland of the Thorns was dyed with the blood, and that other garland (of Blood) and the head, all was one colour, as clotted blood when it is dry. The skin of the flesh that shewed (of the face and of the body), was small-rimpled; with a tanned colour, like a dry board when it is aged; and the face more brown than the body." (Ibid. pp. 33, 39.)

But the Freudian psychoanalyst would be specially interested in Lady Julian's Vision of the Fiend, who visited her in her sleep.

"I lay still till night, trusting in His mercy, and then I began to sleep. And in the sleep, at the beginning, methought the Fiend set him on my throat, putting forth a visage full near my face, like a young man's, and it was long and wondrous lean: I saw never none such. The colour was red like the tilestone when it is new-burnt, with black spots therein like black freckles - fouler than the tilestone. His hair was red as rust, clipped in front, with full locks hanging on the temples. He grinned on me with a malicious semblance, shewing white teeth: and so much methought it the more horrible. Body nor hands had he none shapely, but with his paws he held me in the throat, and would have strangled me, but he might not." (Ibid. pp. 165, 166.)

And I am afraid pathologists will not be inclined to accept Lady Julian's own interpretation of her Vision of the Child and the dead body.

"And in this time I saw a body lying on the earth, which body shewed heavy and horrible, without shape and form, as it were a swollen quag of stinking mire. And suddenly out of this body sprang a full fair creature, a little Child, fully shapen and formed, nimble and lively, whiter than lily; which swiftly glided up into heaven. And the swollenness of the body betokeneth great wretchedness of our deadly flesh, and the littleness of the Child betokeneth the cleanness of purity in the soul. And methought: With this body abideth no fairness of this Child, and on this Child dwelleth no foulness of this body." (Ibid. pp. 160, 161.) 
When you remember that these visions came to the mystic in her little anchoress's house in the graveyard of the church of St. Julian, the wonder is, not that they were so terrible but that they were not much worse.

And besides being morbid and unbalanced the mystics - not Lady Julian, but other mystics - show a certain arrogance. For all their humility and self-surrender they show arrogance. The saint is exalted because she has won God's love, because she is chosen above other women to be the Spouse of Christ. The Blessed Angela of Foligno declared that the Lord had told her he loved her "above any other woman in the valley of Spoleto." 48 You seldom hear of the other spouses, the other loves. The attitude is entirely self-centred. It would be interesting to know what Saint Teresa would have said to Lady Julian, or Saint Catharine of Siena to the Blessed Angela.

We do know what Saint Teresa thought of her own nuns when they had aspirations. In her normal state the "undaunted daughter of desires "was one of the wisest and strongest-minded of the saints, second only to Saint Catharine of Siena in wisdom and strongmindedness and practical common sense. She was suspicious of experiences, especially of other people's experiences; and she owns to a profound distrust of "vision." There is often no sign by which the soul can tell a vision sent by God from a vision sent by Satan. ${ }^{49}$ She recognizes that in this very region of phantasy and symbol there lie hidden the deepest pitfalls for the soul. Therefore, whatever risk she herself was prepared to take, she did not allow her nuns to seek these adventures - passing on the discouragement she had received from her own spiritual directors. Spiritual jealousy - the last infirmity of saints - may have had something to do with these prohibitions; but it is far more likely that they were meant as safeguards against the deadliest perils of the monastic life. The spiritual directors were the psychoanalysts of their day; and when a great 
mystic pleaded that his or her case was exceptional we can imagine them replying with all the finality of their science: There are no exceptions. And the modern psychoanalyst argues, with every show of reason, thus: If in nine hundred and ninety-nine cases out of a thousand the same symbolic phantasy has been found to stand for the same thing, how, when the thousandth case presents that symbolic phantasy, can we admit its plea to be regarded as an exception? You say that it depends on the context; and you are told ruthlessly that the context is the same. There are no exceptions. Out of their own mouths the great mystics stand condemned.

So far from there being any way out and forwards in this direction, it would seem that the Mystic Way is the surest way backwards and in. For two reasons. First, because in the mystic longing and the mystic union Sublimation is still imperfect. The "libido," although it is transferred from a human and bodily object to a divine and spiritual one, is not transformed. It is simply "carried over" in a more or less unsublimated state. Secondly, because the mystic look is essentially an inward one. The mystic seeks God, for the most part, not in the outer world of art and science and action, but in the darkest and most secret recesses of his own soul. And it is precisely this darkness and secrecy that the psychoanalyst has the most reason to mistrust.

If anybody could persuade me that all was and is well with the mystics it would be Miss Evelyn Underhill. She does not blink the patent, and indeed blatant, fact of "mystical ill-health."

"If we see in the mystics, as some have done, the sporadic beginning of a power, a higher consciousness, towards which the race slowly tends; then it seems likely enough that where it appears nerves and organs should suffer under a stress to which they have not yet become adapted, and that a spirit more highly organised than its bodily home should be able to impose 
strange conditions on the flesh. ... It is at least permissible to look on the strange psychological state common amongst the mystics as just such a rebellion on the part of a normal nervous and vascular system against the exigencies of a way of life to which it has not yet adjusted itself." (Mysticism, pp. 73, 74.)

This is, I think, broadly and roughly true. But it would be more closely and finely true to say that the mystic consciousness presents in a marked degree the pathological phenomena of "dissociation."

M. Janet's account of the matter in his État mentale des Hystériques, leaves us in no doubt as to what is actually happening here. He shows that the root of the neuroses and psychoses, of all mental maladies in fact, lies in dissociation: the break between one idea, or group of ideas, and its normal context and logical connections; the cutting off of one psychic state, or group of states, from the stream of consciousness itself. This isolated and abandoned tract is the home of all the obsessions, the fixed ideas, the morbid "complexes" unearthed by the psychoanalysts, the day-dreams and phantasies of neurotic and insane persons; it is the home of lapsed instincts and memories, of things forgotten because of their dreadfulness or simply because of their uselessness; it is our ancestral and racial territory, the place of our forgotten and yet undying past, of what has been conscious once, and is no longer conscious. Portions of our present that we have no use for and that would only hamper us are continually going to join this forsaken past. But if we are to keep the image of consciousness as a "stream" we had better say that they sink to the bottom and stay there until some eddy in the deep stirs them up again. You can reverse the image, if you like, and think of consciousness as some city of the sea, raised on land partly submerged, partly reclaimed from the sea; a sea that threatens perpetually to overflow the thresholds of its palaces.

But (without bothering about territories and streams 
and bottoms and seas and thresholds), the point to bear in mind is that all lapses and losses of a present memory or aptitude (barring physical lesion or decay), all perversions of instinct and desire, all suppressions, obsessions and possessions, all cases of double or multiple personality, are states primarily and essentially of dissociation. And that detachment, which is the one indispensable condition of mystical experience, is, primarily and essentially, a state of dissociation. And it is, as mystics themselves are perfectly well aware, a very dangerous state. There is not one step of the "Mystic Way," from meditation, through illumination, introversion (contemplation and quiet) to deliverance and to ecstasy, that is not a step further in the process of dissociation. The mystic, deliberately seeking Ultimate Reality, has left normal consciousness behind him; he has closed all the approaches in that direction; and he has opened doors (another image, but I can't help it), he has opened doors to anything that may be waiting for him below or beyond the threshold.

$\mathrm{He}$ is out or " in" for a dreadfully perilous adventure; and what happens to him will depend on whether this region beyond normal consciousness is only the too welltrodden territory of the past or also the "untrodden country" of the future. In the one case his mystical experience will be a sinking downwards or a turning backwards : in the other it may be a rising upwards or a going on. And there is a third alternative - it may be both. Quite easily it may be both; for we have now to do with a more or less divided and disintegrated personality.

I think that - still keeping the saints and mystics of the Salpêtrière well in sight - we shall find that there are some grounds for supposing that the country of abnormal consciousness stretches forwards as well as backwards, and belongs every bit as much to our future as to our past. Our normal, everyday, present consciousness lies between what has been and what shall be; it has been developed, as 
we have seen, by processes of forgetting, that is to say of dissociation, carried to perfection; it exists as it is now by virtue of its defiance and its rupture with the past that it suppresses but is powerless to destroy. So that, if it is to advance at all beyond its normal state, it can only do so by a process of detachment or dissociation; by that letting go and forgetting of the actual, by that renunciation and self-surrender, that dying to live which is the secret of the mystic life.

Let us suppose then that in his abnormal state the mystic has before him the entire range of the "Unconscious" and "Subconscious"; that his psyche hovers between its old forgotten playground of the past and its unknown playground of the future. It may be the prey and the victim of powers, of instincts and of memories, which once served its development, and which have dropped from it by disuse; or it may be the experimenter with undeveloped powers of which it is by no means the master. At best it can only advance a little way, a very little way along the path it is ultimately destined to travel. But it can go back very easily down that well-trodden path by which it came. It can go a short way, or even a fairly long way and yet return. But if it goes too far it is lost; it is hopelessly estranged from itself and from the life of the normal living; it is (not to mince matters) mad.

Or it may go up and down on the two paths. And its tendency to go up and down, or to go downwards most of the time, and seldom if ever to go upward all the time, or even for very long at any one time, is recorded in the confessions of all the saints.

In the face of these confessions we might feel suspicious of our supposition but for two things: we have personal experience of psychic " dissociation" every night when we dream; and we have authentic evidence bearing on the existence of a fairly extensive borderland, lying between 
Magic and Mysticism - the region of the so-called "psychic powers."

Professor Freud has said two notable things about dreams: "Dreams are a piece of the conquered life of the childish soul," and "The dream is a disguised fulfilment of a repressed wish." 50 He might have said with equal truth: Dreams are a piece of the yet unconquered life of the soul that is to be. Or: The dream is a fulfilment of the repressed desire to transcend our normal powers, seeing that in our dream-consciousness we do transcend them. In every dream adventure we make experiments with the sonl that is to be.

If dreaming were not the common and accustomed thing it is, we should be astounded at our own performances every time we dream. When people come down in the morning and tell you that they have had a very remarkable dream, what they mean is that their dreams are more remarkable than other people's dreams; but it does not occur to them how remarkable it is that anybody should have a dream at all.

It was no doubt a good thing for the race when it definitely made up its mind that we are dealing with realities when we wake and with unrealities when we dream; but it is mainly owing to this really very rash assumption that an extraordinarily interesting and significant form of consciousness should have been left to the imaginative layman and the quack investigator until the psychoanalysts took it over. I am not forgetting the admirable work done by the Society for Psychical Research. This has been mainly in collecting and sifting material for Psychology to deal with; but recent discussion has tended towards recognition of the dream's peculiar and profound reality. ${ }^{51}$

Dream experiences are not explained by calling them ballucinations; nor yet when we have named their cause "unconscious cerebration." Cerebration is always uncon- 
scious, and it accompanies and perhaps in some way conditions waking consciousness too. That there should be inside excitements and reverberations, nerve-cells and brain-cells keeping up their activity on their own, after the outside stimulus has ceased, is not more remarkable than any other physical event. But we should expect the psychic events that correspond with this activity to be the faded images, the fainter reverberations of waking states; to be as broken, as confused, and as fantastic as you please, but still to obey the ordinary fundamental conditions of space and time. So far as it accounts for anything, unconscious cerebration might account for such a dream-consciousness as this; but not for the dream-consciousness we know. The unaccountable things are the conditions of the dream itself; the dream-space, the dream-time, the dream-unity of consciousness, the dream itself. No amount of unconscious cerebration can explain the facts that at one and the same time I am or seem to be several other persons besides myself, while preserving my own identity in them; ${ }^{52}$ that I can penetrate into walled spaces without opening doors; that I can arrive at positions in space without occupying intermediate positions in space; that I can go through a continuous series of performances, involving an expenditure of time that may be anything between five hours and five days, or, with suitable breaks, cven five years; all in what proves to have been three seconds by the watch at my bedside. In my nerve and brain records there can be no memory of my ever having done these things; and they cannot well be explained as "compounds" of fragments of the things I have done. Surely the obvious inference is that I do them, not in the space of waking consciousness, and not in three seconds of watch-time, but in another space and in another time; and that in doing them "I" have been both the waking I and another more marvellous I, and to some extent others? For the waking I remembers the dream experience, though not always perfectly; and 
the dream I remembers parts, at any rate, of the waking experience.

That is to say, while preserving selfhood, it has transcended normal consciousness.

It is probable that racial consciousness is resurgent in the dreams even of normal people, and that it plays an enormous part in the dreams of neurotics and of lunatics. It is probable that in dreams the psyche goes backwards. It is no less probable, I think, that, urged by its half-conscious and wholly prophetic need, it goes forwards too, and grasps at and reaches powers that will ultimately be its normal, conscious possession.

And besides the dream-powers, there are the other powers of the Borderland, the "psychic" powers that belong to the world of Mysticism and Magic and the occult, and are claimed equally by scoundrels and by saints. Until comparatively recent years they, and the peculiar form of consciousness they involve, were in the same case as the dream-powers; they were left to the quack practitioner and the amateur investigator. Most of us can remember the time when the existence of telepathy was not admitted by persons who had a scientific reputation to take care of, and "suggestion" was on its trial. As for faith-healing, palmistry, clairvoyance, clair-audience, automatism, mediumship, and the rest, they are still mixed up with such fraud and humbug and silliness, and with persons so disgraceful, so discredited, so absurd, that it is not easy to write about them in a work that is, at any rate, trying to be serious. I feel (to be disgustingly egoistic) that any reputation I may have is already so imperilled by my devout adhesion to the Absolute that I simply cannot afford to be suspected of tenderness, or eren toleration for the professors of the occult. The Society for Psychical Research may be trusted to deal appropriately with unorganized imposture; but the organized variety is another 
matter. And there are at least two organizations which seem to be beyond the power of any Society, or of any Government or State to control them - Theosophy and Christian Science.

They are dangerous, not because they have had an ancient history, but because they have had and are having a modern one. Christian Science is by far the more dangerous, though not the less dubious, of the two. It is dangerous because of its successes. It is dangerous because its best exponents are really sincere and truthful and profoundly spiritual persons. But these are not always its most successful practitioners. For, when all is said and done, and its misses and its failures are counted, its gains make quite a considerable " show." Its traffic in the world of appearances is, indeed, astounding, also its profit; seeing that it ignores the known methods of procedure, and the proved facts, and the ascertained sequences and connections of that world. With a mouthful of phrases and formulas, and a few ill-assorted bits of popular " philosophy," picked up haphazard, with an utter ignorance of what it calls "Western Science," it is trying to undo in a day the work of centuries, the elaborate and patient work of the most beneficent of all physical sciences.

And it is succeeding. Not long ago, in a country village, I came on an innocent family of four persons. They were trying to get well there. The father's and the mother's health was impaired, and the two children's quite efficiently shattered by the effects of the scarlet fever they had had a year ago. They had had it owing to the view their neighbour held that, because Christian Science can cure nervous headaches and hysterical paralysis and take down inflammation, it can cure scarlet fever too, or at any rate can allow children displaying all the appearances of scarlct fever (scarlet fever itself not being a reality) to run loose about a city without damage to the public safety. And the neighbour is probably of that opinion 
still; and when his children get diphtheria they will probably be allowed to spread it abroad in the same way. But, though Christian Science despises appearances in the form of disease germs and the laws of nature, it does not despise them in the form of dollars and of goods. It is too much messed up with appearances altogether. It does not discriminate. It will not render unto Appearance the things that are Appearance's, and unto Reality the things that are Reality's.

I find it hard to write fairly of Theosophy, possibly because I have suffered from theosophists. I do not like their way of handling the Sacred Books of the East. I object to having the Bhagavad-Gîtâ and the Sutta of all the Âsavas thrown at my head, as if they had been portions of Scripture appointed for the day, and specially applicable to my unspiritual case. I hate it when a woman I disapprove of tells me that if I would only extinguish all my desires I should attain Nirvâna to-morrow. I know it. But I do not want to attain Nirvâna quite so soon. When I am eating chicken and my host is eating lettuce, I resent his telling me that a vegetarian cannot endure the presence of a flesh-eater, but that he conceals his repulsion because he is holier than the flesh-eater. And I am really frightened when I am introduced to a female " adept" who cannot walk through a churchyard without seeing what goes on in the graves, and who insists on describing what she has seen.

Surely there is something very wrong there?

Now there are theosophical Societies like the Quest Society that are innocent, and there are theosophists like Mr. A. P. Sinnett and Mr. G. R. S. Mead who command the greatest admiration and respect; but I would rather think of Mr. Sinnett and Mr. Mead as scholars and experts in strange religions than as theosophists at all. If I had to choose between Pragmatism and Theosophy I would without hesitation choose Pragmatism. 
But that there are "powers," some powers, is, I think, no longer in dispute. I am quite sure that, but for my will-not-to-be-healed, a Christian Scientist could heal me if I offered the appropriate disorder. I daresay the "powers" of Mr. Leadbeater and Mrs. Annie Besant, or their Mahatmas, conld blast my career if I came under their influence. If a Bhikku should desire to ride cross-legged through the sky, I do not think that he will be able to do it, but he will probably be able to create an illusion of doing it, so strong that the illusioned will see no difference between the appearance and the reality. All these people are more or less adepts in the art of suggestion and auto-suggestion; they have more or less control over whatever powers are involved in telepathy, clairvoyance, automatism, and mediumship. But their powers are not more interesting or wonderful than the powers of quite ordinary people who have never heard of a Mahatma, or else think it is the island New York City is built on.

For the most elcmentary power of telepathy and suggestion (which, I believe, include all the others) is, if you come to think of it, a very remarkable and significant thing; almost as remarkable and significant as dreaming. It means that the ordinary methods of communication by speech and sign are "transcended"; that faith is literally "the substance of things not seen" (a Bhikku riding cross-legged through the sky would surely be a variety of such a substance); that, if it cannot move mountains, or even mole-hills, it can move molecules ; it can, within limits, break up and alter their chemical arrangements; otherwise physical healing by suggestion could not occur. It looks as if thoughts flew about, and could be caught casually on the wing; only that things do not always happen in that haphazard way. There are certain clear and steady sequences that point to a definite and deliberate agency; they involve desire and design. The selves can apparently exert 
an inward spiritual influcnee as strong as, or stronger than, an outside or material stimulus.

Suggestion, then, seems to be best defined as the power that immaterial beings have to make psychic events happen. In this sense we may say that it covers all the ground of Magic and of Mysticism and the Borderland. It must have been used deliberately in primitive ritual and in all the Mysteries. It accounts for all the "psychic phenomena " of Mysticism: the miracles, the visions, the ecstasies, the sense of Union. It probably accounts for the efficacy of prayer. Prayer is one of our oldest ancestral instincts and habits; it is therefore one of the strongest engines of suggestion at our service.

But though it covers all the facts it does not account for all of them; and it does not cover or account for itself. It does not account for the supreme fact - the choice of Ultimate Reality as the object of desire. It does not account for the desire itself, the hunger and the thirst for Life, for New Life and more abundant Life, which is the driving motive of the mystic adventure. It does not account for the gradual, steady sublimation of that desire, nor for the corresponding changes in the conception of its object. It does not account for the means by which it is brought into operation; for the ascertained uniformity in the stages of the Mystic Way all the world over; a uniformity which raises the practice of Mysticism from magic to a science and an art. It does not account - I know this statement will be challenged, but I believe it does not account - for the peculiar certainty that comes, not always through illumination and contemplation, and not through vision or ecstasy, but in spite of them; a certainty that is not part of the psychic phenomena at all, and that, so far as I know, both psychic phenomena and the suggestion that gives rise to them are powerless to produce. 
And it does not account for itself. When we have said that suggestion gives rise to psychic events, we do not know why, or even how it does so. We have not said from what centres or on what levels it is working. Apparently it can work from all the centres and on all the levels of our conscious or subconscious life. If we say that its chief function is to create illusion, we are very far from the truth. Its chief and highest function is to create reality; to heighten the sense and sharpen the perception of reality; to restore the links with reality where they have been broken. Otherwise there could be no healing by suggestion. And the most important of its healing functions are the recovery of the lost Will-to-live, and the joining up of psychic states abnormally dissociated.

Now in detachment, the state of mystic dissociation from normal consciousness, we said that two ways were made open to the psyche: one looking backwards and downwards, on which it can go a long way with ease; and one going forwards and upwards, on which it can only go a little way with difficulty.

And the psychic powers of the borderland can go up and down too. Suggestion can evoke the instincts and memories of states past and forgotten. It can also invoke the instinct and the premonition of a state not attained. It cannot create Ultimate Reality, or the perception of it. But it would seem that it can create a state in which, for moments of most uncertain duration, Ultimate Reality is discerned.

In Western Mysticism, above all, in Catholic Mysticism, the lower and the higher forms of suggestion alternate, and there is a dreadful tendency for the lower form to hold the field. And if the great mystics had not been the most marvellous analysers of their own states, we should have had no possible means of distinguishing in their case between the two.

Luckily their moments of certainty seldom, if ever, came 
when they were deliberately sought; they came - as they come to every one who has ever known them - unsought, and unexpected and with a shock of surprise. In true mystic experience you may say the expected never happens.

Still, remembering the saints of the Salpêtrière, and Lady Julian's morbidities, and Saint Teresa's "impetuosities," and all the terrifying and revolting amorousness of the religious mystic, we might suspect this certainty if these revelations were all the record that we had of it. Not only all religious experience is full of it, but every poet, every painter, every musician knows the shock of contact with reality. The vision of absolute beauty while it lasts is actually a laying hold on eternal life. I would say every lover knows it, but that sexual passion is the source of our most profound illusion. Still, even the betrayed and disillusioned lover may know that in loving he found his own innermost reality; illusion was not in him, but in the perfidious heart of the beloved; while he loved he truly lived. Nothing can take from him that certainty. The wrong of sexual treachery lies in the fact that it deprives the lover (for the time being) of life.

And there is an even higher state of certainty than these. Almost every other hero knows it; the exquisite and incredible assurance, the positively ecstatic vision of Reality that comes to him when he faces death for the first time. There is no certainty that life can give that surpasses or even comes anywhere near it. And the world has been full of these mystics, these visionaries, since August, 1914. Sometimes I think they are the only trustworthy ones. How pure, how absolute is their surrender; how candid and untroubled their confession; how spontaneous and undefiled their witness.

And see how they back up all the Others

This is the kind of certainty we want to tide us over 
the straits where Western Mysticism often leaves us floundering.

I say Western Mysticism, because in the Buddhist Sacred Books and in the Upanishads and the Vedânta, and in the Mysticism of Kabîr, you do not find anywhere the same repulsive qualities. You enter a purer and a subtler air; and the Light of Godhead, "das Fliessende Licht der Gottheit," does not flow; it is strong and very still.

There are reasons, as we shall see, for this difference. The Western mind comes to Mysticism by a peculiarly dangerous and difficult path. For one thing, it came to it a bit too early. The art and science of it were perfected in Asia, if not before the first principles had been discovered in Europe and Asia Minor, at any rate long before they had had a chance to develop. The Christian Mystics seem never to have quite perfected the technique of the thing; and seldom to have achieved a perfect and a safe detachment. Admirable psychoanalysts as they were, they lacked that minute psychological theory and practice which the Indian seems undoubtedly to have possessed. They plunged into the dangerous adventure without adequate preparation, as one who should jump into the Atlantic without a safety-belt. In the language of modern phychology, they had not learned how to "sublimate their libidos."

And this apparently was what the subtle Indian had learned before ever he set out on the adventure. The Western Mystic did not know, or had forgotten, that the desire of Life, even physical desire, is an indestructible and holy, thongh a dangerous thing. He suppressed physical desire; he stamped it down into the Unconscions; and then, in a state of passivity or trance, he went down there after it, and was met by the resurgence of all his savage and ancestral memories. He retrogressed. He did not know that this would happen to him (he knew nothing at all or very little about the Unconscious); and every time it did happen he was agonized and astonished. But the Indian 
Mystic knew very well what would happen, and why it happened; and when he went travelling in the untrodden country he took good care to close the gates of the paths that led downwards. Sometimes they swung to of their own accord and the Christian mystic was safe.

Still, there is a great gulf fixed between Eastern and Western Mysticism. Sometimes the Catholics bridge it, when they are metaphysical, which is seldom. But Julian of Norwich, for one, managed to get over. Her First Revelation of Divine Love might have come straight from the heart of Asia.

"In this same time our Lord shewed me a spiritual sight of His homely loving.

"I saw that He is to us everything that is good and comfortable for us: He is our elothing that for love wrappeth us, claspeth us, and all encloseth us for tender love, that He may never leave us; being to us all-thing that is good, as to mine understanding.

"Also in this He shewed me a little thing, the quantity of an hazel-nut, in the palm of my hand; and it was as round as a ball. I looked thereupon with eye of my understanding, and thought: What may this be? And it was answered generally thus: It is all that is made. I marvelled how it might last, for methought it might suddenly have fallen to naught for little (ness). And I was answered in my understanding: It lasteth, and ever shall (last) for that God loveth it. And so All-thing hath the Being by the Love of God." (Revelations of Divine Love, p. 10.)

Compare this with the well-known duologue in the Khândogya-Upanishad.

" 'Fetch me from thence a fruit of the Nyagrodha tree.'

" 'Here is one, Sir.'

"' 'Break it.'

"' It is broken, Sir.'

" "What do you see there?"

" 'These seeds, almost infinitesimal.'

" 'Break one of them.'

" 'It is broken, Sir.'

"'What do you see there?' 
" "Not anything, Sir.'

"The father said: "My son, that subtle essence which you do not perceive there, of that very essence the great Nyagrodha tree exists.

" "Believe it, my son. That which is the subtle essence, in it all that exists has its self. It is the True. It is the Self, and thou, O Svetaketu, art it." 53

Observe what is happening. It is as if Mr. Barlow were instructing Sandford and Merton in the Hegelian Dialectic. Observe that it is said of Svetaketu that "he understood. Yea, he understood." The Indian takes to the Absolute like a duck to water. He may attain Deliverance before he is sixteen, instead of having to wait for it till he is sixty, when the passions cease from troubling of their own accord.

In her clearest moments Julian is as devout a pantheist as any Indian mystic. She had even her pantheistic formula to match the "Thou art it" (Tat tvam asi) of the Upanishad.

"I it am, I it am: I it am that is highest; I it am that thou lovest; I it am that thou enjoyest; I it am that thou servest; I it am that thou longest for: I it am that thou desirest; I it am that thou meanest, I it am that is all." (Revelations of Divine Love, pp. 54,55.)

We are very near the secret of the psychic backsliding and spiritual torment of the Christian mystic. They are due, not only to imperfect psychological technique, but to imperfect metaphysics. In spite of the refinements of tho Schoolmen, the Christian idea of God was never wholly sublimated by thought. It rests on a naif and obstinate dualism that resists the process.

It is to the East that we must turn to find the highest and the purest form of Mysticism; a Mysticism that has passed through the fire of metaphysical thinking, and is itself sublimated. 
But before we compare Western with Eastern Mysticism, as I am going to do, to the disadvantage of the Christian variety, three things must be kept well in sight.

First, that the final goal of Christian Mysticism is not "experience," not vision, not ecstasy, but the Unitive Life, the life lived in union with Reality. Life lived, not merely contemplated; a life of "fruition and activity," lifted for ever above the powers of the Subconscious. Of this state Evelyn Underbill says that in it man's nature

“. . . has become conscious in all its parts, has unified itself about its highest elements. That strange, tormenting vision of a perfect peace, a joyous self-loss, annihilation in some mighty Life which over-passed his own, which haunts man through the whole course of his history, and finds a more or less distorted expression in all his creeds, a justification in all his ecstasies, is now traced to its source: and found to be the inevitable expression of an instinct by which he recognised, though he could not attain the noblest part of his inheritance." (Mysticism, p. 520.)

She denies on, I think, somewhat insufficient grounds, that this state was conspicuously attained in Eastern Mysticism. That is to say, in Eastern Mysticism that was not influenced by Christianity. ${ }^{54}$ But the Christian apologist has still to admit that in the West it was usually reached late in life, and that certain physical cessations may have contributed. Howerer that may be, it is the end of "mystical ill-health."

Again, the Christian saint brings to the quest for Reality something that is not always found in mysticisms that hare been highly sublimated by thought.

Julian of Norwich says of her hazel-nut:

"In this little thing I saw three properties. The first is that God madeth it; the second is that God loveth it; the third is that God keepeth it. But what is to me verily the Maker, the Keeper, and the Lorer, I cannot tell." (Revelations of Divine Love, p. 10.)

And she speaks for all her kindred. Her way is the way 
of the mystic Kabîr, and of the Vaishnavists, the Humanists of India.

"Few," says Kabîr, "are the lovers who know the Beloved. The devout seeker is he who mingles in his heart the double currents of love and detachment."

Lastly, Mysticism itself is a thing of gradual development, and the Eastern and the Western forms of it are tending to approach, with the result that Pantheism is absorbing Christian Humanism, to Humanism's great gain.

This tendency is so conspicuous in the modern literature of East and West, that it may be fairly called the New Mysticism. It has been, I think, not only an affair of influence, but of the slow yet inevitable maturing of the Western mind. It is no food for sick souls; it has put the disease of asceticism behind it; it is a robust and joyous Mysticism, reconciled to the world.

When Sir Rabindranath Tagore was over here, in the years before the War, he told us that the destiny of the East was "to spiritualize the West." Complacent westerners smiled at the saying, as if the great poet had been offering to teach his grandmother an art that she had perfected bcfore he was born. Yet his was simply the calm statement of a truth.

Still, if some of our poets and mysties had not gone before him, we should not have been as ready for him as we were.

Before the publication of his translation of the One Hundred Poems of Kabir, his own Gîtânjali stood almost alone, representing for many of us all that is purest and highest in Mysticism. Therefore, I venture to repeat here what I wrote of it four years ago. There is hardly a word of it that will not apply equally to the work of his forerunner, Kabîr.

To the Western mind there is a gulf fixed between the common human heart and Transcendent Being. The 
European and the American, in their quest of Reality, are apt to be taken in by appearances; they do not readily make the great distinction. That is partly why, with the exception of the classics of Mysticism, the devotional poetry of the West, Catholic and Protestant alike, is so unsatisfying. Most of it is written by people who are not poets. But the worst of it is that it is not supremely devotional. It does not deal directly with the Transcendent, but proceeds, fervently indeed, but always by way of dogma and tradition, as it were by perpetual makeshifts, and through the most horrible tangle of material and carnal imagery, to a visionary Throne of Grace. You never seem to arrive. Your heart may be soothed by the assurance of atonement; but your finer metaphysical hunger is left for ever unappeased.

But take these songs of Divine Love from the Gitânjali:

"In the deep shadows of the rainy July, with secret steps, thou walkest, silent as night, eluding all watchers.

"The woodlands have hushed their songs, and doors are all shut at every house. Thou art the solitary wayfarer in this deserted street. Oh, my only friend, my best beloved, the gates are open in my house - do not pass by like a dream."

"The day is no more, the shadow is upon the earth. It is time that I go to the stream to fill my pitcher.

"I know not if I shall come back home. I know not whom I shall chance to meet. There at the fording in the little boat the unknown man plays upon his lute."

In the poems of this mystic the world appears no longer in its brutality, its vehemence, its swift yet dense fluidity; it is seized in the very moment of its passing, and fixed in the clarity and stillness of his vision. It is always the same everyday world, the dusty road, the deserted street, the solitary fording, "the bank in the shady lane" where "the yellow leaves flutter and fall." At the coming of the Unknown Traveller "the leares rustled overhead; the 
cuckoo sang from the unseen dark, and perfume of babla flowers came from the end of the road." A world vivid to every sense, yet the stage of a supersensual drama, the scene of the divine adventure. So vivid and so actual is it, that only its strange fixity stirs in you the thrill of the supersensual.

And through this fixity, this stillness of rhythm and of mood, there is a mysterious trouble and excitement, an awful tension of expectancy. It is the stillness of intense vibration, of life inconceivably living, the ecstasy of supreme passion consummated and consumed.

There is nothing in the Western world to compare with these poems but the writings of those mystics who were also saints: Saint Augustine, Saint Thomas à Kempis, Saint Francis of Assisi, Julian of Norwich, Saint Teresa, Saint Catherine of Genoa who said, "My Me is God, nor do I recognize any other Me, except my God Himself." (Vita e dottrina.) Above all, Saint John of the Cross, in The Dark Night of the Soul:

"Upon my flowery breast,

Wholly for Him and save himself for none, There did I give sweet rest

To my beloved one;

The banners of the cedars breathed thereon!"

(Translation by Arthur Symons.)

All these impassioned lovers of the Godhead use the same language, telling of the same unique experience; and it is invariably the language of human passion; for the simple and sufficient reason that there is no other. At the same time, with the exception of Dante's Paradiso and Vita Nuova, it would be lhard to find in all the poetry of Western mysticism a perfect parallel to the passion of the Gîtânjali. There are few Western mystics who do not somewhere betray the restlessness that lies around their rest. Until the final attainment of the Unitive Life, their peace would seem to have been harder won, to be held 
more perilously, to be always on the point of passing; so vivid is the sense they give of effort, of struggle, of frantic desperation. There is a corresponding vehemence and violence in their language. Saint Teresa says of the state of the enraptured soul: "No consolation reaches it from heaven, and it is not there itself ; it wishes for none from earth, and it is not there either, but it is, as it were, crucified between earth and heaven, enduring its passion."

Saint John of the Cross speaks of an "intense and amorous impetus," answering to Saint Teresa's " impetuosities."

For, as we have seen, the language of the Catholic mystic is often the language of sensuous, almost of sensual emotion; so voluptuous that it lends itself very easily to the interpretation of the profane. But it is impossible to doubt the "spirituality" of these Bengali songs of Divine Love. They are at the very highest level of attainment in their kind. They have the serenity and purity of supreme possession. Mystic passion embraces while it transcends the whole range of human passion. Like human passion, it works through body, heart and soul. It is the soul and the heart of passion that you find in the Gitânjali; its secret and invisible things, small and great; all in it that is superb, inviolate, undying; all that is lowly, and most fragile; its impalpable, incommunicable moods, its evanescences, its dreams, its subtleties, its reticences and courtesies; its fears and delicate shames.

"I asked nothing from thee; I uttered not my name to thine ear. When thou took'st thy leave I stood silent."

There is no querulousness and no grossness of impatience, no restlessness in this passion of the expectant soul.

And on the part of the pursuing God there are none of those impetuosities that overwhelmed Saint Teresa. He comes "with silent steps." He is the lover waiting in the shadows. He is the watcher by the bed, the solitary way- 
farer in the deserted street, the traveller at the well; he is Krishna, the lute-player, the " unknown man" playing in the little boat at the fording. I know nothing so persuasive as the glamour of this Eastern stillness, nothing that evokes so irresistibly, so inevitably the sense of the Unseen.

"There, where spreads the infinite sky for the soul to take her flight in, reigns the stainless white radiance. There is no day nor night, nor form nor colour, and never, never a word."

Before this austerity and restraint all foregoing comparisons break down. There is, through all their likeness, an unmistakable difference between those great Western mystics and Rabindranath Tagore.

Their passion utters a more poignant lyrical cry. They experience a more violent rapture in union, and a deeper tragedy in separation. Nothing could well be farther from his spirit than their emotionalism. Individual temperament has no doubt something to do with it; but it is not the whole secret. This tumult and tragic pain of theirs has its own law. It displays itsclf in proportion to their asceticism, to the violence of their rupture with the divine visible world. It is the outcome of the dualism inherent in Christianity. There never was a religion that promised so much and gave so little; that kept man's soul in such an awful poise between heaven and hell; that left his passion for God so agonized and unappeased. Its dualism, its asceticism, frustrates the longing of its saints. Their holiest ecstasies are troubled with the resurgence of the source it has polluted.

To the devotee of a Creator inconceivably different, infinitely remote and separate from his creation, the visible world is necessarily undivine, abhorrent and unholy. In renouncing the world the Eastern ascetic denies its reality. But the Christian, in the very act of renunciation, affirms its shocking independent entity. Thus his deliver- 
ance is never either physically or metaphysically complete. That is the Christian's tragedy. He cannot, without an agonizing struggle, get rid of the world that weighs on him; whereas it is comparatively easy for the Oriental to divest himself, as it were, of his cosmic clothing. It is doubtful if any Eastern ascetic, Brahman or Buddhist, could feel the same furious hatred and horror of the world; seeing that to him the world, the whole visible universe, is at its worse no more than an illusion. You may refuse to become attached to an illusion, you may withdraw from it with every circumstance of profound repudiation; but you cannot furiously hate and abhor a thing which, for you, has no real existence of its own.

In the Gîtânjali you will find none of this hatred and abhorrence, none, either, of this serene indifference and denial.

"Deliverance is not for me in renunciation." ... " $\mathrm{I}$ will never shut the doors of my senses. The delights of sight and hearing and touch will bear thy delight."

"What divine drink," he cries, "would'st thou have, my God, from the overflowing cup of my life?" And again, echoing Kabîr :

"The same stream of life that runs through my veins night and day runs through the world and dances in rhythmic measures.

"It is the same life that shoots in joy through the dust of the earth in numberless blades of grass, and breaks into tumultuous waves of leaves and flowers."

"Is it beyond thee," he asks, "to be glad with the gladness of this rhythm? to be tossed and lost and broken in the whirl of this fearful joy?" To him the life of God is an "abounding joy that scatters and gives up and dies every moment." The whole complexity of things, the veil of Mâyâ, the illusion of the world, is simple and translucent to him, so simple and so translucent that Reality is neither 
hidden by it nor obseured. That wearing of the veil of illusion is the jest of the Divine Lover hiding himself from his beloved that he may be the more passionately desired.

"It is he who weaves the web of this mâyâ in evanescent hues of gold and silver, blue and green, and lets peep out through the folds his feet, at whose touch I forget myself."

Everywhere in these pocms there is this acceptance of humanity, this ecstasy of joy in movement and in beauty, this adoration of life.

"Let all the strains of joy mingle in my last song - the joy that makes the earth flow over in the riotous excess of the grass, the joy that sets the twin brothers, life and death, dancing over the wide world, the joy that sweeps in with the tempest, shaking and waking all life with laughter, the joy that sits still with its tears on the open red lotus of pain, and the joy that throws everything it has upon the dust, and knows not a word." 55

It looks at first sight as if this all-embracing mysticism were different in its very nature from the view of the Catholic recluse prisoned in his cell. And it has apparently even less affinity with Indian mysticism of the Pantheistic type. And this is a little disconcerting. Surely, you say, there must be things in the Upanishads from which some at least of these poems are descended? You take down your Upanishads and hunt through them excitedly for those things, but in vain; unless you are prepared to accept wholesale the interpretation of the ingenious Râmânuja, who contended that even in union with Brahma the individual self maintained its separate identity. And it is only now and again in the Gîtânjali that there comes any reverberation of the mystic words, "Tat tvam asi," "Thou art it," of those resonant and resplendent passages which proclaim the absolute, inseparable identity of all things, of all selves in the Great Self.

Now, the metaphysician may deny or affirm that identity as his appetite or his instinct prompts him. Nothing can 
be more certain than that, for some mystics, the personal relation is an experience, a fact. All the same it, and the separation it implies, is an experience and a fact that begins and ends in their own individual consciousness. It is irreducible, indescribable, incommunicable. Metaphysically, it stands for nothing more nor less than that moment in which the human soul becomes conscious of itself in God. The thing is duplex only in one aspect. Around it, continuing in it and transcending it, are all the unity, all the identity you can desire. The separation is not real; not absolute; any more than death or birth is; it is part of the illusion; part of the great game; "the hiding and seeking of thee and me."

"It is the pang of separation that spreads throughout the world and gives birth to shapes innumerable in the infinite sky.

"It is this sorrow of separation that gazes in silence all night from star to star and becomes lyric among rustling leaves in rainy darkness of July.

"It is this overspreading pain that deepens into loves and desires, into sufferings and joys in human homes; and this it is that ever melts and flows in song through my poet's heart."

To find Rabindranath Tagore's true sources and affinities you must go back, first of all, to the fifteenth and sixteenth centuries; to Kabîr the mystic; to the great Vaishnavists who were the Humanists of India; to Chandidas the poet; to Chaitanya Devi, the God-intoxicated saint and seer. But going back further still, as far back as you can go, you find this naif personal attitude in the Vedic Hymns. The ancient Rishis, as lamentably as any Christian, felt "self" to be separated from their deity or deities by the fact of sin. It was those who came after them, the more philosophic Rishis of the Upanishads, the Buddhists who came after them and the expert metaphysicians of the Vedânta, who reversed this view and found sin in the illusion of separation. And all the later mystic poetry of India, from Kabîr onwards, springs from 
the conflict and reconciliation between that immemorial feeling of separation and that profound and supersensual certainty of oneness. This indeed is the source of all the mysticism that ever was. Only in India the feeling of separation is the baffling thing. The supersensual certainty is taken for granted, while in Christianity it is all the other way. In India it is simply a question of whether you are going to agree, say, with the ingenious Râmânuja that the individual soul preserves its identity in union; or with the learned Sankarâcharya that it has never had any separate identity to lose; or with the poets, who are the seers of Reality, that it may have identity and lose it, and recover it and lose it again. For there is always this third alternative.

It is clear that what the mystics are seeking is transcendent identity. There are three who, by their double genius of passion and of insight, have the right to speak for all of them.

One is Julian of Norwich.

"Till I am Substantially oned to Him, I may never have full rest nor very bliss: that is to say, till $I$ be so fastened to him that there is right nought that is made betwixt my God and me." (Revelations of Divine Love, p. 10.)

One is Rabindranath Tagore.

And one is the greatest of them all - Kabîr.

Kabîr is a test case. Before the appearance of the One Hundred Poems (translated and edited by Rabindranath Tagore and Evelyn Underhill), the only Kabîr that I could lay my hands on was a book of select passages, translated and edited by a Christian missionary.

I don't suggest that the missionary "did anything" to Kabîr. Still, the repudiators of Pantheistic Monism have used Kabîr freely as a proof that Christianity had "spiritualized" India; and when this was all we had of 
him it was possible to admit that there might be something in it. At least it was possible to give the dualists the benefit of a doubt.

I find that I gave it them myself in 1913, when I could write this sort of thing:

"Kabîr, conscious of the separation, conceives union as a mingling in which the soul is certainly $\lceil!\rceil$ not lost. "The soul (âtma) and the Great Soul (Param Âtma) for many ages remained apart; the true Guru (teacher) came as a dealer (dallah, middleman) and made of them a beauteous mixture.' 'The power that cannot be described, the form that imparts life, whoever becomes one with him (as milk with water) that man, says Kabîr to Dharm Dass, Kâli cannot destroy.' 'Thou art the ocean; I am the fish of the water,' he says, 'I dwell in the water, without the water I am done for.' But he does not say he is a dewdrop and that he slips into the shining sea. And though he protests "Whatever I did, you did; I did nothing myself; should men say I did it, it was in your strength that it was done,' he makes it clear that he preserves his separate identity all the same."

The champions of Christian Dualism are welcome to all they can get out of Kabîr's fish, and his milk, and his middleman; and to all they can get out of any other image he may use to express his relation to the Absolnte. I cannot conceive how they can read the rest of the Hundred Poems and not see that India has absorbed him body and soul. $\mathrm{He}$ has the true intransigeance of the convert. $\mathrm{He}$ is closer, far closer than Tagore - to the pure metaphysical Monism of the Svetâsvatara-Upanishad. His mysticism is only free from metaphysics becanse it has passed through the last fires of thought. It is utterly sublimated.

Take the least metaphysical and most purely poetic of the Hundred Poems:

XII

"Tell me, O Swan, your ancient tale,

From what land do you come, O Swan? to what shore will you fly? 
Where would you take your rest, O Swan, and what do you seek?

"Even this morning, O Swan, awake, arise, follow me!

There is a land where no doubt nor sorrow have rule: where the terror of Death is no more.

There the woods of spring are a-bloom, and the fragrant scent ' $\mathrm{He}$ is I' is borne on the wind.

There the bee of the heart is deeply immersed, and desires no other joy."

\section{Again :}

"The creature is in Brahma, and Brahma is in the creature: they are ever distinct; yet ever united.

$\mathrm{He}$ Himself is the tree, the seed, and the germ.

He Himself is the flower, the fruit, and the shade.

He Himself is the sun, the light and the lighted.

He Himself is Brahma, ereature, and Mâyâ.

He Himself is the manifold form, the infinite space.

He is the breath, the word, and the meaning.

He Himself is the limit and the limitless, and beyond both the limit and the limitless is He, the Pure Being.

$\mathrm{He}$ is the Immanent Mind in Brahma and in the creature."

" $\mathrm{He}$ is immersed in all consciousness, all joys and all sorrows; He has no beginning and no end;

He holds all within his bliss." (xxvi.)

"Before the Unconditioned, the Conditioned dances.

"Thou and I are one!' His trumpet proclaims." (xLV.)

"The water-filled pitcher is placed upon water, it has water within and without.

It should not be given a name, lest it call forth the error of dualism." (XLVI.)

(What could possibly be plainer?)

$\operatorname{LXXX}$

"The true Name is like none other name! 
The distinction of the Conditioned from the Unconditioned is but a word:

The Unconditioned is the seed, the Conditioned is the flower and the fruit.

Knowledge is the branch, and the Name is the root.

Look and see where the root is: happiness shall be yours when you come to the root.

The root will lead you to the branch, the leaf, the flower, and the fruit:

It is the Encounter with the Lord, it is the attainment of bliss, it is the reconciliation of the Conditioned and the Unconditioned."

Evelyn Underhill points out in her Introduction that the mystic intuition recognizes " a universe of three orders: Becoming, Being, and that which 'More than Being,' i.e. God."

It is well said. And yet I confess I don't see how the haters of Monism can, without blushing, quote Kabîr any longer in support of their contention; nor how the apologists for Christianity can conjure a Trinity out of him. His world of "Becoming" is surely the world of Mâyâ, of Illusion. And the world of Illusion, like Dr. McTaggart's Absolute, is " not a Person."

As for "the error of Dualism"- it may have touched the ingenious Râmânuja ; but it certainly does not seem to have contaminated Kabîr. In his world, discussions as to individuality lost, or individuality preserved have little meaning.

\section{III}

Now it is quite clear that in the classies of Mysticism we are dealing not only with a peculiar kind of experience, but with a peculiar kind of genius. And, again, having made all allowance for the influence of "mystical illhealth," the lover of literature must protest against the grossness of the interpretations that have been brought to these texts. The writings of the great mystics are not all charged with " unsublimated libido." 
I do not see how we can deny that Julian of Norwich has the imagination and the style of a great poet, as well as the temperament of a saint. Nobody but a poet could have conceived such blending of loveliness in horror. To bring nothing but the literalism of the pathologist to bear on her Revelations is absurd. Even in the worst instances - I am thinking of certain utterances of Gertrude of Eisleben, ${ }^{56}$ of the Blessed Angela of Foligno, and of Saint Teresa herself - there is a perpetual striving after something stronger than the sonl's passive blessedness, and higher than its voluptuous spiritual ecstasy. This excess of feeling demands and finds expression; now and then it flashes into metaphysical intuition; again it crystallizes into some perfect and transparent phrase; and you have the beginning of a naif art; and where art is there is sublimation. Thus the Blessed Angela says that the Divine Love "came towards me after the manner of a sickle. Not that there was any actual and reasonable likeness, but when first it appeared unto me it did not give itself unto me in such abundance as I expected, but part of it was withdrawn. Therefore do I say after the manner of a sickle." The Blessed Angela may or may not be deceived as to the spiritual nature of her experience; however that may be, two things are clear: that she is using the language of poetic imagination, and that she is struggling with almost fantastic honesty for precision of language and of thought. It seems to me that, whatever their spiritual value may be, such utterances should be judged, not with the crude literalism of her critics and of her admirers, but with the liberal judgment accorded to works of the imagination.

But no. Professor Jung finds megalomania in an ancient Egyptian text, the Hymn of the ascending soul, proclaiming its unity with God.

"I am the God Atum, I who alone was,

I am the ('isl Rê at his first splendour, 
I am the great God, self-created, God of Gods, To whom no other God compares."

"My impurity is driven away, and the sin which was in me is overcome. I washed myself in those two great pools of water which are in Heracleopolis, in which is purified the sacrifice of mankind for the great God who abideth there."

"Thou, who standest before me, streteh out to me thy hands; it is I, I am become one of thee. Daily am I together with my Father Atum." 57

He finds resurgent lust in the Brahman's vision of the Absolute.

"The person (purûsha) of the size of a thumb, stands in the middle of the Self, as lord of the past and the future, and henceforward fears no more. This is that.

"That person, of the size of a thumb, is like a light without smoke, lord of the past and future, he is the same to-day and to-morrow. This is that." (Katha-Upanishad, ii. 4.)

"The person (purûsha), not larger than a thumb, dwelling within, always dwelling in the heart of man, is perceived by the heart, the thought, the mind; they who know it become immortal." (Svetâsvatara-Upanishad, iii. 13.)

Professor Jung's interpretation of these passages is entirely Freudian. ${ }^{5 s}$

At this rate there is no reason why he should not find megalomania and resurgent lust in Dedekind's and Cantor's theories of the Infinite, or in Mr. Bertrand Russell's pursuit of the Fourth Dimension, on the grounds that they involve "generation of series."

We have admitted that Psychoanalysis had much to say; but when it has said it, the secret of mystic passion and of mystic certainty remain alike insoluble. Its criticism rests on the assumption that ends have the same form as origins; which is contrary not only to erolution, but to the psychoanalyst's own pet theory of sublimation. 
But this arraignment of Mysticism need not concern us any more. It only applies to those manifestations that belong to the transition periods of its childhood and its youth. Where they persist, they persist by way of survival or reaction or disease, and they are doomed to disappear.

For if we are right in supposing that what is supernormal consciousness now will be normal consciousness some day, we may expect its perfection to be reached by forgetfulness of its old labour and effort, unconsciousness of the very practice that will have made it perfect. Pantheistic Mysticism begins where Mysticisms that are not pantheistic end. It takes for granted that, as between God and the world, the Absolute and the finite selves, there is no separation. For all her Catholic sympathies, Evelyn Underhill is a pantheist at heart. Witness her "Immanence" and "Theophanies."

"I come in the little things

Saith the Lord.

Yea! on the glancing wings

Of eager birds, the softly pattering feet

Of furred and gentle beasts, I come to meet

Your hard and wayward heart. In brown bright eyes

That peep from out the brake, I stand confest.

On every nest

Where feathery Patience is content to brood And leaves her pleasure for the high emprize Of motherhood there doth my Godhead rest."

And M. Bergson, though his logic lands him sometimes in an upsetting Dualism, is a good pantheist at heart. He sees as the mystic sees, that the Élan Vital is the energy of one Being which makes matter its means of manifcstation, its vehicle, its tool. He sees that the process of Becoming is a spiritual process of ascension.

Thus, though we cannot say what the Mysticism of the future will be, we may be pretty sure what it will not be. 
It will not be sickly; it will not be morbid and hysterical, or sentimental. In exchanging God the Father for God the Absolute Self, it will have lost that irresponsible dependence which has kept men and women for centuries in a pathetic infancy. Sooner or later the mystic has to grow up like other people. He will know that he fulfils the absolute purpose best by trying to become, as far as possible, a self-determined being. He knows already that, if " auto-suggestion" is anything at all, it is self-determination.

And he will not be violent. "The Kingdom of Heaven suffereth violence until now, and the violent take it by force." That was where the imperfect mystic made his great mistake. Just as primitive man desired to get by magic physical things that would have come to him without it of their own accord, in due season, so the imperfect mystic desires to get spiritual things by mysticism that will come to him without it of their own accord in due season. The savage is trying to force Nature's hand. The imperfect mystic is trying to force God's hand.

Not so the accomplished lover of the Absolute. His passion may be overpowering and importunate, but not its method. He will not forestall its perfect consummation by one hour. The more certain he is, the more he can afford to wait.

"Kabîr says: . . . stay where you are, and all things shall come to you in time." 


\section{VIII}

\section{CONCLUSIONS}

IT is clear that we have to choose between some form of Pluralism and Monism.

There is nothing new in this. It is the old problem and the old choice that has lain before Philosophy in the beginning; but with this difference, that whereas Philosophy had no valid grounds for a conclusion as long as it travelled on the "high priori road," it is now in a rather better position for bringing its conclusions to the test of experience.

It is not, and it camnot be, a question of certainty. No reasonable person demands certainty at this time of day. The utmost he is entitled to demand is a certain balance of probabilities. Perhaps not even that. Perhaps only here a balance and there a chance, and there, again, an off-chance, a bare possibility.

So, instead of asking Which conelusion is the more eertain? we may only ask Which hypothesis, Pluralism or Monism, is the more likely, the more in keeping with the facts?

This is not a pragmatic question, nor is it a pragmatic test. It is not to be confused with the demand that metaphysical truth shonld square with the requirements of human conduct. By the "facts" I do not mean merely the facts of life. I mean the sum total of our knowledge, or knowledges up to date. Our knowledge of consciousness and our knowledge of knowledge must take their place in the collection, together with our knowledge of the so-called external world.

The facts, therefore, will not all stand on an equal foot290 
ing. The ultimate appeal must always be to the knowledge of knowledge.

If the facts favour one hypothesis more than the other, then we may ask further, which hypothesis has the better metaphysical support? If we are lucky enough to get a reasonable conformity on all heads, then and not till then we may ask further which hypothesis, Pluralism or Monism, is on the whole more satisfying to collective human emotion and to the moral sense? And we must be very careful that by these we do not mean "more satisfying to me."

At first sight it looks as if Pluralism had all the facts on its side. It can point to a universe in which the earth is a comparatively insignificant dot on a field covered with several million heavenly bodies, a physical universe of apparently unending multiplicity, of apparently unceasing change and flux. It can break up the flux itself into an infinity of elements of which you can only say that each is where it is at the instant when it is. Supposing matter to be made up of an infinite number of atoms (or, if you like, of electrons), it cannot be said with positive certainty that any atom yet discovered is ultimate and indivisible. Pluralism can refer us to a world of selves, of psychic entities, whose chief distinction is that they repel and repudiate each other, besides harbouring a host of conflicting instincts, desires, and memories, whose presence makes for continual disruption; consciousness itself abounding with irreconcilable multiplicities. Foremost among these are pain and evil, which ontrage every just and compassionate and holy instinct of the selves.

Pluralism can even insist with considerable plansibility on a final and irreconcilable dualism between these two worlds.

And its very Logic, its knowledge of knowledge, is atomistic. 
And yet the Pluralist himself must admit that this is an inadequate and superficial view of the facts. The more we explore this multiplicity, the more it reveals the secret of its unity. And this unity is not simply imposed on multiplicity by immediate consciousness and by the laws of thought. It is not only a question of the way we are obliged to think things, but of the way things behave. Every generalization of physical science, and every correlation of physical laws, amounts to a plain statement that within the range of the generalization the order of things is one. The law of conservation of energy is nothing if not a confession that, as far as the physical world goes, incorrigible multiplicity and difference do not obtain. It would even seem that, ultimately, the entire physical world is definable in terms of energy. And if the ultimate constitution of matter is invisible, imponderable, impalpable to any sense (its density disappeared long ago); if all the grossness, all the heaviness and hardness, all the intractable lumpiness of matter, all its so-called material qualities are not to be found in it, but only in our consciousness of it, we need no longer juggle with terms that are so interchangeable. The realist and idealist are both agreed that there is no physical It behind those qualities. And unless we are satisfied that he is right in contending that they exist, " on their own," we may as well say straight out that these two worlds, anyhow, are one; and that the ultimate reality of " matter" is spiritual energy.

We have seen that it is his implacable moral consciousness that urges the Pragmatist to plant his Pluralism in the very heart of reality itself; and to insist that there is no ultimate spiritual energy, one in many forms, but that there are as many energies as there are forms, and that spiritual energy is only one of them. I hope it has also been seen how his moral consciousness goes back on him, and lands him in the oneness he abhors.

And in the world of living organisms, before a moral 
consciousness was ever heard of, we saw that the LifeForce, the Will-to-live, revealed itself in the process of evolution as one indestructible energy, and one desire striving for fulfilment and for sublimation, an energy made manifest in such forms and in such a manner as to declare its spiritual source. We saw that the mere physical process was only intelligible if we admitted the psychic factors of desire and design. We saw the growth and building up and shaping of the organism by the psyche for its own ends. We saw that desire and design and performance were only intelligible if we presupposed a self that is something over and above its memory. We saw that biology, so far from merging the individual self in its own ancestral heritage, presupposes its independence and its supreme importance as a factor in heredity itself.

We found confirmation of this view, where we least expected it, in the facts of psychopathology and the results of psychoanalysis. They showed us one indestructible primal energy at work in all the functions of the psyche. They showed the persistent symbols of its presence throughout the whole region of the "unconscious." They showed that all aberrations and perversions are reversions, the turning back of the individual on the ancestral paths by which he came. They also showed by what processes of sublimation he asserts himself against the backward pull of the instincts that tend to merge him with the race.

Again, Psychology, besides endorsing the biological evidence, showed us that consciousness is a unity that could hardly be if there were no self over and above consciousness, unaffected by its multiplicity, its change and flux. We found that the self is not passive, and that thought has its own energetic way of dealing with the stuff of consciousness; that it multiplies and divides, makes finite and makes infinite, and that of all that it 
scatters it gathers again. Apart from the work of thought, we found that the stuff of consciousness is not divided; that it is given in a continuous unity; that its sequences overlap; and that states of consciousness have more than sequence; as William James says, they have "thickness." And we saw that if anything ever was one it is this thickness.

We found that here our choice lay between Animism and Psychophysical Parallelism. We saw how the Dualism of the parallelist broke down under an examination of the psychophysical facts.

We also found that Psychology was powerless to solve its own problems, and flung us back on Metaphysics. We had then to choose between some form of Pluralism and Monism. We were obliged to dismiss all à priori arguments for Monism as worthless, so long as they remained unsupported by actual experience, and so long as they left whole tracts of experience out of their account. But so far as they explain experience, and so far as experience corroborates them, they are not to be lightly set aside. After all, our way of thinking justifies itself. Where the necessities of thought agree with the necessities implied by the behaviour of consciousness and the behaviour of things, they must count as real necessities. Our problem then was: Is unity or is boundless multiplicity the supreme necessity of thought?

Comparing one philosophical system with another, we thought we saw that the end and goal of the metaphysical quest has been mainly one nltimate principle, rather than two or more ultimate principles. We found this secret passion for the Absolute and the One breaking out in the very Dualisms that repudiated it; and we traced the root and the cause of all philosophical dilemmas to the search for oneness and for ultimate reality in the wrong place. Pragmatism and Humanism stood out as 
the great exceptions. If you cannot say that they have looked for ultimate reality in the wrong place, since they were not looking for it at all, they have looked on at the usurpation of its place and power. And Pragmatism betrayed its own inherent dilemmas.

On the balance of the evidence before us, we were driven to the conclusion that the ultimate reality of things and the ultimate reality of consciousness is one; and that this one reality is Spirit.

We might have rested there, complacent and happy, but for the New Realism whose violence took our kingdom of heaven by storm.

And so our problem narrowed itself down. We had to choose between our Spiritualistic Monism and this particular brand of Realistic Pluralism.

We distinguished between the premisses and the conclusions of the New Realism; between its science and its system; and again between its construction and its critique. We found that while much of its critique must be of enduring value in philosophy, it applied rather to the pseudo-monisms than to ours. We found that, though its foundations were sure as the axioms of pure mathematics and of Analytic Logic could make them, the superstructures reared on this imposing base were somewhat lacking in coherence and solidity. We found that in applying the axioms and conclusions of the mathematical and physical sciences as a test of the reality of phenomena, it has brought us no nearer to the root of the question in debate - the nature of ultimate reality. And though we were prepared to admit it was within its rights in renouncing the quest of ultimate reality, we found that it failed to establish its negative conclusions beyond the reach of doubt; and that its positive conclusions yielded contradictions every bit as compromising (to $i t$ ) as those it undertook to solve. 
We also saw that it was possible to state the principle of Spiritualistic Monism in terms which at any rate exclude contradiction.

Thus we conceded that, as a restatement of mathematical and logical first principles, the New Realism is almost as impregnable as it professes to be. But, in spite of its combined air of certainty and scientific caution, we could not admit that as a system of metaphysics it justifies its existence better than other philosophies that plunge.

Therefore my imaginary monist refused to relinquish the principle he (perhaps rashly) stakes his all on. $\mathrm{He}$ refused to be driven from his position by the multiplicity of anything that Pluralism, or Science for that matter, has to show. He is not going to be scared out of it by the bluff of physical Atomism. He does not care how many elements are involved in magnetic force, or how many tricks the physicist's mysterious electrons play him. Why should he? Once his Absolute starts the business of appearing, a little multiplicity more or less cannot break it. He would not be greatly distressed if the law of conservation of energy were exploded to-morrow, as it very well may be. It does not matter to him how many appearances and laws of appearances there may be two or three million, or an infinite number. If anything, he prefers an infinite number, because it provides him with the reassuring contradictions he is looking for.

It will be said of my monist that he cannot clear himself of one reproach: from first to last he is only juggling with the unity of consciousness, which his opponents do not admit to be a unity at all. And he must admit, not that he has helped himself to the unity of consciousness, but that the unity of consciousness has helped him considerably. It is only not a unity if you adopt the extreme realistic theory of knowledge, which he thinks he has shown good reason for repudiating. It is the only 
thorough-going unity he knows. He finds this unity, not in or among his states of consciousness, shaken about with them in the same bag, as it were, but in the irreducible, ultimate fact of selfhood. He finds that the Self resists all attempts to analyse it into the separate states or stages of its own consciousness; that it is more than the sum of these states; more, that is to say, than consciousness.

To this Something More he gives the name of Spirit; for the reason that while, in ultimate analysis, matter may be resolvable into terms of immaterial being; spirit, or self, is not by any means so resolvable into terms of matter.

Before Monism can work it must have a principle which shall be both static and dynamic. But as long as the monist was tied to his bare epistemology, he could find no means of defining "Thought," so as to include in it things that are not "thoughts." To say that "Thought thinks itself" is not enough. From the unsubstantial forms of its thinking it can build no bridge from its own world to the world where things are and are done. But Spirit can be supposed to do things. He can define it as that which thinks, and wills, and energizes in one undivided act. His principle is as static and dynamic as he pleases.

If he is asked whether he has any precise conception of the principle to which he gives the name of Spirit, he can at least answer that his definition amounts to a fairly precise conception.

If he is asked if he has any conception at all of the ultimate nature of Self or Spirit, he can retort that he has no more conception of the ultimate nature of Self or Spirit than the new realist has of the ultimate constitution of matter, or of conscionsness, or of universals; and he claims the realist's right not to go behind reality; but to regard it as itself ultimate and irreducible.

If he is asked how he proposes to justify his leap from 
the presumably finite and relative self or spirit, of which he has a more or less precise conception, to the Self or Spirit he has declared to be absolute, he must own that he is not justified in making any leap. Ile can only say that in the unity of his own conscionsness the term spirit covers will and action and passion, as well as thought and sense. $\mathrm{He}$ finds that love and thought and will behave as energies, as motive powers, or even as causes, within the unity of his consciousness. He has every reason for concluding that they behave as energies and motive powers or even as causes in other consciousnesses besides his own. And he sees no reason why they should not behave with greater energy and motive power and causal efficiency within greater consciousnesses than his or other people's. He finds that the behaviour of this finite and relative consciousness of his, its knowledge and its relation to its knowledge, are inexplicable without the assumption of an infinite and absolute consciousness, as the ground of all its knowing. He finds that the very existence of his self is inexplicable without the assumption of an absolute, selfsubsisting Self, as the ground of its existence and his real Self. And he sees no reason why the spiritual energies of such a Self should not be equal to the evolution of such manifestations as this spectacular universe and its spectators.

In the matter of manifestation he knows that, if his own self is to know itself and to make itself known, it must think and feel and will and act through forms and forces that are called material. And so he sees no reason why the Absolute Spirit, his real Self, desiring to know itself, and to make itself known, should not manifest itself also through forms and forces that are called material.

He sees no reason why not; and nobody has yet advanced any really valid and satisfactory reason why not.

If this is to juggle, he juggles. 
No really valid reason why not. But one apparently valid reason, which is the crux of Pantheism: the alleged absurdity of a reality knowing itself and making itself known through what is, after all, an endless procession of spectacular illusions. At this rate, it may be said, the Absolute is juggling, too. And there is a sort of general feeling that it is beneath its dignity to juggle.

Now it is pretty certain, judging by appearances, that if the Absolute had stood on its dignity it would never have appeared at all. It is also certain that, so far as there is any meaning in this objection, it is our sense of dignity that is offended. And our sense of dignity is part of the illusion.

Still, a talent for producing endless illusions about itself does seem incompatible with a veracious Reality. We might, of course, credit Reality with the utmost veracity of its absolute and transcendent Self, and charge all the illusion to the account of the finite selves. But the trouble is that, on the theory, Reality is also supposed to be appearing to itself, getting to know itself, introducing itself to itself, as it were, through an endless round of cosmic "At Homes."

If the round is really endless, it cannot, any more than a finite self, succeed in completely making its own acquaintance. And the pluralist has every right to ask the monist what he is going to do about it.

Now, I think, it must be owned that this endless procession, or series of manifestations does land the monist in a very awkward predicament, if he really means that a complete knowledge of every single one of its finite manifestations in time is necessary to the Self's absolute knowledge of itself. The only thing he can do is not to take that line. His only possible reply is, that on Realism's own showing, knowledge depends on universals, not on simple enumeration of particulars; and that, if it is not necessary for a finite self to reel off a list of all the 
particulars it knows, before it can be said to know anything, it must be still more unnecessary for an absolute and infinite Self to know every single one of its manifestations before it knows Itself. On the contrary, just because it is absolute, as well as infinite, it must be supposed to know itself completely at each instant of its manifestation.

There are, however, considerable difficulties about an Absolute Reality that insists on publishing itself, as it were, in serial instalments. But I think they must be charged to the account of the finite selves, who are obliged to "take in" their Absolute in serial form. They arise from our persistent habit of regarding the Self's knowledge of the finite as a finite knowledge, and its passage through time as part of its eternity.

Practically the reverse problem is presented by the existence of evil. The pragmatist complains that you are "taking a moral holiday" if you refuse to regard such things as badness, and nastiness, and silliness, and ugliness, and a kick in the ribs, as so many knock-you-down arguments against Monism.

Well, you have not got to take a moral holiday to see that they are staggering facers for the realist, who regards them as eternal and immutable realities. The realist having, apparently, no other outlet for his cosmic emotion, grows almost lyrical over his incorruptible world of the universals, enduring for ever and ever, out of space, out of time, in their stainless, intangible perfection. But, if goodness, and niceness, and wisdom, and loveliness, and the absence of a kick in the ribs, are realities that endure for ever and ever, so are badness and nastiness and the rest of it. I do not know how the realist contrives to have his emotion. I suppose he just thinks of Beauty and Goodness sitting up there, and tries to forget that his wife's temper and the kitchen saucepan are sitting there, 
too. He cannot conjure them out of his universe by any juggling. They are absolute. He has said it.

What is even worse, every particular instance of badness and nastiness and silliness is absolute too. The realist may say that silliness is not silly, but what he means is that it is something far sillier.

But the monist saves the essential cleanness and sanity of the universe in denying that nastiness and silliness and a kick in the ribs subsist, as such, and as realities, in the transcendent life of Spirit. He denies that the Absolute is obliged to listen for ever and ever to the stories that Brown tells Robinson when Mrs. Robinson has left the room. If, in the infinite reverberations of the universe, there endure infinite echoes of Brown's story, they are echoes that only finite and incarnate spirits catch.

And if you insist that, as immanent in the finite and all too incarnate spirit of Robinson, the Absolute has heard Brown's story and enjoyed it; and that, as immanent in the finite spirit of Brown, it has also told it, the monist will have no objection; provided you add that, as immanent in the person of Mrs. Robinson, it has disapproved of it (and of Brown, and of Robinson) severely.

He might go farther and affirm that there is justification for the apparently incredible and inexcusable existence of Brown and Robinson. Light is thrown on their mystery by the existence of Mrs. Robinson, whose spiritual beauty is set off and made more desirable by contrast, whose spiritual strength grows by exercise in the gymnasium of spiritual adversity that marriage to Robinson provides for her.

"Why rushed the discords in but that harmony should be prized?"

That - the dependence of goodness upon evil, the endurance of evil for the sake of good - was the old Ideal- 
ism's solution of the moral problem. Not a bad solution, as far as it went, whenever you could get it to go.

"The evil is null, is nought, is silence implying sound."

Yes; it is all very soul-stirring and uplifting; but it is not true in the world where its truth matters; this tragic world of space and time. The pleasant faney of evil as negation is no more convincing to a logical mind than it is consoling and satisfying to the unreasoning heart. It won't work. It won't wash. Go to the victims of war and pestilence, and tell them that their torment is only the opposite of rapture. Tell a starving population that its hunger is merely the absence of satisfaction. Tell the sweated workers in the East End that their poverty is purely relative to affluence, and but subserves another's gain; tell a mother who has just lost her only son that bereavement is simply the negation of possession, and see how it washes and works.

Besides, if you are going to take it that way, goodness will be null in itself, will be nought in itself, will be sound implying silence, and depending on silence.

There is nothing to be said for pain and evil, thus devitalized. You have robbed them of their only title to existence when you have taken away their positive and stimulating character, their antagonism, their brave, stoic challenge to the fighter. They are not negative. They are tremendons powers. They eall forth all the stern virtnes and all the tendernesses that without them conld not have becn. They make and remake the souls of saints and heroes. By even sordid suffering, decently borne, the humblest and most insignificant sonl may be exalted.

You may know that all this is true. You may know that great suffering, great adversity, may be the greatest and the best thing that can happen to anybody. You may know that your own suffering, your own adversity was 
the best thing that could have happened to you; and you would not, if you could, have spared yourself one single pang of it. But you also know that there are vast millions of other people for whom suffering and adversity are not good at all; for whom none of these truths are true. And when all is said and done, it is intolerable that these people should suffer. It is intolerable that the heroic and tender virtues of a few superior persons should be nourished on the sufferings of these millions. It is really paying too big a price for individual virtue. Nobody has any right to be either eompassionate or heroic at his or her neighbour's expense. And no theory can make it tolerable.

But it may be more intolerable on one theory than on another. And it is most intolerable on the theory that makes pain and evil real and absolute and eternal, and that allows for no vision of any state of being in which they cease to be. The one thing that helps us to enduranee is our sense that pain and evil have not, after all, an immortal life. The one thing that makes them intelligible is the assumption that the only life they have is an unreal one. The one thing that would make them bearable would be the unshaken convietion that we have an immortal life in which they are overeome; in which we receive, or make for ourselves, or give to others whom we have injured, eompensation.

('The demand for compensation is a humanistic and pragmatic demand, and belongs to another line of argument altogether.)

Of purely metaphysical theories, Monism is the only one that supports our sense of the illusion of evil and the assumption of its unreality.

Now, true as it may be, his theory of the mere relativity of evil does not carry the monist very far. Still, as long as he had no other solution of the problem, he was glad cnough to be delivered from the horror of real evil, eter- 
nalized and absolute, even at the cost of parting for ever with real good, eternalized and absolute.

But this awful choice is no longer binding on him.

The New Realism has taught him how he may raise up the New Idealism on the ruins of the old.

$\mathrm{He}$ is dead right about the relativity of the evil that we know. The goods and evils of our earthly life are purely relative both to each other and to human conditions. They are even interchangeable. Goodness may be sought for, now in this set of actions, now in that. It may be attached to things once accounted evil. Evil may be attached to things once accounted good. Goodness itself remains as an eternal and immutable Idea.

It may or it may not be real. The finite selves do not know it as a reality. They only know it as a mysterious logical function by which its appearances are reeognized and known. What it may be in itself or " in the Absolute" they do not know.

Badness also remains as an eternal and immutable Idea. So that we do not seem to have gained much. But we have gained this, that we are not compelled to attribute reality to badness. It also is, for us, the mysterious and harmless logical function by which its appearances are recognized and known. What it may be in itself, or "in the Absolute" the finite selves do not know.

They only know (and this is our immense gain) that in themselves, or in the Absolute, Goodness and Badness are no longer relative to each other.

Therefore it will not follow that if one is real in the Absolute Self, the other also is real; and that if one is the complete and perfect expression of the transcendent nature of that Self, the other is its complete and perfect expression. It will not follow that, if Goodness is all powerful, Badness is all powerful too. It will not follow that badness is more than the logical function of knowledge we already know it to be. 
But all these consequences follow, rigorously and inevitably, from the realistic theory of universals. The New Realism closes the door to any possibility that the lovers of Goodness can endure to contemplate.

The New Idealism leaves the door open to our vision of Goodness, Beauty, and Truth, eternal and real, surpassing all goods and beauties and truths we know; incorruptible; inassailable by evil.

It may be that some universals are only logical functions, and that such Ideas will have no more than a potential immortality, and that evil, ugliness, and the rest may be such Ideas. So that, for a Self that refused to know evil and ugliness, or had no longer any use for such knowledge, evil and ugliness would literally not be.

We have seen that the old Idealism, with its doctrine of relativity, deprived us of our highest moral ideal, without any compensation for the loss beyond its academic assurance of the illusory character of evil. We have seen that Pragmatism and Humanism provided no metaphysical ground for the ethical claim they make paramount, and that Pragmatism, at any rate, sets up a false and unethical criterion of the Good. We have seen that the New Realism threatens us with the eternal reality of evil. Where so much is uncertain, I do not want to claim a superior certainty for this tentative reconstruction that I call the New Idealism; but I do think that, more surely than any other theory, it opens a way of escape from the worst entanglements of the moral problem.

Meanwhile, it should be clearly understood that my monist's distinction between appearance and reality is not a distinction that robs one single appearance of its own peculiar and relative reality. On the contrary, he would not be a good monist if he did not contend that the absolute Reality which is Spirit is its own appearances. His principle is such that it confers more reality on ap- 
pearances than it takes away. There is no earthly reason why he should not call himself a Realist, except that the title has already been appropriated by his opponents. $\mathrm{He}$ is only obliged to insist on his distinction in order to resist the conclusion they offer him as an alternative.

What he says is: This multiplicity and change that you find in the universe I also find. There is not one sensible or intelligible fact in the whole collection to which I should refuse the name of reality, provided it be understood that not one of these is the Reality I am looking for. There is no sort of necessity to go out and look for multiplicity and change when you have got them all around you. I want to know what, if anything, lies behind or at the bottom of multiplicity and change.

You say there is nothing behind or at the bottom of them, and that change and multiplicity are sufficient unto themselves. And I repeat: Are they? I ask you how there can be multiplicity without something that multiplies itself, or change without something that persists throughout change.

It is not that you cannot conceive multiplicity without unity, or change without the unchanging. You can very well conceive them by a process of logical disintegration. It is that, that without the unchanging One, the many and the changing cannot $b e$. Take away the persistent reality underlying any process of change, or any chain of changes; and both process and chain split up into an infinite series, of which you cannot say of any one moment that it constitutes a change. Everything is at the infinitely divisible instant when it is. You have, in fact, no change at all, but the monotony of an endless series of absolute entities. The one underlying reality, then, is the only means by which a process of change can be carried on; and this, whether you regard a process of change, incorrectly, as an unending chain laid out along 
one straight line, or, correctly, as an intricate system of apparently unending chains.

Whatever charges can be brought against this form of Monism, it cannot be taxed with "thinness," or barrenness, or immobility. Nothing could well be thicker, more multitudinous and less monotonous than the life of a Self and Spirit that is one. But by every retrenchment of its unity - that is to say, by cutting it off from any section of the universe - you at once diminish its multiplicity and deprive your section of the possibility of change. By removing it altogether, the pluralistic realist knocks the bottom out of his pluriverse.

It is even more obvious that, if this Self or Spirit is to be conscious of the change and multiplicity of its own manifestations, it must be one. For if it ceased to be one and the same self at each moment of change, no moment of these momentary selves could be more than one momentary monotone. Thus Pluralistic Realism robs its spectacle of any continuous spectator.

And so, on a balance of considerations, my monist refuses to relinquish his principle.

At the same time he must be prepared to relinquish it the instant he receives proof positive of its untenability. This is as good as a confession that he holds it provisionally, as a likely hypothesis, and not as an absolute certainty.

He is painfully aware that the very existence of his Absolute Spirit is problematical; that, outside certain extremely rare forms of mystical experience, it is not discoverable by any experimental method known to man. Neither is it provable by any strict deduction from known laws of the existent. He cannot uphold it either as a conclusion or as a necessary presupposition of all thinking. All he can say is that his hypothesis does not conflict with any proved certainty, and that it seems to him 
to cover more facts than any other that has been put forth hitherto. He might even urge that there are some facts the outer fringe of which no other hypothesis so much as touches.

This brings us to the end of our reasoned arguments.

Throughout the foregoing metaphysical discussion one point must have struck the unmetaphysical reader, as it certainly strikes the mere writer: that a good half of the problems under consideration arose solely from the limitations of language. We can argue with perfect propriety as to whether things are or are not out of time and out of space; and whether one body is or is not outside another body; and whether it is a part or a whole; and if a part, whether of this whole or that. Of things occupying space we can argue as to whether they run parallel to each other or not, or whether they stand at the circumference or the centre.

But when it comes to discussing whether things are inside or outside of consciousness; whether consciousness is a part or a whole; whether, if it runs, it runs parallel with physical processes, or runs altogether in some other manner; whether, if it stands, it stands at the circumference or the centre; and whether consciousness stands or runs at all, it seems almost obvious that we are being made the victims of our own metaphors.

Idealists and realists seem to have suffered most from the confusion that results. When the idealist says that the world arises in consciousness, quite palpably he lies. But when the realist says that consciousness arises in the world he is no nearer to the truth. When he says that the world exists outside consciousness, he can only mean that it exists outside his body. When he says consciousness is a part of his pluriverse and not the whole, what he means, or should mean, is that his body is a part of it. Again, 
when the idealist says that consciousness is the centre of his universe, again, palpably, he lies; not because he has said too much, but because he has said too little.

For, when the realist swears by all his realities that consciousness stands at the circumference, he is perjured. When he reveals his pluriverse as an infinite number of entities, mutually repellent, yet co-existing, even interpenetrating, much as the infinite planes of space interpenetrate each other, he may be getting at the truth of the matter as nearly as his spectacular methods will allow him. But, when he invites you to consider consciousness as only one of those entities, standing to all the others in the relation of a spectator to a spectacle, then, in spite of all the useful distinctions that he makes between things in space and time, and things out of space and time, it is clear that he is visualising consciousness as somehow occupying both.

If we once grasp the utter irrelevance of all this symbolic language as applying to consciousness and the relation of subject to object, half the difficulties in accepting some conscious principle as the ultimate reality will have disappeared; and the pluralist's claim to have decentralized Philosophy falls through.

After this, the unphilosophic reader will perhaps see no reason why the idealist lamb should not lie down by the pluralist lion. But the reason is clear enough. The lamb does not do the smallest damage to the lion. He does not interfere with any one of his adventures. It is the lion that will not consent to live and let live. The prestige of Spirit is seriously endangered by the restrictions Realism has laid on it. But Reality is not one whit the worse because Idealism chooses to regard Spirit as its source. It is no more a dance of bloodless categories than it was before. Existence remains as fullblooded and gorgeously coloured, as variegated and multitudinous, as everlastingly exciting, mysterious and sur- 
prising whether you call it the manifestation of Spirit or a collection of ultimate realities.

The only question that concerns us is: Which theory is the more likely to be true?

We found that on a balance of the reasoned evidence we had some grounds for supposing Spiritualistic Monism more likely to be true than Pluralistic Realism, and no valid grounds for supposing it to be false.

But, if the reasoned evidence had failed us so far as to leave the balance even, we should not then have despaired. For we found a mass of evidence over and above; which, whether we regard it as springing from a higher and purer, or from a lower and more troubled source than reason, is not altogether to be gainsaid. We found that one of our oldest, deepest, and most enduring possessions is the sense of the Unseen. We saw it grow from a primitive sense, a blind and savage instinct, to a transcendent spiritual passion. We distinguished between the higher and the lower forms of Mysticism. We found that, when criticism had done its worst, it was possible to separate the purer from the baser elements of the same emotion; and that after the most implacable analysis there remained something indestructible, irreducible, indefinable, bearing its own peculiar certainty.

At the same time we acknowledged that the certainty of spiritual instinct is one thing, and the certainty of reason is another; and that the highest degree of certainty can only be reached when at all points the two corroborate and support each other. Such a degree of certainty we are very far from having reached, though at some points we may have found this corroboration and support. 
We have now to find the bearing of our conclusions, such as they are, on the question of Personal Immortality.

Before we can do this, however, we shall have to consider certain evidence from other sources, sources that we have left, so far, unexplored.

First of all, there is the huge mass of that so-called "evidence," which the Society for Psychical Research makes it its business to investigate and sift; the evidence drawn from the communications of mediums, from automatic writing, from "cross-correspondence"; the alleged apparitions of the departed, "materializations" and veridical dreams.

I do not propose to investigate and sift this evidence all over again. People who are interested in "Spiritualism," critically or otherwise, should study the literature of the subject for themselves. When they have read and digested the Journals and Proceedings of the Society up to date, and the records of foreign organizations devoted to the same adventure, together with Mr. F. W. Myers on Human Personality and Sir Oliver Lodge's Raymond, they had better read Mr. Frank Podmore's Studies in Psychical Research also. I shall, therefore, be very brief.

Briefly, then, we shall do well to distinguish between what are, broadly speaking, two kinds of eridence: Indirect communications, made through mediums, with their accompanying apparitions or materializations, and: Direct communications, made spontaneously and without any apparent machinery of suggestion, such as "veridical" dreams and apparitions seen withont the help of mediums. Under both these heads there is an enormous body of perfectly well-authenticated testimony borne by irreproachable persons. Some of it, but only a very little, has even been brought forward by sceptical and indifferent persons, persons without any interest in the result one way or other. 
Briefly, again, I think there cannot be a doubt in the mind of any unprejudiced person that, both through the agency of mediums and otherwise, things happen; things that are not explainable by any trickery; things interesting enough, and even uncanny enough to charm the most fastidious lover of the occult. (Unfortunately, lovers of the occult are very seldom hampered in their researches by over fastidiousness.)

The question is: What happens?

Take the regular Spiritualistic phenomena first. Mrs. Piper, say, seems to be giving messages from the spirits of Mr. Myers or Dr. Verrall. Their authenticity seems to be sufficiently attested by allusions to intricate and subtle points of scholarship said to be known only to Dr. Verrall and Mr. Myers. The automatic writer writes words that she herself would never have dreamed of, as if under an irresistible and supernatural compulsion. What she has written tallies with something said to be known only to the departed. Hands are certainly seen to be waving where human hands are not. Bunches of flowers, and even still more solid objects materialize apparently from nowhere out of nothing.

It cannot all be fraud, all the time, though some of it may be sometimes. Exposure in ninety-nine cases affords no absolutely valid grounds for denying that the hundredth case may be genuine.

What, then, is going on?

So far as psychical research has been carried yet, I cannot see that, even under the most carefully prepared test conditions, there is an atom of evidence to show that what is going on is an actual communication, or effort at communication, of the discarnate with the iscarnate.

It may be so. But until we have eliminated every possible source of suggestion from the living we have no right to assume an even remote suggestion from "the other side." And to ensure this test condition we should 
have to exterminate the living. The test will not be watertight until the communicant is alone with the communicator; and then there will only be his word for it.

On this side, whatever Spiritualism may be, telepathy is a fact; and whatever the precise limits and possibilities of telepathy may be, we have not yet discovered them.

Can we be sure that the things said to be known only to the discarnate are not among the subconscious memories of the communicant or of some person present at the séance? Or that they are not known by any living mind on earth? Nothing in the annals of Psychical Research is more astonishing than the series of cross-correspondences in the case of Mrs. Holland and Mrs. Verrall. Mrs. Holland in India received by automatic writing one half of a supposed communication; the other half was received by Mrs. Verall in England, neither making sense by itself. The two writers were unacquainted, and each was unaware of what the other was doing. 'The perfect dove-tailing of the fragments could not be accounted for on any theory of coincidences. The two writings clearly dealt with the same context; for quotations from certain known poems, broken off or garbled in one fragment, were completed or emended by the other.

Here the test conditions were all that could be desired. It was a manifest case of tapping a "wireless." Yet who could say that the probability of wireless from the living was ruled out? The state of desire and expectancy, in which all these efforts to communicate are made, renders the minds of the investigators peculiarly open to suggestion. And - an extremely important point - the more transparently honest the mind, the more passive it will be, therefore the more open.

And if the messages are suspect, what shall we say of the manifestations? In these cases how can we possibly rule out suggestion? Certain experiments have been made by Janet and his son on their patients at the Salpêtrière, 
which show that both positive and negative hallucinations ean be produced by suggestion. The patient, that is to say, can be made, not only to see things that are not there and to behave as if they were there, but not to see things that are there and to behave as if they were not there; both hallueinations remaining intact until the experimenter releases the enchanted one from her enchantment. And not only eminent alienists, but obscure amateurs have done as much. Why then should not the magic of the medium be equally effective? Why should not an expert suggestor create both positive and negative hallucinations at will? Is it a question of poeketing the "sendings" and taking them home with youl, why should he not introduce into the blankly innocent scene all the paraphernalia of materialization he requires, by simply inhibiting the perception of them, until the moment comes for handing round the evidential trophies? This would aceount for the indubitably solid objects, the plaster-casts of "spirit-hands," the flowers, the little girls, and the teaspoons which have figured at certain twentieth-century séanees.

However this may be, if psyehical researchers are not inereasing their knowledge of "the other side," they are preparing excellent material for psychologists on this side.

The other sort of evidence, the direct and spontaneous sort, is, I think, in rather better case. It would be stupid to deny that there have been well-authenticated apparitions, and so-called veridical dreams, which appeal to our belief beeanse of their directness and spontaneity; by the fact that they have come to people who were not looking for them, in many eases to people who would have gone out of their way to aroid them if they had known that they were eoming. The sudden unexpectedness of these encounters through the veridical dream and the valedictory apparition is in their favour.

But, here again, the possibility of telepathy between 
the living is by no means ruled out. So far, if I am not mistaken, most of the verified or verifiable instances of apparitions have occurred, not after death but before it, or at the actual moment of passing, and cannot be taken as evidence of survival. The vision of the dead body may be explained by suggestion from the living attendants of the dead. So may the instance of the dream that comes true. And there is always coincidence.

There remain certain (also well-authenticated) cases of the continuous apparition, the ghost that haunts. It seems hardly likely that they are all the products of a disordered brain or a habit of mendacity. But I have never come across any more satisfactory explanation of them. We may invent hypotheses to account for them: for instance, that the impact of all visible and audible events is continued in an infinite series of finer and finer vibrations, the swing, as it were, of infinitely dirisible etheric particles; so that, long after the date of the original event, its ghostly simulacra are seen or heard by senses pitched to their rates of vibration. But even if some unforeseen discovery in physics were to give encouragement to this theory, it would incolve a corresponding theory of an infinite series of finer and finer senses, pitched to the finer and finer vibrations; and even if this received encouragement from psychology, we should still be no nearer knowing why some of these erents should be perceired and not others.

And we should be as far as ever from any evidence of survival.

There is yet another very ancient and widespread belief, on which many people still found their hope of personal immortality: the belief in Reincarnation.

If the belief itself were well founded it would be as good a foundation as we could wish to have. If we have lived 
many times before, there is, to say the least of it, an antecedent probability that we shall live again. There would even be no reason why we should ever stop living.

Now there are three theories of Reincarnation, and two of them are mutually exclusive. One is primitive and savage; one ancient and pseudo-metaphysical; one modern, and, if not scientific, fairly well founded on scientific grounds.

According to the primitive and savage belief, we are all reincarnations of the dead. Ghosts are germs and germs are ghosts. As the flower and the corn return to earth, we return. The ghosts of the newly dead hang about, in woods and at cross-roads, for choice, waiting for women to pass by that they may enter their bodies and be born again. The places where they hang about are haunted places.

According to the second and most fascinating form of the belief (which involves the doctrine of Karma), we are born again and again as full-blown human individuals, breaking through the knitted chain of the generations at points that may be divided by many ages.

According to the third, we have been incarnate again and again in the bodies of our parents and our ancestors, in such sort that the chain of generation is never broken. This, as we have seen, is the doctrine of Pan-Psychism.

Observe that both the primitive and the modern theory are the most satisfactory and comrageous in tackling the crux of reincarnation - its modus operandi. The theory of Karma leaves this essential part of the problem altogether too vague. And I am bound to confess that it is the savage who scores in simplicity and precision.

But it is the theory involving Karma that people mean when they talk about reincarnation. It exerts an irresistible fascination for certain temperaments that would be repelled by the Pan-Psychism of Samuel Butler or of anybody else. 
The belief has been for ages the actual, living belief of millions in India, China and Japan. In spite of its inherent difficulties it is still more or less sincerely held by many perfectly sane people in Europe and America at the present day. You used to meet them at the Ritz or Rumpelmeyer's (it was in the days before the War), when they would tell you as a matter of course that they remembered being a dancer at the court of Amen Hotep III., or the queen-consort of Assurbanipal, or a concubine of Sennacherib, or a priestess in the temple of Krishna, or a great hetaira of the age of Pericles. (The odd thing is that the Reincarnated have always been something royal or hieratic or improper; something sufficiently afar from the sphere of their sorrow, Eastern or Egyptian preferred; something, whatever it may be, that they are not now.) And they expect you to believe them.

They are not content to have taken part in the thousand or the million incarnations of their own ancestors, in a thousand or a million experiences; they are not content with their thousandth or their millionth share in the adventures of the dancer at the court of Amen Hotep III.; they want all the adventure to themselres. It is the fullblown dancing individual they claim to have been. And the plain facts of biology are all against it. You cannot thus break through the unbroken chain of the generations. The difficulty for the devotees of this form of reincarnation is, not that there is no proof that they have never lived before, but that there is too much proof that they have never stopped living. They have never escaped from the chain until the day when they were born as the individual they are now.

Pan-Psychism is a theory, not of Reincarnation, but of continuous Incarnation. And unless there are grounds and I have tried to show that there are grounds - for supposing that the Self is something over and above its own experience, its own memories, and its own organism, the 
mere fact that we have never stopped living so far is no guarantee that we shall go on living after the final dissolution of that organism. But if we have appropriated it rather than inherited it, our previous existence becomes, I think, a very considerable guarantee.

Now it may be objected that this self orer and above is a pure blank. Yet it seems to be all that is left to us. And if the pure self is as pure as that, what good is it to anybody? If there is nothing in it, how is it going to carry on and to carry us on?

I own that it doesn't look as if the self-over-and-above could give much support to the hope of immortality, or that in its nakedness it is likely to appeal to the plain man. The pure self is not looked upon with favour even by idealists. Kant, who as good as discovered it, fought shy of it. Realists are fond of reminding you that you cannot prove existence, you can only perceive it. Is there, then, any reasonable sense in which it can be said to exist? If it isn't pereeived, and if it isn't memory, if it isn't consciousness, what is it? My friend, Dr. Me'Taggart, says it is nothing. And its blankness must seem to many people every bit as terrifying as the blankness of death.

Yet it is in this pure self that I am asking you to put your trust.

For all these objections rest on the monstrous assumption that what you eannot perceive does not exist and is not real. And this is to elaim greater authority for finite and human perception than it can possibly possess. Remember, it is only the purity of the self that is so universally objected to. And the self is not more pure, more utterly beyond touch and sight than space and time are. It is not more empty to perception than matter is in the last analysis. And we saw what dangers and dilemmas we avoided by putting selfhood where the plain man (unaware of its purity) puts it - first.

Personally, I am not dismayed by this blankness of the 
self behind me. Rather, because of it, I can face the blankness before me without flinching. I can conceive all my memory, that is to say, all the experience I had acquired in this life, everything that makes me recognizable and dear to myself and to other people; I cannot only conceive, but think of it as going from me with my death and of myself as yet continuing.

I would rather keep that experience intact - I have already lost much by simple, casual forgetting, and if I have lived long enough I may have lost all that is worth keeping of it - I had rather keep that memory and carry it over with me, for the living interest of the thing; but if I am driven to conclude that I must lose it, I do not therefore think of myself as lost. It may be that, here again, a more perfect forgetting is, as it was before, the condition of a more perfect consciousness. I know that I could, and probably shall, embrace a wholly new experience with the same eager interest with which I have embraced the old. For, through forgetfulness of my past lives, my present life began to all intents and purposes as a blank, an experience that I knew nothing of, and that knew nothing of me.

And supposing that no rehicle of individuality, such as my body was, awaits me at the instant of death. Supposing that no refined simulacrum of my body exists, either as an inner or outer vehicle, or as an interpenetrating and energizing substance, inscrutably present with my physical body and enduring after my death. (Many quite sane people believe in such a vehicle, on evidence I know nothing about except that it satisfics them.) Supposing that no such vehicle is at my disposal, and that I have to wait untold ages before I can find one, or the germ of one, in order to appear and to be conscious again; those untold ages will not trouble me. They will no doubt exist as the time-schemes of other consciousnesses, other thoughts, and other emotions. Other sclves, living at another pace and 
with another intensity, will beat out the measure and will keep the record of those times, just as some superhuman and superorganic consciousness must have kept the record and beaten out the measure of prehuman and preorganic times. They do not concern me. In the first instant that I am conscious again my world arises, as if there had been no age-long break, no break at all; not so much as an infinitesimally small interval, and I shall conceive my world as without beginning and without end.

The actual break is the worst that can happen to me, and, whether it be long or short, I shall know nothing of it.

It may be still objected that in cutting the self adrift from memory I am burning the only ship that will bring me safe to shore. But this implies that the underwriters have ensured that ship, and will continue to ensure her, which is very far from being the case. I am leaving an unseaworthy vessel whose foundering, if she does founder, will sink me with her to the bottom. I might possibly be afraid to sink with the ship; to drown, battened down with the rats in the hold, but for the probability that neither I nor the rats would know anything about it. I am not in the least afraid to throw myself into the open sea.

But this theory of Pan-Psychism provides another and a stronger argument for human immortality. It supposes that all Life and the evolution of every living organism depends on the desire and the design of an indestructible psyche; and that, under favourable conditions, when the desire and the design have been strong enough and suitable, they have been fulfilled. And as far as the living organism goes, design has followed, slavishly, desire. So that, if the human psyche has a strong desire for immortality, and if its design is in accordance with that desire, immortality, in spite of the fact that it is a large order, should follow.

There are few arguments for Personal Immortality that 
have not some danger. And this argument from human instinct and desire is imperilled by the objection that this particular instinct and desire is by no means universal, and that no psychic design, so far as we know, in any way depends on it. It may be distinctly lacking in highly civilized societies. The less instinctive and the more intellectual man becomes, the more he is apt to repudiate both the belief in immortality and the desire and the hope of it.

The belief apparently rests on instinct. But the desire and the hope do not seem to be as instinctive, or at any rate as primitive as the belief. Where the belief is practically universal, as among savages, the life after death and all that belongs to it are dreaded rather than desired. The savage may desire the dead man's strength, his mana; but the discarnate ghost itself is a thing of terror.

And the belief is more a belief in survival than in immortality. For the primitive mind is a child's mind. It cannot grasp the idea of any long period of definite time, much less the idea of immortality.

The hope and the desire are virile instincts. With one apparent exception, they seem to have dominated the youth of the race and its maturity ; to belong to those stages of its development that lie between primitive savagery and extreme civilization; and to be intimately associated with the rise and decline of personal religion.

The one exception, which is the stock argument against the belief in personal immortality, is of course Buddhism. Buddhism, it is said, the ancient and permanent religion of millions of the human race, is a religion founded on the negation of immortality. And wherever it exists it is the religion, not of a handful of metaphysicians but of the priesthood and the common people.

And as, with the progress of science and speculative thought, the belief tends to disappear, so with the progress of civilization the desire itself weakens. It is not only that the intellectuals doubt or disbelieve for intellectual reasons, 
and spread their doubt or disbelief through all the circles that they influence. Other and simpler people are indifferent; and the root of their indifference is moral and physical rather than intellectual. The belief in immortality is no longer popular; at any rate, it has no longer the vogue it once had.

And we have reason to be cautious in approaching it, when we find the distinguished historian of the origin of this belief regarding it with a half-amused and half disdainful scepticism.

It must be confessed that the result of Sir James Frazer's researches are not such as to make sensitive people in love with the belief in human immortality. They are not such as to make intelligent people conclude that there is anything in humanity that deserves to endure even for a day. It is quite possible to bring forward an array of facts to show that the whole history of this pitiful race is one long record of cowardice and uncleanness, cruelty and imbecility.

Listen to these two voices that debate the destiny of man :

"Surely, they say, such a glorious creature was not born for mortality, to be snuffed out like a candle, to fade like a flower, to pass away like a breath. Is all that penetrating intellect, that creative fancy, that vaulting ambition, those noble passions, those far-reaching hopes, to come to nothing, to shrink up into a pinch of dust? It is not so; it cannot be. . .."

"Shall a creature so frail and puny claim to live for ever, to outlast not only the present starry system, but every other that when earth and stars have crumbled into dust, shall be built upon their ruins in the long, long hereafter? It is not so, it cannot be. ..."

"Those who take this view of the transitoriness of man compared with the vastness and permanence of the universe find little in the beliefs of savages to alter their opinion. They see in the savage conception of the soul and its destiny nothing but a product of childish ignorance, the hallucinations of hysteria, the ravings of insanity, or the concoctions of deliberate fraud and imposture." 59 
You see the historian trying to hold the balance scrupulously even; but there is little doubt as to which of those two voices is the more insistent. He also reminds us that Buddhism is a conspicuous and extensive and damaging fact.

And when we remember that our positive metaphysical arguments rest on the slender foothold of debatable hypothesis, and that we were obliged to fall back on the biological and psychological arguments from desire and design, and that these arguments apparently cannot stand the light of an impartial historical survey; when we are reminded, further, that William James prefaced his immortal essay on Immortality with the emphatic statement that he personally had no desire for it whatever, it looks as if the prospects for human immortality were black; as if we should have, after all, to content ourselves with the negative encouragement we are at least sure of - the impossibility of proving that it cannot be.

Yet we were in worse case a little while back, when we tried to discover whether Mysticism had anything in it that escaped the violence of its detractors. We found then that, for all its dubious or disgraceful history, and for all its elements of grossness and absurdity, there was something intangible and invulnerable that escaped. We found that you might as well judge poetry by the practice of the worst poetasters as judge Mysticism by the practice of its worst exponents or by the lapses of its best.

And so I think that, if we look closer, we shall find for one thing that, in spite of its savage history, there is nothing either absurd or ignoble in the belief in immortality itself.

To begin with, the belief has been evolved. It has not remained in its primitive savagery. And even in its primitiveness it was not, after all, such a very imbecile belief. It arose, in the first place, from a most intelligent and reasonable desire for fertility. The ghost, imagined as 
surviving, was, originally, the source of mana, the mysterious power of life. ${ }^{60}$ The savage tribesman had no personal aspirations. He did not think of himself as a person. Therefore he took short views, and it did not occur to him that he might eventually become a spirit and the source of power. He only aspired to get power, to get life, from season to season, to be fruitful and to bring fruitfulness to his trees and grain and to his flocks and herds. He buried the seed, and he saw that it came up again as a green blade. He buried his father, and he looked for him to come up again in children born to the tribe.

There must have been an immense step between this primitive idea of subjective immortality and the idea of the ghost's life as independent and continuous. First of all, the ghost is a buried, underground thing; it is later that he moves about on the face of the earth and becomes the dreadful supernatural thing, the haunter, the watcher by the cross-roads and the sacred tree ${ }^{61}$; much later, then, he becomes the departed who has journeyed to the Islands of the Blessed and will not return.

Apparently it is not until this stage is reached that it occurs to primitive man that he may very well live again like his fathers, and that where they have gone he may go. It is later still that he conceives the idea of the spiritual dying and new birth; and with it the passion for God and the desire of immortality for its own sake.

Yet not altogether for its own sake. He wants to be wherever his gods are. When he has once for all placed his god in heaven rather than under the earth, it is to heaven that he wants to go.

The desire of immortality is one thing, then, and the primitive belief in a survival on earth is another. And the desire of immortality comes last, and comes with man's consciousness of himself as an immaterial being. Immaterial, therefore immortal. He desires to be what he is not yet; but he does not desire it until he is ready for it, until 
he knows it to be possible. And in all this his religion is not the driving and compelling power; it follows the lead of the developing and dominant desire. It once centred round his natural and tribal life, then around his social life. It now centres round his individual and spiritual life; that is all. The individual is adapting himself to the wider reality that his prophetic need discerns.

Presently he seeks metaphysical grounds for his belief and ethical justification for his desire.

Last of all, in the decadence of over-civilized races, when they are about to be conquered by the younger and the stronger race, the belief and the hope and the desire of immortality weaken and die.

This is where the passionate concentration on origins would seem to be misleading. It diverts attention from the fact that there are such things as ends. The study of what has been is important; it is interesting; but it is interesting and it is important chiefly as throwing light on what is and what will be, which are even more important and more interesting than it.

So that when we see the thing through, its history does not show up this belief as ignoble, infantile, and absurd. It shows the desire for immortality strengthening with man's youth and his maturity, and declining and decaying only with his weakness and decay.

It has been said that wherever the belief has existed it has proved harmful, therefore contrary to the design of the psyche and its organism, therefore destined to disappear.

This objection also ignores what has happened and is happening. It is true that there has always been a disastrous period of transition, when man has not yet adjusted the claims of his natural and spiritual life; when he has been so unaware of the metaphysical grounds of his immortality that he has tried to bargain with his God for it, to buy his soul's life with the sacrifice of his body. The cruelties and violences of asceticism proved that he was by 
no means sure that his passion for God and immortality was requited. This period may stand for the crisis of spiritual adolescence with its uncertainty and disturbanco and self-torture. The passion for God and immortality are no more discredited by it than human passion is by the physical crisis of its coming.

It is also true that the nineteenth century was a vigorous and virile century; yet disbelief in immortality was then almost de rigueur among people with any pretensions to scientific training. But this was partly because the first triumphs of physical science had turned the heads of its professors. It may be observed that Professor Huxley did not discover his " mechanical equivalent of consciousness" ; he lived, in fact, to recant so far as to confess that Nature could not possibly have evolved the laws of Ethics which exist in violent opposition to Nature's laws. And the twentieth century is not unanimously backing the illusory by-product theory of consciousness.

In any century the desire of immortality, or at any rate, of life after death, is a sign of youth and vitality and vigour in those who feel it keenly. The strong man wants to go on living, to have more and more ontlet for his energies, to do more, to feel more, to know more. He wants it instinctively; for the stronger and healthier he is the less he is likely to think about it at all. When he is old and weak and worn out, or young and weak, and bored to premature extinction with living, he does think about it. $\mathrm{He}$ wants, not instinctively, but consciously, to lie down and go to sleep, to stop the intolerable nuisance of living.

On the whole, then, the argument from desire and design holds good. It is the weak and inefficient, the unwise in the affairs of life, the bunglers and the failures, the bankrupts and the unhappy lovers who most want to leave off living. Think of the number of suicides that occur every year through bankruptcy and unhappy love alone. 
Count in the suicides through poverty; and remember that these are all people whose vitality has been lowered by worry or frustrated passion and starvation, and that their aim is to end life, and not to obtain it more abundantly.

Count in the philosophers who profess a noble indifference to the issue, and still a suspicion of lowered vitality arises.

And if suicide is to be reprobated on the grounds that it is dishonourable and selfish, the desire to go on living cannot very well be reprobated on the same grounds. Its motive may be, and often is, the passion for metaphysical truth and for a righteousness not obtainable on earth. It may be, and often is, in the highest degree aesthetic.

For the universe as it stands is ethically and aesthetically incomplete. It has a certain significance for our peculiarly human consciousness, which nerer for one moment, seize it where we may, tails off into insignificance. It appeals to us in an incalculable number of intensely exciting sentences, which it hurls at our heads and leaves provokingly unfinished. It has made us spectators of its stupendous drama; what is more, it has honoured us with free passes as critics of the performance; worse still, it involves us personally in important and dramatic situations, which it leaves undeveloped. It involves itself in perpetual engagements to us which hitherto it has not fulfilled. It creates desires which certainly cannot be satisfied in one life-time, or in the conditions of the only life we know. There is some evidence that it has created, or is creating, powers in us whose exercise demands another and more extensice sphere. And we find it preposterous that a universe which has unbent so far as to consider us in this programme should leave us ultimately in the lurch.

And when we look back on the long course of our prehuman history, we judge that, if Life does turn traitor at the last, it will be behaving 'contrary to all precedent. There should be no arraigmment of Nature so sweeping as 
to obscure the fact that there has been precedent. Organic forms, locked in the infermal struggle for existence, have, after all, evolved; and the struggle has been an important factor in their evolution. Eliminate catastrophe: the wholesale fortuitous destruction of living forms by storn and flood and sudden changes in enviromment, and the encounter with inorganic conditions disastrous to any life; eliminate waste: the careless handling of the vehicle of life, the fate of the germs that have never had a chance to develop; eliminate the struggle of the already evolved: the slaughter accomplished by one species on another and by individuals within the species; assume, with Pan-Psychism, that fitness is the expression of the individual's desire to survive, and it will be seen that Nature has not behaved unfairly to her organisms after all. She has destroyed countless forms of the unfit, in whom we may presuppose no very keen desire to survive; she has preserved at their original low level millions of humble forms whose desire was chiefly that they might stay there; but she has rewarded greatly the great desires, the great ambitions, the great accomplishments. She has even more rewarded the small desires, the small ambitions that were faithful and persistent.

Nature abhors incompetence. . But apparently no patient and efficient psyche ever desired the physical vehicle or tool that it did not obtain. No appropriate need was left long unsatisfied, no organ left to wither by disuse as long as its function was appropriate and the fulfilment of that function desired.

If we may assume with Pan-Psychism that need and desire were prophetic; that is to say, always a little in advance of the actual conditions, without which advance evolution would seem to have been impossible, the analogy is complete, and we are justified in asking, Why pursue this policy of indulgence to all the ambitious animal forms and stop short at man? May he not go on doing what he did 
in his mother's womb, what he has been doing ever since his psyche and the first speck of protoplasm came together? Why this sudden, arbitrary prohibition now, just when he is beginning to be interested in the universe around him, as well as in his own performance?

Now, if there is anything in Pan-Psychism, this argument will stand whether we are pluralists or monists. But I believe it will have most support from the theory which presupposes that

"There is one ruler, the Self within all things, who makes the one form manifold ...

"There is one eternal Thinker, thinking non-eternal thoughts, who, though one, fulfils the desires of many...." (KathaUpanishad, ii. 5.)

Buddhism alone, the Great Exception, stands, we are told, in the way of the argument from desire.

But is Buddhism really so obstructive as it is said to be? Isn't it just possible that the Great Exception may prove the rule? Consider how it came by its doctrine of Nirvâna. (Granting, for the moment, that by Nirvâna it means what we mean by Extinction.) As far as it is a theory and not a religion, Buddhism presupposes the metaphysical doctrine of the Absolute laid down in the Upanishads. So far as it is a religion, it is founded on compassion and pity and the revolt against the cruelty of caste. The revolt against caste itself presupposes some influence from the doctrine of Brahma, the Great Self, in whom all men and all things are one.

On its metaphysical side the Nirvâna of the Buddhist is the state of union with the Absolute; or, if you like, the utter extinction of the individual as such. On its religious side it is the ceasing from the sorrow of divided life. Desire is the cause of Life, which is the cause of sorrow ; therefore Nirvâna, the state of blessedness, is attained by simply 
ceasing to desire. Metaphysically, Nirvâna is the state of pure, absolute, unconditioned Being. It is the very last and subtlest refinement of the One of the Vedas, the Great Self of the Upanishads; defined by contradictions and negations. Nirvâna is defined only by negations. The mystic of the Upanishads says: "Who is able to know that Self who rejoices and rejoices not?" The Buddhist of the Suttas goes one better. Who is able to know that he does not know? If the sixth stage of mental deliverance is to think that "nothing at all exists," the seventh stage is the passing "quite beyond all idea of nothingness" to "a state to which neither ideas nor the absence of ideas is specially present"; and that is topped by the eighth stage, in which nothing is affirmed and nothing is denied, but "both sensations and ideas have ceased to be." (Mahâparinibbâna Sutta, iii.)

This is the mental discipline by which thought reaches up to Nirvâna, the state which transcends thought. It is "ecstasy of contemplation."

You may say that Buddhism ends where Hegelianism begins, with the statement that Being and non-Being are the same; that it reverses the movement of the Triple Dialectic; that, instead of resolving the contradiction in the synthetic affirmation of Becoming, it proceeds by way of the negation of Becoming, the denial of the world of appearances, to its definition of Being.

Buddhism is the denial of all the metaphysical systems that were before it. You might think a metaphysical system did not matter. But it matters horribly. A metaphysical system is a deadly thing. It may bind a man to the wheel of life by giving him wrong ideas about reality.

In the Sutta of All the Assavas or Book of the Deadly Things you will read of the six delusions of metaphysical thought:

"I have a self: 
"I have not a self:

"By myself I am conscious of myself:

"By rnyself I am conscious of my not-self:

"This soul of mine can be perceived; it has experienced the result of good and evil actions committed here and there:

"This soul of mine is permanent, lasting, eternal, unchangeable; it will endure for ever and ever." 62

The delusion consists not in having these ideas, but in ascribing truth and reality to them.

You may say that Buddhism lands you in utter nescience, since it denies every conceivable statement that can be made about reality.

But observe the nature of the denial in each case. It is the negation of a negation. In the supreme interests of the Absolute, Buddhism denies the reality of the appearing world; it strips Being bare of each unreal quality one by one, till not one shred of illusion is left clinging to it. Beyond this it makes no affirmation or denial. As the qualities are expressly stated to be unreal, the stripping process is anything but negation. It is the affirmation of Reality carried to passion and excess.

So that the unreal individual life must therefore be held to be utterly extinguished in Nirvâna. But it is hardly even an open question whether Nirvâna is or is not a state of Being; of pure and perfect bliss, beyond speech, beyond sense, beyond thought, beyond dream and desire or any form of consciousness we know. To define it, as the Buddhist defines it, by a series of negations, is simply a way of saying, with the utmost metaphysical hyperbole, that where there is Nothing there is All.

But whatever esoteric Buddhism might have said or meant, it was not entirely with that seemingly unreal glamour that it charmed the heart of Asia. For everything that was lacking in Nirvâna it made up by its very robust and substantial doctrine of Reincarnation. To disciples 
who had no fancy for extinction, it offered an endless and exciting round of rebirths. Nobody forced Nirvâna on you if you didn't want it. You could postpone your flight to the Absolute practically to all eternity by a judicious system of backsliding. You had only to neglect some obvious duty in each life as you returned to it to ensure another return.

In fact, you had not even to do that. You had only to desire to live again, and you lived. Your Karma might indeed force you back again against your will; but then you are responsible for your Karma. The whole thing is in your own hands. Desire binds you to the wheel of Life. Desire shapes your destiny for you within the wheel. Your desire, not God's ; not anybody else's. It is Pan-Psychism all over again.

You grow your own organism because you want to.

This amounts to Personal Immortality — as much immortality as you want, and for as long as you want it.

So that Buddhism should really not be used by scepties to justify their scepticism. One imagines that Buddhists who declare for Nirvâna in preference to reincarnation are the decadents, and the professors of philosophy, and the mystics - who know what they know.

But there is a third objection that may be made.

In the beginning we found the perfection of individuality in perfect adaptation to reality. And it may be said that the argument from desire overlooks the compulsion that is laid on the individual to conform. Things are not in his own hands. The Will-to-live is not his will. From step to step the psyche follows in the lines set by a reality outside it, of which its physical organism is part. The panpsychist looks at the process from the inside. Adaptation, he says, does not suggest that the individual's will is coerced and determined by the reality outside and beyond him, since it could not have taken place at all but for the indi- 
vidual's inner disposition or will. All the same, physical or spiritual death will be the price of his utter defiance. The individual must adapt himself or go under; and if that is not coercion, I own it looks uncommonly like it.

Yet, consider what (on the pan-psychist's theory) has really happened: that the individual's psyche has been present throughout the entire experience of the race, and that the individual could never have been what he is at each moment of his ascension if he had not needed, wanted, desired, and willed to be something that he was not yet. Consider that he would never have grown, never have developed at all, would be limited - as many unambitious individuals are - for all time to the companionship of the original speck of protoplasm he first took up with. Even if he advanced to the cell stage, without what strikes the outsider as his insane ambition to grow another cell, he would have remained a unicellular organism all his life.

Therefore, on the very supposition that his earlicst adaptations were to a reality as yet outside and beyond him, his earliest developments must have entailed some slight defance of the existing order, and his earliest need was a prophetic need.

And when we come to the human individual, his latest and highest developments mean a very considerable defiance of existing order, a very considerable prophetic need. And his latest and highest efforts at adaptation show an audacity that still suggests defiance rather than submission. Whatever it may look like from outside, adaptation seen from within, as the pan-psychist sees it, looks much more like the fulfilment of desire than its coercion.

If the perfect individual is the self perfectly adapted to reality through the successive sublimations of his will, the monist will grant you the compulsion you insist on. If the laws of nature are the laws of the appearance of the Self, in whom all selves arise and have their being, the compulsion that is upon the selves to obey them is not an out- 
side compulsion. It is the compulsion of their own nature in its will to appear.

III

To sum up the metaphysical argument that wo left behind us. It supposes one infinite and absolute Spirit manifesting itself in many forms to many finite spirits. It supposes the selves of the many finite spirits to receive and to maintain their reality in and through the one infinite Self as truly as their organisms received and maintained their life through Its appearance as one Life-Force.

For though the finite selves may exist over and above their organisms and their experience, and apart from each other, they do not subsist; they are not over and above and apart from the one Self in whom they have their reality. But the finite selves may be supposed to be potentially infinite, since they have conceived infinity. It would seem hardly worth while for the infinite Spirit to have revealed himself so far if the tremendous and significant process was not to be carried on. Appearances may be unreal, but they are significant. Why be at the pains of accumulating experiences through countless generations if the whole is to be squandered in one passionate instant of death?

But - on the theory - it will not by any means follow that, if we survive, we shall survive as the individuals we are now, or even as individuals at all. Selfhood, as we have seen, is not necessarily individuality. If our selves existed at all before birth, they would seem to have existed as members of a group-self, or as mysterious partakers in the experiences of millions of individuals; anyhow in a manner utterly incompatible with individuality as we understood it here and now. And yet, on that theory, selfhood seemed to have been very efficiently maintained.

Even in our experience here and now, though our selfhood would seem to remain inviolable, onr individuality holds its own precariously, at times, and with difficulty 
against the forces that tend to draw us back to our racial consciousness again. The facts of multiple personality, telepathy and suggestion, the higher as well as the lower forms of dream-consciousncss, indicated that our psychic life is not a water-tight compartment, but has porous walls, and is continually threatened with leakage and the flooding in of many streams.

It may be that individuality is only one stage, and that not the highest and the most important stage, in the real life-process of the self. It may be that a self can only become a perfect self in proportion as it takes on the experiences of other selves; just as it could only become a perfect individual by taking on the experience of millions of other individuals.

The individual, that is to say, may have to die that the self may live.

On the theory, this sacrifice would not mean what is called "subjective immortality," but rather the very opposite. In subjective immortality the individual lives precariously in the memory of posterity which may, after all, prefer to forget him. In any case it is a form of consciousness to which, on this theory, he has contributed but does not share. He has no consciousness of anything any more at all. But the life after death of the perfected self would mean an enormous increase of consciousness, through a spiritual communion in which all that is imperfect in passion, all that is tentative in compassion and insight and inspiration is finished and complete.

But the greatest objection to the acceptance of this form of Monism turns on the difficulty, not to say the impossibility, of conceiving how the selfhood of the finite selves is maintained in and through their fusion with the infinite Self.

Now there are certain forms of dream-consciousness in which precisely such a transfusion is apparently effected 
and maintained. I can vouch for one authentic dream which began in the most ordinary fashion by the dreamer imagining a complex dramatic situation involving three persons, not counting the dreamer herself. The situation itself was normal, and imagined in a perfectly normal way, without a single element of phantasy. The dreamer, so far, was simply dreaming the outline of a very ordinary novel or a play.

But no sooner did the outline and the parts to be played by the three persons become clear, then the dreamer became the three persons, and experienced, in one and the same moment, three sets of emotions, all distinct from each other, two of which were conflicting and two downright contradictory; she accomplished in one and the same moment, through the three persons, three distinct and different acts, two of which were mutually exclusive; besides maintaining three distinct and appropriate attitudes to the total event.

While playing, with perfect difference yet perfect unity, these three parts in the drama, the dreamer also stood apart and looked on, an unprejudiced and unmoved yet interested spectator. The actors, who appeared as very vividly incarnate, bore no sort of resemblance to the dreamer or to any person known to her. From beginning to end, not only three distinct experiences, but three distinct selfhoods were preserved in one experience and one selfhood.

It may be objected that, as dreams are hallucinations, we cannot argue from what happens in a dream to what may happen in reality; that under analysis this particular dream presents no more remarkable features than any other dream; and that the peculiar qualities claimed for it are classic features of the Freudian hypocritical dream: multiplication of the dreamer's person by substitution of other persons, and representation of events consecutive in time by juxtaposition in space. ${ }^{63}$

The third objection, which might have been serious, does 
not hold good of this dream. Emotions and moral attitudes, and the sense of personal identity, whether simple and distinct, or complex and transfused, are not representations in space, either in dream-consciousness or in any other. And in the dream they were not symbolized, but felt; in the perfect, intimate immediacy of feeling.

And the other objections are beside the point. It does not matter whether dreams are or are not hallucinations; it does not matter what interpretation we put upon this dream, or what elements it yields under analysis. Dream consciousness is a form of consciousness like another; it has its own reality. It is not claimed for this dream that a "real" transfusion of conscionsness and of selves took place in it, only that it gave a perfect and indubitable sense of such transfusion, of what it would feel like if the transfusion did take place; also that, as the dream was at least clear enough and coherent enough to be remembered and analysed by the dreamer, their remained in waking consciousness a valid conception of the whole synthetic event - a synthetic event which was said to be inconceivable.

Ruling out irrelevant objections, then, there are only three points that need concern us. We have in this dreamconsciousness a plurality of illusory consciousnesses, a plurality of illusory selves, held together by one "real" self, and existing in and through and for one real consciousness, and that without loss to the integrity of one illusory item of the illusory complex, without any rupture of the unity of the one self.

The complex is illusory only by comparison with the peculiar reality of waking consciousness. It, however, exists; it has its own dream reality. It arises, presumably, be cause the dream consciousness is free from those conditions of real space and real time which determine the psycho-physical life of the individual when awake.

For "illusory" read "finite," and you have an exact rendering of the situation assumed by pantheistic Monism: 
A plurality of finite consciousnesses, a plurality of finite selves, held together by one Real Self, existing in and through and for one Real consciousness; and that without loss to the integrity of one finite item of the finite complex, without rupture to the unity of the one Self. You may say that the finite complex is unreal only by comparison with the peculiar reality of the infinite Real. It has its own reality. And you may say that the situation assumed by the monist presupposes a corresponding transcendence of the conditions of finite space and finite time.

The one Infinite Spirit, then, is the finite selves. That the selves are not conscious of this union is the tragedy of their finitude. In our present existence we are spirit; but so limited in our experience that we know the appearances of Spirit far better than we know Spirit itself. If we knew them all, and if, in order to know them, it so happened that we increased the pace of the rhythm of time as it is increased in our dream-consciousness, only to an immeasurably more intense degree, the chances are that we should know Spirit, not as it appears, but as it is. ${ }^{63}$ Appearances would be whirled for us, as it were, into the one Reality, as the colours of the spectrum, painted on a revolving disc, are whirled into one whiteness by the sheer rapidity of its revolutions.

There are, after all, different kinds of certainty. And all our certainties that count, here and now, come to us after this fashion. Our inner states do succeed each other at different rates of vibration, and what escapes us on the slow, steady swing, we seize when the pace quickens. Our perceptions, like our passions, maintain themselves at higher and lower intensities. It is with such rapid flashes of the revolving disc, with such hurrying of the rhythm of time, with such heightening of psychic intensity that we discern Reality here and now.

No reasoning allows or accounts for these moments. But lovers and poets and painters and musicians and 
mystics and heroes know them: moments when eternal Beauty is seized travelling through time; moments when things that we have seen all our lives without truly seeing them, the flowers in the garden, the trees in the field, the hawthorn on the hillside, change to us in an instant of time, and show the secret and imperishable life they harbour; moments when the human creature we have known all our life without truly knowing it, reveals its incredible godhead; moments of danger that are moments of sure and perfect happiness, because then the adorable Reality gives itself to our very sight and touch.

There is no arguing against certainties like these. 



\section{APPENDIX}

\section{THE PAN-PSYCHISM OF SAMUEL BUTLER}

\section{Pages 1-43}

1. Psycho-analysis and the problems it raises are the subject of a sequel to this volume, The Way of Sublimation.

2. "The neurotic, far more plainly than the normal psyche shows us that "Through the great Being that surrounds and interpenetrates us stretches a great Becoming that strives for perfected Being." " (Dr. Alfred Adler, Ueber den Nervösen Character, p. 195.)

3. See Freud, The Interpretation of Dreams, On Dreams; and Jung, Analytical Psychology (translation by Dr. Constance Long) and The Psychology of the Unconscious (translation by Dr. Beatrice Hinkle, M.D., New York).

4. See The Way of Sublimation.

5. See Life and Habit, Unconscious Memory, Evolution Old and New, Luck or Cunning? God the Known and God the Unknown, and The Note-Books of Samuel Butler.

6. See Unconscious Memory; translation of Professor Ewald Hering's Address on "Memory as a Universal Function of Organized Matter."

7. Note-Books, p. 56.

8. It is worth while noting that consciousness of all these functions may be partially restored through disease or disorder of the organs involved, and that we have even in normal health a certain very limited and temporary control over our breathing, while in illness we "fight for our breath"- make an effort to breathe. We have in normal circumstances a certain still more limited control over the beating of our hearts; that is to say, we can increase or reduce palpitation by attention or inattention. This fact is so well recognized by doctors that they will not always allow a patient to know that he has "something the matter" with his heart. But by no fighting and no effort can normal people, even in abnormal circumstances, re-establish control over their digestive functions, which are the oldest of all.

Abnormal people, however, can accomplish a good deal in this 341 
line. The practisers of Yogi have so far organized control over the "Unconscious" that they can lower the action of the heart and lungs till both functions are apparently suspended; they can reverse the movements of the intestines; inhibit the physical phenomena of hunger, and play other tricks, more or less revolting, with their organs. Persons suffering from profound hysterical neurosis can do as much. Probably most instances of the ability to fast for abnormal periods come under this head. So that it would seem that the links between the Conscious and the Unconscious, between reflex and voluntary action have never been completely lost. It is even conceivable that, if we cared to pay the price, we could recover them completely, and "by taking thought" become once more mere breathing and digesting organisms, animated by a rudimentary psyche. People who pride themselves upon the possession of such abnormal powers should realize precisely what it is that they are doing.

9. Life and Habit, p. 47.

10. ". . . We may assume it as an axiom with regard to actions acquired after birtl, that we never do them automatically save as the result of long practice, and after having thus acquired perfect mastery over the action in question." (Life and Habit, p. 53.)

11. "Shall we say, then, that a baby of a day old sucks (which involves the whole principle of the pump and hence a profound practical knowledge of the laws of pneumatics and hydrostatics), digests, oxygenizes its blood (millions of years before Sir Humphry Davy discovered oxygen), sees and hears - all most difficult and complicated operations, involving a knowledge of the facts concerning optics and acoustics, compared with which the discoveries of Newton sink into utter insignificance? Shall we say that a baby can do all these things at once, doing them so well and so regularly, without being even able to direct its attention to them, and without mistakes, and at the same time not know how to do them, and never have done them before?" (Life and Habit, p. 54.)

Of course if you are going to be pedantic and literal about it, jou can say that the baby's action may indeed "involve" the "principle" of the pump, but that it need not and does not involve a "knowledge of the laws of pneumatics," etc. "Involving" is a treacherous word in this connection; but Butler's meaning is clear: that the baby's instinctive and practical knowledge is superior (for its purposes) to all other kinds of knowledge.

12. Life and Habit, pp. 55,56 . 
13. Note-Books of Samuel Butler, pp. 53, 54.

14. Life and Habit, p. 130.

15. Life and Habit, p. 131.

16. Life and Habit, p. 51.

The older physiology might have accounted for the coincidences on the grounds that our visceral functions are controlled by that system of reflexes which used to be known as the "sympathetic" system, working "on its own." But now that the voluntary and involuntary sensori-motor arcs are found to be connected, Butler's coincidence remains as singular as ever from the purely physical standpoint.

"The muscles of the visceral system are connected by sensori-motor arcs principally with sense-organs that are embedded in the viscera, and are stimulated by movements, pressures, and chemical changes in the viscera; and these arcs constitute a system of nerves that was for long considered to be quite separate from, and independent of, the other larger system, and was known as the sympathetic system. We know now, however, that the two systems of sensori-motor ares, the skeletal or voluntary" [involved in "all those movements of the limbs, trunk, head, and organs of speech by which relations with the outer world are maintained"], "and the visceral or involuntary are intimately connected." (William McDougall, Physiological Psychology, p. 16.)

17. Note-Books, pp. 39-92.

18. For these extensions and confirmations of Butler's theory, see Life and Habit, pp. 166-197 and 220-251.

19. Dr. McDougall, in his one reference to Butler in Body and Mind, supposes him to have declared that all memory and instinct are merely habit, whereas Butler maintains the very opposite. 20-70.

20. Life and Habit, p. 49. See also Luck or Cunning? pp.

21. Note-Books, pp. 47-55; Life and Habit, pp. 78-124; Luck or Cunning? pp. 23, 24, 25.

22. See Lotze, Metaphysik, p. 602.

Also infra, pp. 120, 121.

\section{SOME ULTIMATE QUESTIONS OF PSYCHOLOGY}

\section{Pages $67-108$}

23. "Feeling-tone, as the word implies, is in some way dependent on the sensations. Nevertheless, the feeling-tone is in some degree independent of scnsation-quality; for one quality 
of sensation may be at one time pleasant, at another unpleasant, and at a third have no appreciable feeling-tone." (William McDougall, Physiological Psychology, pp. 79, 80. See also Body and Mind, pp. 312-313.)

24. See infra, pp. 76, 77, 112, 113.

25. Body and Mind, pp. 211 et seq., pp. 215-220.

". . . we may believe that the essential peculiarity of living organisms is that they serve as channels of communication or of transmission of energy or influence from the psychical to the physical sphere; and we may believe also that the evolution of organisms has been essentially a process by which they have become better adapted to play this unique rôle." (Body and Mind, p. 221.)

26. Ibid. pp. 151, 180.

27. See Fechner, Psycho-Physik, In Sache der Psycho-Physik, Ueber die Seelen Frage, Zend-Avesta.

28. Body and Mind, pp. 319-321, 340, 341, 343; also Physiological Psychology, p. 146.

29. Certain experiments seem to show that it is possible to measure the output of nervous energy by studying the influence of fatigue in the curve of muscular work or in the reduction of sensitivity to stimuli. And still we are as far as ever from a satisfactory demonstration of strict psycho-physical parallelism. For in the nature of the case results, when obtainable, will be drawn, not from comparison of complicated experiences, involving an extensive psychic output, but from single, simple operations, such as the raising of a weight, or (in the case of stimulation of the optic nerve) the rapid turning of a coloured disc. Even granted that these experiments are successful, the proportion thus established between muscular innervation and muscular fatigue, between nerve stimulus and nerve fatigue falls within the nervous system; that is to say, it holds good only on the physical line. The psychic process (which is not to be confounded with the neural process) eludes the test. As you can never catch, as it were, your psychic total, psychic increment can neither be proved nor disproved.

SOME ULTIMATE QUESTIONS OF METAPHYSICS

Pages 109-126

30. Supra, "Vitalism," pp. 44-48.

\section{PRAGMATISM AND HUMANISM}

Pages 127-150.

31. Humanism and Riddles of the Sphinx.

32. F. C. S. Schiller, Preface to Humanism, p. xviii. 


\section{THE NEW REALISM}

Pages 151-239

33. "Symbolic," because the laws of Formal Logic concern only the connections between propositions, and these propositions can be stated in terms of "variables." For example: If $x$ is greater than $y$ and $y$ is greater than $z$, then $x$ is greater than $z$.

The connection between the propositions holds good for every value (variable) of $x$ and $y . \quad X$ and $y$ thus stand as "symbolic" of everything to which the proposition can validly apply.

34. "The distinction of mathematics from logic is very arbitrary, but . . . it can be made as follows. Logic consists of the premisses of mathematics, together with all other propositions which are concerned exclusively with logical constants and with variables, but do not fulfil the above definition of mathematics. ${ }^{1}$ Mathematics consists of all the consequences of the above premisses which assert formal implications containing variables, together with such of the premisses themselves as bear these marks. Thus some of the premisses of mathematics, e.g. the principle of the syllogism if $p$ implies $q$ and $q$ implies $r$, then $p$ implies $r$, will belong to mathematics, while others, such as "implication is a relation," will belong to logic, but not to mathematics. But for the desire to adhere to usage we might identify mathematics and logic, and define either as the class of propositions containing only variables and logical constants." (Principia Mathematica, p. 9.)

"The distinction between a variable and a constant is somewhat obscured by mathematical usage. . . . A constant is to be something absolutely definite, concerning which there is no ambiguity whatever. Thus $1,2,3$, e, $\pi$, Socrates, are constants, and so are man and the human race, past, present, and future, considered collectively. Proposition, implication, class, etc., are constants; but a proposition, any proposition, some propositions are not constants, for these phrases do not denote one definite object." (Ibid. p. 6.)

1 "Pure Mathematics is the class of all propositions of the form of $p$ implies $q$ where $p$ and $q$ are propositions containing one or more variables, the same in the two propositions, and neither $p$ nor $q$ contains any constants except logical constants. And logical constants are all notions definable in terms of the following: Implication, the relation of a term to the class of which it is a member, the notion of such that, the notion of relation, and such further notions as may be involved in the general notion of propositions of the above form. In addition to these, mathematics uses a notion which is not a constituent of the propositions which it considers, namely, the notion of truth." (Principia Mathematica, p. 3.) 
"The connection of mathematics with logic, according to the above account, is exceedingly close. The fact that all mathematical constants are logieal constants, and that all the premisses of mathematics are concerned with these, gives, I believe, the precise statement of what philosophers have meant in asserting that mathematies is a priori. The fact is, that when once the apparatus of logic has been accepted, all mathematies necessarily follow." (Ibid. p. 8.)

35. Bertrand Russell, Our Knowledge of the External World, pp. 87 et seq. Also infra, American Edition, pp. 168, 169, 170.

It should be borne in mind that the conclusion, so distressing for the idealist, is not forced on him by the mathematical definition of continuity. Physies, Mr. Russell tells us, accepts the ideal elements of mathematics without enquiry into their reality. "It is unnecessary, for the enunciation of the laws of physics, to assign any reality to idcal elements: it is enough to accept them as logical constructions, provided we have means of knowing how to determine when they become actual." After all, the fact remains that mathematical continuity is based on purely fictitious or "ideal" points and instances, assumed for the purpose of constructing a self-consistent definition.

"Les axiomes géométriques ne sont... ni des jugements synthétiques a priori, ni des faits expérimentaux.

"Ce sont des conventions; notre choix parmi toutes les conventions possibles, est guidé par des faits expérimentaux; mais il reste libre et n'est limité que par la nécessité d'éviter toute contradiction ....; les axiomes de la géométrie ... ne sont que des définitions déguisées." (Poincaré, La Science et l'Hypothèse, p. 66.)

Since, further, mathematical space and time are absolute and infinite, and actual space is an affair of relations and correlations, you cannot argue from the continuity of mathematical space to the continuity of actual space and of the things that occupy it. How, then, are we to determine when the ideal elements "become actual"? All that Realism can hope to gain is the proof that its own logical constructions-founded on a purely ideal " convention"-can be manipulated so as to exclude contradiction. The erucial problem for Realism will be how to effect such constructions and correlations as shall be equally self-eonsistent; how, in short, to reduce "the haphazard, untidy world of immediate sensation to the smooth, orderly world of geometry and kineties." In immediate experience correlation is going on all the time.

"The first thing to notice is that different senses have dif- 
ferent spaces. The space of sight is quite different from the space of touch: it is only by experience in infancy that we learn to correlate them. ... The one space into which both kinds of sensations fit is an intellectual construction, not a datum. ... The one all-embracing space, though convenient as a way of speaking -"

(Still more convenient, one would imagine, as a way of thinking)_-" need not be supposed really to exist." (Our Knowledge of the External World, p. 113.)

What could the idealist wish for more?

However, Dr. Whitehead has invented a method "for the purpose of showing how points might be manipulated from sensedata." It amounts to this: You can, by an effort of attention, regard your bit of finite space (volume or surface) as consisting of parts contained in a whole. You obtain your points by a system or series of diminishing enclosures converging to a point. The "enclosure-relation" is called a "point-producer." Again, I must leave the process to Mr. Russell to explain.

"Given any relation of enclosure, we will call a set of objects an enclosure-series. We require a condition which shall secure that an enclosure-series converges to a point, and this is obtained as follows: Let our enclosure-series be such that, given any other enclosure-series of which there are members enclosed in any arbitrarily-chosen member of our first series, then there are members of our first series enclosed in any arbitrarily-chosen member of our second series. In this case, our first enclosure-series may be called a 'punctual enclosure-series.' Then a 'point' is all the objects which enclose members of a given 'punctual enclosure-series.' In order to ensure infinite divisibility, we require one further property to be added to those defining point-producers, namely, that any object which encloses itself also encloses an object other than itself. The 'points' generated by point-producers with this property will be found to be such as geometry requires." (Ibid. p. 115.)

You hare got, that is to say, by logical manipulation, another self-consistent definition; but you are no nearer to solving the problem of how ideal elements "become actual." All this "manufacture" and "manipulation" and "construction" is far more like the despised "work of thought" than that passive contemplation of spectacular realities which atomistic Realism assumes. And the entire universe of space and time depends on it!

Again, Poincaré:

"On voit que l'expérience joue une rôle indispensable dans la 
genèse de la géométrie; mais ce serait une èrreur d'en conclure que la géométrie est une science expérimentale, même en partie. ...

"La géométrie ne serait que l'étude des mouvements des solides; mais elle ne s'occupe pas en réalité des solides naturels, elle a pour objets certain solides idéaux, absolument invariables, qui n'en sont qu'une image simplifiée et bien lointaine.

"La notion de ces corps idéaux est tirée de toutes pièces de notre esprit et l'expérience n'est qu'une occasion qui nous engage à l'en faire sortir.

"Ce qui est l'objet de la géométrie, c'est l'étude d'un 'groupe' particulier; mais le concept générale de groupe préexiste dans notre esprit au moins en puissance. Il s'impose à nous, non comme forme de notre sensibilité, mais comme forme de notre entendement." (La Science et l'Hypothèse, p. 90.)

Could anything be plainer?

36. Bertrand Russell, The Problems of Philosophy, pp. 142, 157 ; Cecil Delisle Burns, William of Ockham on Universals.

37. Bertrand Russell, "The Monistic Theory of Truth" in Philosophical Essays.

Also Ralph Barton Perry, "A Realistic Theory of Independence," and William Pepperell Montague, "A Realistic Theory of Truth and Error" in The New Realists: A Symposium of Six. (The Macmillan Company, New York.)

38. It is on this narrow plot of thought that Hegel's critics and his followers have joined issue, and to the unprejudiced spectator of their conflicts they seem to have been leagued together to suppress every word that Hegel ever wrote outside the three fat volumes of his Logic. Of course if you take the Logic as the whole of Hegel, and as the beginning and end of the Transcendental Philosophy, there is no charge that his opponents ever brought against him, and no travesty of his system that his followers ever perpetrated, so absurd that it could not be justified.

And if this were all, Hegelianism would be, indeed, what some unsympathetic person said it was, "a dance of bloodless categories." I forget who was responsible for the pleasant fancy that when German philosophies die their ghosts go to Oxford. It was certainly the ghost of Hegelianism that inhabited Balliol in the 'eighties, till its ceaseless hauntings provoked the healthy reaction of Pragmatism and Humanism. Goodness knows why Hegel's disciples should have conceived that it was their sacred mission to mutilate their master so as to leave out of his system the one principle that made it vital, and to whittle it down to a bare epistemology. 
Epistemology - a metaphysic based on the sterile abstract categories of the Understanding whose utter impotence he was never tired of demonstrating. One can only suppose that the Triple Dialectic was too much for the disciples, and that they thought they were simplifying him.

There is, however, this excuse for them, that, though Hegel was perfectly clear about what he meant, he was not always cautious about what he said. What he meant - and said so often that there should have been no possible doubt as to his meaning - was that Spirit is the prius, and that Thought is only part (an important part, but still only part) of the whole gorgeous, concrete, and abundant life of Spirit. But being a poet with an imagination, as well as a philosopher with a system, he also said that Thought was the diamond-net in which the universe is hung; and all his opponents and his followers took this saying literally.

Literally, and yet not literally enough. For the net is surely not the thing it snares. However, as Thought was a thing both critics and followers were fairly familiar with, and Spirit presumably was not, wherever and whenever afterwards Hegel spoke to them of Spirit, they refused to listen to him. Had he not said at the end of the third fat volume of his Logic that the Idea, the Transcendental Idea, was the Whole? Had he not said that Thought was the Ding-an-sich?

What he did say, criticizing Kant, was that the Thing-inItself is what the Absolute is, of which "nothing is known but that everything is one in it." (Logik, Book I. p. 121. Berlin, 1841.) He defined it, with ferocious asperity, as a "dead-head," the "utterly abstract and entirely empty, only definable as the Beyond, the negative of idea and feeling and of definite thinking." He said it was surprising "how often we are told that we don't know what the Thing-in-Itself is," and added sarcastically that "nothing was easier than to know it." (Encyclopädie, p. 67.) He said that "the Logic was the setting forth of what the Thing-in-Itself in truth is, of what is truly in it"; and that "by 'In-Itself' something better than an abstraction is to be understood, namely, what something is in its concept," the concept being a very concrete and definite affair. (Logik, p. 121.) And he certainly did say that the Transcendental Idea was the Whole, meaning the logical Whole that he was dealing with in the three fat volumes. Then he paused to take breath before letting his system rip in the vaster Dialectic of the Spirit. That pause was fatal to him. For whatever he might say afterwards nobody attended to him. His followers had got their catchword! "Thought is the Ding-ansich." 
Yet it should be elear to every unprejudieed reader of the Encyclopädie and the Phänomenologie that Spirit and not Thought is the all-embraeing term; the beginning and end of Being and Beeoming; the through-all and in-all; the only principle that ean be first in thought and first also in existence. The whole course of the Triple Dialectic depends on it. And he is explieit enough:

"The absolute Idea alone is Being, imperishable life, truth that knows itself, and it is all truth"- as far as thought goes. (Logik, Book III. p. 318.)

But Spirit is "that which is the truth and the end of Nature, and the true Reality of the Ideal." (Encyclopädie, p. 211.)

For the " Logic" "this Idea is as yet logieal; it is shut within pure thought; it is the Knowledge only of the divine idea. The systematic carrying-out of it is itself realization-but contained within this sphere" (p. 342).

"At every stage of its wider determination it upheaves the whole mass of its foregoing eontent; and through its dialeetic process it not only leaves nothing behind, but it carries with it all that it has won, it enriches and thickens itself in itself."

"Every stage of the outgoing, of wider determination, is an ingoing; the greater the extension the higher the intensity. Therefore, what is richest is also the most conerete and the most subjective; the mightiest and that which has the biggest streteh is that which finds itself again in the depth of simplieity. The highest, the sharpest point is pure Personality." (Logik, Book I. pp. 60,61 .)

It is the Absolute Spirit which at the end of the process is known "as the concrete and the last highest truth of all Being."

"The essential thing for knowledge is not so much that it should begin (as the Logic begins) with the purely immediate, but that its whole of knowledge should be a cirele returning into itself, in which the First is also the Last, and the Last is also the First." (Logik, Book I. pp. 60, 61.)

39. Mr. E. B. Holt's argument, even if psycho-physically sound, euts both ways.

"And now I can reply to the anti-realist's question: How ean realism pretend to assert the rcality of the odour, sound, and so forth which are vividly present in the dreams of a person sleeping, it may be, in a box no bigger than his coffin? Realism, I say, ean assert this because the nervous system, even when unstimulated from without, is able to generate within itself 
nerve-currents of those frequencies whose density factor is the same as in ordinary peripheral stimulation." (The New Realism, p. 352.)

The anti-realist may agree that he gets nerve-stimulation in either case, just as he agrees that hallucinations can be distinguished from "external realities" by their contexts. (For the matter of that a hallucination may appear as externalized in public space.) I do not see why he should be represented as worrying about "the box no bigger than his coffin," since a box no bigger than his head contrives to house the nerve-eentres that are implicated. His question is: What kind of reality, or of appearance, is to be ascribed to the objects of sense-perception? His anti-ness would declare itself rather in contending that if you will ascribe absolute outside reality to all spaces and to all times and to all objects in space and time, then, when you've proved that your nervous system is able " to generate within itself nerve-currents of those frequencies whose density factor is the same as in ordinary peripheral stimulation," it is, to say the least of it, a little odd that your motor experiences in dream space are so very far from being "the same" as your motor experiences in "ordinary" space.

The realist argues as if the nerve-currents had everything to do with the "reality" of dream-experiences and hallueinations. Very well, then. Establish the same conditions of " frequency," "density factor," and the rest of it, and what you ought to expect from your dream is a sober expedition in a space conformed in every way to ordinary space, and the sober spectacle of objects behaving in an ordinary spatial manner, and not expeditions and spectacles so far from ordinary as to presuppose a dream-space and a dream-time and a dream-behaviour that do not conform at all.

\section{THE NEW MYSTICISM}

\section{Pages 240-289}

40. Jane Harrison, Protegomena to Greek Religion, pp. 9 et seq., 32-76, 163 et seq.; also p. 64. Themis, pp. 270, 275.

Sir James G. Frazer, The Belief in Human Immortality, pp. 201, 226, 239, 247, 259, 288, 289, 348, 367 et seq.; also pp. 346, 371. 380. Adonis, Attis, Osiris, pp. 45 et seq., 219 et seq.

41. Jane Harrison, Protegomena, pp. 21, 327 et seq. Themis, p. 261 et seq.

42. Buddhist Suttas, translated by Professor Rhys Davids. 
Âkankheya-Sutta, pp. 14, 15. (Sacred Books of the East, edited by Professor Max Müller.)

43. Jung, Psychology of the Unconscious, pp. 100 et seq., 260. (Translated by Beatrice M. Hinkle, M.D., New York.)

Pierre Janet, L'Automatisme psychologique. État mental des hystériques, vol. ii. Les accidents mentaux. The Major Symptoms of Hysteria.

Anna Robeson Burr, Religious Confessions and Confessants, pp. 194-284.

44. Life of St. Teresa, Written by Herself, ch. xx. xxix.

45. Life of St. Catherine of Genoa, by Baron von Hütten.

46. St. John of the Cross, The Dark Night of the Soul (translation by Gabriela Cunningham Grahame), pp. 235-237.

47. St. John of the Cross, The Dark Night, pp. 47-55, 100, $116,120$.

48. Anna Robeson Burr, Religious Confessions, p. 357.

49. Life of St. Teresa, ch. xxv.

50. Interpretation of Dreams; On Dreams.

51. Journal of the Society for Psychical Research, May, June, and July 1916; and January 1917.

52. See infra, "Conclusions," pp. 335, 336, 337.

53. The Upanishads, translated by Max Müller. Part I. (Sacred Bools of the East, vol. i.)

54. "It is right ... to state here that Oriental Mysticism insists upon a further stage beyond that of union, which stage it regards as the real goal of the spiritual life. This is the total annihilation or reabsorption of the individual soul in the Infinite." (Mysticism, p. 207.)

"The tendency of Indian mysticism to regard the Unitive Life wholly in its passive aspect, as a total self-annihilation, a disappearance into the substance of the Godhead, results, I believe, from ... a one-sided distortion of truth. The Oriental mystio 'presses on to lose his life upon the heights'; but he does not come back from the grave and bring to his fellow-men the lifegiving news that he has transcended mortality in the interests of the race. The temperamental bias of Western mystics towards activity has saved them from such a one-sided achievement as this; and hence it is in them that the Unitive Life, with its 'dual character of activity and rest,' has assumed its richest and its noblest forms." (Ibid. p. 520.)

"In the East... the contemplative and world-renouncing quest of the Absolute ... . which developed under the influence of Hindu philosophy, has been from the first divorced from the 
warmly vital and more truly mystic, outgoing and fruitful, world-renewing attitude of Love. . . .

"... The search for transcendence, as we see it in orthodox Hinduism and Buddhism, represents in its general tendency, not a movement of expansion, not the generous industry of insatiable love; but a movement of withdrawal, the cultivation of an exquisite and aristocratic despair. Inspired by the intellect rather than by the heart, the whole mystical philosophy of the Hindus has as its presupposition a strong feeling of the transitoriness and unreality of existence." (The Mystic Way, pp. 21, 22.)

In the case of Suffi-ism, Miss Underhill admits that the interpretations of European students may be incorrect, and that $\mathrm{Al}$ Ghazzali's description of the Süf's Eighth Stage of Progress " is certainly more applicable to the Unitive Life as understood by Christian contemplatives than to the Buddhistic annihilation of personality." (Mysticism, p. 207.)

It would not be fair to quote Miss Underhill as claiming, in 1913, a Christian influence for the mysticism of the Vaishnavists Rāmānuja and Rāmānanda (see The Mystic Way, pp. $23,24,25)$, since in 1914 she has admitted very handsomely that "this is a point upon which competent authorities hold widely divergent views." (Introduction to One Hundred Poems of Kabir.) But I hope she will forgive me if I take a mean advantage of her footnote referring to Vaishnavism.

"The fact that this movement, on its lower and popular side, gave support to the most erotic and least desirable aspects of the Krishna cult, ought not to prejudice our judgment of its higher and purer aspect. The wholesale condemnation of a faith on account of its worst by-products is a dangerous principle for Christian critics." (The Mystic Way, p. 23.)

It is, of course, a dangerous principle for anybody, as it cuts pretty badly both ways. All the same, the sticklers for the "Influence" are in a dilemma. Either Christianity really had nothing to do with the Humanist forms of Eastern mysticism, or it was responsible for their lowest and impurest aspect.

Perhaps the less said about eroticism the better.

55. "Dance, my heart! dance to-day with joy.

"The strains of love fill the days and the nights with music, and the world is listening to the melodies:

"Mad with joy, life, and death, dance to the rhythm of this music. The hills and the sea and the earth dance. The world of man dances in laughter and tears." (The Thirty-Second Poem of Kabîr.) 
56. "To amuse and to delight Gertrude of Eisleben, He sang duets with her ' in a tender and harmonious voice.' The same saint writes of their 'incredible intimacy'; and here, as in later passages of Angela da Foligno, the reader is revolted by their sensuality." (Anna Robeson Burr, Religious Confessions and Confessants, p. 357.)

57. Psychology of the Unconscious, pp. 97, 98.

58. Ibid. pp. 130, 132.

\section{CONCLUSIONS}

Pages 290-339

59. Sir James G. Frazer, The Belief in Human Immortality, pp. $470,471$.

60. Ibid., pp. 371,380 .

61. Ibid., loc. cit. See also Jane Harrison on "The Hero as Snake" and "The Snake as Well and Tree-Daimon," Themis, pp. 261 et seq., and pp. 430, 431, 432.

62. Sabbâsava-Sutta (Sacred Books of the East, vol. xi.; The Buddhist Suttas, translated by Professor Rhys Davids).

In Professor Rhys Davids' translation the last sentence runs: "... this soul of mine is permanent, lasting, eternal, has the inherent quality of never changing, and will continue for ever and ever."

I do not offer the phrase "Deadly Things" as a rendering of "Âsavas." But it may pass as a picturesque and disorderly substitute. The Pâli word appears to have no exact moral equivalent. Professor Rhys Davids says:

"I am unable to suggest any good translation of the term itself - simple though it is. It means literally 'a running or flowing' (thence), a leak; but as that figure is not used in English in a spiritual sense, it is necessary to choose some other figure, and it is not easy to find one that is appropriate. 'Sin' would be very misleading, the Christian idea of sin being inconsistent with Buddhist Ethics. A 'fault' in the geological use of the word comes somewhat nearer. 'Imperfection' is too long, and for 'stain' the Pâli has a different word. In the Book of the Great Decease I have chosen 'evil '; here I leave the word untranslated." (Introduction.)

May I suggest that, though the original figure "running or flowing" has no "spiritual" sense in English, it has in various languages of philosophy a metaphysical sense, which is of the first importance in this highly metaphysical Sutta? We have 
"the flux of things," the "stream of consciousness," so why not "The Book of All the Life-Streams"?

63. See Bergson, Matière et Mémoire, p. 231.

“En rèalité il n'y a pas un rythme unique de la durée, on peut imaginer bien des rhythmes différents, qui, plus lent ou plus rapides, mesureraient le degré de tension ou de relâchement des consciences, et, par là, fixeraient leurs places respectives dans la série des êtres."

THE END 
$T_{\text {HE following pages contain advertisements of }}$ Macmillan books by the same author. 
This book is DUE on the last date stamped below

\author{
University of California \\ SOUTHERN REGIONAL LIBRARY FACILITY \\ 405 Hilgard Avenue, Los Angeles, CA 90024-1388 \\ Return this material to the library \\ from which it was borrowed.
}

OCT 2

MI

$\sqrt{69}$

JAN

Form 
UC SOUTHERN REGIONAL LIBRARY FACILITY AA 000005 s AA 0000095158 
